\title{
TAXONOMIC AND PHYLOGENETIC STUDIES ON ANAMORPHIC ASCOMYCOTA ASSOCIATED WITH PLANT DEBRIS
}

\author{
Dissertation \\ zur Erlangung des Doktorgrades \\ der Naturwissenschaften \\ vorgelegt beim Fachbereich Biowissenschaften \\ der Johann Wolfgang Goethe - Universität \\ in Frankfurt am Main \\ von \\ Gregorio Delgado \\ aus Havana
}

Frankfurt am Main (2019)

(D30) 
vom Fachbereich Biowissenschaften

der Johann Wolfgang Goethe-Universität als Dissertation angenommen.

Dekan: Prof. Dr. Sven Klimpel

Gutachter: Prof. Dr. Meike Piepenbring

Prof. Dr. Roland Kirschner

Datum der Disputation: 7 July 2020 
"Without a phylogenetic context, taxonomy loses its value as a record of biological information" (Vilgalys \& Hibbett, 1993) 


\section{TABLE OF CONTENTS}

SUMMARY

ZUSAMMENFASSUNG

9

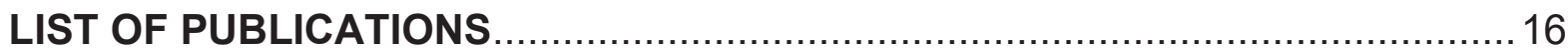

LIST OF FIGURES

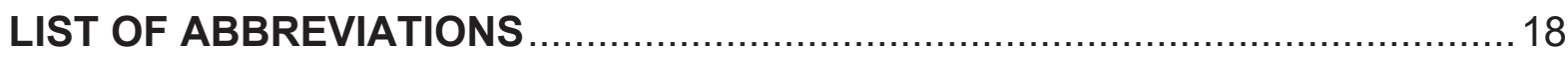

1 INTRODUCTION

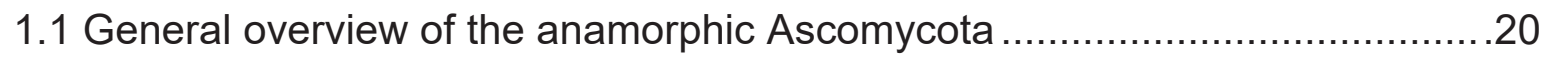

1.1.1 The filamentous Ascomycota: life cycle, pleomorphism and asexuality....20

1.1.2 Morphological and developmental diversity of anamorphic Ascomycota ..25

1.1.3 Ecology and importance of anamorphic Ascomycota ...............................31

1.2 Traditional approaches in the taxonomy of anamorphic Ascomycota ..............33

1.2.1 The Saccardoan system and its limitations.............................................34

1.2.2 The Hughesian system and its limitations............................................... 35

1.2.3 Suprageneric classifications and nomenclature of anamorphic Ascomycota 38

1.3 Molecular phylogenetics in the taxonomy of anamorphic Ascomycota ...........40

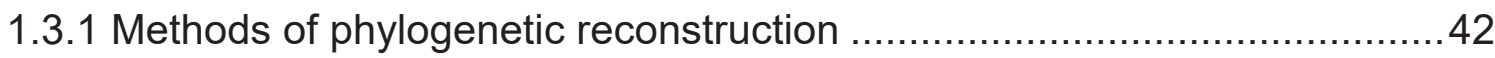

1.3.2 Molecular markers of relevance in ascomycete phylogenetics .................46

1.3.3 Molecular identification and DNA barcoding ........................................47

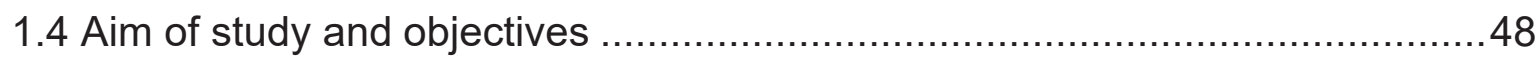

2 DISCUSSION

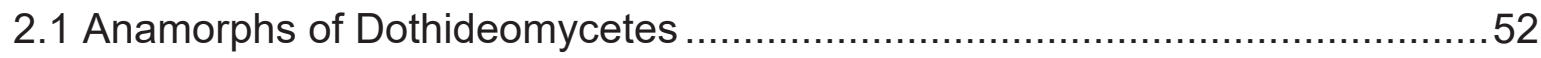

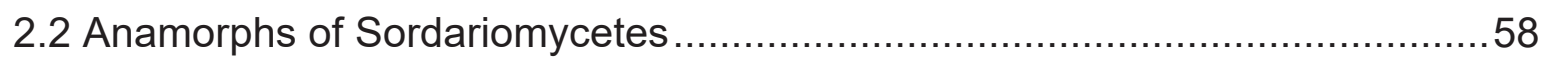

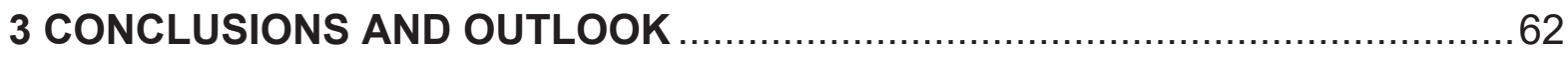


Delgado et al. (2017)

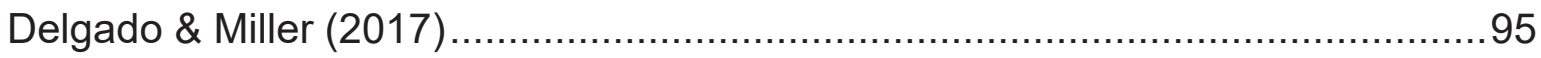

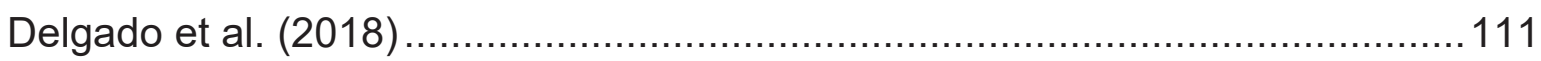

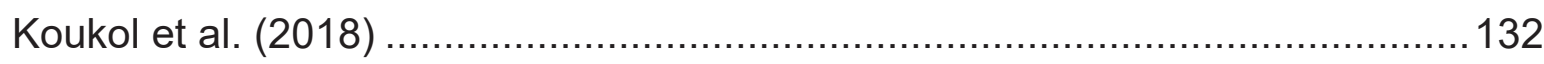

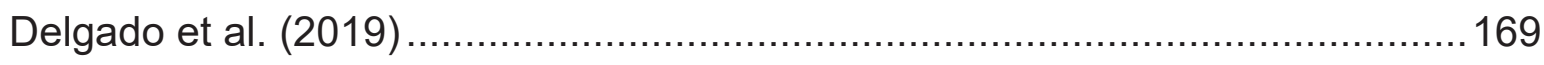

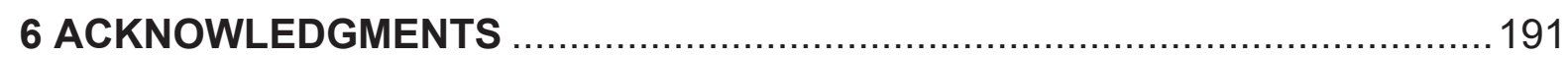

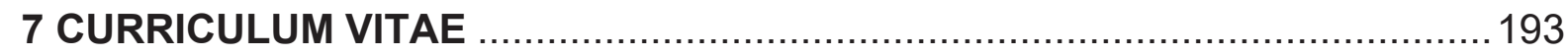




\section{SUMMARY}

The division Ascomycota (Fungi) contains a large number of taxa known to reproduce only asexually by the formation of conidia or other non-motile propagules produced by mitotic cellular devisions. They are called anamorphic, mitosporic, asexual or conidial fungi and their sporulating structures exhibit a striking diversity of morphological and developmental features that has been traditionally used to identify and classify them. Ecologically, they are ubiquitous in ecosystems and able to colonize a wide range of niches and microhabitats but particularly they are often found associated with plant debris in different stages of decay. Compared with anamorphic species of economic importance, saprobic anamorphs of ascomycetous affinities are in general poorly studied. Phylogenetic relationships are unknown for many of them and they are still largely underrepresented in the current phylogenetic classification system of Fungi. Their outstanding diversity is currently underexplored and many morphologically defined anamorphic taxa are still awaiting taxonomic reassessment in the light of molecular approaches. The increasing usage of molecular markers combined with robust statistical methods has allowed their phylogenetic affinities to be revealed and to gradually incorporate many of them into the different taxonomic groups of the division Ascomycota. However, the phylogenetic placement and taxonomic status of a large number of saprobic taxa remain unresolved due to the lack of DNA sequence data.

The present dissertation aims to explore the rich but understudied diversity of those anamorphic fungi traditionally known as hyphomycetes that inhabit dead plant debris. It consists of five publications in which a polyphasic approach integrating morphological, developmental, cultural and molecular data was used to incorporate novel or incertae sedis taxa within Ascomycota and to make more sound decisions regarding their taxonomic status. Specific objectives include: 1. the collection, isolation and morphological characterization of selected anamorphic fungi representing putative new or interesting taxa of uncertain phylogenetic placement; 2 . the generation of novel DNA sequence data to infer their phylogenetic relationships and to resolve their taxonomic affinities within Ascomycota; 3. the testing of any previously available morphologically based hypotheses on their putative position, generic placement or relationships with teleomorphic, pleomorphic or other 
anamorphic taxa; and 4. the determination of their generic validity, monophyly and taxonomic boundaries using molecular data and phylogenetic analyses methods.

Materials studied in these five projects consisted of specimens collected during field work carried out by the author or collaborators in different countries including USA, the Czech Republic and Panama between the years 2014 and 2017. The target substrates were dead leaves of different palm trees, dead wood and bark of pines and twigs or stems of unknown shrubs and woody vines that are all known to harbor a rich saprobic mycobiota. Putative novelties or anamorphic taxa with unknown or poorly studied phylogenetic affinities were selected for further morphological and molecular investigation. Dried herbarium specimens from Belgium, Cuba, India and the United Kingdom deposited in international herbaria (IMI, MUCL, PRC) were examined for comparison with fresh material. Micromorphological studies were based on fungal structures observed on natural substrate, herbarium specimens and in culture. Detailed descriptions including morphological, developmental and cultural features were made along with line drawing illustrations and photographs. Voucher specimens, types and living cultures were deposited in international herbaria (BPI, ILLS, PRC, PMA) and culture collections (CBS, CCF). In all cases genomic DNA was extracted from cultures and PCR amplification followed by Sanger sequencing was carried out according to protocols used at the author or collaborators' institutions. Relevant molecular markers usually used in fungal phylogenetic studies such as the nrlTS region, the D1/D2 domains of the nrLSU and fragments of protein-coding genes such as $\beta$-TUB, RPB2 and TEF1- $\alpha$ were used. Newly obtained DNA sequence data were analyzed following a standard phylogenetic analysis pipeline. Sequences were subjected to BLAST searches in GenBank to first assess their identity. Datasets were assembled and aligned using algorithms in softwares such as MUSCLE or MAFFT. Phylogenetic relationships were reconstructed by character-based methods such as Maximum Likelihood and Bayesian inference using computer programs such as RAxML, MEGA or MrBayes.

In Delgado et al. (2017), the phylogenetic placement of the saprobic anamorph Ernakulamia cochinensis in Ascomycota was revealed for the first time based on a specimen collected on rotten leaves of Astrocaryum standleyanum (Arecaceae) in Panama. Multigene phylogenetic analyses of DNA sequence data belonging to the ITS, LSU and the $\beta$-TUB genes suggest that $E$. cochinensis belongs 
to the family Tetraplosphaeriaceae within the order Pleosporales (Dothideomycetes). This placement was supported by additional molecular data from a second isolate that originated in Japan. An existing morphologically based hypothesis suggesting that $E$. cochinensis has appendiculate conidia similar to some members of Tetraplosphaeriaceae was confirmed by molecular data. The Panamanian specimen was compared with an isotype from India and determined to be conspecific. Further evidence of relatedness was found by placing their conidia in sodium hypochlorite solutions. Bleached conidia revealed the presence of internal hyphal structures similar to those found in members of related genera in Tetraplosphaeriaceae. Ernakulamia was supported as a distinct genus within the family by conidial morphology and DNA sequence data. Molecular data also rejected previous generic placements within the unrelated Petrakia (Melannomataceae, Pleosporales) or the distant Piricauda (Capnodiales, Dothideomycetes).

In Delgado \& Miller (2017), a new saprobic species of Taeniolella discovered on the petiole of a dead leaf of Sabal palmetto (Arecaceae) in Florida, USA was proposed and described. The fungus differed from morphologically similar species of Taeniolella in several respects that warranted the introduction of a new taxon named $T$. sabalicola to accommodate it. Phylogenetic analyses based on nuclear ribosomal DNA sequence data suggested that the fungus is distinct from Taeniolella species with available molecular data and showed affinities with members of Sordariomycetidae (Ascomycota) but its ordinal or familial position within the subclass remained uncertain. Molecular data also confirmed the highly polyphyletic status of Taeniolella within the class Sordariomycetes with species scattered across the subclasses Sordariomycetidae and Hypocreomycetidae. These results indicate that the genus is in need of extensive reassessment. Moreover, the generic type $T$. exilis was recently placed within the family Kirschsteiniotheliaceae in the distant class Dothideomycetes (Ertz et al. 2016). Therefore, T. sabalicola does not belong to Taeniolella s. str. and should be eventually reclassified in a new or different genus. However, most saprobic species of Taeniolella still lack molecular data and their phylogenetic relationships remain uncertain. Based on the rather preliminary knowledge about affinities of taeniolella-like taxa a broad generic concept was momentarily adopted to accommodate $T$. sabalicola until more data become available. 
In Delgado et al. (2018), the taxonomic status and phylogenetic placement of the saprobic anamorph Sporidesmium pachyanthicola were revisited based on a specimen collected on a dead leaf of Sabal palmetto (Arecaceae) in Florida, USA. The fungus was formerly placed within the broadly defined family Teratosphaeriaceae in Capnodiales (Dothideomycetes). Our phylogenetic analyses based on ITS-LSU sequence data combined with a broad taxon sampling at family level suggest that the fungus is instead a member of the sister family Extremaceae. This placement is distant from the family Sporidesmiaceae in Sordariomycetes including species of the genus Sporidesmium s. str. and therefore the new generic name Castanedospora was introduced to accommodate S. pachyanthicola. The fungus was epitypified with the Florida specimen in the absence of a preserved extype living culture and the depauperated state of the holotype material originated from neighboring Cuba. A hypothetical relationship between Castanedospora and another sporidesmium-like capnodiaceous anamorph named Sporidesmajora pennsylvaniensis was tested using the newly generated molecular data. Despite their ordinal placement in Capnodiales and strong morphological resemblance in culture they were not congeneric but phylogenetically distant and the latter was recovered for the first time as a member of the capnodiaceous family Phaeothecoidiellaceae.

In Koukol et al. (2018), five new species of the anamorphic genus Hermatomyces were proposed and described from rotten twigs and dead stems of various plants collected in Panama. They were named Hermatomyces bifurcatus, $H$. constrictus, $H$. megasporus, $H$. sphaericoides and $H$. verrucosus. All these novel taxa were supported by molecular data in addition to distinct morphological features. Previously described species such as $H$. tucumanensis, $H$. reticulatus and $H$. sphaericus were also identified. Phylogenetic analyses of nuclear ribosomal (ITSLSU) and protein coding genes ( $\beta$-TUB, RPB2, TEF1- $\alpha$ ) sequence data placed all species within the monophyletic family Hermatomycetaceae (Pleosporales, Dothideomycetes) comprising so far the single genus Hermatomyces. This is the first comprehensive study of Hermatomyces in the Neotropics in which the phylogenetic placement of $H$. tucumanensis, the generic type, was assessed for the first time using molecular data and based on three representative specimens. A critical overview of ten other Hermatomyces species not found in Panama was provided. A new combination named $H$. reticulatus was proposed and four previously described 
taxa were reduced to synonyms based on morphological and molecular evidence for a total of sixteen accepted species within the genus. In addition to traditional phylogenetic analysis methods, species delimitation in Hermatomyces was tested for the first time using species-tree estimation under a coalescent model. This approach has been rarely applied in studies of saprobic anamorphs and novel insights into the evolution of the genus such as evidence of incomplete lineage sorting and possibly hybridization events on a few species with incongruent tree topologies was obtained. The peculiar morphology and consistent monophyly of accepted Hermatomyces species supported the recognition of the family as a well delimited monophyletic taxon within Pleosporales.

In Delgado et al. (2019), a new species of Septonema discovered on woody debris of Pinus spp. in the USA and the Czech Republic was proposed and described. The fungus is morphologically distinct from previously described species and therefore a novel taxon named $S$. Iohmanii was introduced to accommodate it. Multigene phylogenetic analyses using LSU and TEF1- $\alpha$ genes sequence data suggested that both collections are conspecific despite their disjunct distribution and belong within the order Mytilinidiales (Dothideomycetes). This is the first time a septonema-like anamorph is linked to Mytilinidiales in a phylogenetic framework using molecular data and its placement fully agreed with previous cultural or circumstantial evidence of their relatedness. Molecular data were also generated from a putative strain of $S$. secedens, the generic type, in order to elucidate its systematic position and to test the hypothesis whether our fungus belongs within Septonema s. str. The strain was placed within the family Venturiaceae (Venturiales, Dothideomycetes) but morphological examination of the corresponding herbarium specimen, however, revealed that it belongs to the different species $S$. fasciculare for which a phylogenetic placement was resolved for the first time. The phylogenetic status of the generic type remained inconclusive preventing any generic redispositions and the current broad concept of Septonema was momentarily adopted until fresh collections and further molecular data become available. If the position of the generic type outside Mytilinidiales is confirmed then S. Iohmanii may be accommodated in a novel genus. The disparate phylogenetic positions of these Septonema species within Dothideomycetes confirmed the polyphyletic nature of the genus and the need for an extensive taxonomic reassessment. 
In the present dissertation, molecular phylogenetics is confirmed as the tool of choice for resolving relationships in novel or incertae sedis anamorphic fungi inhabiting plant debris. It allows to fully incorporate them in Ascomycota and to provide a foundation for better taxonomic decisions on their classification. The lack of DNA sequence data is currently the main challenge hampering their complete integration and study in a molecular-based taxonomic framework. Efforts should be focused on recollecting and isolating them in order to generate novel molecular data and to harness their unique biology for future phylogenetic, mitogenomic and phylogenomic studies. Once recollected, the validity of morphologically circumscribed genera and species will need to be tested in order to delimit more natural taxa. This will be a daunting task considering that there are more than 1500 described genera of anamorphic Ascomycota representing thousands of species. Large and polyphyletic genera such as Taeniolella, Sporidesmium and Septonema, partially treated in this work and containing mostly saprobic species of obscure affinities, are in need of further attention. Many anamorphic novelties are also expected to be discovered worldwide based on the recent estimates of fungal diversity ranging from 2.2 to 3.8 million species thought to exist in contrast with the more or less currently known 140,000 species of Fungi (Hawksworth \& Lücking, 2017; Lücking \& Hawksworth, 2018). Mycological surveys with emphasis on recollection and isolation should therefore continue in relatively well explored areas of North America and Europe but also in underexplored tropical countries where many anamorphs are still awaiting discovery and many others still lack DNA sequence data. In order to stabilize the application of names of anamorphic taxa careful epitypification or neotypification procedures based on sequenced specimens should be implemented. The increasing availability of genome-scale data due to their decreasing costs will make well-documented specimens and isolates of critical importance in the ongoing transition from analyzing small datasets with a few loci to analyzing whole genomes and the consequent impact in future phylogenetic and taxonomic studies of the group. 


\section{ZUSAMMENFASSUNG}

Die Abteilung Ascomycota (Pilze) enthält eine große Anzahl von Taxa die sich nur ungeschlechtlich reproduzieren, indem sie Konidien oder andere nicht bewegliche, durch mitotische Zellteiling erzeugte, Propagula bilden. Sie werden als anamorphe, mitosporische, asexuelle oder konidiale Pilze bezeichnet. Ihre sporulierenden Strukturen weisen eine bemerkenswerte Vielfalt an morphologischen und entwicklungsbedingten Merkmalen auf, die traditionell zur Identifizierung und Klassifizierung verwendet wurden. Ökologisch gesehen sind sie allgegenwärtig und in der Lage, eine Vielzahl von Nischen und Habitaten zu besiedeln. Insbesondere werden sie häufig in Verbindung mit Pflanzenresten in verschiedenen Stadien des Verfalls gefunden. Im Vergleich zu anamorphen Arten von wirtschaftlicher Bedeutung sind saprophytische, anamorphe Ascomycenten im Allgemeinen schlecht untersucht. Die phylogenetischen Beziehungen sind für viele von ihnen unbekannt und im gegenwärtigen phylogenetischen Klassifikationssystem der Pilze immer noch weitgehend unterrepräsentiert. Ihre herausragende Vielfalt ist derzeit noch wenig erforscht, und viele morphologisch definierte anamorphe Taxa warten noch auf eine taxonomische Neubewertung aufgrund molekularer Ansätze. Die zunehmende Verwendung molekularer Marker in Kombination mit robusten statistischen Methoden hat es ermöglicht, ihre phylogenetischen Zusammenhänge aufzudecken und viele von innen schrittweise in die verschiedenen taxonomischen Gruppen der Division Ascomycota einzubeziehen. Dennoch bleibt die phylogenetische Platzierung und der taxonomische Status einer großen Anzahl von saproben Taxa aufgrund mangelder DNA-Sequenzen ungelöst.

Die vorliegende Dissertation untersucht die reiche, aber wenig erforschte Vielfalt jener anamorphen Pilze, die traditionell als Hyphomyceten bekannt sind und tote Pflanzenreste besiedeln. Sie besteht aus fünf Veröffentlichungen mit mehrphasigem Ansatz, der morphologische, entwicklungsbezogene, kulturelle und molekulare Daten einbezieht. Dies ermöglicht eine solide Entscheiding zu treffen bezüglich der Bestimmung und Integration von neuer oder Incertae Sedis Taxa in der Abteilung Ascomycota. Spezifische Ziele sind: 1. Sammlung, Isolierung und morphologische Charakterisierung anamorpher Arten mit unsicherer phylogentischer Einordnung die entweder potentiell neue oder interessante Taxa representieren; 2. Entschlüsselung neuer DNA-Sequenzen, um ihre phylogenetischen 
Zusammenhänge herauszufinden und ihre taxonomischen Beziehungen innerhalb von Ascomycota zu lösen; 3. Überprüfung von Platzierungen oder verwandschaftlicher Beziehungen zwischen teleomorphen, pleomorphen oder anderen anamorphen Taxa die aufgrund verfügbarer morphologischen Eigenschaften gemacht wurden; und 4. Bestimmung und Bestätigung ihrer monophilen und taxonomischen Grenzen unter Verwendung molekularer Ergebnisse und phylogenetischer Analysemethoden.

Die Materialien, die in diesen fünf Projekten untersucht wurden, bestanden aus Proben, die von den Autoren oder von Mitarbeitern in verschiedenen Ländern, einschließlich USA, der Tschechischen Republik und Panama, zwischen den Jahren 2014 und 2017 gesammelt wurden. Die Zielsubstrate waren abgestorbene Blätter verschiedener Palmen, totes Holz und Rinde von Kiefern und Zweige oder Stängel unbekannter Sträucher und holziger Reben mit reicher saprober Mykobiota. Für weitere morphologische und molekulare Untersuchungen wurden potentiell neue oder anamorphe Taxa mit unbekannten oder schlecht untersuchten phylogenetischen Beziehungen ausgewählt. Getrocknete Herbariumproben aus Belgien, Kuba, Indien und Großbritanien, die in internationalen Herbarien (IMI, MUCL, PRC) deponiert waren, wurden zum Vergleich mit frischem Material untersucht. Mikromorphologische Untersuchungen basierten auf Strukturen, die auf natürlichem Substrat, Herbariumproben und in Kultur beobachtet wurden. Detaillierte Beschreibungen einschließlich morphologischer Eignschaften während der Entwicklung und in Kultur wurden mit Zeichnungen und Fotografien dokumentiert. Belegexemplare, -typen und lebende Kulturen wurden in internationalen Herbarien (BPI, ILLS, PRC, PMA) und Kultursammlungen (CBS, CCF) hinterlegt. Von allen Materialien wurde von Mitarbeitern des Autoren oder der Koautoren genomische DNA aus Kulturen extrahiert und eine PCR-Amplifikation durchgeführt gefolgt von Sanger-Sequenzierung gemäß etablierter Protokollen. Relevante molekulare Marker, die üblicherweise in phylogenetischen Untersuchungen von Pilzen verwendet werden, wie die nrITS-Region, die D1/D2-Domänen der nrLSU und Fragmente von Protein-kodierenden Genen wie $\beta$-TUB, RPB2 und TEF1- $\alpha$, wurden verwendet. Neu erhaltene DNA-Sequenzdaten wurden nach standardmäßigen phylogenetischen Methoden analysiert. Sequenzen wurden zunächst mithilfe des Suchprogramms BLAST mit GenBank Einträgen verglichen um ihre Identität zu bestimmen. Datensätze wurden dann mithilfe von Algorithmen in Softwareprogrammen wie zum 
Beispiel MUSCLE oder MAFFT zusammengestellt und abgeglichen. Zuletzt wurden die phylogenetischen Beziehungen aufgrund Maximum Likelihood und Bayesian Inference unter Verwendung von Computerprogrammen wie RAxML, MEGA oder MrBayes rekonstruiert.

In Delgado et al. (2017) wurde die phylogenetische Einordnung des saproben Anamorphs Ernakulamia cochinensis in Ascomycota zum ersten Mal anhand einer Probe etabliert, die auf faulen Blättern von Astrocaryum standleyanum (Arecaceae) in Panama gesammelt wurde. Multigene phylogenetische Analysen von DNASequenzdaten der Gene ITS, LSU und $\beta$-TUB legen nahe, dass E. cochinensis zur Familie der Tetraplosphaeriaceae innerhalb der Ordnung Pleosporales (Dothideomyceten) gehört. Diese Platzierung wurde durch zusätzliche molekulare Daten eines zweiten Isolats aus Japan unterstützt. Eine bestehende morphologisch begründete Hypothese, die nahe legt, dass E. cochinensis appendikuläre Konidien aufweist, ähnlich wie einige andere Mitglieder der Tetraplosphaeriaceae, wurde durch molekulare Daten bestätigt. Das panamaische Exemplar wurde mit einem Isotyp aus Indien verglichen und als spezifisch befunden. Ein weiterer Hinweis auf verwandtschaftliche Beziehungen wurde durch Behandlung der Konidien mit Natriumhypochloritlösungen gefunden. Gebleichte Konidien zeigten das Vorhandensein innerer Hyphenstrukturen, die denen von anderen Mitgliedern der Tetraplosphaeriaceae ähnelten. Ernakulamia wurde durch konidiale Morphologie und DNA-Sequenzdaten als eigenständige Gattung innerhalb der Familie eingestuft. Molekulare Daten wiesen eine frühere Einordnung innerhalb der nicht verwandten Petrakia (Melannomataceae, Pleosporales) oder der entfernten Piricauda (Capnodiales, Dothideomycetes) zurück.

In Delgado \& Miller (2017) wurde eine neue saprobe Taeniolella-Art vorgeschlagen und beschrieben, die am Stiehl eines toten Blattes von Sabal palmetto (Arecaceae) in Florida, USA, entdeckt wurde. Der Pilz unterschied sich von morphologisch ähnlichen Taeniolella-Arten in mehrfacher Hinsicht, was die Einführung eines neuen Taxons namens, $T$. Sabalicola, rechtfertigte. Phylogenetische Analysen, die auf ribosomalen DNA-Sequenzen basieren, deuten darauf hin, dass sich der Pilz von anderen Taeniolella-Arten mit verfügbaren molekularer Informationen unterscheidet und mit Mitgliedern von Sordariomycetidae (Ascomycota) verwandt ist. Seine Position bezüglich Ordnung und Familie innerhalb der Unterklasse ist jedoch weiterhin ungewiss. Molekulare Daten bestätigten auch 
den hochpolyphyletischen Status von Taeniolella in der Klasse der Sordariomyceten mit Arten, die über die Unterklassen Sordariomycetidae und Hypocreomycetidae verstreut sind. Diese Ergebnisse zeigen, dass die Gattung eine umfassenden Neubewertung benötigt. Darüber hinaus wurde der generische Typ T. exilis kürzlich in die Familie der Kirschsteiniotheliaceae in der weit entfernten Klasse der Dothideomyceten eingeordnet (Ertz et al. 2016). Daher gehört T. sabalicola nicht zu Taeniolella s. str. und müßte eigentlich in eine neue oder andere Gattung eingeornet werden. Den meisten saproben Arten von Taeniolella fehlen jedoch noch molekulare Daten, und ihre phylogenetischen Beziehungen bleiben ungewiss. Basierend auf dem eher vorläufigen Wissen über die verwandtschaftlichen Beziehungen von Taeniolella-ähnlichen Taxa wurde vorübergehend ein bestehendes generisches Konzept für $T$. sabalicola übernommen, bis weitere Daten verfügbar sind.

In Delgado et al. (2018) wurden der taxonomische Status und die phylogenetische Einordnung der saproben anamorphen Art Sporidesmium pachyanthicola anhand eines Exemplars überprüft, das auf einem toten Blatt von Sabal palmetto (Arecaceae) in Florida, USA, gesammelt wurde. Der Pilz wurde früher in Capnodiales (Dothideomyceten) innerhalb der breit definierten Familie Teratosphaeriaceae eingeordnet. Unsere phylogenetischen Analysen basierend auf ITS-LSU-Sequenzen in Kombination mit einer breiten taxonomischen Probenahme hingegen legen nahe, dass der Pilz ein Mitglied der Schwesterfamilie Extremaceae ist. Diese Position ist von der Familie der Sporidesmiaceae in Sordariomyceten weit entfernt einschließlich Arten der Gattung Sporidesmium s. str. Deshalb wurde der neue Gattungsname Castanedospora eingeführt, um $S$. pachyanthicola einzubeziehen. Der Pilz von der Florida-Probe wurde in Abwesenheit einer konservierten Lebendkultur epitypifiziert, und das aus Kuba stammende Vergleichsmaterial war depauperiert. Eine hypothetische Vewandtschaft zwischen Castanedospora und einem anderen Sporidesmium-ähnlichen Anamorph der Ordnung Capnodiales namens Sporidesmajora pennsylvaniensis wurde unter Verwendung der neu ermittelten molekularen Daten getestet. Trotz ihrer ordinalen Platzierung in Capnodiales und starken morphologischen Ähnlichkeit in der Kultur waren sie nicht artverwandt, sondern phylogenetisch weit entfernt. Letztere wurde zum ersten Mal als Mitglied der Familie Phaeothecoidiellaceae innerhalb der Ordnung Capnodiales eingeordnet. 
In Koukol et al. (2018) wurden fünf neue Arten der anamorphen Gattung Hermatomyces vorgeschlagen, die an faulen Zweigen und toten Stängeln verschiedener in Panama gesammelter Pflanzen isoliert wurden. Sie wurden Hermatomyces bifurcatus, $H$. constrictus, $H$. megasporus, $H$. sphaericoides und $H$. verrucosus genannt. Die Beschreibung der neuen Arten wurde zusätzlich zu morphologischen Merkmalen auch durch molekulare Daten gestützt. Zuvor beschriebene Arten wie $H$. tucumanensis, $H$. reticulatus und $H$. sphaericus wurden ebenfalls charakterisiert. Durch phylogenetische Analysen der Sequenzen von ribosomalen (ITS-LSU) und proteinkodierenden Gene ( $\beta$-TUB, RPB2, TEF1- $\alpha$ ) wurden alle Arten der monophyletischen Familie Hermatomycetaceae (Pleosporales, Dothideomycetes) zugeordnet, die bisher nur die Gattung Hermatomyces beinhaltet. Dies ist die erste umfassende Studie zu Hermatomyces in der Neotropis, bei der die phylogenetische Plazierung von $H$. tucumanensis, dem Holotypus, zum ersten Mal anhand molekularer Daten und anhand von drei repräsentativen Proben untersucht wurde. Es wurde ein kritischer Überblick über zehn andere in Panama nicht vorkommende Hermatomyces-Arten gegeben. Eine neue Kombination mit dem Namen $H$. reticulatus wurde vorgeschlagen, und vier zuvor beschriebene Taxa wurden auf der Grundlage von morphologischen und molekularen Nachweisen für insgesamt sechzehn akzeptierte Arten innerhalb der Gattung zu Synonymen reduziert. Zusätzlich zu den traditionellen phylogenetischen Analysemethoden wurde erstmals die Artenabgrenzung in Hermatomyces innerhalb des Stammbaums unter Verwendung eines Koaleszenzmodells getestet. Dieser Ansatz wurde in Studien zu saproben Anamorphen bisher nur selten angewendet. Es wurden neue Erkenntnisse über die Entwicklung der Gattung gewonnen, wie zum Beispiel Hinweise auf eine unvollständige Sortierung der Abstammungslinien und möglicherweise Hybridisierungsereignisse bei einigen Arten mit inkongruenten Stammbaumtopologien. Die besondere Morphologie und die konsequente Monophyse der akzeptierten Hermatomyces-Arten unterstützten die Anerkennung der Familie als gut abgegrenztes monophyletisches Taxon innerhalb von Pleosporales.

In Delgado et al. (2019), wurde eine neue Septonema-Art, die auf Holzresten von Pinus spp. in den USA und in der Tschechischen Republik entdeckt wurde, vorgeschlagen und beschrieben. Der Pilz unterscheidet sich morphologisch von den zuvor beschriebenen Arten, weshalb ein neues Taxon namens S. Iohmanii 
eingeführt wurde. Multigene phylogenetische Analysen unter Verwendung von Sequenzdaten von LSU- und TEF1- $\alpha-G e n e n$ legten nahe, dass beide Sammlungen trotz ihrer disjunkten Verteilung spezifisch sind und zur Ordnung Mytilinidiales (Dothideomycetes) gehören. Dies ist das erste Mal, dass ein Septonema-ähnlicher Anamorph mit Hilfe molekularer Ergebnisse zur Ordnung Mytilinidiales eingestuft wrude und die Einordnung auch vollständig mit bisher bekannten Kultur- und anderen traditionellen Beweismethoden übereinstimmt. Molekulare Daten wurden auch von einem S. secedens Isolat, dem Holotyp dieser Art, generiert, um seine systematische Position zu klären und die Hypothese zu testen, ob unser Pilz zu Septonema s. str. gehört. Der Stamm wurde in die Familie der Venturiaceae (Venturiales, Dothideomycetes) eingeordnet, aber die morphologische Untersuchung der entsprechenden Herbariumprobe ergab eine Zuordnung to der Art S. fasciculare, für die erstmals eine phylogenetische Plazierung bestimmt wurde. Der phylogenetische Status des Holotyps blieb unschlüssig welches eine Redisposition verhinderte. Die derzeitige Einordnung von Septonema wurde vorübergehend übernommen, bis neue Sammlungen und weitere molekulare Daten verfügbar sind. Wenn die Position des Holotyps außerhalb von Mytilinidiales bestätigt wird, kann S. lohmanii in einer neuen Gattung untergebracht werden. Die unterschiedlichen phylogenetischen Positionen dieser Septonema-Arten innerhalb von Dothideomyceten bestätigten die polyphyletische Natur der Gattung und die Notwendigkeit einer umfassenden taxonomischen Neubewertung.

In der vorliegenden Dissertation wird die molekulare Phylogenetik als das Mittel der Wahl zur Bestimmung von verwandtschftlichen Beziehungen für neu entdeckte oder anamorphe Pilze, die Pflanzenreste bevölkern, bestätigt. Sie ermöglicht es, sie vollständig in Ascomycota zu integrieren und eine Grundlage für bessere taxonomische Entscheidungen über ihre Klassifizierung zu schaffen. Das Fehlen von DNA-Sequenzen ist derzeit die größte Herausforderung für die vollständige Integration und Untersuchung in einem molekularen taxonomischen Rahmen. Die Bemühungen sollten sich darauf konzentrieren, sie zu sammeln und zu isolieren, um neue molekulare Daten zu erhalten und ihre einzigartige Biologie für zukünftige phylogenetische, mitogenomische und phylogenomische Studien zu nutzen. Nach der Erfassung muss die Gültigkeit morphologisch beschriebener Gattungen und Arten geprüft und korrigiert werden. Dies ist eine herausfordernde Aufgabe, wenn man bedenkt, dass es mehr als 1500 beschriebene Gattungen 
anamorpher Ascomycota gibt, die Tausende von Arten darstellen. Große polyphyletische Gattungen wie Taeniolella, Sporidesmium und Septonema, die teilweise in dieser Arbeit behandelt wurden und hauptsächlich saprobe Arten mit fragwürdigen verwandtschaftlichen Beziehungen enthalten, bedürfen weiterer Aufmerksamkeit. Die Neuentdeckung vieler anamorphen Arten ist zu erwarten aufgrund der jüngsten Schätzungen der Artenvielfalt von 2,2 bis 3,8 Millionen Pilzen im Gegensatz zu den derzeit mehr oder weniger bekannten 140.000 Pilzarten (Hawksworth \& Lücking, 2017; Lücking \& Hawksworth, 2018). Mykologische Untersuchungen mit Schwerpunkt auf Wiederentdeckung und Isolierung sollten daher in relativ gut erforschten Gebieten wie Nordamerika und Europa fortgesetzt werden. Sie sollten jedoch auch in untererforschten tropischen Ländern, in denen viele Anamorphe noch auf ihre Entdeckung warten und wo oft noch keine DNASequenzdaten vorliegen, stattfinden. Um die Anwendung von Namen anamorpher Taxa zu etablieren, sollten sorgfältige Epitypifizierungs- oder Neotypisierungsverfahren basierend auf sequenzierten Proben durchgeführt werden. Die zunehmende Verfügbarkeit von Genomischer Information aufgrund der sinkenden Kosten wird gut dokumentierte Proben und Isolate zum Schwepunkt dieser Gruppe machen für den Übergang von der Analyse kurzer Sequenzen zu Umfangreichen Analyse ganzer Genome und den daraus resultierenden Auswirkungen auf zukünftige phylogenetische und taxonomische Studien. 


\section{LIST OF PUBLICATIONS}

The present dissertation is based on the research work contained in the following papers:

Delgado G, Koukol O, Cáceres O, Piepenbring M (2017) The phylogenetic placement of Ernakulamia cochinensis within Pleosporales (Dothideomycetes, Ascomycota). Cryptogamie, Mycologie 38 (4): 435-451.

Delgado G, Miller AN (2017) South Florida microfungi: a new species of Taeniolella (anamorphic Sordariomycetes) isolated from cabbage palm. Nova Hedwigia 105 (12): 1-14.

Delgado G, Miller AN, Piepenbring M (2018) South Florida microfungi: Castanedospora, a new genus to accommodate Sporidesmium pachyanthicola (Capnodiales, Ascomycota). Cryptogamie, Mycologie 39 (1): 109-127.

Koukol O, Delgado G, Hofmann TA, Piepenbring M (2018) Panama, a hot spot for Hermatomyces (Hermatomycetaceae, Pleosporales) with five new species, and a critical synopsis of the genus. IMA Fungus 9 (1): 107-141.

Delgado G, Koukol O, Miller AN, Piepenbring M (2019) Septonema lohmanii G. Delgado \& O. Koukol, sp. nov., a new species in Mytilinidiales (Dothideomycetes) and the phylogenetic position of S. fasciculare Corda. Cryptogamie, Mycologie 40 (2): 3-21. 


\section{LIST OF FIGURES}

Figure 1. Schematic diagram of a typical life cycle in Pezizomycotina.

Figure 2. Morphological and developmental diversity of the anamorphic Ascomycota studied in this dissertation.

Figure 3. Best scoring RAxML maximum likelihood tree showing the phylogenetic position of studied anamorphic fungi (in bold) within the class Dothideomycetes.

Figure 4. Best scoring RAxML maximum likelihood tree showing the phylogenetic placement of Taeniolella sabalicola (in bold) and related taxa within the class Sordariomycetes. 


\section{LIST OF ABBREVIATIONS}

actA actin

BI Bayesian inference

BLAST Basic Local Alignment Search Tool

bp base pairs

BPI U.S. National Fungus Collections, Beltsville, USA

$\beta$-TUB $\beta$-tubulin

CaM Calmodulin

CBS Westerdijk Fungal Biodiversity Institute, Utrecht, The Netherlands

CCF Culture Collection of Fungi, Charles University, Prague, Czech Republic

GAPDH Glyceraldehyde-3-phosphate dehydrogenase

HIS3 Histone $\mathrm{H} 3$

ICBN International Code of Botanical Nomenclature

ILLS Illinois Natural History Survey Fungarium, Champaign, USA

IMI Fungarium of the Royal Botanic Gardens, Kew, United Kingdom

MAFFT Multiple Alignment using Fast Fourier Transform

MAT Mating-type

MEA malt extract agar

MEGA Molecular Evolutionary Genetics Analysis

ML Maximum likelihood

MSA Multiple Sequence Alignment

MUCL Mycothèque Université catholique de Louvain, Louvain-la-Neuve, Belgium

MUSCLE Multiple Sequence Comparison by Log- Expectation

ITS nuclear ribosomal internal transcribed spacer region

LSU 28S nuclear ribosomal large subunit

SSU $18 S$ nuclear ribosomal small subunit

PCR polymerase chain reaction

PDA potato dextrose agar

PMA Herbarium of the University of Panama, Panama City, Panama

PRC Herbarium of the Charles University, Prague, Czech Republic

PSC Phylogenetic Species Concept

RAxML Randomized Axelerated Maximum Likelihood

RPB1 RNA polymerase II largest subunit 
RPB2 RNA polymerase II second largest subunit rRNA Ribosomal ribonucleic acid

sp. species

spp. species pluralis

s. I. sensu lato

s. str. sensu stricto

SEM scanning electron microscopy

TEF1- $\alpha$ translation elongation factor 1-alpha

TEM Transmission electron microscopy

WA water agar 


\section{INTRODUCTION}

\section{1 General overview of the anamorphic Ascomycota}

\subsubsection{The filamentous Ascomycota: life cycle, pleomorphism and asexuality}

Ascomycota is the largest and most diverse division of the kingdom Fungi (Schoch et al. 2009). It currently comprises 6600 accepted genera with approximately 80000 species and an estimate of 1000-1500 new taxa introduced each year (Wijayawardene et al. 2017a, 2018). They are characterized by the presence of a specialized sac-like meiosporangium named the ascus in which sexually produced meiospores called ascospores are formed as a result of nuclear fusion immediately followed by meiosis. Most ascomycetes are filamentous or hyphal but others are unicellular, yeast-like or even capable of developing complex thalli by cell division as in the case of the class Laboulbeniomycetes. Together with their sister division Basidiomycota and the recently introduced Entorrhizomycota they form the subkingdom Dikarya defined by the putative synapomorphic character state of dikaryotic hyphae (Hibbett et al. 2007; Tedersoo et al. 2018). Three major phylogenetic lineages ranked as subdivisions have been resolved within Ascomycota (Kurtzman \& Sugiyama, 2015). They are: the early diverging Taphrinomycotina, lacking ascogenous hyphae and including the plant parasitic Taphrina spp. and other fungi with yeast stages and without ascomata; the Saccharomycotina, lacking also ascomata and including ascomycetous yeasts reproducing asexually by budding such as Saccharomyces cerevisiae, the baker's yeast, and the Pezizomycotina. This is the largest subdivision accounting for more than $90 \%$ of all members of Ascomycota and including the vast majority of filamentous, ascoma-producing species, although dimorphic taxa capable of both yeast and filamentous growth at certain point in their life cycles also exist (Spatafora et al. 2006; Taylor et al. 2004).

In filamentous ascomycetes belonging to Pezizomycotina the thallus consists of haploid, monokaryotic hyphae that grow and extend in the substrate forming the vegetative mycelium. Under specific conditions during their life cycle, vegetative hyphae differentiate and produce reproductive structures for either sexual or asexual reproduction or both (Fig. 1). In the case of heterothallic or self-incompatible species, two hyphae belonging to different mating types each one carrying genetically 
compatible nuclei must meet to start the development of fruiting bodies or ascomata. This is in contrast to homothallic or self-compatible species in which every strain is able to complete the sexual cycle without a mating partner (Pöggeler et al. 2004). In many species of Ascomycota, dissimilar gametangia named female ascogonia and male antheridia differentiate and fuse by gametangiogamy once the ascomata primordium develops in a process in which the male nuclei move through a conjugation bridge toward the female nuclei. In other species of Ascomycota, fertilization occurs by spermatization when antheridia are not produced and a small immotile gamete with one haploid nucleus named spermatium fuses with a receptive hypha (Piepenbring, 2015). Fertilization is followed by a short dikaryotic phase in which different nuclei associated in pairs called dikarya are present in ascogenous hyphae. Nuclei of a dikaryon fuse by karyogamy in the ascus mother cell and form a diploid nucleus. This one immediately divides by meiosis resulting in four haploid nuclei which number is often doubled to eight by an additional mitotic division in an endogenous development leading to the production of mature asci and the free-cell formation of ascospores inside them. Besides sexual reproduction, most Ascomycota also reproduce asexually by haploid spores named conidia. They are generated by mitosis and may be produced exogenously on specialized hyphae named conidiophores or enclosed within asexual fruiting bodies named conidiomata.

Ascomycetes reproducing by more than one independent kind of spores or propagules organically connected to each other throughout their life cycles are called pleomorphic (Hennebert, 1987). The terms anamorph and teleomorph have been applied to their asexual and sexually reproductive states, respectively, while the term holomorph refers to the whole fungal life cycle with all its manifested or potential expressions (Hennebert \& Weresub, 1977; Reynolds, 1993; Weresub \& Hennebert, 1979). Karyological terms such as mitotic or meiotic have also been applied to these states to describe spores that are formed as a result of mitotic or meiotic divisions during asexual or sexual reproduction, respectively (Sutton, 1993). Pleomorphism is a diverse condition in Fungi and particularly in Ascomycota. Reynolds (1993) considered three basic life cycles when referring to holomorph diversity: the pleomorphic holomorph, known from both sexual and asexual states, the meiotic holomorph known only from its sexual reproductive state, and the mitotic holomorph known only from its asexual state. Besides the duality anamorph-teleomorph, Hennebert (1987) recognized an extra level of pleomorphy named pleoanamorphy 


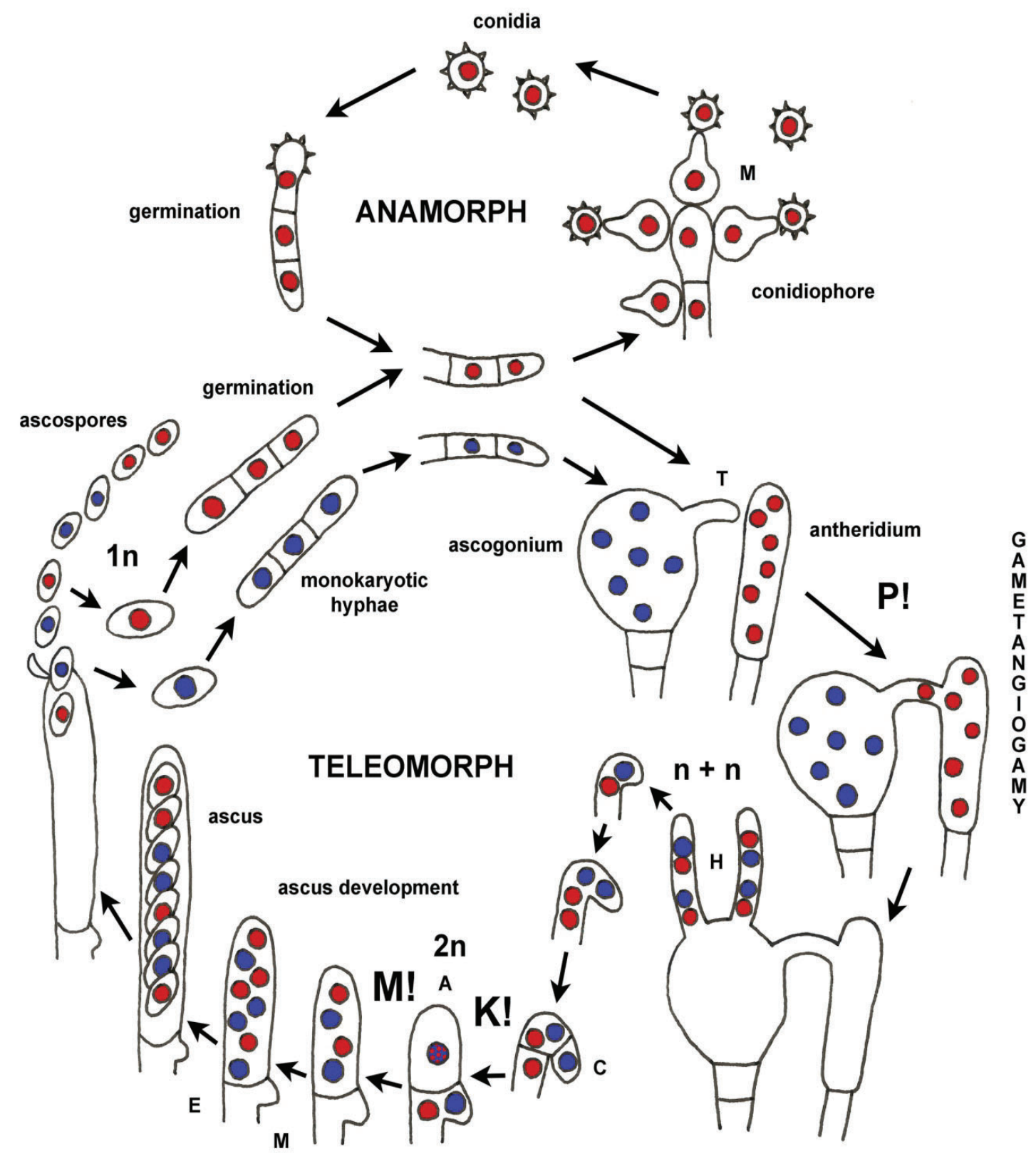

Figure 1. Schematic diagram of a typical life cycle in Pezizomycotina. A. Ascus mother cell. C. Crozier. E. Endospore formation. H. Ascogenous hypha. K! Karyogamy. M! Meiosis. M. Mitosis. P! Plasmogamy. T. Trichogyne. Modified from Piepenbring (2015).

represented by two or more distinct anamorphs called synanamorphs coexisting and recognized separately. These different reproductive states of pleomorphic Ascomycota may develop side by side and a connection between them can be made in nature or in culture media. However, they commonly occur and mature at different times or on different substrates, being often discovered or described independently 
making a link between them difficult or impossible to establish using only morphology-based methods (Gams, 2013; Seifert et al. 2011). Moreover, most members of Ascomycota, particularly within the subdivision Pezizomycotina, frequently reproduce by asexual or clonal means to the point that a large number of them are known only by their asexual states. They are called anamorphic, mitosporic, asexual, imperfect or conidial fungi, Fungi Anamorphici or more traditionally deuteromycetes. The group is the focus of the present dissertation and as a whole includes all those fungal taxa disseminated by propagules not formed from cells where meiosis has occurred (Kirk et al. 2008).

The most common type of asexual propagule is the conidium but others are also derived from unspecialized vegetative mycelium and produced by fragmentation or budding in the case of dimorphic species (Alexopoulos et al. 1996). Conidia have dispersal and survival functions in ascomycete life cycles allowing dissemination and restart of an individual, identical copy of the parental genome in a physically different place (Seifert \& Samuels, 2000). Monoanamorphic ascomycetes consisting of a single anamorph or synnanamorphic taxa producing two or more anamorphs can be categorized according to their phenotypes and role in life cycles as follows: mycelial or those lacking well-defined conidiophores; mononematous or having welldifferentiated conidiophores; conidiomata or forming fruiting-bodies; germinative or those comprising conidiogenous cells emerging directly from germinating conidia or ascospores; survival including single-celled or multicelled propagules such as chlamydospores, aleuriospores and sclerotia; yeast-like or masses of wet or slimy budding cells; spermatial or having dispersive conidia that germinate or not to form mycelium but serve as gametes; and vegetative anamorphs in which no distinct propagules are produced. Anamorphic fungi studied during this work are mononematous taxa having distinct conidiophores, mycelial species lacking them or capable of forming cushion-like conidiomata and they all reproduce by conidia.

Many of the different anamorphs outlined above have been correlated with some teleomorphic counterparts. However, the majority of the already described anamorphic taxa have not been connected yet to any sexual state and most of them apparently have lost the capacity to form a telemorph becoming permanently anamorphic (Seifert \& Gams, 2001). This is seemingly the case of all species investigated in the course of the present dissertation. None of them possesses a known teleomorph or meiotic state and therefore they are considered anamorphic or 
mitotic holomorphs. Reynolds (1993) estimated that mitotic holomorphs comprise $40 \%$ of Ascomycota species and Wijayawardene et al. (2017b) listed 1531 anamorphic genera with putative ascomycetous affinities but not linked to any known teleomorph. Asexual reproduction certainly confers advantages including energy efficiency, increased reproductive rates and preservation of well-adapted genomic configurations or haplotypes (Sun \& Heitman, 2011). However, clones have low genetic diversity, less capacity for adaptation to changing environments and less efficiency in purging deleterious mutations and selecting beneficial ones. Nevertheless, population genetics analyses, induction of sexual cycles, wholegenome approaches and identification, distribution and functional studies of MAT genes regulating sexual compatibility have provided evidence of recombination and cryptic sexuality in conidial fungi such as Aspergillus fumigatus, A. flavus, Penicillium chrysogenum, $P$. roqueforti and many other species considered largely or exclusively clonal (Dyer \& Kück, 2017). They may therefore take advantage of the many benefits of sex including the generation and maintenance of genetic variation within populations and the opportunity to generate novel genotypes for adequate response to environmental changes and long-term survival of species (Dyer \& Paoletti, 2005). This may also imply that the majority of asexually reproducing fungi have indeed the potential for sexual reproduction with very few truly asexual species and that reproduction in Ascomycota generally includes a combination of asexual reproduction interspersed with sex (Nieuwenhuis \& James, 2016). Sexual processes such as spermatization, somatogamy or non-meiotic recombination may occur in anamorphic fungi and asexual and sexual behaviors are not strictly separated in Fungi (Kirschner, 2019). With the exception perhaps of important pathogens and biotechnologically relevant or model species, life cycles of Ascomycota are in general poorly known and most aspects of the biology of anamorphic or mitotic holomorphs whose role in nature is mainly ecological are poorly studied. This is particularly relevant in the case of the anamorphic taxa treated in this dissertation which all display a saprobic lifestyle and basic information about their evolutionary relationships, for example, was lacking for most of them until the present research. 


\subsubsection{Morphological and developmental diversity of anamorphic Ascomycota}

The striking diversity of morphological and developmental features exhibited by the conidial anamorphs of Ascomycota (Fig. 2) has been used in their identification, characterization and classification attempts. The morphology of their sporulating structures including conidiophores, conidiogenous cells and conidia are currently used to describe genera and species although hyphae, mycelium and colony features are also included. The present dissertation is focused on those anamorphs traditionally known as hyphomycetes. They produce conidia on exposed conidiophores not enclosed inside discrete conidiomata as in the case of the group known as coelomycetes. The integrative terminology of essential works such as Carmichael et al. (1980), Cole \& Samson (1979), Ellis $(1971,1976)$ and Seifert et al. (2011) has been widely applied in formal descriptions of hyphomycetous anamorphs on natural substrate and can be used as well for taxa isolated in culture media.

Conidiophores are specialized, modified hyphae supporting single or multiple conidiogenous cells on which conidia are formed. They may arise terminally or laterally on the hyphae and according to their degree of similarity they can be classified as macronematous when they are usually erect and morphologically very different from a vegetative hypha, micronematous or reduced when they closely resemble a hyphae or semimacronematous when they differ only slightly and are often ascending but seldom erect. Examples among species included in this research are Ernakulamia cochinensis having micronematous conidiophores or lacking them, Septonema lohmanii or Taeniolella sabalicola which possess semimacronematous, somewhat repent or ascending ones and Septonema fasciculare with well distinct, macronematous conidiophores (Fig. 2 C, G, I). They may be simple or unbranched, sparingly or richly branched when conidiophore branching does not follow a defined pattern. If a pattern is discernible a conidiophore could be dichotomous with two diverging branches, verticillate with one or more whorls of branches or conidiogenous cells, or aspergilloid, penicillate or trichodermoid if they resemble the branching pattern typical for Aspergillus, Penicillium or Trichoderma spp., respectively (Seifert et al. 2011). Conidiophores in hyphomycetous anamorphs may be determinate when extend and cease to grow in length after the production of a terminal conidium or be indeterminate when they are capable of continued growth. They are single, also called mononematous, or can be aggregated in conidiomata named synnemata or sporodochia. A synnema consists 
of conidiophores tightly appressed together or even fused along most of their length forming a compact, erect, sometimes branched stipe bearing conidia at the apex or along the sides. A sporodochium is a cushion-like or pulvinate conidioma, usually superficial but sometimes also semi-immersed, with an open mass of conidia and closely packed, relatively short conidiophores arising from a basal mass of interwoven or stromatic hyphae. Conidiomatal structure varies considerably and intermediate forms exist between these categories (Seifert \& Okada, 1990). None of the anamorphic fungi studied in the course of the present work produced synnemata. However, species belonging to the genus Hermatomyces, for example, are characterized by forming conspicuous sporodochial conidiomata with a peculiar nestlike shape. These fruiting-bodies are composed of melanized, sterile hyphae surrounding a fertile sporulating center where conidia are located. Conidiomatal structures of several Hermatomyces species were described in detail in one of the publications included in the present dissertation (Koukol et al. 2018).

Conidiogenous cells are fertile cells usually developing on conidiophores that are capable of producing one or several conidia. According to their position on the conidiophore they can be terminal or intercalary when located between the apex and the conidiophore base. They also may be integrated when incorporated within the main axis of the conidiophore or discrete when separated from it and usually have a distinct shape. Two general modes of conidium ontogeny or conidiogenesis named blastic and thallic are typically recognized in conidiogenous cells. The blastic conidium development is characterized by the blowing out or marked enlargement of a conidium initial before it is delimited by a septum. The thallic conidium development usually does not involve enlargement of the conidium initial and conidia arise from differentiation and disarticulation of fertile hyphal cells after being previously delimited by septa. Each mode is morphologically and developmentally diverse but blastic conidiogenesis in particular is the most common among hyphomycetous anamorphs and was found among all studied fungi in spite of their disparate phylogenetic affinities. It can be divided on the basis of wall relationships in holoblastic, when both the outer and inner walls of the conidiogenous cells are continuous and take part in the formation of the blown-out conidium or enteroblastic, when only the inner wall of the conidiogenous cell or neither wall is involved in the formation of the conidium (Ellis, 1971, 1976). 
Blastic processes may be monoblastic or polyblastic if single or multiple conidia are formed at conidiogenous loci. Species of the genus Septonema described during this research, for example, were found to be mono or polyblastic having one or two loci per fertile cell each one capable of producing conidia (Delgado et al. 2019). Conidiogenous cells may stop growing and be determinate or extend enteroblastically forming closely spaced annular extensions and be annellidic. Another important type of enteroblastic development is the phialide where conidia are produced endogenously in a basipetal succession within a flask-shaped or cylindrical conidiogenous cell often with a distinct funnel-shaped collarette at the tip. A particular type of apparently enteroblastic process is the tretic conidiogenesis where conidia are produced through one or multiple pores in the wall of the conidiogenous cells. Among those anamorphs investigated in the present study, the genus Ernakulamia produce globose or subglobose, tretic conidiogenous cells with a single pore that after conidial secession leave another visible pore at the base of the mature seceded conidium (Fig. $2 \mathrm{H}-\mathrm{I}$ ). Other examples of polyblastic conidiogenous cells are synchronous, when many blastic conidia are blown-out simultaneously from many loci or sympodial, referring to a continuous growth in a geniculate, zig-zag shaped fertile zone called a rachis. Thallic conidiogenesis, on the other hand, is less common among anamorphic Ascomycota. It may be divided in holothallic or thallicsolitary, in which a terminal or intercalary hyphal cell converts into a single conidium named thalloconidium or thallic-arthric, in which the fertile hypha converts into a series or chain of conidia called arthroconidia that are liberated into single cells by fragmentation and disarticulation (de Hoog et al. 2000). None of the anamorphic genera studied in the course of this work possessed thallic development.

Conidia are the asexual, non-motile spores characteristic of most anamorphic Ascomycota that are produced by mitosis on conidiogenous cells. They are very variable in shape, size, color, septation, ornamentation and origin (Fig. 2). The conidial nomenclature of Saccardo has been traditionally used to characterize conidia and includes seven morphological types based on a combination of shape and septation. They are: amerospores for one-celled conidia, didymospores for twocelled ones, phragmospores for conidia with two or more transverse septa, dictyospores if they have both transverse and oblique or longitudinal septa, scolecospores for long, slender conidia, staurospore if conidia are star-shaped and helicospores for spirally coiled ones. These terms can be easily applied to 
characterize conidia produced by those anamorphs included in the present dissertation. Examples are Castanedospora pachyanthicola having scolecoconidia, Ernakulamia cochinensis producing stauroconidia or Taeniolella sabalicola with phragmoconidia. Multicellular conidia are referred to as distoseptate if a secondary thickening of cell walls and septa is visible and cell lumina are seen reduced (Seifert et al. 2011). This is in contrast to euseptate, the most common type of conidial septation, in which only one wall layer is visible, secondary thickening is lacking and cell lumen is not distinctly reduced.

The surface of conidial walls is variable and can be smooth or ornamented and ranging from finely or minutely verruculose to distinctly verrucose or warted but also spinulose or echinulate when having minute or small spines. Example is the fungus Septonema lohmanii, newly described in the course of this research (Delgado et al. 2019), which is characterized by distinctly ornamented conidiophores, branches, conidia and hyphae, ranging from verruculose to strongly verrucose with prominent rounded warts (Fig. 2 C-D). Conidial walls may also bear arms or appendages in different positions on the conidium and they play an important role in attaching the conidia to the substrate and ensure their germination (Crous et al. 2012). Two of the anamorphic genera studied during the present dissertation, Ernakulamia and Piricaudilium, possess appendiculate conidia bearing numerous appendages (Delgado et al. 2017). Conidia may be single or catenate and form chains. Basipetal chains have the youngest conidium at the base and the oldest at the top while acropetal chains are often branched and extend at the distal end having the youngest conidium at the top. Septonema fasciculare, for example, is characterized by simple or rarely branched acropetal chains of up to 9 conidia while Taeniolella sabalicola is capable of forming acropetal chains of up to 10 conidia when grown in culture media (Delgado \& Miller, 2017; Delgado et al. 2019). Conidia typically separate or secede from conidiogenous cells or chains by two different processes. They are named schizolytic if secession occurs by the splitting of the delimiting septum leaving behind a scar, or rhexolytic when the conidium is liberated by the fracture of an intermediate cell below the conidium leaving behind wall remnants called frills at the base of the conidium and the apex of the conidiogenous cell (Cole \& Samson, 1979; Seifert et al. 2011). Conidia belonging to all anamorphic taxa treated in the present work secede by schizolytic detachment processes. 


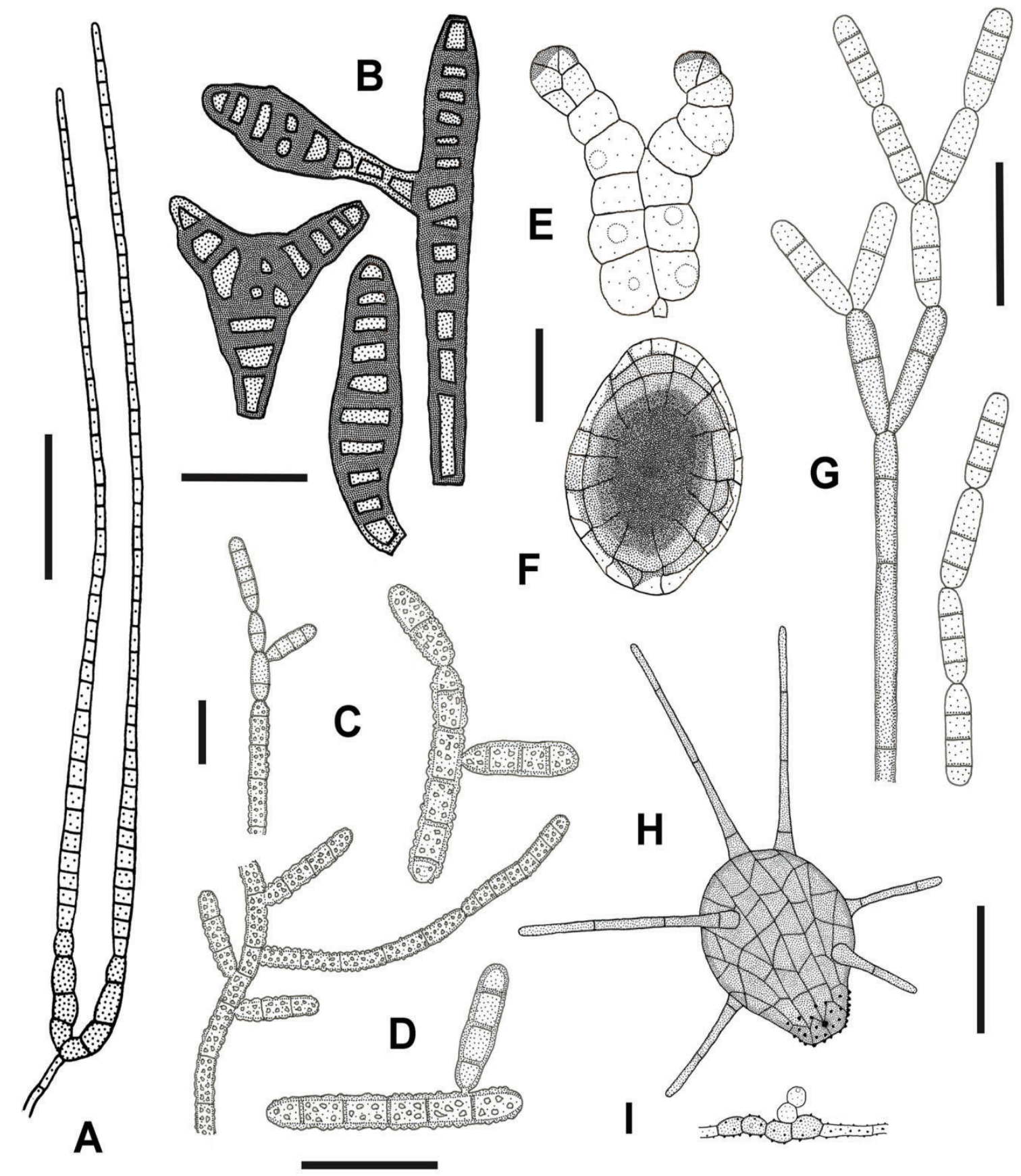

Figure 2. Morphological and developmental diversity of anamorphic Ascomycota studied in this dissertation. A. Castanedospora pachyanthicola. Conidiophores, conidiogenous cells and conidia. B. Taeniolella sabalicola. Conidia. C-D. Septonema lohmanii. C. Conidiophores, branches and conidia. D. Conidia in chains. E-F. Hermatomyces megasporus. Cylindrical and lenticular conidia. G. S. fasciculare. Conidiophores, ramoconidia and conidia in chains. $\mathbf{H}-\mathbf{I}$. Ernakulamia cochinensis $\mathbf{H}$. Conidium. I. Tretic conidiogenous cells. Taken or redrawn from: A. Delgado et al. (2018); B. Delgado \& Miller (2017); C-D, G. Delgado et al. (2019); E-F. Koukol et al. (2018); H-I. Delgado et al. (2017). Scale bars: $A=30 \mu \mathrm{m}, \mathrm{B}-\mathrm{I}=20 \mu \mathrm{m}$. 
Colonies, whether on natural substrate or artificial media, are also widely variable. On natural substrate, colonies are often effuse but they can also be compact, punctiform, granular or differ in texture and be hairy, velvety or powdery among other possibilities. Mycelium may be immersed or superficial in the substratum or a combination of both and composed of septate hyphae ranging from colorless or hyaline to darkly pigmented in pale or dark brown colors. Hyphae may aggregate forming cushion-like structures called stromata that can be prosenchymatous when hyphae are still recognizable or pseudoparenchymatous when they resemble parenchymatic cells of plant tissues. They may also intertwine forming loose mats under conidiomata called subicula or be modified in structures such as setae. These are hair-like, erect and thick-walled hyphae intermixed with conidiophores and having a protective function.

Many anamorphs grow well on artificial media when incubated at standard room temperature $\left(22-25^{\circ} \mathrm{C}\right)$ exhibiting a diversity of colony features that together with micromorphological studies are very useful for identification at generic or specific level. Colony diameter, for example, depends on the fungus growth rate. It may be very slow or restricted, reaching only a few millimeters in months like in the case of Taeniolella sabalicola newly described in the course of this research (Delgado \& Miller, 2017), or be fast growing and spread out quickly on the agar plate. Colonies may also exhibit a wide range of colors, textures and topographies including the color of the colony reverse when seen from the bottom of the agar plate. Colonies also may produce diffusible pigments into the agar or exudates in the form of liquid droplets with different colors. Colony texture may be cottony or woolly due to abundant aerial mycelium, velvety when aerial mycelium is more compact or powdery and dusty in appearance when rich in conidia among others. Colony topography may range from flat to umbonate or raised at the center, with furrows and regular or irregular margins, or zonate and developing concentric rings or bands with different color or texture. In general, nutrient-rich media increase the formation of aerial mycelium but nutrient-poor media enhance sporulation (de Hoog et al. 2000). Commonly used media such as MEA or PDA promote rapid mycelial growth but low nutrient WA, for example, favor starvation or nutritional depletion that stimulates sporulation (Su et al. 2012). In the course of the present dissertation, all anamorphic fungi subject of study were grown on rich or poor culture media and their colony 
features were described in detail in both natural and artificial conditions as part of their morphological or cultural characterization.

\subsubsection{Ecology and importance of anamorphic Ascomycota}

Hyphomycetous anamorphs of Ascomycota together with other microfungi are able to occupy a wide variety of niches and microhabitats in most terrestrial but also freshwater and marine ecosystems. They are usually generalists that may exploit a wide range of nutrient sources living mostly as saprobes that play an active role in the decomposition of non-living, organic or inorganic matter and actively contributing to the recycling and distribution of nutrients or chemical compounds in ecosystems (Rossman, 1997). In contrast, many others are specialist living as parasites or endophytes on other organisms, although many parasitic species are capable of living on dead organic materials and be either facultative parasites or facultative saprobes (Alexopoulos et al. 1996). Their capacity to produce large numbers of conidia allows them to be easily disseminated by the wind, splash water, insects or other animals and rapidly encounter new habitats to colonize. Examples of the many different substrates and food sources that conidial anamorphs are able to occupy include the organs of living vascular plants, their leaf surfaces and exudates; parts of dead vascular plants; other fungi, lichens, algae and bryophytes; the skin, feathers, hair, dung and nests of vertebrates; exoskeletons of insects and their nests; nematodes and other animal hosts such as collembolan, copepods and rotifers; rocks, soil, water foam or litter and wood immersed in sea or freshwater even the water retained in bromeliads among many others (Hawksworth \& Mueller, 2005).

Accordingly, hyphomycetous anamorphs can be divided in many ecological groups based on their habitats and the roles they play, with conidia often having distinct morphologies in response to particular environmental conditions (Alexopoulos et al. 1996; Subramanian, 1983). These groups are: the aquatic or Ingoldian, typically having tetraradiate or sigmoidal conidia that are trapped and dispersed by foam in well-aerated water bodies; the aeroaquatic, with more or less globose and mesh-like structures or three-dimensional, spirally-shaped propagules for trapping air bubbles inside and floating in stagnant freshwater bodies; coprophilous or those inhabiting dung of herbivores and carnivores animals; fungicolous attacking a variety of fungal hosts particularly agarics; the predacious of small animals in which the nematode-destroying are the best known; the 
entomopathogenic or arthropod-associated including necrotrophs that kill and grow inside the host or biotrophs and obligate parasites that obtain their nutrients from a living host; the human and animal pathogens producing superficial to systemic mycoses of internal organs and affecting normal or immunocompromised patients; the plant pathogens infecting a wide range of economically important crops as well as plants in wild vegetation; the soil-dwelling which constitute a large fraction of the soil biomass along with other fungi and microorganisms; and the airborne or those occurring in the air in which conidia are important components of the air spora. Finally, a large number of anamorphic Ascomycota are saprobic on dead plant debris. They are capable of degrading dead plant matter by the production and secretion of a large array of extracellular enzymes becoming essential players in carbon recyclying in ecosystems. This group is the subject of the present dissertation and they are known as foliicolous, corticolous or lignicolous if involved in leaf litter, bark or wood decomposition, respectively.

The diversity of anamorphic Ascomycota has made possible to effectively exploit them in several positive ways. They currently have many useful applications in biotechnology, medicine, food industry, bioremediation, metabolite discovery and production, biocontrol or as bioindicators (Pointing \& Hyde, 2001). In contrast, they negatively impact many human activities when producing very toxic secondary metabolites known as mycotoxins or when causing diseases and biodeterioration. Some of their most important applications are the production of secondary metabolites including antibiotics, statins for cholesterol-management and immunosuppressant drugs. Notable examples are the penicillin obtained from Penicillium chrysogenum, the cyclosporin produced by Tolypocladium inflatum and the pravastatin obtained from $P$. citrinum to name a few (Raja et al. 2017). Saprobic microfungi such as those studied in this work possess a limitless but still untapped potential for metabolic variation (Bills \& Gloer, 2016). They are often suitable targets for bioprospecting or bioscreeening programs conducted by pharmaceutical companies or academic institutions as possible sources of novel bioactive compounds or promising commercial drugs. Industrial strains of seven anamorphic fungi such as Trichoderma reesei, T. harzianum or Aspergillus niger produce nearly $70 \%$ of all fungal extracellular enzymes used in food and animal feed industries, the detergent industry and the production of biofuel ethanol (Meyer et al. 2016; Raghuwanshi et al. 2016; Willis, 2018). Other microfungal strains belonging to the 
genera Paecilomyces, Penicilium, Aspergillus or Trichoderma are actively used in bioremediation processes including bioconversion of soluble or insoluble substances, treatment of waste gases or decontamination of soils with aromatic hydrocarbons, heavy metals or radioactive materials (de Carvalho, 2016). On the other hand, anamorphic members of Orbiliales (Orbiliomycetes) or Hypocreales (Sordariomycetes) are well known antagonistic of plant-parasitic nematodes. They kill or disrupt their life cycle acting as important agents in biological control and becoming an ecologically friendly alternative to chemical nematicides (LaMondia \& Timper, 2016).

In contrast, anamorphic Ascomycota adversely affect human welfare in many important ways. Species such as the brain infecting agent Cladophialophora bantiana, the main aflatoxin producer Aspergillus flavus or the indoor black mold Stachybotrys chartarum are considered among the world's ten most feared fungi (Hyde et al. 2018). Fungal pathogens and opportunists of ascomycetous affinities cause serious human infections usually difficult to treat. They currently account for 263 hyphomycetous anamorphs involved in diseases such as invasive aspergillosis produced by members of the genus Aspergillus or ringworm caused by species of the anamorphic genera Epidermophyton, Microsporum or Trichophyton among the most prevalent (de Hoog et al. 2001). Fungi are among the dominant causal agents of plant diseases and anamorphic ascomycetes such as Pyricularia oryzae, Botrytis cinerea, Fusarium graminearum and F. oxysporum are among the most destructive pathogens causing devastating losses in crop production (Dean et al. 2012). Certain anamorphs also produce mycotoxins that are capable of causing disease or death in humans and animals when consumed as part of food or feed (Miller, 2016). Agriculturally important mycotoxins are the ochratoxins produced by Penicillium verrucosum or Aspergillus ochraceous, fumonisin produced by Fusarium species and the carcinogenic aflatoxins produced by $A$. flavus and $A$. parasiticus. Finally, the interaction of airborne conidia with humans in both indoor and outdoor environments can cause sensitization, fungal related hypersensitivity diseases and fungal related allergy symptoms associated with mold sensitivity (Amado \& Barnes, 2016).

\subsection{Traditional approaches in the taxonomy of anamorphic Ascomycota}

Anamorphic taxa, including those with putative affinities to Ascomycota, have been traditionally grouped for practical purposes in a deliberately artificial system as 
a concession to the necessity of identifying and naming them (Gams, 1995). In the absence of a known sexual state and the impossibility to classify them together with their teleomorphic counterparts, morphological or developmental characters of conidiophores, conidiogenous cells and conidia were considered of primary importance and regarded as taxonomically informative. They have been used to delimit genera, species or even suprageneric taxa that often do not reflect phylogenetic relationships and therefore they represent form-taxa and not natural entities or groups. These artificial taxa often group together anamorphic fungi which greatly differ or separate others that are related by a common phylogeny, morphology and biology. The two major historical breakthroughs that greatly influenced morphology-based taxonomic studies of these fungi are the Saccardoan or sporological system, developed by P.A. Saccardo in the late 19th century, and the Hughesian or ontogenetic system developed by S. J. Hughes in the middle 20th century (Subramanian, 1983; Seifert et al. 2011).

\subsubsection{The Saccardoan system and its limitations}

The Saccardoan system was preceded by the simplistic division of Fungi made by the German mycologist Karl W.G.L. Fuckel into Fungi Perfecti for sexual forms and Fungi Imperfecti for asexual forms and the latter was later adopted by Saccardo as the class Deuteromycetes which translates as secondary or inferior fungi (Kendrick, 1981; Weresub \& Pirozynski, 1979). Based on primary characters such as presence or absence and types of fruiting-bodies, Saccardo divided the deuteromycetes into four form-groups: the Sphaeropsideae and Melanconieae, both including coelomycetous anamorphs, the Hyphomyceteae for hyphomycetous anamorphs, and the Mycelia Sterilia for taxa lacking spores. He divided the hyphomycetes into four form-families named the Mucedineae, the Dematieae, the Stilbeae and the Tubercularieae using conidiophores aggregation and the color of mature conidia and hyphae as criteria (Seifert et al. 2011). The Mucedineae and Dematieae were introduced for taxa with solitary conidiophores and hyaline or pigmented structures, respectively, while the Stilbeae included hyphomycetes forming synnemata and the Tubercularieae for those producing sporodochia. These families were divided according to septation and conidial shape into seven sections corresponding to equal number of morphological types. They are: the Amerosporae for one-celled conidia; Didymosporae for two-celled spores; Phragmosporae 
including conidia with two or more transverse septa; Dictyosporae with conidia having both transverse and oblique or longitudinal septa; Scolecosporae including long, slender spores; Staurosporae for star-shaped conidia; and Helicosporae for spirally coiled conidia. These sections were further subdivided on the basis of other morphological criteria such as subsections Micronemeae and Macronemeae for short and long, distinct conidiophores, respectively, or whether conidia are solitary or catenate.

Saccardo's system prevailed for subsequent years because it was highly practical and based on general and easily identifiable characters of conidia and conidiophores (Subramanian, 1983). However, its artificial and subjective nature was early recognized and its reliability soon questioned as more and more taxa were discovered. Many of the characters considered of primary importance are highly variable or inconsistent, particularly when seen in culture, while his orders and families did not reflect natural relationships and were often heterogeneous serving only to group morphologically similar taxa in an artificial classification (Goos, 1956; Barron, 1968). Nevertheless, Saccardo's terminology remains at the root of many morphological terms in current use today and his groups are still colloquially used for identification purposes as good descriptors. Relatively recent works such as Barnett \& Hunter (1998), although recognizing its artificiality, still employed his system considering it the best way to first learn the practicalities necessary for identification of anamorphic fungi. More recently, Kirk et al. (2008) used Saccardo's spore groups as part of their coding system of entries for anamorphic genera while Seifert et al. (2011) arranged their synoptic plates of hyphomycetous genera based on conidial septation and Saccardo's spore types. Both examples illustrate how these criteria are still relevant and useful today in facilitating morphological identification. In the present dissertation, terms rooted in Saccardo's system such as macronematous or micronematous among others are included in morphological descriptions of the studied fungi and the name hyphomycete is often used to refer to the group of anamorphic taxa subject of this study.

\subsubsection{The Hughesian system and its limitations}

The Hughesian or ontogenetic system (Hughes, 1953), on the other hand, gave primary emphasis to conidial ontogeny and developmental criteria as more stable for classifying anamorphs, relegating Saccardoan characters of conidial color, 
shape, septation or conidiophores aggregation to secondary importance. Hughes's premise was that there are only a limited number of ways in which conidia can develop from conidiogenous cells and anamorphic fungi will be better classified together when the precise methods of conidium ontogeny was first considered for taxa delimitation. He classified the hyphomycetes in eight sections and two subsections based on developmental criteria such as conidiophore growth, whether acropetal or growing at the apical region or basipetal or growing at the basal region, and the type of conidium development. This approach was later refined and expanded by subsequent authors such as Tubaki (1958), Subramanian (1962) or Barron (1968) who divided or added extra sections to the original ones proposed by Hughes and also recognized different types of conidia.

In 1969 the First International Conference on Criteria and Terminology in the Fungi Imperfecti took place at Kananaskis, Canada, to discuss and standardize the concepts, definitions and terms of the ontogenetic approach of Hughes (Kendrick, 1971). Related topics such as anamorph-teleomorph connections, pleoanamorphism and early ultrastructural studies of conidiogenous cells in hyphomycetes were also covered. As a result, an updated scheme of Hughes' system was proposed for separating and characterizing hyphomycetous anamorphs by coded ontogenetic groups. A similar arrangement and terminology was adopted by Ellis $(1971,1976)$ in his two influential compilations of dematiaceous hyphomycetes where genera were keyed out and defined in the context of the ontogenetic system but restricted to single modes of conidiogenesis. The so called Kananaskis-I conference stimulated an increasing usage of techniques beyond the light microscope such as time-lapse photography or scanning and transmission electron-microscopy aimed to clarify the subtle details of developmental processes involved in conidiogenesis. Cole \& Samson (1979) summarized and expanded these ultrastructural studies with profuse SEM, TEM and diagrammatic illustrations of a large number of anamorphic fungi greatly improving our understanding of the diversity of these key processes.

In 1977 a second international conference entitled "The Whole Fungus, the Sexual-Asexual Synthesis" was held again at Kananaskis not only devoted to anamorphs but also focused on the taxonomic and nomenclatural complexities of related pleomorphic and pleoanamorphic fungi (Kendrick, 1979). The terms anamorph, teleomorph and holomorph were adopted from the beginning and an extensive attempt to link the taxonomic system of ascomycetous teleomorphs with 
their known anamorphs was made based on poorly to well documented connections available at the time (Kendrick \& DiCosmo, 1979). During this conference, evidence was provided that some different modes of blastic conidiogenesis may interconverse between each other under certain environmental conditions or due to age and therefore these developmental processes were of less taxonomic and phylogenetic significance than previously believed (Madelin, 1979). Wang (1979) also showed that pleoanamorphic fungi were not restricted to particular modes of conidial formation and several examples exist that the same anamorph can exhibit more than one mode of conidiogenesis. An early admission related with Hughes's system was that developmental features were not as stable as originally thought, many intermediate or transitional events were discovered as more and more taxa were studied and therefore they alone cannot be the basis of a more natural classification of anamorphic fungi despite their widespread acceptance as valuable taxonomic characters (Kendrick \& Nag Raj, 1979). Nevertheless, Kendrick (1981) acknowledged the great impact that developmental data have made to our understanding of anamorphic fungi and realized that only the integration of morphology, development and teleomorph connections can make progress toward their classification.

The original terminology and criteria of Hughes continued to be scrutinized and questioned as simplistic or contradictory in some cases for generic circumscription and improvements or refinements were further proposed. Sigler (1989), for example, found difficulties in applying the basic terms of thallic and blastic to the mode of conidiogenesis in anamorphs of Onygenales, which show intergradation between them due to morphological plasticity. She also raised concerns over differentiating members of the group based on ontogenetic differences that may result in separating fungi similar in many respects. Minter et al. (1982, 1983), on the other hand, proposed that a continuum of developmental stages within once considered discrete modes of conidial production should be recognized in order to allow proper description of the many variants of conidiogenous events. These stages were the initiation, maturation, delimitation and secession of conidia as well as the proliferation and regeneration of the conidiogenous cell. On the basis that conidial structures are modified hyphae Minter (1987) also considered that the key to interpreting conidiogenesis lies in understanding the three types of cell-wall building production at the hyphal tip named apical, diffuse and ring processes together with 
the developmental plasticity of hyphal growth. The combination of these developmental events led Hennebert \& Sutton (1994) to recognize 43 of them which presumably should allow to characterize and identify any conidial fungus. However, they added a layer of complexity often difficult to apply by most taxonomists who prefer instead to use well-established terms describing a multistep developmental process and to note variations from the general pattern (Seifert \& Gams, 2001). Despite the limilations of Hughes's system, many generic and species concepts in anamorphic Ascomycota are still based on the modes of conidiogenesis he first delineated and therefore, morphological descriptions of all novel or interesting anamorphs studied in the present dissertation include details of conidiogenesis events.

\subsubsection{Suprageneric classifications and nomenclature of anamorphic Ascomycota}

Anamorphic fungi with unknown teleomorph connections such as those treated in this work were traditionally classified within the form-division Deuteromycota or at other taxonomic ranks named Deuteromycotina, Deuteromycetes or Fungi Imperfecti. These suprageneric form-taxa were given formal taxonomic status and often treated equal in rank to the more naturally defined divisions of Ascomycota or Basidiomycota. Deuteromycota was accepted as a polyphyletic and artificial assemblage containing the asexually reproducing states of these fungal divisions together with those 'orphan' anamorphs lacking a known teleomorph but assumed to be their relatives by analogy (Hennebert, 1995). Most anamorphic fungi are morphologically similar to the anamorphic states of some wellknown Ascomycota and to a lesser extent of Basidiomycota and therefore they could be considered members of these phyla whose teleomorphic stages are rarely formed in nature and have not been discovered yet or were lost in the course of their evolution (Guarro et al. 1999). Septal and wall ultrastructure also helped to recognize whether a particular anamorphic fungus has ascomycetous or basidiomycetous affinities. The presence of simple, uniperforate septa with associated Woronin bodies and two-layered hyphal walls in many of them, including a thin electron-dense outer layer and a relatively electron-transparent inner layer, also supported that most anamorphs were related to Ascomycota (Cole, 1986). At the class level, conidial and mycelial anamorphs were traditionally divided into three morphological groups that 
received formal rank: Hyphomycetes or mycelial forms which bear conidia on separate or aggregated hyphae but not inside discrete conidiomata, Coelomycetes which produce conidia in enclosed conidiomata, and Agonomycetes or sterile, mycelial forms that may produce chlamydospores, sclerotia or related vegetative structures (Kirk et al. 2008). Nowadays, however, all these suprageneric form-taxa without phylogenetic significance are considered obsolete and they have long been abandoned as a result of the increasing usage of molecular data to integrate anamorphic fungi into the different taxonomic levels of Ascomycota and Basidiomycota (Seifert, 1993; Taylor, 1995).

Similarly, anamorphic genera are also considered form-taxa whose phylogenetic relationships are unknown for most of them. Seifert et al. (2011) delineated the five restrictions placed to their use by previous editions of the formerly named International Code of Botanical Nomenclature (ICBN) which allowed a dual nomenclature or the application of separate names to the different states of pleomorphic fungi. These restrictions were: 1) form-generic names only apply to the state or morph represented by their type and not to the whole organism with more than one morph; 2) they are not mutually exclusive and a single species may have synanamorphs in two or more form genera; 3 ) form genera are not formally assigned to families or orders of Ascomycota or Basidiomycota; 4) the nomenclature of the holomorphs takes precedence over and is independent of the nomenclature of anamorphic genera, and 5) when anamorphic and teleomorphic names are unequivocally connected, the latter has preference independent of priority. Since the recent abolishment of dual nomenclature and the adoption of the 'one fungus-one name' principle starting January $1^{\text {st }}, 2013$, a fungus under the renamed International Code of Nomenclature for algae, fungi, and plants can only have a single name and all legitimate names compete equally for priority regardless of which state they were typified by (Hawksworth, 2011). The Code in its latest Melbourne and Shenzhen editions now recognizes that fungal names, whether they belong to anamorphic or teleomorphic states, most conform to the same provisions applied to all other Fungi. This modern view of anamorphic taxa together with their increasing classification side by side to their relatives in Ascomycota or Basidiomycota using molecular approaches and the consequent redefinition of anamorphic genera and species in a phylogenetic context are gradually enhancing their transition into less artificial, more natural taxa. 


\subsection{Molecular phylogenetics in the taxonomy of anamorphic Ascomycota}

Due to the limitations of morphological and developmental characters to establish reliable classification and identification systems for anamorphic fungi, additional molecular, biochemical and physiological characters were also investigated in the context of taxonomic studies of the group. They included gene sequences, secondary metabolites, ubiquinone systems, fatty acid and cell wall composition, enzyme and protein profiles, enzymatic activities and growth rates among others (Hennebert, 1995; Guarro et al. 1999). Molecular data, however, have emerged as the tool of choice in fungal systematics having a tremendous impact on the taxonomy and nomenclature of anamorphic fungi (Shenoy et al. 2007; Taylor, 2011). Molecular characters offer several advantages over morphological ones including their larger number for inference of phylogenetic relationships, especially in groups such as Fungi that are in general poor in morphological features; their intrinsic discrete code in contrast to morphological data that are prone to subjectivity and coding errors; and their smaller amount of homoplasy compared to morphological traits in which similarity is often due to convergent evolution and not to common ancestry (Berger et al. 2011). In the case of pleomorphic or anamorphic fungi, the ubiquity of molecular characters makes them independent of the reproductive states expressed by the fungus (Taylor, 1993).

Nowadays, the wide availability and decreasing cost of molecular techniques such as PCR amplification and DNA sequencing have made molecular data easier than ever to obtain and incorporate in taxonomic studies of anamorphic Ascomycota and Fungi in general. The standard PCR method includes a series of heating and cooling steps repeated through a number of cycles in which short pieces of singlestranded DNA called primers allow the exponential amplification of DNA segments in the presence of the thermostable enzyme DNA polymerase (Kirk et al. 2008). PCR products are then sequenced to determine the consecutive order of their DNA bases usually using the Sanger chain termination method although more powerful highthroughput sequencing technologies are available nowadays. White et al. (1990) developed specific PCR primers and protocols designed to amplify and direct sequence various regions of the nuclear and mitochondrial ribosomal DNA for phylogenetic studies of fungi. Their contribution led the way to the pioneer work of Berbee \& Taylor (1992) where one anamorphic taxon Sporothrix schenckii was linked for the first time to the teleomorphic genus Ophiostoma using DNA sequence 
data. PCR amplification and Sanger sequencing, preceded by DNA extraction from fungal colonies grown on agar media, were used in the course of the present dissertation to obtain molecular data for inferring phylogenetic relationships among the studied fungi.

These advances paved the way to the Fungal Holomorph Conference that took place in Oregon, USA, in 1992. During this meeting, morphological and molecular perspectives on the taxonomy of anamorphic fungi were brought together and their integration into the natural classification system of Fungi using molecular data was envisioned as possible with the consequent abandonment of the artificial Deuteromycotina (Reynolds \& Taylor, 1993). Previous sporadic attempts to correlate the classification systems of Ascomycota with that of the deuteromycetes (Kendrick \& DiCosmo, 1979; Tubaki, 1981) proved that the systems were too divergent to permit a common base for integrating anamorphic taxa (Sutton, 1996). Hawksworth \& Mouchacca (1994) and Reynolds (1994) considered at the moment the complete integration of meiotic, pleomorphic and particularly mitotic holomorphs into the Ascomycota as the most challenging long-term task and specific goal toward advancing ascomycete systematics.

Subsequently, the increasing incorporation of molecular data in fungal systematics as a whole and particularly in Ascomycota motivated major taxonomic and nomenclatural changes. Examples were the abolishment of the Article 59 of the former ICBN which allowed the dual nomenclature of pleomorphic fungi and the transition to a single-name system for all Fungi in spite of the reproductive state they manifest (Hawksworth et al. 2011; McNeill et al. 2012). In the case of anamorphic taxa, molecular data made possible to reveal the phylogenetic position of many genera and species and to gradually incorporate them into the natural classification system of Ascomycota (Hyde et al. 2011; Wijayawardene et al. 2012, 2017b). They also showed that well-recognized anamorphic genera such as Acremonium, Chalara, Diplococcium, Fusarium, Myrothecium, Penicillium or Sporidesmium including many saprobic species were polyphyletic or paraphyletic and in need of extensive revision (Shenoy et al. 2007). Increasing efforts to recollect and isolate anamorphs on agar media combined with molecular data analysis also led to resolve many anamorphteleomorph connections of saprobic taxa (Huhndorf \& Fernández, 2005; Réblová \& Seifert, 2004; Tanney \& Miller, 2017). Epitypification and neotypification procedures based on fresh specimens including cultures and molecular data have more often 
been implemented in order to stabilize and fix the application of old generic and species names (Ariyawansa et al. 2014; Crous et al. 2015). Whole genome and mitogenome projects have been completed or are currently in progress for a large number of anamorphic Ascomycota. They will allow to resolve difficult phylogenetic relationships and to study species delimitation, ecological and phenotypic diversification, biogeography and population genetic processes at a genomic scale (Rannala \& Yang, 2008; Dornburg et al. 2017).

However, despite these and other considerable advances, anamorphic Ascomycota are still relatively underrepresented in molecular phylogenetic studies. A large number of them, particularly saprobic taxa without economic importance, are apparently rare or at least they have been scarcely collected and known only from their holotype specimens. Therefore, many of them have never been cultured or subjected to DNA sequence analyses. Consequently, phylogenetic relationships based on molecular data still remain either poorly known or completely unknown for many uncommon hyphomycetous anamorphs inhabiting plant debris such as those studied in the present dissertation. In fact, the current phylogenetic classification of the kingdom Fungi largely suffers from the lack of numerous anamorphic taxa (Crous et al. 2009a).

\subsubsection{Methods of phylogenetic reconstruction}

The use of molecular data such as nucleotide sequences to reconstruct evolutionary relationships among genes or organisms is the main purpose of molecular phylogenetics (Vandamme, 2009). Three principles largely based on cladistic concepts first introduced by the German entomologist Willi Henning are at the root of phylogenetic analyses (Kirk et al. 2008). They are: 1) that natural relationships among taxa are based on shared derived characters called synapomorphies; 2) that recognized groups sharing evolutionary origins must decend from a common ancestor, and 3) that the most parsimonious hypothesis is the one requiring the least number of steps to resolve relationships among taxa and the most likely to be correct. Groups or taxa that include all organisms descending from a common evolutionary ancestor are called monophyletic or clades, those that consist of some but not all organisms descending from a common ancestor are called paraphyletic and groups of organisms that don't share a common ancestor are named polyphyletic. Paraphyletic and polyphyletic groups are not natural 
evolutionary units and should be abandoned in favor of phylogenetic classifications in which groups must meet the criterion of monophyly in order to achieve more informative, accurate, stable and predictive schemes (Simpson, 2010; Ward et al. 2016).

Molecular phylogenetics has promoted the application of a Phylogenetic Species Concept among anamorphic taxa considering the limitations in applying other concepts to putatively asexual fungi (Taylor et al. 2000). The Morphological Species Concept defines species on the basis of overall morphological similarities but morphospecies often comprise more than one cryptic entity when diagnosed using other concepts (Shenoy et al. 2007). The Biological Species Concept refers to species as interbreeding populations that are reproductively isolated from other populations but it is difficult to apply in anamorphic fungi lacking the ability of mating. These limitations can be overcome by the recognition and naming of monophyletic groups using a PSC that even allows the identification of phylogenetically distinct lineages when new species have formed that are not yet morphologically distinct (Stewart et al. 2014). Many anamorphic fungi with a cosmopolitan distribution have shown to exhibit cryptic speciation and they are actually composed of multiple phylogenetic species often geographically separated (Nguyen et al. 2015). Phylogenetic approaches such as the Genealogical Concordance Phylogenetic Species Recognition that relies on concordant clades of multigene genealogies have been useful in identifying closely related phylogenetic species in anamorphic genera such as Alternaria, Fusarium, Penicillium or Wallemia (Nguyen et al. 2015; Stewart et al. 2014). Molecular phylogenetic studies and the recent changes to the Code have also estimulated the introduction or resurrection of suprageneric taxa typified by anamorphic fungi, particularly at familial and ordinal level, for well supported monophyletic clades with a distinct and unitary morphology (Su et al. 2016; Hernández et al. 2017). These families and orders presumably represent asexual lineages that have evolved within Ascomycota and they are expected to incorporate more taxa in the future as more anamorphic fungi are sequenced although sometimes teleomorphic taxa have been added later.

In order to infer phylogenetic relationships from molecular data, a general phylogenetic analysis pipeline should include the following steps in which one step serve as input to the analysis of the next one (Anisimova et al. 2013; Hall, 2013). 
They are: 1) Detecting homologs, in which the DNA markers obtained from the studied fungi serve as query sequences for similarity searches in GenBank or another online databases using the BLAST algorithm or similar. The purpose of this step is to identify and evaluate homologous sequences or those sharing common ancestry with the sequences of interest (Bottu, 2009); 2) Multiple Sequence Alignment, in which the set of homologous sequences are imported into a data matrix and aligned using different MSA algorithms contained in computer programs such as MUSCLE (Edgar, 2004) or MAFFT (Katoh et al. 2002). Sequence alignments are considered hypotheses of homology and homologous residues arranged in columns are assumed to have diverged from a common ancestral state (Higgins \& Lemey, 2009); 3) Quality control, in which the correct taxonomic assignment of each sequence together with annotation errors are verified; 4) Selection of the best-fitting evolutionary model for the data. These are models of nucleotide substitution that describe the different probabilities of change from one nucleotide to another along a phylogenetic tree (Posada, 2009). They can be selected among a set of competing models by estimators such as the Akaike information criterion implemented in computer programs like JModelTest (Posada, 2008); and 5) Phylogeny inference, in which phylogenetic relationships of a set of homologous sequences are inferred by tree-building methods using complex statistical algorithms and their results are branching diagrams known as phylogenetic trees. This pipeline, including its different steps, was applied to the phylogenetic analysis of novel or existing molecular data generated during this research work.

Tree-building methods can be divided in distance-based or algorithmic and character-based or optimality methods (Yang, 2006; Yang \& Rannala, 2012). In distance-based methods such as neighbour joining the genetic distances between each pair of sequences are calculated and trees are constructed from the resulting distance matrix using a clustering algorithm. In character-based methods such as maximum parsimony, maximum likelihood or Bayesian inference, on the other hand, all sequences in the alignment are compared at each homologous site to calculate a score for each tree. An optimality criterion is used to measure how a tree fit the data, which is the minimum number of changes in MP, the log-likelihood value in ML and the posterior probability in $\mathrm{BI}$, and the tree with the optimal score is identified by comparing all possible trees. Nowadays, the maximum likelihood and Bayesian approaches are the most widely used methods of phylogenetic inference (Anisimova 
et al. 2013). They have sound statistical properties and superior inferential power, can accommodate probabilistic evolutionary models and provide a convenient statistical framework for model selection and biological hypothesis testing. In the course of the present dissertation, both statistical methods were incorporated for estimating phylogenetic trees. Maximum likelihood was implemented in the computer programs RAxML (Stamatakis, 2014) or MEGA (Tamura et al. 2013) while Bayesian inference was carried out using the software MrBayes (Ronquist \& Huelsenbeck, 2003). In the resulting phylogenetic trees the topology or order of nodes in the tree and the branch lengths depict information about evolutionary relationships between genes or taxa. A group of terminal nodes representing existing taxa and sharing a common internal node representing a hypothetical ancestor is treated as a clade or monophyletic group (Vandamme, 2009). The robustness of phylogenetic inferences is assessed, for example, by bootstrapping techniques which consists of resampling the data repeatedly to see how often the same result is obtained from the resampled datasets.

In the case of closely related species, phylogenetic trees estimated from DNA sequences of a single or multiple concatenated genes are called gene trees. They may or may not be concondant with the underlaying evolutionary history of species represented in the so called species trees despite their intimate link. Evolutionary processes such as incomplete lineage sorting, when multiple gene lineages persist through speciation events, horizontal gene transfer in which genetic material is transferred from one species to another, gene duplication when a copy of a particular gene is inserted into the genome followed by the separate evolution of the two copies or hybridization events when two distinct species interbreed resulting in hybrids sharing genetic material from each parental organisms, may led to discordance between gene trees and species trees (Knowles \& Kubatko, 2010). The coalescent process is a model for estimating relationships between gene and species trees by randomly joining sampled gene lineages as they are followed back in time to the point at which they converged into a single common ancestor (Baum \& Smith, 2013). Coalescent-based methods of species tree inference using ML or Bayesian approaches have recently been applied to delimitation of cryptic species within anamorphic taxa such as Alternaria alternata s.l. (Stewart et al. 2014) or Aspergillus section Restricti (Sklenar et al. 2017). A species tree of representative members of the anamorphic genus Hermatomyces was estimated in a Bayesian 
framework under the coalescent model as part of one of the publications included in the present dissertation (Koukol et al. 2018). Species tree inference was performed using the computer program *BEAST (Heled \& Drummond, 2010).

\subsubsection{Molecular markers of relevance in ascomycete phylogenetics}

Several molecular markers have been evaluated for use in fungal systematics (Stielow et al. 2015). However, the nuclear ribosomal RNA cistron including three genes encoding for the RNA component of the ribosomes, the $18 \mathrm{~S}$ small subunit, the $5.8 \mathrm{~S}$ and the $28 \mathrm{~S}$ large subunit together with the two internal transcribed spacers, has been consistently used for fungal diagnostics and phylogenetics studies for more than twenty years now (Schoch et al. 2012). In particular, the two hypervariable spacers flanking the highly conserved $5.8 \mathrm{~S}$ gene, altogether referred to as the ITS region, has become the most frequently sequenced marker in Fungi. This locus has been widely used in species-level phylogenetics, metagenomics and environmental sequencing, identification of pathogenic fungi among other applications due to its high copy number per cell, easy accessibility via PCR and widely tested primers (Nagy et al. 2012). The three ribosomal regions show different evolutionary rates and varying levels of genetic variation with the ITS region evolving the fastest and having the highest variation while the SSU rRNA gene evolves the slowest and posses the lowest variation among taxa (Raja et al. 2017). The SSU rRNA gene is therefore useful in phylogenetic placement of a fungus at higher taxonomic levels such as family, order or class, the LSU rRNA gene allows placements at intermediate taxonomic levels such as family or genera and the ITS for species level identification. In particular, the ITS region together with the LSU, which contains two hypervariable domains designated D1 and D2, have been extensively used in fungal phylogenetics to the point that they have become nowadays an integral part of fungal classification (Liu et al. 2012; Porras et al. 2014). Nuclear ribosomal DNA sequence data were generated for all anamorphic fungi studied during the present research work and phylogenetic relationships were estimated from ITS or LSU markers in most cases.

In many instances, however, nuclear ribosomal genes have been of limited utility for inferring relathionships. Therefore, other alternative, phylogenetically more informative markers of higher resolution such as protein-coding genes have been employed in phylogenetic analyses or species identification proving in many cases to be superior in clarifying relationships at various taxonomic levels (Raja et al. 2011; 
Schoch et al. 2012; Stielow et al. 2015). Most commonly used protein-coding gene markers for phylogenetic inference in Ascomycota are the largest and second largest subunits of the RNA polymerase II, the multisubunit enzyme involved in transcription of the messenger RNA; the translation elongation factor 1-alpha, a highly conserved ubiquitous protein with a key function in the elongation phase of translation; the protein $\beta$-tubulin, a major component of the cell microtubules, and the minichromosome maintenance complex component 7 , a licensing factor required for initiation of DNA replication and cell proliferation (Ayliffe et al. 2001; Liu et al. 1999; Raja et al. 2011; Roger et al. 1999). In the course of the present dissertation, $\beta$-TUB, TEF1- $\alpha$ and RPB2 gene sequences were obtained and used to infer phylogenetic relationships among studied fungi.

\subsubsection{Molecular identification and DNA barcoding}

Identification is a crucial aspect in taxonomic studies of organisms along with their description, nomenclature and classification. Due to the many pharmaceutical, biotechnological and agricultural applications of Fungi, particularly anamorphic Ascomycota, their identification at species level is critical in many basic and applied areas. Examples are the accurate determination of fungal pathogens in medical mycology or plant pathology laboratories for implementation of suitable treatments and biocontrol measurements or in fungal biodiversity and ecological studies that depend on reliable identifications to understand their abundance or community composition (Badotti et al. 2017). However, traditional identification procedures which relay on macro- or micromorphological features and other phenotypic criteria are notoriously difficult, slow or limited due to the complex life cycles and remarkable diversity of microfungi, the production of morphologically similar structures that may be absent or degenerate in certain conditions and the presence of cryptic species complexes among other limitations (Liu, 2011). The incorporation of molecular techniques such as PCR amplification and DNA sequencing of specific molecular markers have become a viable alternative to morphology-based methods. They provide reliable diagnostic tools for rapid and accurate identification of fungal taxa in medical, veterinary, industrial or even forensic settings.

The DNA barcoding approach in particular has emerged and became popular as a way to facilitate species level identification across all kingdoms of eukaryotic life. This approach is based on using standardize 500-800 bp DNA sequences or 
molecular barcodes obtained from reliably identified vouchers deposited in biological collections (Seifert et al. 2011). In the case of Fungi, the ITS region was formally proposed as the standard fungal barcode among six other DNA regions as this marker combines the highest resolving power for discriminating closely related species with a high PCR and sequencing success rate across a broad range of fungal groups (Schoch et al. 2012). However, the ITS region alone has shown to be insufficient to separate closely related species in certain highly speciose anamorphic genera such as Aspergillus, Cladosporium, Fusarium or Penicillium due to having none or a narrow barcode gap, the so called difference between inter and intraspecific variation within a DNA barcode marker (Raja et al. 2017). Therefore, the use of secondary barcodes has been proposed for different genera and fungal clades in addition to the primary ITS (Stielow et al. 2015). Examples of alternative identification markers in some anamorphic genera are $\beta$-TUB, RPB2 or CaM for Aspergillus species, the latter gene encoding the calcium-binding protein Calmodulin essential for growth (Joseph \& Means, 2002; Samson et al. 2014); EF1- $\alpha$ and GAPDH for Bipolaris, the latter gene encoding the glycolytic enzyme Glyceraldehyde-3-phosphate dehydrogenase (Manamgoda et al. 2014; Tan et al. 2016); CaM and HIS3 for Cercospora, the latter gene encoding for the Histone H3 protein involved in chromatin formation (Groenewald et al. 2013; Yun \& Nishida, 2011); and EF1- $\alpha$ and actA for Cladosporium, the latter gene encoding for the cytoskeletal protein Actin forming microfilaments (Bensch et al. 2012; Walker \& Garrill, 2006) among others. A large number of saprobic hyphomycetous anamorphs without economic importance are still lacking the standard fungal ITS barcode for their identification. During the present work, several DNA markers linked to welldocumented specimens were generated for all studied fungi and they may perform in the future as identification barcodes for the treated genera and species.

\subsection{Aim of study and objectives}

The aim of the present dissertation is to investigate the rich but still poorly known diversity of hyphomycetous anamorphs belonging to the fungal division Ascomycota. This is a continuation of my previous studies in the group carried out in southern Florida, USA and other locations worldwide (Delgado, 2008a, b, 2009, 2010, 2013, 2014; Delgado et al. 2015; Moro et al. 2015, 2016, 2018; Delgado \& Koukol, 2016). Lignicolous and palmicolous taxa living as saprobes on dead wood 
and palm tree debris are the focus of study. They include many undescribed species and a large number of those previously described has never been cultured and still lack DNA sequence data. Consequently, phylogenetic relationships based on molecular data still remain either poorly or completely unknown for many of them and despite considerable advances in recent years the current phylogenetic classification of the division Ascomycota largely suffers from the lack of anamorphic taxa with putative ascomycetous affinities.

In this context, the present dissertation comprises five papers in which novel or poorly known saprobic anamorphs are studied employing traditional and molecular tools. Specific objectives are the following:

1. To collect, isolate and morphologically characterize selected anamorphic fungi representing putative new or interesting taxa of unknown or uncertain phylogenetic placement.

2. To generate novel DNA sequence data in order to infer their phylogenetic relationships and to resolve their taxonomic affinities within Ascomycota.

3. To test any previously available morphologically based hypotheses on their putative position, generic placement or possible relationships with teleomorphic, pleomorphic or other anamorphic taxa.

4. To determine their generic validity, monophyly and taxonomic boundaries using molecular data and phylogenetic analyses methods.

These objectives were implemented for each publication in the following manner:

Delgado et al. (2017) Phylogenetic placement of Ernakulamia cochinensis

In this first paper, the phylogenetic placement of the saprobic anamorph Ernakulamia cochinensis was investigated for the first time using molecular data obtained from a specimen collected on rotten leaves of Astrocaryum standleyanum (Arecaceae) in Panama. An existing morphology-based hypothesis about its position in the pleosporalean family Tetraplosphaeriaceae (Dothideomycetes) was tested. The fungus was originally described whithin the genus Petrakia and later transferred to Piricauda based on morphological resemblance. Therefore, our study aimed to test the generic placement and validity of Ernakulamia among related taxa. 
Delgado \& Miller (2017) South Florida microfungi: a new species of Taeniolella

In this second paper, a new saprobic species of Taeniolella discovered on the petiole of a dead leaf of Sabal palmetto (Arecaceae) in Florida, USA was proposed and described. Novel nuclear ribosomal DNA sequence data was obtained and used to investigate its phylogenetic affinities with other Taeniolella species having available molecular data. Its relationship with $T$. exilis, the generic type, which was recently sequenced and placed within the family Kirschsteiniotheliaceae in the class Dothideomycetes (Ertz et al. 2016), was also tested in order to find out if our fungus belongs in Taeniolella s. str.

Delgado et al. (2018) South Florida microfungi: Castanedospora, a new genus

In this third paper, the taxonomic status and phylogenetic placement of the saprobic anamorph Sporidesmium pachyanthicola were revisited based on a specimen collected on a dead leaf of Sabal palmetto (Arecaceae) in Florida, USA. The fungus was formerly placed within the broadly defined family Teratosphaeriaceae in Capnodiales (Dothideomycetes) based on a single LSU sequence obtained from a specimen collected in China. However, this position is distant from Sporidesmium s. str. currently accepted within the family Sporidesmiaceae (Sordariomycetes) and therefore its generic rearrangement was considered. A hypothetical relationship between S. pachyanthicola and another sporidesmium-like capnodiaceous anamorph named Sporidesmajora pennsylvaniensis was investigated using the newly generated molecular data.

Koukol et al. (2018) Panama, a hot spot for Hermatomyces (Pleosporales)

In this fourth paper, five new species of the saprobic genus Hermatomyces, collected on rotten twigs and dead stems of various plants in Panama, were proposed and described based on novel morphological and molecular data. Three other previously described species were also identified. Their phylogenetic placement within the recently introduced pleosporalean family Hermatomycetaceae (Dothideomycetes), their interspecific relationships and species delimitations were investigated. The position of $H$. tucumanensis, the generic type, remained unknown and was assessed for the first time based on molecular data from three representative specimens. 
Delgado et al. (2019) Septonema lohmanii, a new species in Mytilinidiales

In this fifth paper, a new species of the saprobic genus Septonema, discovered on woody debris of Pinus spp. in the USA and the Czech Republic, was proposed and described. The conspecificity of both collections was tested using morphological and molecular data and their phylogenetic placement was investigated. The systematic position of S. secedens, the generic type, was unknown at the moment and it was not previously assessed. Therefore, molecular data were also generated from a putative strain of the fungus obtained from an international culture collection in order to elucidate its placement and generic status. Additionally, the hypothesis whether our newly proposed fungus belongs within Septonema s. str. was also tested. 


\section{DISCUSSION}

The last outline of Ascomycota listed 13 classes, 124 orders and 507 families within the subdivision Pezizomycotina in which the production of anamorphic states in their life cycles is a widespread feature (Wijayawardene et al. 2017a, 2018). Its members are ecologically diverse playing numerous ecological roles in nature but particularly they are involved in wood and litter decay (Spatafora et al. 2006). In the course of the present research, only anamorphic fungi belonging to the classes Dothideomyces and Sordariomycetes were collected and studied. These are the largest and second largest classes of Ascomycota in number and diversity of species (Hyde et al. 2013; Maharachchikumbura et al. 2015). They are both anamorph-rich groups and include a vast array of hyphomycetous and coelomycetous taxa (Zhang et al. 2006; McKenzie et al. 2014). With the advent of molecular data and their incorporation in fungal systematics, many conidial anamorphs without previously known phylogenetic affiliations have been revealed to possess dothideomycetous or sordariomycetous affinities. Similarly, many anamorphic taxa with currently unknown phylogenetic placements are expected to be members of these two classes once sequenced. Moreover, several new fungal families and a few single-family orders based on or including only anamorphic fungi have been recently introduced or resurrected mostly within Dothideomycetes and Sordariomycetes. In the following two subchapters, saprobic anamorphs studied in Delgado et al. (2017), Delgado \& Miller (2017), Delgado et al. (2018), Koukol et al. (2018) and Delgado et al. (2019) are placed in a phylogenetic context at the class level and the results, conclusions and impact of these publications are summarize below. Relevant orders, families and genera treated in these papers are discussed and gaps in knowledge are identified for future research.

\subsection{Anamorphs of Dothideomycetes}

The class Dothideomycetes is by far the largest and phylogenetically most diverse within Ascomycota including a heterogeneous array of fungi capable of occupying the most diverse ecological niches possible (Schoch et al. 2009). It formerly included the so called 'Loculoascomycetes' or ascomycetes characterized by ascolocular development in which bitunicate asci having two wall layers with different functions are formed in one or more locules surrounded by vegetative, 
compacted hyphae (Piepenbring, 2015). The last outline of the class includes 32 orders, 114 families and 1261 genera with a large number of taxa showing pleomorphism (Liu et al. 2017). Members of Dothideomycetes are mostly saprobic but others are also endophytes, epiphytes, fungicolous, lichenized or lichenicolous fungi and many anamorphic taxa are important plant pathogens (McKenzie et al. 2014). Wijayawardene et al. (2017b) listed 334 genera of hyphomycetous anamorphs associated with Dothideomycetes. A phylogeny of the class based on LSU sequence data is presented in Figure 3 showing the different phylogenetic positions of the anamorphic fungi studied in the present dissertation.

Among the dothideomycetous orders and families rich in anamorphic fungi is Pleosporales. This is the largest order in Dothideomycetes currently including an outstanding number of 75 families (Wijayawardene et al. 2018). Pleosporaceae, for example, is an anamorph-rich family with many important and widespread genera such as Alternaria, Bipolaris or Curvularia including plant pathogenic, opportunistic and saprobic anamorphs occurring on wood and dead herbaceous stems or leaves (Ariyawansa et al. 2015). Many newer or recently resurrected pleosporalean families such as Dictyosporiaceae, Periconiaceae or Torulaceae are typified by anamorphic genera. Molecular studies have shown that these are well-supported monophyletic clades including mostly anamorphic taxa and a few teleomorphs (Boonmee et al. 2016; Su et al. 2018; Tanaka et al. 2015).

In Delgado et al. (2017), multigene phylogenetic analyses of novel DNA sequence data belonging to the ITS, LSU and the $\beta$-TUB genes suggested that the saprobic anamorph E. cochinensis belongs to the recently introduced pleosporalean family Tetraplosphaeriaceae (Tanaka et al. 2009). This placement was supported by additional molecular data from a second isolate originated in Japan. An existing morphologically based hypothesis suggesting that $E$. cochinensis has appendiculate conidia similar to some members of Tetraplosphaeriaceae was confirmed by molecular data. The Panamanian material was compared with an isotype specimen from India and determined to be conspecific. Further evidence of relatedness was found by placing conidia from both specimens in sodium hypochlorite solution. Bleached conidia revealed the presence of internal hyphal structures similar to those found in members of related genera in Tetraplosphaeriaceae. Ernakulamia was supported as a distinct genus within the family by conidial morphology and DNA sequence data. Molecular data also rejected previous generic placements within the 


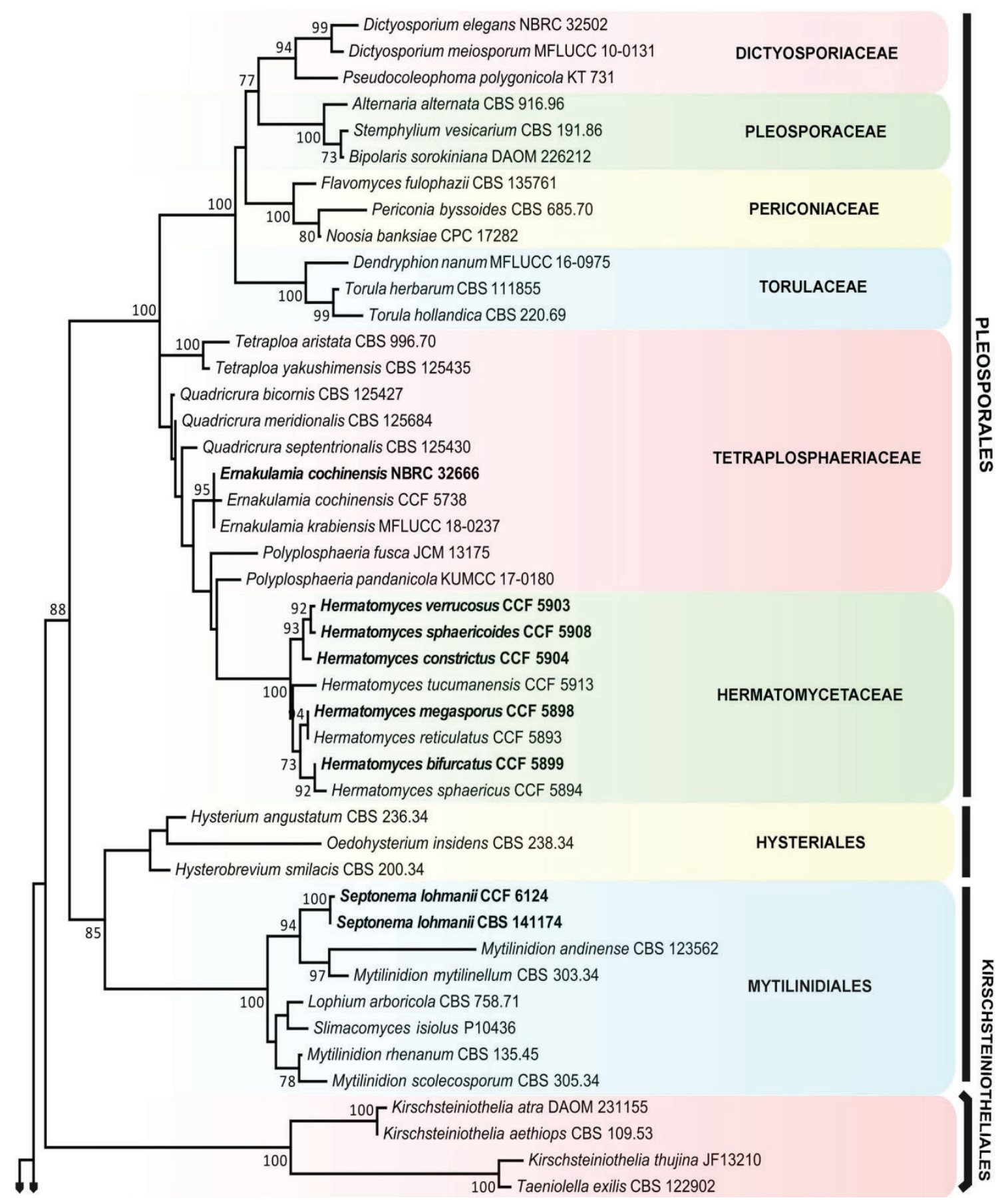

Figure 3. Best scoring RAxML tree showing the phylogenetic position of studied anamorphic fungi (in bold) within the class Dothideomycetes. The tree is based on an LSU dataset consisting of 79 taxa representing seven orders and 14 families. Orders are indicated by vertical lines and families by colored blocks. RAxML bootstrap support values $\geq 70 \%$ are given at the nodes. Aspergillus nidulans and Capronia pilosella (Eurotiomycetes) were selected as outgroup taxa to root the tree. Based on Liu et al. (2017). 


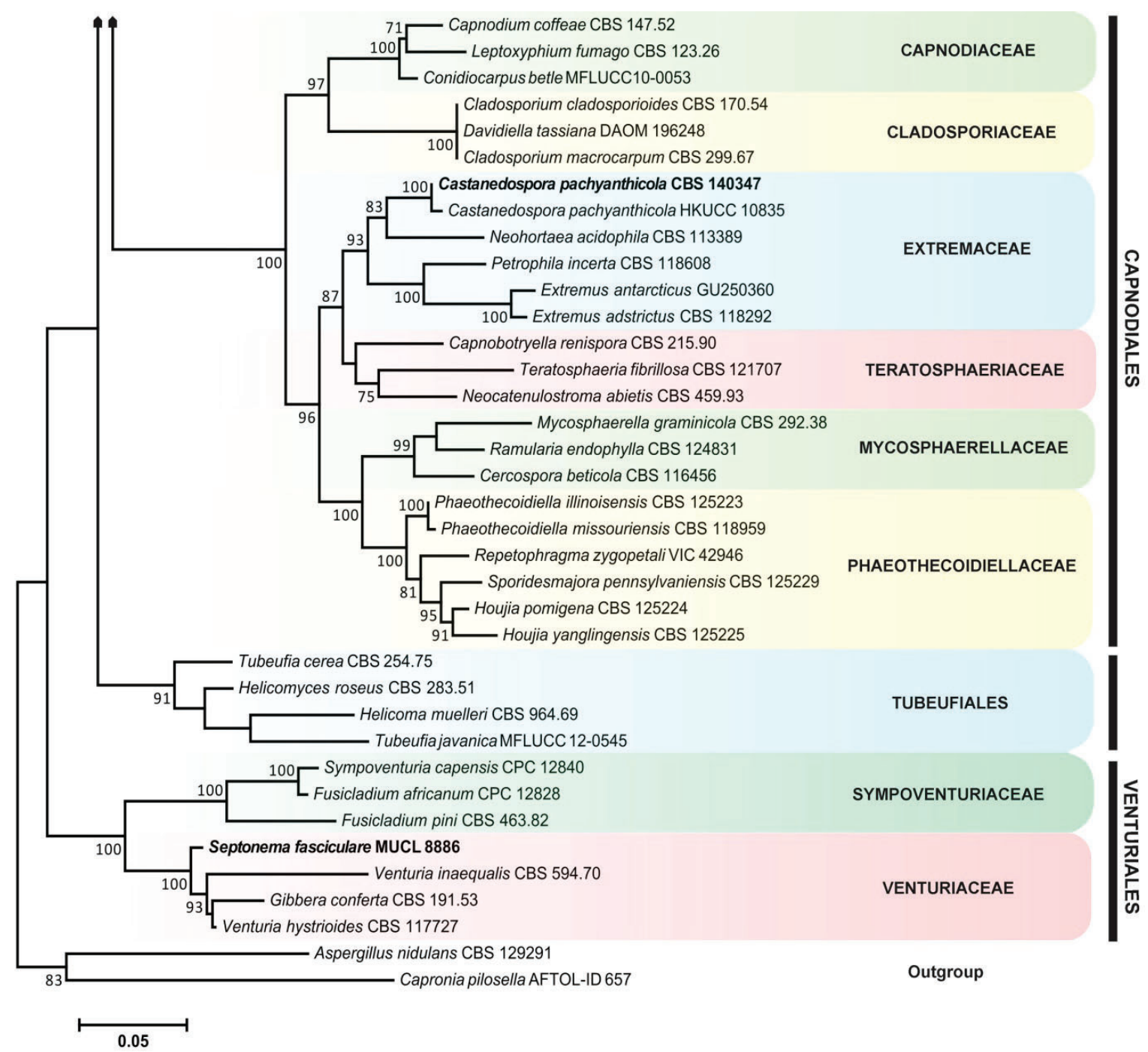

Figure 3. (continued)

unrelated Petrakia, currently placed within Melannomataceae (Pleosporales) or the distant Piricauda which is a member of the order Capnodiales (da Silva et al. 2016; Jaklitsch \& Voglmayr, 2017). The holotype specimen of Piricaudilium lobatum, a morphologically similar fungus (Holubová-Jechová, 1988), was examined and its putative phylogenetic position in Tetraplosphaeriaceae was proposed based on morphology. However, in the absence of DNA sequence data, future research should focus on its recollection and isolation to confirm this hypothesis and to clarify its relationship with the genus Quadricrura, which differ only in conidiogenesis and it is probably congeneric. Following the publication of our paper, a second species of Ernakulamia named E. krabiensis was described from decaying pods of Acacia sp. 
in Thailand (Jayasiri et al. 2019). The authors proposed this novel fungus on the basis of differences in ITS nucleotide composition and morphology with our strain.

In Koukol et al. (2018), molecular data in addition to distinct morphological features supported the recognition of five new species belonging to the saprobic genus Hermatomyces. They were named $H$. bifurcatus, $H$. constrictus, $H$. megasporus, $H$. sphaericoides and $H$. verrucosus. Previously described species such as $H$. tucumanensis, $H$. reticulatus and $H$. sphaericus were also identified. Phylogenetic analyses of nuclear ribosomal (ITS-LSU) and protein coding genes ( $\beta$ TUB, RPB2, TEF1- $\alpha$ ) sequence data placed all species within the recently introduced monophyletic family Hermatomycetaceae in Pleosporales comprising so far the single genus Hermatomyces (Hashimoto et al. 2017). This is the first comprehensive study of Hermatomyces in the Neotropics in which the phylogenetic placement of $H$. tucumanensis, the generic type, was resolved for the first time within Hermatomycetaceae. A critical overview of ten other Hermatomyces species not found in Panama was provided. A new combination named $H$. reticulatus was proposed and four previously described taxa were reduced to synonyms based on morphological and molecular evidence for a total of sixteen accepted species within the genus. In addition to traditional phylogenetic analysis methods, species delimitation in Hermatomyces was tested for the first time using species-tree estimation under a coalescent model. This approach has been rarely applied in studies of saprobic anamorphs and novel insights into the evolution of the genus such as evidence of incomplete lineage sorting and possibly hybridization events on a few species with incongruent tree topologies was obtained. The peculiar morphology and consistent monophyly of accepted Hermatomyces species supported the recognition of the family Hermatomycetaceae as a well delimited monophyletic taxon within Pleosporales. Our extensive revision has estimulated interest in this peculiar group of anamorphs and in less than a year three additional species named $H$. bauhiniae, $H$. biconisporus and $H$. trangensis has been described from Thailand and China (Hyde et al. 2019; Nuankaew et al. 2019; Tibpromma et al. 2018) using the large dataset generated in this paper.

Another dothideomycetous order rich in anamorphs is Capnodiales. It traditionally included the sooty molds, a group of epiphytes growing on insect exhudates and forming a black growth on leaf surfaces, fruit and twigs. However, recent phylogenetic studies have shown that it also incorporates many saprobes, 
plant pathogens and even colonizers of hair shafts of mammals (Crous et al. 2009b). Capnodiaceous families such as Cladosporiaceae accomodates the large and cosmopolitan genus Cladosporium and related anamorphs having mycosphaerellalike teleomorphs previously assigned to the genus Davidiella (Bensch et al. 2012). Another large family is Mycosphaerellaceae which comprises the so called cercosporoid anamorphs with well-known plant-pathogenic hyphomycetous genera such as Cercospora, Pseudocercospora, Ramularia, Passalora or Polythrincium among many others including parasitic or saprobic species (Videira et al. 2017).

In Delgado et al. (2018), phylogenetic analyses using novel ITS-LSU sequence data combined with a broad taxon sampling at family level suggested that the capnodiaceous anamorph Sporidesmium pachyanthicola is instead a member of the family Extremaceae and its former position within the sister family Teratosphaeriaceae (Crous et al. 2009b) was not supported. This placement was confirmed to be distant from the family Sporidesmiaceae in the class Sordariomycetes, which includes species of the genus Sporidesmium s. str., and therefore the new generic name Castanedospora was introduced to accommodate S. pachyanthicola. The fungus was epitypified with the Florida specimen in the absence of a preserved ex-type living culture and the depauperated state of the holotype material originated from neighboring Cuba. The hypothetical relationship between Castanedospora and the sporidesmium-like, capnodiaceous anamorph Sporidesmajora pennsylvaniensis based on their morphological resemblance in culture was not supported and the latter was recovered for the first time as a member of the capnodiaceous family Phaeothecoidiellaceae. Another sporidesmiumlike anamorph with available DNA sequence data, Repetophragma zygopetali (Buyck et al. 2017), was included in the analyses and found to belong within this latter family as well. This might suggest that the sporidesmium-like morphology, although still poorly sampled at ordinal level, might be rather widespread in Capnodiales. Future research should focus on the many members of Sporidesmium s. I. currently with unknown phylogenetic affinities due to the lack of DNA sequence data for analysis and the possibility of a more comprehensive understanding of taxonomic relationships within this widespread group of anamorphs. Regarding the impact of this publication, Trovão et al. (2019) already cited our paper and included the molecular data generated in this study to support the description of the new capnodiaceous family Aeminiaceae and the novel anamorphic genus Aeminium. 
In contrast to Pleosporales and Capnodiales, anamorphic fungi belonging to the order Mytilinidiales have not been extensively studied. Members of this monophyletic group are characterized by rigid, brittle, carbonaceous hysterothecial ascomata, conchate or bivalve shell in shape (Boehm et al. 2009). They are tipically temperate in distribution usually occurring as saprobes on wood, bark, resin, cones, needles or scales of gymnosperms and their anamorphs are primarily coelomycetous or less frequently hyphomycetous and septonema-like in morphology. In Delgado et al. (2019), morphological and molecular data supported a new species of Septonema named S. Iohmanii. Multigene phylogenetic analyses of LSU and TEF1- $\alpha$ sequence data suggested that both collections on which the fungus is based are conspecific despite their disjunct distribution and they belong within the order Mytilinidiales (Dothideomycetes). This is the first time a septonema-like anamorph is linked to Mytilinidiales in a phylogenetic framework using molecular data and its placement fully agreed with previous cultural or circumstantial evidence of their relatedness. Molecular data generated from a putative strain of $S$. secedens, the generic type, placed it within the distant family Venturiaceae (Venturiales, Dothideomycetes). However, morphological examination of the corresponding herbarium specimen revealed that it belongs to the different species $S$. fasciculare for which a phylogenetic placement was resolved for the first time. Therefore, the systematic position of the generic type remained inconclusive and future research should focus on clarifying its status. A current broad concept of Septonema was momentarily adopted to accomodate $S$. Iohmanii until fresh collections and further molecular data become available. If the position of the generic type outside Mytilinidiales is confirmed then S. Iohmanii may be accommodated in a novel genus. The disparate phylogenetic positions of these Septonema species within Dothideomycetes confirmed the polyphyletic nature of the genus and the need for an extensive taxonomic reassessment in the future.

\subsection{Anamorphs of Sordariomycetes}

The class Sordariomycetes is another monophyletic group within Pezizomycotina that includes the majority of nonlichenized ascomycetes with flaskshaped, ostiolate ascomata known as perithecia or less frequently with closed, nonostiolate cleistothecial fruiting bodies (Zhang et al. 2006). Perithecial 
ascomycetes were formerly known as 'pyrenomycetes' but phylogenetic analysis of molecular data no longer supported this taxon and the term is currently used informally without taxonomic significance. The most recent outline of the class includes six subclasses, 32 orders, 105 families and 1331 genera (Maharachchikumbura et al. 2016). Members of Sordariomycetes are cosmopolitan in distribution and include mainly terrestrial but also aquatic species with many saprobes involved in decomposition and nutrient recycling. A large number of them are pleomorphic and produce mostly hyphomycetous or less commonly coelomycetous anamorphs but many others lack a known sexual morph. Wijayawardene et al. (2017b) listed 453 hyphomycetous genera associated with this class.

In Delgado \& Miller (2017), a new saprobic species of Taeniolella was proposed based on morphological and molecular data. It differed from other species of Taeniolella in several respects that warranted the introduction of a novel taxon named T. sabalicola to accommodate it. Phylogenetic analyses based on nuclear ribosomal DNA sequence data suggested that the fungus was distinct from Taeniolella species with available molecular data and showed affinities with members of Sordariomycetidae (Ascomycota) but its ordinal or familial position within the subclass remained uncertain at the moment of publication. Molecular data also confirmed the highly polyphyletic status of Taeniolella within the class Sordariomycetes and indicated that the genus is in need of extensive reassessment. Moreover, $T$. sabalicola was distant from $T$. exilis, the generic type placed in Dothideomycetes, and therefore the fungus does not belong to Taeniolella s. str. and should be eventually reclassified in a new or different genus. However, most saprobic species of Taeniolella still lack molecular data and their phylogenetic relationships remain uncertain. Based on the rather preliminary knowledge about affinities of taeniolella-like taxa a broad generic concept was momentarily adopted to accommodate $T$. sabalicola until more data become available in the future.

In the course of this dissertation, a revised phylogeny of Sordariomycetes based on LSU sequence data and including a more extensive taxon sampling was obtained and is presented in Figure 4. It provides an updated phylogenetic position of $T$. sabalicola within the class and shows that the fungus now occurs within a maximum supported $(100 \%$ BS) monophyletic clade corresponding to the family Distoseptisporaceae. This is a recently introduced sordariomycetous family that 
accommodates sporidesmium-like anamorphic taxa clustering outside Sporidesmiaceae s. str. (Su et al. 2016). This updated result agrees well with Heuchert et al. (2018) who recently provided a comprehensive taxonomic revision of the genus Taeniolella including $T$. sabalicola. These authors suggested that our fungus was quite distinct from $T$. exilis and all other saprobic species of Taeniolella and it was instead ecologically and morphologically related to species of Sporidesmium s. I. They also stated that $T$. sabalicola might require a genus on its own or may belong to one of the numerous sporidesmium-like genera in Sordariomycetes with pending placement due to the lack of DNA sequence data drawing similar conclusions to those in our paper. 


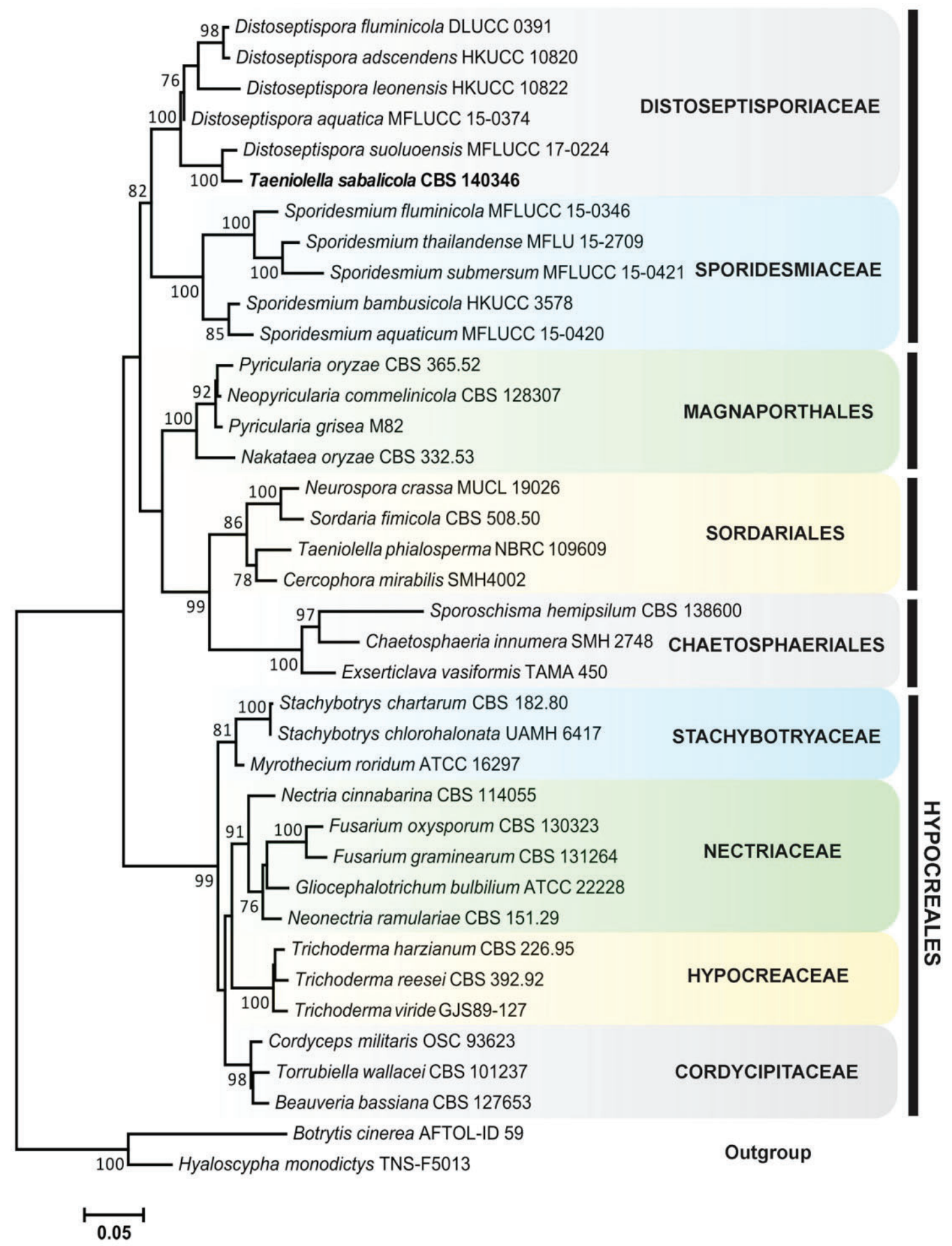

Figure 4. Best scoring RAxML tree showing the phylogenetic placement of Taeniolella sabalicola (in bold) and related taxa within the class Sordariomycetes. Phylogenetic relationships were inferred using an LSU dataset of 39 taxa representing four orders and six families. Orders are indicated by vertical lines and families by colored blocks. RAxML bootstrap support values $\geq 70 \%$ are given at the nodes. The tree was rooted with Botrytys cinerea and Hyaloscypha monodictys (Leotiomycetes) as outgroup taxa. Based on Hongsanan et al. (2017). 


\section{CONCLUSIONS AND OUTLOOK}

In the present dissertation, anamorphic Ascomycota inhabiting dead plant debris was shown to be a largely untapped source of biodiversity and information still in need of further exploration. A new capnodiaceous genus Castanedospora, seven new species named Taeniolella sabalicola, Hermatomyces bifurcatus, $H$. constrictus, $H$. megasporus, $H$. sphaericoides, $H$. verrucosus and Septonema lohmanii, and two new combinations, Castanedospora pachyanthicola and $H$. reticulatus, are proposed based on morphological and DNA sequence data. Molecular phylogenetics was confirmed as the tool of choice for the inference of relationships in novel or incertae sedis anamorphic fungi that are otherwise difficult to assess in the absence of a teleomorphic state. They were first resolved or revisited for several saprobic species such as Ernakulamia cochinensis, $H$. sphaericus, $H$. tucumanensis or Septonema fasciculare in a suitable framework for phylogenetic hypothesis testing. Molecular data allowed to fully incorporate all these taxa in Ascomycota, particularly within the classes Dothideomycetes and Sordariomycetes, and to provide a foundation for better taxonomic decisions on their classification. Large and polyphyletic genera such as Taeniolella, Sporidesmium and Septonema, partially treated in this work and containing mostly saprobic species of obscure affinities, remained in need of further investigation. Locations such as the southern tip of Florida peninsula in the relatively well-explored North America or Europe were verified to harbor a rich but poorly studied microfungal diversity. The Neotropical country of Panama was found to be a hotspot for the genus Hermatomyces and it is likely to be equally diverse for many other anamorphic genera once more extensive sampling efforts are carried out.

Despite recent advances in the taxonomy and phylogeny of anamorphic Ascomycota, the lack of DNA sequence data is still the main challenge hampering their complete integration and study in a molecular-based taxonomic framework. Efforts should be focused on recollecting and isolating them in order to generate novel molecular data and to harness their unique biology for future phylogenetic, mitogenomic and phylogenomic studies. Once recollected, the validity of morphologically circumscribed genera and species will need to be tested in order to reassess and delimit more natural taxa. This will be a daunting task considering that there are more than 1500 described genera of anamorphic Ascomycota representing thousands of species (Wijayawardene et al. 2017b). They should be more frequently 
included in large-scale phylogenetic studies of Ascomycota as a way to continue identifying still obscure anamorphic lineages within the division. Many anamorphic novelties are also expected to be discovered worldwide based on the recent estimates of fungal diversity ranging from 2.2 to 3.8 million species thought to exist in contrast with the more or less currently known 140,000 species of Fungi (Hawksworth \& Lücking, 2017; Lücking \& Hawksworth, 2018). Exploring this outstanding diversity will be achieved only through collaborative research initiatives between mycologists of which the publications included in this dissertation are good examples. Mycological surveys with emphasis on recollection and isolation should therefore continue in areas of North America and Europe but they are specially needed in underexplored tropical countries where many anamorphs are still awaiting discovery and many others still lack DNA sequence data. In order to stabilize the application of names of anamorphic taxa careful epitypification or neotypification procedures based on sequenced specimens should be implemented. The increasing availability of genome-scale data due to their decreasing costs will make welldocumented specimens and isolates such as those generated in the present work of critical importance for future taxonomic and phylogenetic studies. They will be particularly significant in the ongoing transition from analyzing small datasets with a few loci to analyzing whole genomes and the consequent impact in generating more robust and well resolved phylogenies for anamorphic Ascomycota and other fungal groups. 


\section{REFERENCES}

Alexopoulos CJ, Mims CW, Blackwell M (1996) Introductory Mycology 4th edn. John Wiley \& Sons, New York.

Amado M, Barnes C (2016) Allergenic microfungi and human health: a review on exposure, sensitization, and sequencing allergenic proteins. In: Li DW (ed.) Biology of Microfungi. Springer, Cham, pp. 429-449.

Anisimova M, Liberles DA, Philippe H, Provan J, Pupko T, von Haeseler A (2013) State-of the art methodologies dictate new standards for phylogenetic analysis. BMC Evolutionary Biology 13: 161(1-8).

Ariyawansa HA, Hawksworth DL, Hyde KD, Jones EBG, Maharachchikumbura SSN, Manamgoda DS, Thambugala KM, Udayanga D, Camporesi E, Daranagama A et al. (2014) Epitypification and neotypification: guidelines with appropriate and inappropriate examples. Fungal Diversity 69: 57-91.

Ariyawansa HA, Thambugala KM, Manamgoda DS, Jayawardena RS, Camporesi E, Boonmee S, Wanasinghe DN, Phookamsak R, Hongsanan S, Singtripop C et al. (2015) Towards a natural classification and backbone tree for Pleosporaceae. Fungal Diversity 71: 85-139.

Ayliffe MA, Dodds PN, Lawrence GJ (2001) Characterization of a beta-tubulin gene from Melampsora lini and comparison of fungal beta-tubulin genes. Mycological Research 105: 818-826.

Badotti F, de Oliveira FS, Garcia CF, Vaz AB, Fonseca PL, Nahum LA, Oliveira G, Goes A (2017) Effectiveness of ITS and sub-regions as DNA barcode markers for the identification of Basidiomycota (Fungi). BMC Microbiology 17: 42(1-12).

Barnet HL, Hunter BB (1998) Illustrated genera of Imperfect Fungi 4th edn. APS Press, Saint Paul.

Barron GL (1968) The Genera of Hyphomycetes from Soil. The Williams \& Wilkins Co., Baltimore.

Baum DA, Smith SD (2013) Tree Thinking: An Introduction to Phylogenetic Biology. Roberts \& Co. Publs, Greenwood Village.

Bensch K, Braun U, Groenewald JZ, Crous PW. (2012) The genus Cladosporium. Studies in Mycology 72: 1-401.

Berbee ML, Taylor JW (1992) 18S ribosomal RNA gene sequence characters place the human pathogen Sporothrix schenckii in the genus Ophiostoma. Experimental Mycology 16: 87-91.

Berger S, Stamatakis A, Lücking R (2011) Morphology-based phylogenetic binning of the lichen genera Graphis and Allographa (Ascomycota: Graphidaceae) using molecular site weight calibration. Taxon 60: 1450-1457.

Bills G, Gloer J (2016) Biologically active secondary metabolites from the Fungi. Microbiology Spectrum 4: FUNK-0009-2016.

Boehm EWA, Mugambi GK, Miller AN, Hundorf SM, Marincowitz S, Spatafora JW, Schoch CL (2009) A molecular phylogenetic reappraisal of the Hysteriaceae, Mytilinidiaceae and Gloniaceae (Pleosporomycetidae, Dothideomycetes) with keys to world species. Studies in Mycology 64: 49-83.

Boonmee S, D'souza MJ, Luo Z, Pinruan U, Tanaka K, Su H, Bhat DJ, McKenzie EHC, Jones EBG, Taylor JE et al. (2016) Dictyosporiaceae fam. nov. Fungal Diversity 80: 457-482.

Bottu G (2009) Sequence databases and database searching. In: Lemey P, Salemi M, Vandamme AM (eds.) The Phylogenetic Handbook: A Practical Approach 
to Phylogenetic Analysis and Hypothesis Testing 2nd edn. Cambridge University Press, Cambridge, pp. 33-67.

Buyck B, Duhem B, Das K, Jayawardena RS, Niveiro N, Pereira OL, Prasher IB, Adhikari S, Albertó EO, Bulgakov TS et al. (2017) Fungal Biodiversity Profiles 21-30. Cryptogamie, Mycologie 38: 101-146.

Carmichael JW, Kendrick WB, Conners JL, Sigler L (1980) Genera of Hyphomycetes. The University of Alberta Press, Edmonton.

Cole GT (1986) Models of cell differentiation in conidial fungi. Microbiological Reviews 50: 95-132.

Cole GT, Samson RA (1979) Patterns of Development in Conidial Fungi. Pitman Publishing Ltd., London.

Crous PW, Braun U, Wingfield MJ, Wood AR, Shin HD, Summerell BA, Alfenas AC, Cumagun CJR, Groenewald JZ (2009a) Phylogeny and taxonomy of obscure genera of microfungi. Persoonia 22: 139-161.

Crous PW, Carris LM, Giraldo A, Groenewald JZ, Hawksworth DL, Hernández M, Jaklitsch WM, Lebrun MH, Schumacher RK, Stielow JB et al. (2015) The Genera of Fungi - fixing the application of the type species of generic names G 2: Allantophomopsis, Latorua, Macrodiplodiopsis, Macrohilum, Milospium, Protostegia, Pyricularia, Robillarda, Rotula, Septoriella, Torula, and Wojnowicia. IMA Fungus 6: 163-198.

Crous PW, Schoch CL, Hyde KD, Wood AR, Gueidan C, de Hoog GS, Groenewald JZ (2009b) Phylogenetic lineages in the Capnodiales. Studies in Mycology 64: 17-47.

Crous PW, Verkley GJM, Christensen M, Castañeda RF, Groenewald JZ (2012) How important are conidial appendages? Persoonia 28: 126-137.

da Silva M, Pinho DB, Pereira OL, Fernandes FM, BARRETO RW (2016) Naming potentially endangered parasites: foliicolous mycobiota of Dimorphandra wilsonii, a highly threatened Brazilian tree species. PLoS ONE 11(2):e0147895. doi:10.1371/journal.pone.0147895

de Carvalho CCCR (2016) Fungi in fermentation and biotransformation systems. In: Li DW (ed.) Biology of Microfungi. Springer, Cham, pp. 525-541.

de Hoog GS, Guarro J, Gené J, Figueras MJ (2000) Atlas of Clinical Fungi 2nd edn. Centraalbureau voor Schimmelcultures/Universitat Rovira i Virgili, Utrecht/Reus.

Dean R, Van Kan JA, Pretorius ZA, Hammond KE, Di Pietro A, Spanu PD, Rudd JJ, Dickman M, Kahmann R, Ellis J, Foster GD (2012) The top 10 fungal pathogens in molecular plant pathology. Molecular Plant Pathology 13: 414430.

Delgado G (2008a) South Florida microfungi: a new species of Stanjehughesia (hyphomycetes) from Sabal palm. Mycotaxon 103: 229-234.

Delgado G (2008b) South Florida microfungi: new records of saprophytic hyphomycetes on plant debris. Florida Scientist 71: 76-89.

Delgado G (2009) South Florida microfungi: Veramycella bispora, a new palmicolous anamorphic genus and species, with some new records for the continental USA. Mycotaxon 107: 357-373.

Delgado G (2010) South Florida microfungi: Kalamarospora multiflagellata gen. et sp. nov. (hyphomycetes), with additional new records from USA. Mycotaxon 114: 231-246.

Delgado G (2013) South Florida microfungi: a new species of Ellisembia (hyphomycetes) with new records from the USA. Mycotaxon 123: 445-450. 
Delgado G (2014) South Florida microfungi: Linkosia longirostrata, a new hyphomycete on paurotis palm. Mycotaxon 129: 41-46.

Delgado G, Koukol O (2016) Microfungi from Nicaragua in a historical collection kept at the Herbarium of the Charles University in Prague. Cryptogamie, Mycologie 37: 15-36.

Delgado G, Koukol O, Cáceres O, Piepenbring M (2017) The phylogenetic placement of Ernakulamia cochinensis within Pleosporales (Dothideomycetes, Ascomycota). Cryptogamie, Mycologie 38: 435-451.

Delgado G, Koukol O, Miller AN, Piepenbring M (2019) Septonema lohmanii G. Delgado \& O. Koukol, sp. nov., a new species in Mytilinidiales (Dothideomycetes) and the phylogenetic position of $S$. fasciculare Corda. Cryptogamie, Mycologie 40: 3-21.

Delgado G, Miller AN (2017) South Florida microfungi: a new species of Taeniolella (anamorphic Sordariomycetes) isolated from cabbage palm. Nova Hedwigia 105: 1-14.

Delgado G, Miller AN, Fernandez FA (2015) Curviclavula, a new genus of anamorphic Helotiales (Leotiomycetes) isolated from air. Mycological Progress 14: 3(1-7).

Delgado G, Miller AN, Piepenbring M (2018) South Florida microfungi: Castanedospora, a new genus to accommodate Sporidesmium pachyanthicola (Capnodiales, Ascomycota). Cryptogamie, Mycologie 39: 109-127.

Dornburg A, Townsend JP, Wang Z (2017) Maximizing power in Phylogenetics and Phylogenomics: a perspective illuminated by fungal big data. In: Townsend JP, Wang Z (eds.) Fungal Phylogenetics and Phylogenomics. Advances in Genetics 100, pp. 1-47.

Dyer PS, Kück U (2017) Sex and the imperfect fungi. Microbiology Spectrum 5: 122.

Dyer PS, Paoletti M (2005) Reproduction in Aspergillus fumigatus: sexuality in a supposedly asexual species? Medical Mycology 43: 7-14.

Edgar RC (2004) MUSCLE: multiple sequence alignment with high accuracy and high throughput. Nucleic Acids Research 32: 1792-1797.

Ellis MB (1971) Dematiaceous Hyphomycetes. CABI Publishing, Wallingford.

Ellis MB (1976) More Dematiaceous Hyphomycetes. CABI Publishing, Wallingford.

Gams W (1995) How natural should anamorph genera be? Canadian Journal of Botany 73: 747-753.

Gams W (2013) A new nomenclature for fungi. Mycologia Iranica 1: 1-5.

Goos RD (1956) Classification of the Fungi Imperfecti. Proceedings of the lowa Academy of Science 63: 311-320.

Groenewald JZ, Nakashima C, Nishikawa J, Shin HD, Park JH, Jama AN, Groenewald M, Braun U, Crous PW (2013) Species concepts in Cercospora: spotting the weeds among the roses. Studies in Mycology 75: 115-170.

Guarro J, Gené J, Stchigel AM (1999) Developments in fungal taxonomy. Clinical Microbiology Reviews 12: 454-500.

Hall BG (2013) Building phylogenetic trees from molecular data with MEGA. Molecular Biology and Evolution 30: 1229-1235.

Hashimoto A, Matsumura M, Hirayama K, Tanaka K (2017) Revision of Lophiotremataceae (Pleosporales, Dothideomycetes): Aquasubmersaceae, Cryptocoryneaceae, and Hermatomycetaceae fam. nov. Persoonia 39: 51-73. 
Hawksworth DL (2011) A new dawn for the naming of fungi: impacts of decisions made in Melbourne in July 2011 on the future publication and regulation of fungal names. IMA Fungus 2: 155-162.

Hawksworth DL, Crous PW, Redhead SA, Reynolds DR, Samson RA, Seifert KA, Taylor JW, Wingfield MJ, Abaci O, Aime C et al. (2011) The Amsterdam Declaration on Fungal Nomenclature. IMA Fungus 2: 105-112.

Hawksworth DL, Lücking R (2017) Fungal diversity revisited: 2.2 to 3.8 million species. Microbiology Spectrum 5: FUNK-0052-2016.

Hawksworth DL, Mouchacca J (1994) Ascomycete Systematics in the Nineties. In: Hawksworth DL (ed.) Ascomycete Systematics: Problems and Perspectives in the Nineties. Plenum Press, New York, pp. 3-11.

Hawksworth DL, Mueller GM (2005) Fungal communities: their diversity and distribution In: Dighton J, White JF, Oudemans $\mathrm{P}$ (eds.) The Fungal Community: Its Organization and Role in the Ecosystem 3rd edn. CRC Taylor \& Francis, New York, pp. 27-37.

Heled J, Drummond AJ (2010). Bayesian inference of species trees from multilocus data. Molecular Biology and Evolution 27: 570-580.

Hennebert GL (1987) Pleoanamorphy and its nomenclatural problem. In: Sugiyama J (ed.) Pleomorphic Fungi: The Diversity and its Taxonomic Implications. Kodansha, Tokyo \& Elsevier, Amsterdam, pp. 263-290.

Hennebert GL (1995) Taxonomy and nomenclature of the Fungi: reasons for a mycotheque. In: Hennebert GL (ed.) The 100 years of the fungus collection MUCL 1894-1994. Mycotaxon Ltd., Ithaca.

Hennebert GL, Sutton BC (1994) Unitary parameters in conidiogenesis. In: Hawksworth DL (ed.) Ascomycete Systematics: Problems and Perspectives in the Nineties. Plenum Press, New York, pp. 65-76.

Hennebert GL, Weresub LK (1977) Terms for states and forms of fungi, their names and types. Mycotaxon 6: 207-211.

Hernández M, Gené J, Castañeda RF, Mena J, Crous PW, Guarro J (2017) Phylogeny of saprobic microfungi from Southern Europe. Studies in Mycology 86: 53-97.

Heuchert B, Braun U, Diederich P, Ertz D (2018) Taxonomic monograph of the genus Taeniolella s. lat. (Ascomycota). Fungal Systematics and Evolution 2: 69-261.

Hibbett DS, Binder M, Bischoff J, Blackwell M, Cannon P, Eriksson O, Huhndorf S, James T, Kirk P, Lucking R et al. (2007) A higher level phylogenetic classification of the Fungi. Mycological Research 111: 509-547.

Higgins D, Lemey P (2009) Multiple sequence alignment. In: Lemey P, Salemi M, Vandamme AM (eds.) The Phylogenetic Handbook: A Practical Approach to Phylogenetic Analysis and Hypothesis Testing 2nd edn. Cambridge University Press, Cambridge, pp. 68-108.

Holubová-Jechová V (1988) Studies on hyphomycetes from Cuba VIII. A new genus Piricaudilium and some species new for the territory of Cuba. Ceská Mykologie 42: 200-204.

Hongsanan S, Maharachchikumbura SSN, Hyde KD, Samarakoon MC, Jeewon R, Zhao Q, Al-Sadi AM, Bahkali AH (2017) An updated phylogeny of Sordariomycetes based on phylogenetic and molecular clock evidence. Fungal Diversity 84: 25-41.

Hughes SJ (1953) Conidiophores, conidia and classification. Canadian Journal of Botany 31: 577-659. 
Huhndorf SM, Fernández FA (2005) Teleomorph-anamorph connections: Chaetosphaeria raciborskii and related species, and their Craspedodidymumlike anamorphs. Fungal Diversity 19: 23-49

Hyde KD, Al-Hatmi A, Andersen B, Boekhout T, Buzina W, Dawson T, Eastwood D, Jones E, de Hoog S, Kang Y et al. (2018) The world's ten most feared fungi. Fungal Diversity 93: 161-194.

Hyde KD, Jones EBG, Liu JK, Ariyawansa HA, Boehm EWA, Boonmee S, Braun U, Chomnunti P, Crous PW, Dai DS et al. (2013) Families of Dothideomycetes. Fungal Diversity 63: 1-313.

Hyde KD, McKenzie EHC, KoKo TW (2011) Towards incorporating anamorphic fungi in a natural classification - checklist and notes for 2010. Mycosphere 2: 1-88.

Hyde KD, Tennakoon DS, Jeewon R, Bhat DJ, Maharachchikumbura SSN, Rossi W, Leonardi M, Lee HB, Mun HY, Jos Houbraken J et al. (2019): Fungal diversity notes 1036-1150: taxonomic and phylogenetic contributions on genera and species of fungal taxa. Fungal Diversity 96: 1-242.

Jaklitsch WM, Voglmayr H (2017) Three former taxa of Cucurbitaria and considerations

on Petrakia in the Melanommataceae. Sydowia 69: 81-95.

Jayasiri SC, Hyde KD, Jones EBG, McKenzie EHC, Jeewon R, Phillips AJL, Bhat DJ, Wanasinghe DN, Liu JK, Lu YZ et al. (2019) Diversity, morphology and molecular phylogeny of Dothideomycetes on decaying wild seed pods and fruits. Mycosphere 10: 1-186.

Joseph JD, Means AR (2002) Calcium binding is required for calmodulin function in Aspergillus nidulans. Eukaryotic Cell 1: 119-125.

Katoh K, Misawa K, Kuma K, Miyata T (2002) MAFFT: a novel method for rapid multiple sequence alignment based on fast Fourier transform. Nucleic Acids Research 30: 3059-3066.

Kendrick B (1971) Taxonomy of Fungi Imperfecti. University of Toronto Press, Toronto.

Kendrick B (ed.) (1979) The Whole Fungus: The Sexual-Asexual Synthesis Vols. 1 \& 2.

National Museums of Canada, Ottawa.

Kendrick B (1981) The history of conidial fungi. In: Cole GT, Kendrick B (eds) Biology of Conidial Fungi Vol. 1. Academic Press, London, pp. 3-18.

Kendrick B, DiCosmo F (1979) Teleomorph-anamorph connections in ascomycetes. In: Kendrick B (ed.) The Whole Fungus: The Sexual-Asexual Synthesis Vol. 1. National Museums of Canada, Ottawa, pp. 283-410.

Kendrick B, Nag Raj TR (1979) Morphological terms in Fungi Imperfecti. In: Kendrick B (ed.) The Whole Fungus: The Sexual-Asexual Synthesis Vol. 1. National Museums of Canada, Ottawa, pp. 43-61.

Kirk PM Cannon PF, Minter DW, Stalpers JA (2008) Ainsworth \& Bisby's Dictionary of the Fungi 10th edn. CABI Publishing, Wallingford.

Kirschner R (2019) Sex does not sell: the argument for using the terms "anamorph" and "teleomorph" for fungi. Mycological Progress 18: 305-312.

Knowles LL, Kubatko LS (2010) Estimating Species Trees: an introduction to concepts and models. In: Knowles LL, Kubatko LS (eds.): Estimating Species Trees: Practical and Theoretical Aspects. John Wiley \& Sons, Hoboken.

Koukol O, Delgado G, Hofmann TA, Piepenbring M (2018) Panama, a hot spot for Hermatomyces (Hermatomycetaceae, Pleosporales) with five new species, and a critical synopsis of the genus. IMA Fungus 9: 107-141. 
Kurtzman CP, Sugiyama J (2015) Saccharomycotina and Taphrinomycotina: the yeasts and yeastlike fungi of the Ascomycota. In: McLaughlin D, Spatafora J (eds) The Mycota Vol 7B. Springer-Verlag, Berlin, Heidelberg, pp. 3-33.

LaMondia J, Timper P (2016) Interactions of microfungi and plant-parasitic nematodes. In: Li DW (eds) Biology of Microfungi. Springer, Cham, pp. 573614.

Liu D (2011) Introductory remarks. In: Liu D (ed.) Molecular Detection of Human Fungal Pathogens. CRC Press, Boca Raton, pp. 1-23.

Liu JK, Hyde KD, Jeewon R, Phillips AJL, Maharachchikumbura SSN, Ryberg M, Liu ZY, Zhao Q (2017) Ranking higher taxa using divergence times: a case study in Dothideomycetes. Fungal Diversity 84: 75-99.

Liu KL, Porras A, Kuske CR, Eichorst SA, Xie G (2012) Accurate, rapid taxonomic classification of fungal large-subunit rRNA genes. Applied and Environmental Microbiology 78: 1523-1533.

Liu YJ, Whelen S, Hall BD (1999) Phylogenetic relationships among Ascomycetes: evidence from an RNA Polymerase II subunit. Molecular Biology and Evolution 16: 1799-1808.

Lücking R, Hawksworth DL (2018) Formal description of sequence-based voucherless Fungi: promises and pitfalls, and how to resolve them. IMA Fungus 9: 143-166.

Madelin MF (1979) An appraisal of the taxonomic significance of some different modes of producing blastic conidia. In: Kendrick B (ed.) The Whole Fungus: The Sexual-Asexual Synthesis Vol. 1. National Museums of Canada, Ottawa, pp. 63-80.

Maharachchikumbura SSN, Hyde KD, Jones EBG, McKenzie EHC, Bhat JD, Dayarathne MC, Huang SK, Norphanphoun C, Senanayake IC, Perera RH (2016) Families of Sordariomycetes. Fungal Diversity 79: 1-317.

Maharachchikumbura SSN, Hyde KD, Jones EBG, McKenzie EHC, Huang SK, Abdel-Wahab MA, Daranagama DA, Dayarathne M, D'souza MJ Goonasekara ID et al. (2015) Towards a natural classification and backbone tree for Sordariomycetes. Fungal Diversity 72: 199-301.

Manamgoda DS, Rossman AY, Castlebury LA, Crous PW, Madrid H, Chukeatirote E, Hyde KD (2014) The genus Bipolaris. Studies in Mycology 79: 221-288.

McKenzie EHC, Jones EBG, Hyde KD (2014) Taxonomy and phylogeny of Dothideomycetes. Phytotaxa 176: 5-6.

McNeill J, Barrie FR, Buck WR, Demoulin V, Greuter W, Hawksworth DI, Herendeen PS, Knapp S, Marhold K, Prado J et al. (eds.) (2012) International Code of Nomenclature for algae, fungi, and plants (Melbourne Code) Adopted by the Eighteenth International Botanical Congress Melbourne, Australia, July 2011. http://www.iapt-taxon.org/nomen/main.php

Meyer V, Andersen MR, Brakhage AA, Braus GH, Caddick MX, Cairns TC, de Vries RP, Haarmann T, Hansen K, Hertz C et al. (2016) Current challenges of research on filamentous fungi in relation to human welfare and a sustainable bio-economy: a white paper. Fungal Biology and Biotechnology 3: 2-17.

Miller JD (2016) Mycotoxins in food and feed: a challenge for the twenty-first century. In: Li DW (ed.) Biology of Microfungi. Springer, Cham, pp. 469-493.

Minter DW (1987) The significance of conidiogenesis in pleoanamorphy. In: Sugiyama J (ed.) Pleomorphic Fungi: The Diversity and its Taxonomic Implications. Kodansha, Tokyo \& Elsevier, Amsterdam, pp. 241-262. 
Minter DW, Kirk PM, Sutton BC (1982) Holoblastic phialides. Transactions of the British Mycological Society 79: 75-93.

Minter DW, Kirk PM, Sutton BC (1983) Thallic phialides. Transactions of the British Mycological Society 80: 39-66.

Moro LB, Delgado G, Schoenlein IH (2015) Polylobatispora setulosa, a new freshwater hyphomycete from Ilhabela, Sao Paulo state, Brazil. Mycosphere 6: 13-18.

Moro LB, Delgado G, Schoenlein IH (2016) Clathrosporium retortum, a novel aeroaquatic fungus in the Sordariomycetidae (Ascomycota) from Brazil. Phytotaxa 239: 17-29.

Moro LB, Delgado G, Schoenlein IH (2018) Freshwater hyphomycetes from Ilhabela State Park, Brazil. Current Research in Environmental \& Applied Mycology 8: 204-216.

Nagy LG, Kocsubé S, Csanádi Z, Kovács GM, Petkovits T, Vágvölgyi C, Papp T (2012) Re-Mind the Gap! Insertion Deletion data reveal neglected phylogenetic potential of the nuclear ribosomal Internal Transcribed Spacer (ITS) of Fungi. PLoS ONE 7(11): e49794. doi:10.1371/journal.pone.0049794

Nguyen HDT, Jančič S, Meijer M, Tanney JB, Zalar P, Gunde-Cimerman N, Seifert KA (2015) Application of the Phylogenetic Species Concept to Wallemia sebi from House Dust and Indoor Air Revealed by Multi-Locus Genealogical $\begin{array}{llll}\text { Concordance. } & \text { PLoS } & \text { ONE } & \end{array}$ https://doi.org/10.1371/journal.pone.0120894

Nieuwenhuis BPS, James TY (2016) The frequency of sex in fungi. Philosophical Transactions of the Royal Society B 371: 1-12.

Nuankaew S, Suetrong S, Wutikhun T, Pinruan U (2019) Hermatomyces trangensis sp. nov., a new dematiaceous hyphomycete (Hermatomycetaceae, Pleosporales) on sugar palm in Thailand. Phytotaxa 39: 277-288.

Piepenbring M (2015) Introduction to Mycology in the Tropics. APS Press, Saint Paul.

Pöggeler S, Nowrousian M, Kück U (2006) Fruiting-body development in Ascomycetes. In: Kües U, Fischer R (eds.) The Mycota Vol. I. SpringerVerlag, Berlin, Heidelberg, pp. 325-355.

Pointing SB, Hyde KD (2001) Bio-exploitation of filamentous fungi. Fungal Diversity Press, Hong Kong.

Porras A, Liu KL, Kuske CR, Xie G (2014) From genus to phylum: large-subunit and internal transcribed spacer rRNA operon regions show similar classification accuracies influenced by database composition. Applied and Environmental Microbiology 80: 829-840.

Posada D (2008). jModelTest: phylogenetic model averaging. Molecular Biology and Evolution 25: 1253-1256.

Posada D (2009) Selecting models of evolution. In: Lemey P, Salemi M, Vandamme AM (eds.) The Phylogenetic Handbook: A Practical Approach to Phylogenetic Analysis and Hypothesis Testing 2nd ed. Cambridge University Press, Cambridge, pp. 345-361.

Raghuwanshi R, Singh S, Aamir M, Saxena A, Gupta VK, Upadhyay RS (2016) Microfungi in biofuel and bioenergy research. In: Li DW (ed.) Biology of Microfungi. Springer, Cham, pp. 543-571.

Raja HA, Miller AN, Pearce CJ, Oberlies NH (2017) Fungal identification using molecular tools: a primer for the natural products research community. Journal of Natural Products 80: 756-770. 
Raja HA, Schoch CL, Hustad VP, Shearer CA, Miller AN (2011) Testing the phylogenetic utility of MCM7 in the Ascomycota. MycoKeys 1: 63-94.

Rannala B, Yang Z (2008) Phylogenetic inference using whole genomes. Annual Review of Genomics and Human Genetics 9: 217-231.

Réblová M, Seifert KA (2004) Conioscyphascus, a new ascomycetous genus for holomorphs with Conioscypha anamorphs. Studies in Mycology 50: 95-108.

Reynolds DR (1993) The fungal holomorph: an overview. In: Reynolds DR, Taylor JW (eds.) The Fungal Holomorph: Mitotic, Meiotic and Pleomorphic Speciation in Fungal Systematics. CAB International, Wallingford, pp. 15-25.

Reynolds DR (1994) Implications of the Holomorph Concept for Ascomycete Systematics. In: Hawksworth DL (ed.) Ascomycete Systematics: Problems and Perspectives in the Nineties. Plenum Press, New York, pp. 13-19.

Reynolds DR, Taylor JW (eds.) (1993) The Fungal Holomorph: Mitotic, Meiotic and Pleomorphic Speciation in Fungal Systematics. CAB International, Wallingford.

Roger AJ, Sandblom O, Doolittle WF, Philippe H (1999) An evaluation of Elongation Factor $1 \alpha$ as a phylogenetic marker for Eukaryotes. Molecular Biology and Evolution 16: 218-233.

Ronquist F, Huelsenbeck JP (2003) MrBayes 3: Bayesian phylogenetic inference under mixed models. Bioinformatics 19: 1572-1574.

Rossman AY (1997) Biodiversity of tropical microfungi: an overview. In: Hyde KD (ed.) Biodiversity of Tropical Microfungi. Hong Kong University Press, Hong Kong, pp. 1-10.

Samson RA, Visagie CM, Houbraken J, Hong SB, Hubka V, Klaassen CH, Frisvad JC (2014) Phylogeny, identification and nomenclature of the genus Aspergillus. Studies in Mycology 78: 141-173.

Schoch CL, Seifert KA, Huhndorf S, Robert V, Spouge JL, Levesque CA, Chen W, Fungal Barcoding Consortium (2012) Nuclear ribosomal internal transcribed spacer (ITS) region as a universal DNA barcode marker for Fungi. Proceedings of the National Academy of Sciences of the U.S.A. 109: 62416246.

Schoch CL, Sung GH, López F, Townsend JP, Miadlikowska J, Hofstetter V, Robbertse B, Matheny PB, Kauff F, Wang Z et al. (2009) The Ascomycota Tree of Life: A phylum-wide phylogeny clarifies the origin and evolution of fundamental reproductive and ecological traits. Systematic Biology 58: 224239.

Seifert KA (1993) Integrating anamorphic fungi into the fungal system. In Reynolds DR, Taylor JW (eds.) The Fungal Holomorph: Mitotic, Meiotic and Pleomorphic Speciation in Fungal Systematics. CAB International, Wallingford, pp. 79-85.

Seifert KA, Gams W (2001) The taxonomy of anamorphic fungi. In: McLaughlin DJ, McLaughlin EG, Lemke PA (eds.) The Mycota Vol. 7A. Springer-Verlag, Berlin, Heidelberg, pp. 307-347.

Seifert K, Morgan-Jones G, Gams W, Kendrick B (2011) The Genera of Hyphomycetes. CBS-KNAW Fungal Biodiversity Centre, Utrecht.

Seifert KA, Okada G (1990) Taxonomic implications of conidiomatal anatomy in synnematous Hyphomycetes. Studies in Mycology 32: 29-40.

Seifert KA, Samuels GJ (2000) How should we look at anamorphs? Studies in Mycology 45: 5-18. 
Shenoy BD, Jeewon R, Hyde KD (2007) Impact of DNA sequence-data on the taxonomy of anamorphic fungi. Fungal Diversity 26: 1-54.

Simpson MG (2010) Phylogenetic systematics. In: Plant Systematics 2nd edn. Elsevier Academic Press, Burlington, pp. 17-46.

Sigler $L$ (1989) Problems in application of the terms 'blastic' and 'thallic' to modes of conidiogenesis in some onygenalean fungi. Mycopathologia 106: 155-161.

Sklenář $F$, Jurjević Ž, Zalar P, Frisvad JC, Visagie CM, Kolařík M, Houbraken J, Chen AJ, Yilmaz N, Seifert KA et al. (2017) Phylogeny of xerophilic aspergilli (subgenus Aspergillus) and taxonomic revision of section Restricti. Studies in Mycology 88: 161-236.

Spatafora JW, Sung GH, Johnson D, Hesse C, O'Rourke B, Serdani M, Spotts R, Lutzoni F, Hofstetter V, Miadlikowska J et al. (2006) A five-gene phylogeny of Pezizomycotina. Mycologia 98: 1018-1028.

Stamatakis A (2014) RAxML version 8: a tool for phylogenetic analysis and postanalysis of large phylogenies. Bioinformatics 30: 1312-1313.

Stewart JE, Timmer LW, Lawrence CB, Pryor BM, Peever TL (2014) Discord between morphological and phylogenetic species boundaries: incomplete lineage sorting and recombination results in fuzzy species boundaries in an asexual fungal pathogen. BMC Evolutionary Biology 14: 38(1-14).

Stielow JB, Lévesque CA, Seifert KA, Meyer W, Irinyi L, Smits D, Renfurm R, Verkley GJ, Groenewald M, Chaduli D et al. (2015) One fungus, which genes? Development and assessment of universal primers for potential secondary fungal DNA barcodes. Persoonia 35: 242-263.

Su HY, Hyde KD, Maharachchikumbura SSN, Ariyawansa HA, Luo Z, Promputtha I, Tian Q, Lin C, Shang Q, Zhao $Y$ et al. (2016) The families Distoseptisporaceae fam. nov., Kirschsteiniotheliaceae, Sporormiaceae and Torulaceae, with new species from freshwater in Yunnan Province, China. Fungal Diversity 80: 375-409.

Su XJ, Luo ZL, Jeewon R, Bhat DJ, Bao DF, Li WL, Hao YE, Su HY, Hyde KD (2018) Morphology and multigene phylogeny reveal new genus and species of Torulaceae from freshwater habitats in northwestern Yunnan, China. Mycological Progress 17: 531-545.

Su YY, Qi YL, Cai L (2012) Induction of sporulation in plant pathogenic fungi. Mycology 3: 195-200.

Subramanian CV (1962) A classification of the Hyphomycetes. Current Science 31: 409-411.

Subramanian CV (1983) Hyphomycetes: Taxonomy and Biology. Academic Press, London \& New York.

Sun S, Heitman J (2011) Is sex necessary? BMC Biology 9: 56-59.

Sutton BC (1993) Mitosporic fungi (Deuteromycetes) in the Dictionary of the Fungi. In: Reynolds DR, Taylor JW (eds.) The Fungal Holomorph: Mitotic, Meiotic and Pleomorphic Speciation in Fungal Systematics. CAB International, Wallingford, pp. 27-56.

Sutton BC (1996) Conidiogenesis, classification and correlation. In: Sutton BC (ed.) A Century of Mycology. Cambridge University Press, Cambridge, pp. 135160.

Tamura K, Stecher G, Peterson D, Filipski A, Kumar S (2013) MEGA6: Molecular Evolutionary Genetics Analysis Version 6.0. Molecular Biology and Evolution 30: 2725-2729. 
Tan YP, Crous PW, Shivas RG (2016) Eight novel Bipolaris species identified from John L. Alcorn's collections at the Queensland Plant Pathology Herbarium (BRIP). Mycological Progress 15: 1203-1214.

Tanaka T, Hirayama K, Yonezawa H, Hakateyama S, Harada Y, Sano T, Shirouzu T, Hosoya T (2009) Molecular taxonomy of bambusicolous fungi: Tetraplosphaeriaceae, a new pleosporalean family with Tetraploa-like anamorphs. Studies in Mycology 64: 175-209.

Tanaka K, Hirayama K, Yonezawa H, Sato G, Toriyabe A, Kudo H, Hashimoto A, Matsumura M, Harada $Y$, Kurihara $Y$ et al. (2015) Revision of the Massarineae (Pleosporales, Dothideomycetes). Studies in Mycology 82: 75136.

Tanney T, Miller AN (2017) Asexual-sexual morph connection in the type species of Berkleasmium. IMA Fungus 8: 99-105.

Taylor JW (1993) A contemporary view of the Holomorph: nucleic acid sequence and computer databases are changing fungal classification. In: Reynolds DR, Taylor JW. The Fungal Holomorph: Mitotic, Meiotic and Pleomorphic Speciation in Fungal Systematics. CAB International, Wallingford, pp. 3-13.

Taylor JW (1995) Making the Deuteromycota redundant: a practical integration of mitosporic and meiosporic fungi. Canadian Journal of Botany 73: 754-759.

Taylor JW (2011) One Fungus = One Name: DNA and fungal nomenclature twenty years after PCR. IMA Fungus 2: 113-120.

Taylor JW, Jacobson DJ, Kroken S, Kasuga T, Geiser DM, Hibbett DS, Fisher MC (2000) Phylogenetic species recognition and species concepts in Fungi. Fungal Genetics and Biology 31: 21-32.

Taylor JW, Spatafora J, O'Donnell K, Lutzoni F, James T, Hibbett DS, Geiser D, Bruns TD, Blackwell M (2004) The Fungi. In: Cracraft J, Donoghue MJ (eds.) Assembling the Tree of Life. Oxford University Press, New York, pp. 171-194.

Tedersoo L, Sánchez S, Kõljalg U, Bahram M, Doring M, Schigel D, May T, Ryberg M, Abarenkov K (2018) High-level classification of the Fungi and a tool for evolutionary ecological analyses. Fungal Diversity 90: 135-159.

Tibpromma S, Hyde KD, McKenzie EHC, Bhat DJ, Phillips AJL, Wanasinghe DN, Samarakoon MC, Jayawardena RS, Dissanayake AJ, Tennakoon DS. et al. (2018) Fungal diversity notes 840-928: microfungi associated with Pandanaceae. Fungal Diversity 93: 1-160.

Trovão J, Tiago I, Soares F, Paiva DS, Mesquita N, Coelho C, Catarino L, Gil F, Portugal A (2019) Description of Aeminiaceae fam. nov., Aeminium gen. nov. and Aeminium ludgeri sp. nov. (Capnodiales), isolated from a biodeteriorated art-piece in the Old Cathedral of Coimbra, Portugal. MycoKeys 45:57-73.

Tubaki K (1958) Studies on the Japanese Hyphomycetes. V. Leaf \& stem group with a discussion of the classification of the Hyphomycetes and their perfect stages. Journal of the Hattori Botanical Laboratory 20: 142-244.

Tubaki K (1981) Hyphomycetes: their Perfect-Imperfect Connexions. J. Cramer, Vaduz.

Vandamme AM (2009) Basic concepts of molecular evolution. In: Lemey P, Salemi M, Vandamme AM (eds.) The Phylogenetic Handbook: A Practical Approach to Phylogenetic Analysis and Hypothesis Testing. Cambridge University Press, Cambridge, pp. 3-29.

Videira SIR, Groenewald JZ, Nakashima C, Braun U, Barreto RW, de Wit PJGM, Crous PW (2017) Mycosphaerellaceae - Chaos or clarity? Studies in Mycology 87: 257-421. 
Vilgalys R, Hibbett DS (1993) Phylogenetic classification of fungi and our Linnaean heritage. In: Reynolds DR, Taylor JW (eds.) The Fungal Holomorph: Mitotic, Meiotic and Pleomorphic Speciation in Fungal Systematics. CAB International, Wallingford, pp. 255-260.

Walker SK, Garrill A (2006) Actin microfilaments in fungi. Mycologist 20: 26-31.

Wang CJK (1979) Pleomorphic Fungi Imperfecti. In: Kendrick B (ed.) The Whole Fungus: the Sexual-Asexual Synthesis Vol. 1. National Museums of Canada, Ottawa, pp. 81-92.

Ward PS, Brady SG, Fisher BL, Schultz TR (2016) Phylogenetic classifications are informative, stable, and pragmatic: the case for monophyletic taxa. Insectes Sociaux 63: 489-492.

Weresub LK, Hennebert GL (1979) Anamorph and teleomorph: terms for organs of reproduction rather than karyological phases. Mycotaxon 8: 181-186.

Weresub LK, Pirozynski KA (1979) Pleomorphism of fungi as treated in the history of mycology and nomenclature. In: Kendrick B (ed.) The Whole Fungus: The Sexual-Asexual Synthesis Vol. 1. National Museums of Canada, Ottawa, pp 17-30.

White TJ, Bruns T, Lee S, Taylor J (1990) Amplification and direct sequencing of fungal ribosomal RNA genes for phylogenetics. In: Innis MA, Gelfand DH, Sninsky JJ, White TJ (eds.) PCR Protocols: A Guide to Methods and Applications. Academic Press, San Diego, pp. 315-322.

Wijayawardene NN, Hyde KD, Lumbsch HT, Liu JK, Maharachchikumbura SSN, Ekanayaka AH, Tian Q, Phookamsak R (2018) Outline of Ascomycota: 2017. Fungal Diversity 88: 167-263.

Wijayawardene NN, Hyde KD, Rajeshkumar KC, Hawksworth DL, Madrid H, Kirk PM, Braun U, Singh RV, Crous PW, Kukwa M et al. (2017a) Notes for genera: Ascomycota. Fungal Diversity 86: 1-594.

Wijayawardene NN, Hyde KD, Tibpromma S, Wanasinghe DN, Thambugala KM, Tian Q, Wang Y (2017b) Towards incorporating asexual fungi in a natural classification: checklist and notes 2012-2016. Mycosphere 8: 1457-1555.

Wijayawardene NN, McKenzie EHC, Hyde KD (2012) Towards incorporating anamorphic fungi in a natural classification - checklist and notes for 2011. Mycosphere 3: 157-228.

Willis KJ (ed.) (2018) State of the World's Fungi 2018. Royal Botanic Gardens, Kew.

Yang Z (2006) Computational Molecular Evolution. Oxford University Press, New York.

Yang Z, Rannala B (2012) Molecular phylogenetics: principles and practice. Nature Reviews Genetics 13: 303-314.

Yun CS, Nishida H (2011) Distribution of introns in fungal histone genes. PloS ONE 6(1), e16548. doi:10.1371/journal.pone.0016548

Zhang N, Castlebury LA, Miller AN, Huhndorf SM, Schoch CL, Seifert KA, Rossman AY, Rogers JD, Kohlmeyer J, Volkmann-Kohlmeyer B, Sung GH (2006) An overview of the systematics of the Sordariomycetes based on a four-gene phylogeny. Mycologia 98: 1076-1087. 
Declaration of author contributions to the publication / manuscript:

The phylogenetic placement of Ernakulamia cochinensis within Pleosporales (Dothideomycetes, Ascomycota)

Status: published

Name of journal: Cryptogamie, Mycologie 38 (4): 435-451, 2017.

Contributing authors:

Gregorio Delgado (GD)

Ondřej Koukol (OK)

Orlando Caceres (OC)

Meike Piepenbring (MP)

What are the contributions of the doctoral candidate and his co-authors?

(1) Concept and design

Doctoral candidate GD: $70 \%$

Co-author OK: $30 \%$

(2) Conducting tests and experiments

Doctoral candidate GD: Not involved in field work

Co-authors OK: $80 \%$, OC: $20 \%$ Carried out the field work

(3) Compilation of data sets and figures

Doctoral candidate GD: 60\% Obtained morphological and cultural data, generated figures \& drawing

Co-author OK: 35\% Obtained morphological and molecular data, generated figures, MP: $5 \%$ Advised on drawing

(4) Analysis and interpretation of data

Doctoral candidate GD: $60 \%$ Performed interpretations of the data

Co-author OK: 40\% Performed analysis and interpretations of data

(5) Drafting of manuscript

Doctoral candidate GD: $80 \%$ 
Co-authors OK: $15 \%$, MP: $5 \%$

\section{I hereby certify that the information above is correct.}

August 28th, 2019, Houston

Date and place

Signature doctoral candidate

August 30th, 2019, Frankfurt am Main

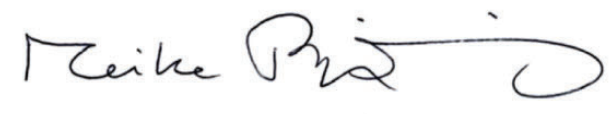

Date and place

Signature supervisor

August 29th, 2019, Champaign

Andrew M. Miller Digitally signed by Andrew N. Miller

Date and place

Signature supervisor 


\title{
The phylogenetic placement of Ernakulamia cochinensis within Pleosporales (Dothideomycetes, Ascomycota)
}

\author{
Gregorio DELGADO ${ }^{a, b^{*}}$, Ondřej KOUKOL ${ }^{c}$, \\ Orlando CÁCERES ${ }^{d} \&$ Meike PIEPENBRING ${ }^{b}$ \\ ${ }^{a}$ EMLab P\&K Houston, \\ 6310 Rothway Street, Houston, TX 77040, USA \\ ${ }^{b}$ Department of Mycology, Institute of Ecology, Evolution and Diversity, \\ Goethe Universität Frankfurt, Max-von-Laue-Str. 13, \\ 60438 Frankfurt am Main, Germany \\ ${ }^{c}$ Department of Botany, Faculty of Science, Charles University, \\ Benátská 2, CZ-128 01 Praha 2, Czech Republic \\ ${ }^{d}$ Centro de Investigaciones Micológicas CIMi, \\ Autonomous University of Chiriquí (UNACHI), 0427, David, Chiriquí, Panama
}

\begin{abstract}
The phylogenetic affinities of the anamorphic fungus Ernakulamia cochinensis are investigated based on a representative specimen recently collected on Astrocaryum standleyanum (Arecaceae) in Panama. Molecular phylogenetic analyses using nuclear ribosomal DNA sequence data of the large subunit and the internal transcribed spacer region together with a fragment of the $\beta$-tubulin gene suggest that the fungus belongs to the Dothideomycetes (Ascomycota) where it groups with members of the family Tetraplosphaeriaceae in Pleosporales. Morphologically, this placement is further supported by the presence of an internal hyphal structure found within the conidia of the Panamanian collection and an isotype specimen of the fungus similar to species of closely related genera within Tetraplosphaeriaceae, e.g., Quadricrura and Polyplosphaeria. The putative phylogenetic position of the morphologically similar Piricaudilium lobatum in Tetraplosphaeriaceae is proposed based on examination of its type specimen.
\end{abstract}

palmicolous / Petrakia / Piricauda / saprobic / taxonomy

\section{INTRODUCTION}

Palm trees (Arecaceae) harbor a wide range of microfungi exhibiting a variety of life strategies such as saprobic, parasitic and endophytic ones (Fröhlich et al., 2000; Fröhlich \& Hyde, 2000; Hyde et al., 2000; Taylor \& Hyde, 2003). The monotypic genus Ernakulamia Subram. (Subramanian, 1994) is one of the saprobic taxa commonly found associated with palm hosts. Ernakulamia cochinensis

* Corresponding author: gdelgado@emlabpk.com 
(Subram.) Subram., the type species, is characterized by semimacronematous, simple conidiophores, monotretic, integrated, terminal or intercalary, cicatrized conidiogenous cells with a well-defined pore in the middle of each scar and muriform, dark brown, euseptate conidia of variable shape that are verrucose at their base and possess numerous straight, unbranched appendages (Ellis, 1976). Subramanian (1957) first described this peculiar anamorph without illustration within the genus Petrakia (Pe.) Syd. \& P. Syd. as Pe. cochinensis Subram. based on a specimen collected on a dead spathe of Cocos nucifera L. in India. He considered it congeneric with Pe. echinata (Peglion) Syd. \& P. Syd., the generic type, based on similar conidial shape, muriform septation and appendiculate conidia. Later, Ellis (1976) illustrated the fungus and transferred it to Piricauda (P.) Bubák as P. cochinensis (Subram.) M.B. Ellis following the generic concept of Hughes (1960) who previously had redescribed its type species P. uleana (Sacc. \& P. Syd.) Bubák (三 P. paraguayensis (Speg.) R.T. Moore). According to this concept, the micronematous, arched conidiophores developing on superficial hyphae and the tretic conidia arising singly from a pore on the conidiogenous cell are the most distinctive features of the genus (Mercado et al., 2005; da Silva et al., 2016). Holubová-Jechová (1988) commented on the similarity of $P$. cochinensis with the morphologically close fungus Piricaudilium (Pi.) lobatum Hol.-Jech. She also noted the impossibility to prove the presence of an internal hyphal structure within the strongly melanized conidia of $P$. cochinensis similar to the one found in the conidia of Pi. lobatum. She further suggested that a detailed study of $P$. cochinensis was needed to confirm if the fungus was congeneric with $P$. paraguayensis despite sharing the same conidiogenesis. Subramanian (1994) introduced Ernakulamia after deciding that the fungus cannot be retained in either Petrakia or Piricauda because of morphological and ecological differences such as conidial septation, conidiogenesis and habitat. In a revision of Piricauda following Hughes' and Ellis' criteria, Mercado et al. (2005) accepted P. cochinensis together with seven other species probably unaware of Subramanian's publication as the name Ernakulamia has been overlooked by most authors reporting this fungus (Capdeet \& Romero, 2010).

Literature and online records show that E. cochinensis is common in tropical and subtropical areas where it has been mostly collected on petioles and dead leaves of palm species belonging to twenty different genera of Arecaceae and several other undetermined palm trees (Bhat \& Sutton, 1985; Holubová-Jechová \& Mercado, 1986, 1989; Mercado et al., 1997b, 2005; Cybertruffle's Robigalia, 2017; HerbIMI Database, 2017; Mycoportal, 2017). Taylor \& Hyde (2003) considered its host range restricted to this family of monocots. However, the fungus has also been recorded on a broader host spectrum including Benthamidia japonica (Siebold \& Zucc.) H. Hara (Cornaceae), Stewartia monadelpha Siebold \& Zucc. (Theaceae), Ilex sp. (Aquifoliaceae), Ocotea leucoxylon (Sw.) De Laness. (Lauraceae), Freycinetia multiflora Merr., Pandanus tectorius Parkinson ex Du Roi, P. monticola F. Muell., Pandanus sp. (Pandanaceae) and Vitex sp. (Lamiaceae) (Delgado \& Mena, 2004; Whitton et al., 2012; Farr \& Rossman, 2017). Nakagiri \& Ito (1995) first isolated and described $E$. cochinensis on corn meal agar (CMA) from a specimen collected on a dead petiole of the palm tree Satakentia liukiuensis (Hatus.) H.E. Moore in Japan. They also conducted scanning electron microscopy studies on conidiogenesis and conidia showing ultrastructural details of the pores at the apex of tretic conidiogenous cells and the conidia basal cells. Phylogenetic relationships using molecular data, on the other hand, have not been previously assessed for Ernakulamia and DNA sequence data are still lacking in GenBank database. Teleomorph connections are currently unknown and the genus is tentatively considered 
Ascomycota incertae sedis (Wijayawardene et al., 2012). Tanaka et al. (2009) suggested that species of Piricauda sensu Mercado et al. (2005) including E. cochinensis have conidia morphologically similar to those present in some members of Tetraplosphaeriaceae, a pleosporalean family they introduced for Massarina-like ascomycetes with appendiculate anamorphs resembling Tetraploa Berk. \& Broome. They also pointed out that molecular studies are necessary to clarify their phylogenetic affinities and their morphological resemblance may be the result of convergent evolution.

During field sampling in south-western Panama one of us (O.K.) collected E. cochinensis on rotten leaves of a palm tree. The fungus grew on agar media and the isolate was characterized by morphological, cultural and molecular data. In order to test the morphology-based hypotheses outlined above and to elucidate a phylogenetic placement for E. cochinensis within the current classification of Ascomycota (Schoch et al., 2009) DNA sequence data of two different gene regions were analyzed. Results are presented here along with morphological and cultural studies of the Panamanian collection and a revision of an isotype specimen. Comments on the putative phylogenetic placement of Pi. lobatum are also provided based on morphological examination of its type material.

\section{MATERIALS AND METHODS}

\section{Morphological and cultural study}

The specimen of E. cochinensis studied here was collected on rotten leaves of the palm tree Astrocaryum standleyanum L.H. Bailey, the black palm, during field work carried out in Chiriquí Province, Panama, in July 2016. A first isolation was made on $2 \%$ malt extract agar (MEA) by removing single conidia from the substrate surface with a sterile needle. Pieces of mycelium were later transferred aseptically to different culture media e.g. MEA, potato carrot agar (PCA), modified cellulose agar (MCA), water agar with sterile wooden toothpicks, and incubated at room temperature $\left(22-25^{\circ} \mathrm{C}\right)$ for cultural characterization and to induce sporulation. Conidia from natural substrate were first bleached in $1 \%$ or $3 \%$ sodium hypochlorite solutions $(\mathrm{NaClO})$ following Tanaka et al. (2009) to detect the presence of internal structures. Partially or fully bleached conidia were then transferred to a drop of Lactocotton Blue to obtain semi-permanent slides. Voucher specimens are deposited in the Herbarium of the Faculty of Science of the Charles University, Prague (PRC) and the University of Panama Herbarium, Panama (PMA). A living culture was also deposited in the Charles University Culture Collection of Fungi (CCF). An isotype specimen of E. cochinensis and the holotype specimen of Pi. lobatum were borrowed from the Fungarium of the Royal Botanic Gardens, Kew (IMI) and the Herbarium of the National Museum, Prague (PRM), respectively, for comparison and observation of the internal conidial structure. Line drawings were made with the aid of a drawing tube (Carl Zeiss, Oberkochen, Germany). Fungal names across the text followed Index Fungorum and host plant names followed International Plant Names Index (www.ipni.org). Herbaria or culture collection acronyms are cited according to Index Herbariorum (http://sweetgum.nybg.org/science/ih/). 


\section{DNA extraction, PCR amplification \& sequencing}

Genomic DNA was extracted from 2 weeks old cultures growing on MEA using a Zymo Research Fungal/Bacterial Kit (Zymo Research, Orange, USA) following the manufacturer's protocols. Nuclear rDNA containing the ITS1-5.8SITS2 region and the highly variable D1/D2 domains of the 28S (further referred to as ITS-LSU) was amplified with primer sets ITS1F/NL4 (O'Donnell, 1993) and a fragment of the $\beta$-tubulin gene was amplified with primer set T1/T22 (O'Donnell \& Cigelnik, 1997). The PCR products were viewed by means of electrophoresis on $1 \%$ (w/v) TAE agarose gel stained with ethidium bromide. The PCR products were purified with the Gel/PCR DNA Fragments Extraction Kit (Geneaid Biotech, Bade City, Taiwan). Both strands of the PCR fragments were sequenced with the primers used for amplification at the Sequencing Laboratory of the OMICS Core Facility, BIOCEV (Vestec, Czech Republic).

\section{Taxon sampling and phylogenetic analyses}

The newly obtained sequence from the freshly isolated strain of E. cochinensis (CCF 5738) was first aligned with an ITS-LSU sequence from the morphologically well-characterized Japanese isolate studied by Nakagiri \& Ito (1995) and accessed through the website of the Biological Resource Center (NBRC) of the National Institute of Technology and Evaluation of Japan (NITE) (http://www. nbrc.nite.go.jp/). Both sequences were identical and BLAST searches of the consensus including also the newly obtained $\beta$-tubulin sequence showed close affinities with members of the family Tetraplosphaeriaceae (Pleosporales, Dothideomycetes). Closest hits and sequences from each genus within the family were selected from previous phylogenetic studies (Tanaka et al., 2009; Ariyawansa et al., 2015; Li et al., 2016) and used to build datasets. Additional taxa from related families in Pleosporales (Hyde et al., 2013; Tibpromma et al., 2016) were also included. Details of strains and sequences used in this study are listed in Table 1. Three separate datasets (ITS, LSU, $\beta$-tubulin) were assembled and aligned using the MUSCLE algorithm implemented in Geneious v.6.1.5 software and manually edited in the same software. The best-fit substitution model for each gene was determined using jModeltest v.2.1.5 (Darriba et al., 2012) and the selected models for the ITS, LSU and $\beta$-tubulin regions employing the Akaike Information Criterion were TIM2 + G, TIM2 + I + G and HKY + I + G, respectively. The three datasets were tested for combinability by using the partition homogeneity test (Farris et al., 1994) implemented in PAUP*4.0b10 (Swofford, 2002), which showed that there was no significant incongruence only between the ITS and LSU datasets (1,000 artificial data sets, $\mathrm{P}=0.41)$. Phylogenetic analyses of the ITS-LSU dataset with both regions set as separate partitions and $\beta$-tubulin were performed by Bayesian inference using MrBayes v.3.2 (Ronquist et al., 2012) and Maximum likelihood (ML) running on the RAxML Web Server v.7.7.1 (Stamatakis et al., 2008). For Bayesian analyses two independent runs of 3,000,000 generations were ran with sampling every 100th generation. The first $25 \%$ of samples were discarded as burn-in and the remaining trees were used to compute a $50 \%$ majority rule consensus tree with posterior probabilities (PP) as Bayesian branch support. The average standard deviation of split frequencies estimating convergence reached the level of 0.004 and 0.001 at the end of analysis of ITS-LSU and $\beta$-tubulin, respectively. The GTRCAT approximation implemented in the ML analysis and nonparametric bootstrapping (BS) with 1000 replicates were used for branch support. 
Table 1. Strains included in this study and their GenBank accession numbers. Newly generated sequences are written in bold

\begin{tabular}{|c|c|c|c|c|c|c|}
\hline \multirow{2}{*}{ Taxon } & \multirow{2}{*}{ Strain } & \multirow{2}{*}{$\begin{array}{l}\text { Country } \\
\text { of origin }\end{array}$} & \multicolumn{3}{|c|}{ GenBank accession numbers } & \multirow{2}{*}{ Reference } \\
\hline & & & ITS & $L S U$ & $\beta$-tubulin & \\
\hline $\begin{array}{l}\text { Aquasubmersa } \\
\text { japonica }\end{array}$ & KT 2863 & Japan & LC061593 & LC061588 & - & $\begin{array}{l}\text { Ariyawansa et al. } \\
(2015)\end{array}$ \\
\hline $\begin{array}{l}\text { Aquasubmersa } \\
\text { japonica }\end{array}$ & KT 2813 & Japan & LC061591 & LC061586 & - & $\begin{array}{l}\text { Ariyawansa et al. } \\
(2015)\end{array}$ \\
\hline $\begin{array}{l}\text { Ernakulamia } \\
\text { cochinensis }\end{array}$ & CCF 5738 & Panama & LT964671 & LT964670 & LT964672 & This study \\
\hline $\begin{array}{l}\text { Ernakulamia } \\
\text { cochinensis }\end{array}$ & NBRC 32666 & Japan & $03266601 *$ & $03266601 *$ & - & Unpublished \\
\hline $\begin{array}{l}\text { Hermatomyces } \\
\text { krabiensis }\end{array}$ & $\begin{array}{l}\text { MFLUCC } \\
16-0249\end{array}$ & Thailand & KX525750 & KX525742 & - & $\begin{array}{l}\text { Tibpromma et al. } \\
\text { (2016) }\end{array}$ \\
\hline $\begin{array}{l}\text { Hermatomyces } \\
\text { sphaericus }\end{array}$ & HMAS 42922 & $\begin{array}{l}\text { P.R. } \\
\text { China }\end{array}$ & KU999956 & KX033549 & KX036229 & Unpublished \\
\hline $\begin{array}{l}\text { Hermatomyces } \\
\text { subiculosa }\end{array}$ & $\begin{array}{l}\text { MFLUCC } \\
15-0843\end{array}$ & Thailand & KX259521 & KX259523 & - & Hyde et al.(2016) \\
\hline $\begin{array}{l}\text { Hermatomyces } \\
\text { tectonae }\end{array}$ & $\begin{array}{l}\text { MFLUCC } \\
14-1140\end{array}$ & Thailand & KU144917 & KU764695 & - & $\begin{array}{l}\text { Doilom et al. } \\
\text { (2017) }\end{array}$ \\
\hline $\begin{array}{l}\text { Hermatomyces } \\
\text { tectonae }\end{array}$ & $\begin{array}{c}\text { MFLUCC } \\
14-1141\end{array}$ & Thailand & KU144918 & KU764696 & - & $\begin{array}{l}\text { Doilom et al. } \\
\text { (2017) }\end{array}$ \\
\hline $\begin{array}{l}\text { Hermatomyces } \\
\text { thailandica }\end{array}$ & $\begin{array}{l}\text { MFLUCC } \\
14-1143\end{array}$ & Thailand & KU144920 & KU764692 & - & $\begin{array}{l}\text { Doilom et al. } \\
\text { (2017) }\end{array}$ \\
\hline $\begin{array}{l}\text { Hermatomyces } \\
\text { thailandica }\end{array}$ & $\begin{array}{c}\text { MFLUCC } \\
14-1144\end{array}$ & Thailand & KU144921 & KU764693 & - & $\begin{array}{l}\text { Doilom et al. } \\
\text { (2017) }\end{array}$ \\
\hline $\begin{array}{l}\text { Lepidosphaeria } \\
\text { nicotiae }\end{array}$ & CBS 559.71 & Algeria & GQ203760 & DQ384106 & - & Kruys et al. (2006) \\
\hline $\begin{array}{l}\text { Lophiotrema } \\
\text { neoarundinaria }\end{array}$ & KT 856 & Japan & AB524786 & AB524596 & AB524848 & Tanaka et al. (2009) \\
\hline $\begin{array}{l}\text { Lophiotrema } \\
\text { neoarundinaria }\end{array}$ & KT 2200 & Japan & AB524787 & AB524597 & AB524849 & Tanaka et al. (2009) \\
\hline $\begin{array}{l}\text { Lophiotrema } \\
\text { nucula }\end{array}$ & JCM 14132 & Sweden & - & AB619021 & - & $\begin{array}{l}\text { Hirayama \& Tanaka } \\
\text { (2011) }\end{array}$ \\
\hline $\begin{array}{l}\text { Lophiotrema } \\
\text { vagabundum }\end{array}$ & JCM 14138 & Sweden & - & AB619025 & - & $\begin{array}{l}\text { Hirayama \& Tanaka } \\
\text { (2011) }\end{array}$ \\
\hline $\begin{array}{l}\text { Paraphaeosphaeria } \\
\text { parmeliae }\end{array}$ & CBS 131728 & Belgium & - & - & KP170703 & $\begin{array}{l}\text { Trakunyingcharoen } \\
\text { et al. (2014) }\end{array}$ \\
\hline $\begin{array}{l}\text { Polyplosphaeria } \\
\text { fusca }\end{array}$ & JCM 13175 & Japan & AB524789 & AB524604 & AB524850 & Tanaka et al. (2009) \\
\hline $\begin{array}{l}\text { Polyplosphaeria } \\
\text { fusca }\end{array}$ & JCM 13173 & Japan & AB524788 & AB524603 & AB524851 & Tanaka et al. (2009) \\
\hline $\begin{array}{l}\text { Polyplosphaeria } \\
\text { thailandica }\end{array}$ & $\begin{array}{l}\text { MFLUCC } \\
15-0840\end{array}$ & Thailand & KU248766 & KU248767 & - & Li et al. (2016) \\
\hline $\begin{array}{l}\text { Pseudotetraploa } \\
\text { curviappendiculata }\end{array}$ & JCM 12852 & Japan & AB524792 & AB524608 & AB524854 & Tanaka et al. (2009) \\
\hline $\begin{array}{l}\text { Pseudotetraploa } \\
\text { curviappendiculata }\end{array}$ & MAFF 239496 & Japan & AB524793 & AB524609 & AB524855 & Tanaka et al. (2009) \\
\hline
\end{tabular}


Table 1. Strains included in this study and their GenBank accession numbers. Newly generated sequences are written in bold (continued)

\begin{tabular}{|c|c|c|c|c|c|c|}
\hline \multirow{2}{*}{ axon } & \multirow{2}{*}{ train } & \multirow{2}{*}{$\begin{array}{l}\text { Country } \\
\text { of origin }\end{array}$} & \multicolumn{3}{|c|}{ GenBank accession numbers } & \multirow{2}{*}{ Reference } \\
\hline & & & ITS & $L S U$ & $\beta$-tubulin & \\
\hline $\begin{array}{l}\text { Pseudotetraploa } \\
\text { curviappendiculata }\end{array}$ & CBS 125426 & Japan & - & - & AB524856 & Tanaka et al. $(200$ \\
\hline $\begin{array}{l}\text { Pseudotetraploa } \\
\text { javanica }\end{array}$ & JCM 12854 & Japan & AB524795 & AB524611 & AB524857 & al. $(200$ \\
\hline $\begin{array}{l}\text { Pseudotetraploa } \\
\text { longissima }\end{array}$ & JCM 12853 & Japan & AB524796 & AB524612 & AB524858 & Tanaka et al. \\
\hline $\begin{array}{l}\text { Quadricrura } \\
\text { bicornis }\end{array}$ & CBS 125427 & Japan & AB524797 & AB524613 & AB524859 & Tanaka \\
\hline $\begin{array}{l}\text { uadricrura } \\
\text { eridionalis }\end{array}$ & CBS 125684 & Japan & AB524798 & AB524614 & AB524860 & Tanaka $e$ \\
\hline $\begin{array}{l}\text { Quadricrura } \\
\text { septentrionalis }\end{array}$ & CBS 125428 & Japan & AB524801 & AB524617 & AB524862 & Tanaka \\
\hline $\begin{array}{l}\text { uadricrura } \\
\text { eptentrionalis }\end{array}$ & CBS 125430 & Japan & AB524800 & AB524616 & AB524863 & Tanaka et al. $(200$ \\
\hline $\begin{array}{l}\text { Shrungabeeja } \\
\text { longiappendiculata }\end{array}$ & 76463 & Thailand & КT376474 & 76472 & - & $\begin{array}{l}\text { Ariyawansa et al. } \\
(2015)\end{array}$ \\
\hline $\begin{array}{l}\text { Shrungabeeja } \\
\text { longiappendiculata }\end{array}$ & BCC 76464 & Thailand & KT376475 & KT376473 & - & $\begin{array}{l}\text { Ariyawansa et al. } \\
(2015)\end{array}$ \\
\hline Tetraploa aristata & CBS 996.70 & Japan & AB524805 & AB524627 & AB524867 & Tanaka et al. (2009 \\
\hline Tetraploa sasicola & JCM 13167 & Japan & AB524807 & AB524631 & AB524869 & Tanaka et al. (2009 \\
\hline $\begin{array}{l}\text { Tetraploa } \\
\text { yakushimensis }\end{array}$ & CBS 125435 & Japan & AB524808 & AB524632 & AB524870 & Tanaka et al. (200 \\
\hline $\begin{array}{l}\text { Triplosphaeria } \\
\text { acuta }\end{array}$ & JCM 13171 & Japan & 3524809 & 24633 & 24871 & Tan \\
\hline $\begin{array}{l}\text { Triplosphaeria } \\
\text { cylindrica }\end{array}$ & JCM 14425 & Japan & AB524810 & AB524635 & AB524872 & Tanaka et al. $(200$ \\
\hline $\begin{array}{l}\text { Triplosphaeria } \\
\text { cylindrica }\end{array}$ & NBRC 106247 & Japan & AB524811 & AB524636 & AB524873 & Tanaka \\
\hline $\begin{array}{l}\text { Triplosphaeria } \\
\text { maxima }\end{array}$ & JCM 13172 & Japan & AB524812 & AB524637 & AB524874 & Tanaka et al. $(200$ \\
\hline Triplosphaeria sp. & NBRC 106248 & Japan & AB524815 & AB524640 & AB524877 & Tanaka et al. $(2009$ \\
\hline Triplosphaeria sp. & NBRC 106249 & Japan & AB524816 & AB524641 & AB524878 & Tanaka et al. (2009 \\
\hline $\begin{array}{l}\text { Triplosphaeria } \\
\text { yezoensis }\end{array}$ & CBS 125436 & Japan & AB524813 & AB524638 & AB52 & $\mathrm{T} \mathrm{T}_{\mathrm{s}}$ \\
\hline $\begin{array}{l}\text { Triplosphaeria } \\
\text { yezoensis }\end{array}$ & CBS 125437 & Japan & AB524814 & AB524639 & AB524876 & Tanaka et al. $(200 s$ \\
\hline $\begin{array}{l}\text { Verruculina } \\
\text { enalia }\end{array}$ & CBS 304.66 & Liberia & GQ203796 & DQ678079 & - & $\begin{array}{l}\text { Kruys \& Wedin } \\
(2009)\end{array}$ \\
\hline
\end{tabular}

* Sequence ID retrieved online from http://www.nbrc.nite.go.jp.

Abbreviations: BCC: BIOTEC Culture Collection, Bangkok, Thailand; CBS: Centraalbureau voor SchimmelculturesWesterdijk Fungal Biodiversity Institute, Utrecht, The Netherlands; CCF: Culture Collection of Fungi, Charles University, Prague, Czech Republic; HMAS: Institute of Microbiology, Chinese Academy of Sciences, Beijing, People's Republic of China; JCM: Japan Collection of Microorganisms, RIKEN BioResource Center, Tsukuba, Japan; KT: Kazuaki Tanaka; MAFF: Ministry of Agriculture, Forestry, and Fisheries Culture Collection, Tokyo, Japan; MFLUCC: Mae Fah Luang University Culture Collection, Chiang Rai, Thailand; NBRC: NITE Biological Resource Center, Kisarazu, Japan. 


\section{RESULTS}

\section{Molecular analyses}

The final concatenated ITS-LSU dataset consisted of 1471 characters, out of which 269 were parsimony informative and 359 variable, and 41 taxa including the outgroup. The 50\% majority rule consensus tree resulting from the Bayesian analysis was similar in topology to the most likely ML tree and show that both our isolate of E. cochinensis CCF 5738 and the Japanese strain NBRC 32666 clustered together with strong support (PP $>0.95$, BS 99\%). They grouped with members of Tetraplosphaeriaceae in Pleosporales (Fig. 1a) and occurred within a moderately supported monophyletic lineage (PP 0.94) containing species of Polyplosphaeria (Po.) Kaz. Tanaka \& K. Hiray. and Quadricrura Kaz. Tanaka, K. Hiray. \& Sat. Hatak. Both genera are characterized by producing globose, appendiculate conidia with internal hyphal structure that are born on monoblastic conidiogenous cells. The only exception also producing this type of conidia, Shrungabeeja longiappendiculata Sommai, Pinruan, S. Nuankaew \& Suetrong, was placed basal to a TetraploaPseudotetraploa clade. The remaining genera, Triplosphaeria Kaz. Tanaka \& K. Hiray., Pseudotetraploa Kaz. Tanaka \& K. Hiray. and Tetraploa were resolved as monophyletic clades with moderate or strong PP and BS supports. Tetraplosphaeriaceae was also recovered as monophyletic with strong PP support (PP > 0.95).

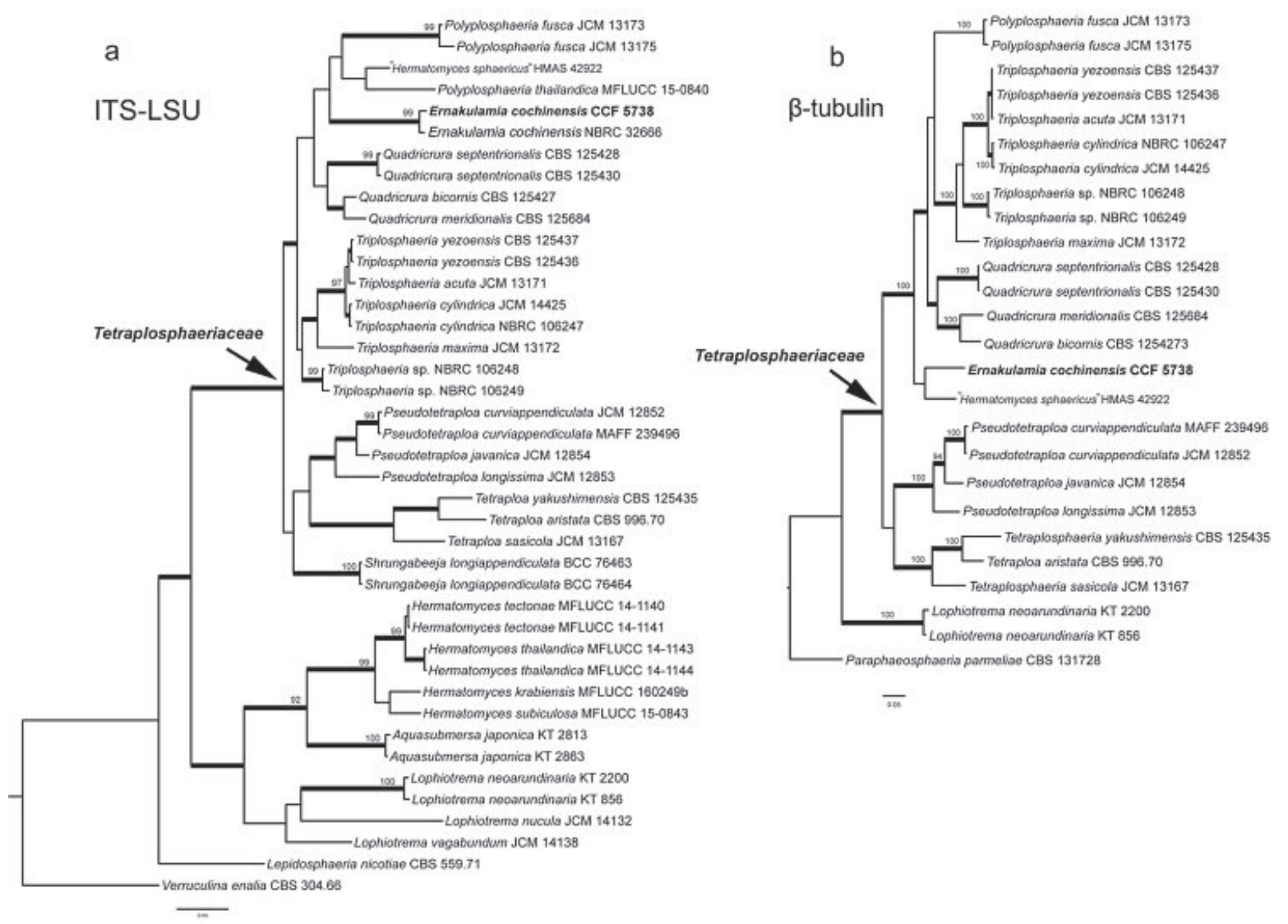

Fig. 1. a. Phylogenetic trees inferred from Bayesian and ML analyses of the a) ITS-LSU nrDNA and b) $\beta$-tubulin showing the placement of Ernakulamia cochinensis among Tetraplosphaeriaceae (Pleosporales). Thickened branches indicate posterior probabilities $>0.95 \%$ and numbers above branches represent ML bootstrap support values BS $>90 \%$. The new strain obtained during this study is in bold. 
The $\beta$-tubulin dataset consisted of 673 characters, out of which 296 were parsimony informative and 323 variable, and 27 taxa including the outgroup. Tetraplosphaeriaceae and each genus within the family received strong support (PP 1, BS 100\%) in the resulting Bayesian and ML trees although the placement of E. cochinensis differed (Fig. 1b). Our isolate CCF 5738 grouped with moderate support (PP 0.92) with a strain named Hermatomyces sphaericus (Sacc.) S. Hughes HMAS 42922 (unpublished) basal to the Polyplosphaeria, Triplosphaeria and Quadricrura clade. This strain was placed sister to Po. thailandica C.G. Lin, Yong Wang bis \& K.D. Hyde in the ITS-LSU tree and apparently represents an incorrectly identified entry because the genus Hermatomyces Speg. is placed outside Tetraplosphaeriaceae (Fig. 1a).

\section{Taxonomy}

Ernakulamia cochinensis (Subram.) Subram., Kavaka 22/23: 67 (1996) [1994]

Figs 2-3

E Petrakia cochinensis Subram., Beih. Sydowia 1: 15 (1957)

$\equiv$ Piricauda cochinensis (Subram.) M.B. Ellis, More Dematiaceous Hyphomycetes: 367 (1976)

Colonies on natural substrate effuse, black. Conidiophores and conidiogenous cells not seen. Conidia variable in shape, subglobose, obconical, broadly ellipsoidal to broadly pyriform, muriform, dark brown to blackish brown, verrucose at the base where a pore is often seen, $24-60 \times 18-53 \mu \mathrm{m}$, internally filled with a mass of

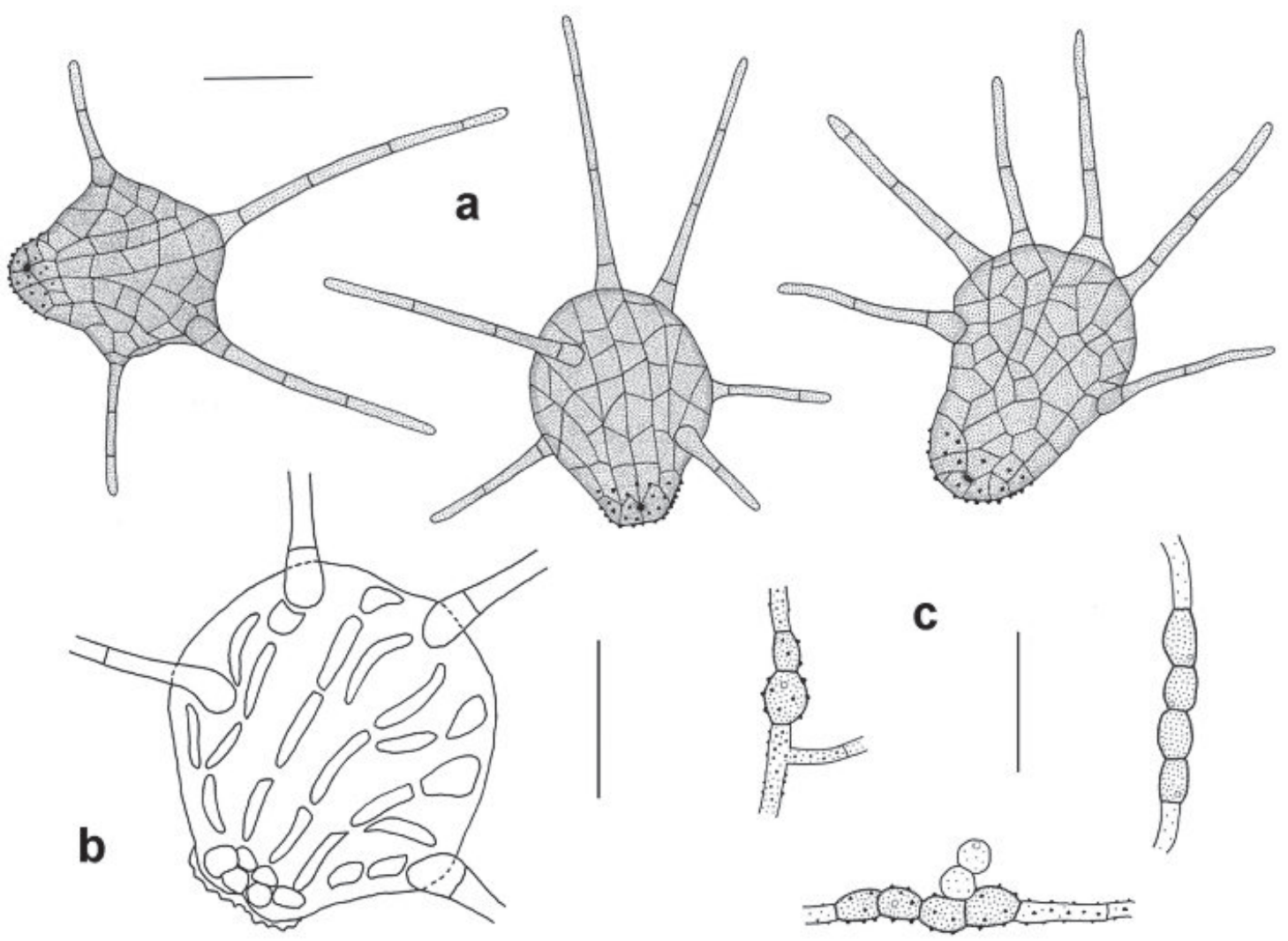

Fig. 2. Ernakulamia cochinensis (PRC 3992). a. Conidia. b. Internal structure of a conidium. c. Tretic conidiogenous cells and chlamydospore-like cells on MEA. Scale bars: a-c $=20 \mu \mathrm{m}$. 
hyaline, septate, $1.5-2 \mu \mathrm{m}$ wide hyphae sometimes with swollen cells up to $5 \mu \mathrm{m}$ wide, appendiculate, with 3-13 cylindrical, straight or flexuous, septate, brown, smooth appendages, up to $132 \mu \mathrm{m}$ long, 3-5 $\mu \mathrm{m}$ wide, 4.5-7 $\mu \mathrm{m}$ wide at base, 2-3 $\mu \mathrm{m}$ wide at the apex.

Colonies on MEA moderately slow growing, reaching 12-16 $\mathrm{mm}$ diam. after 14 days at room temperature $\left(22-25^{\circ} \mathrm{C}\right)$, circular, velvety, gray, slightly darker
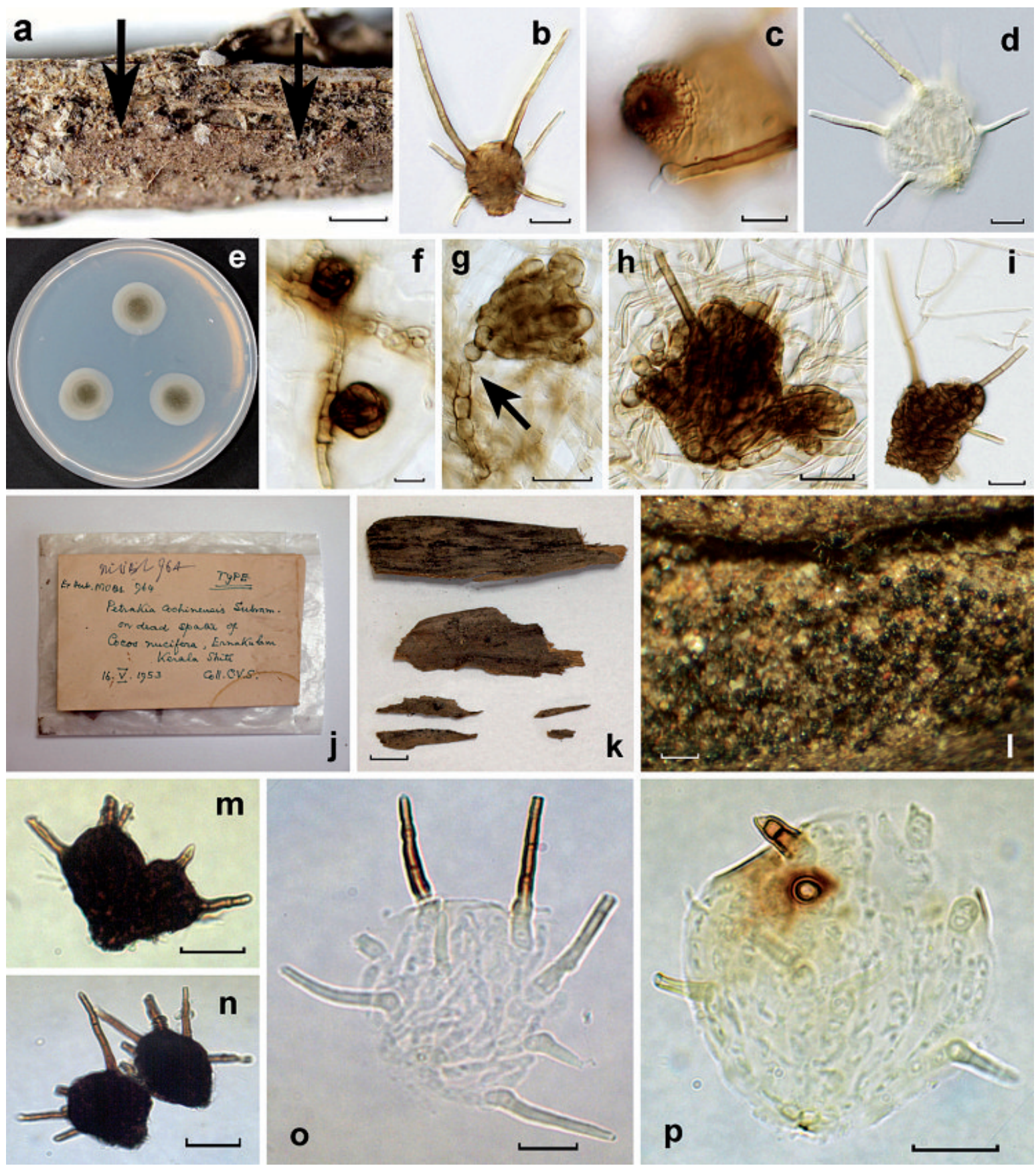

Fig. 3. Ernakulamia cochinensis (PRC 3992 = CCF 5738). On natural substrate. a. Colonies (arrows) b. Conidium. c. Detail of a pore at the verrucose base. d. Bleached conidium showing internal hyphae. In culture (PCA). e. Colonies after 14 days. f. Conidium initials born on chlamydospore-like cells. g. Conidium attached to conidiogenous cell (arrow). h-i. Conidia. Ibid. (IMI 114626, isotype). j. Packet. k. Herbarium material. I. Colony. m-n. Conidia. o-p. Bleached conidia showing internal hyphae. Scale bars: $\mathrm{a}=500 \mu \mathrm{m} b-\mathrm{d}, \mathrm{f}-\mathrm{i}, \mathrm{m}-\mathrm{n}=20 \mu \mathrm{m}, \mathrm{k}=10 \mathrm{~mm}, 1=100 \mu \mathrm{m}, \mathrm{o}-\mathrm{p}=10 \mu \mathrm{m}$. 
in the center and raised 1-2 mm, margin entire, reverse dark gray, sporulation starting late after 6-8 weeks. Colonies on PCA moderately slow growing, reaching 18$21 \mathrm{~mm}$ diam. after 14 days at room temperature $\left(22-25^{\circ} \mathrm{C}\right)$, circular, velvety and gray in the center, flat and creamy-white toward the edge, margin entire, sporulation late. Colonies on MCA very slow growing, reaching 12-15 mm diam. after 2 months at room temperature $\left(22-25^{\circ} \mathrm{C}\right)$, circular, velvety, gray, margin diffuse, reverse black, sporulation not observed even after 3 months. Mycelium composed of branched, septate, smooth, finely rough or verruculose hyphae, subhyaline to pale brown or brown in mass, 1-3 $\mu \mathrm{m}$ wide, frequently forming terminal or intercalary, subcylindrical or inflated, pale brown to brown, thick-walled, smooth or verrucose, 0-1 septate chlamydospore-like cells, $4-14 \times 3.5-7 \mu \mathrm{m}$, single or adjacent to each other in rows of up to 9 and often constricted at the septa between them, with 0-1 pore-like conidiogenous locus. Conidiophores absent or inconspicuous, short, cylindrical or obconical, 5-8 $\times 4 \mu \mathrm{m}$. Conidiogenous cells monotretic, non-cicatrized, globose or subglobose, smooth or verruculose, determinate, subhyaline to brown, 4-8 $\times 5-7 \mu \mathrm{m}$, acropleurogenous, born directly on the hyphae or intercalary between the chlamydospore-like cells, rarely in short chains of 2-3 cells. Conidia variable in shape, sometimes similar to those on natural substrate but more often irregularly or aberrantly shaped, with several lobes and spherical protrusions, also cheiroid, with 1-5 diverging columns of cells 10-32 $\mu \mathrm{m}$ wide, muriform, brown, verrucose at base or along the columns of cells when cheiroid, 36-81 × 19-56 $\mu \mathrm{m}$, with 0-5 appendages, $17-83 \times 3-5 \mu \mathrm{m}$, often swollen at the base and 6-12 $\mu \mathrm{m}$ wide.

Materials examined: Panama, Chiriquí Province, Los Algarrobos village, along a path to Río Majagua, on rotten leaves of Astrocaryum standleyanum, $103 \mathrm{~m}$ a.s.1. (8²9'20.1'N 82²6’01.0”W), 12 July 2016, coll. P. Zehnálek \& O. Koukol (PRC 3992, PMA); ex-living culture KZP240 = CCF 5738; ibid. 11 July 2015, coll O. Koukol (PRC 3730); India, Kerala, Ernakulam, on dead spathe of C. nucifera, 16 May 1953, coll. C.V. Subramanian (IMI 114626, isotype of Pe. echinata). Piricaudilium lobatum Hol.-Jech., Cuba, Santiago de Cuba, Sierra de la Gran Piedra, Isabelica Norte Nature Reserve, on dead branches of an undetermined liana, 23 May 1985, coll. V. Holubová-Jechová (PRM 842755, holotype).

Notes: Bleached conidia of the material of E. cochinensis from Panama (PRC 3992) and the isotype specimen of Pe. cochinensis from India (IMI 114626) revealed the presence of an internal hyphal structure similar to the one found in species of Polyplosphaeria and Quadricrura (Figs. 2b, 3d, o-p). The morphological study of the holotype specimen of Pi. lobatum from Cuba (PRM 842755, Fig. 4) also indicated a strong affinity of this taxon with Tetraplosphaeriaceae particularly in the presence of numerous conidial appendages, internal hyphae and the newly detected peel-like outer wall of conidia.

\section{DISCUSSION}

The present collections represent the first record of Ernakulamia cochinensis from Panama based on specimens including complete collection data. They are morphologically consistent with a well preserved isotype specimen of Pe. cochinensis from India (Figs. 3j-1) of which an ex-type living culture of this or the holotype specimen is currently unavailable. On artificial media the isolate CCF 5738 exhibits phenotypic plasticity and frequently produced irregularly shaped conidia often 


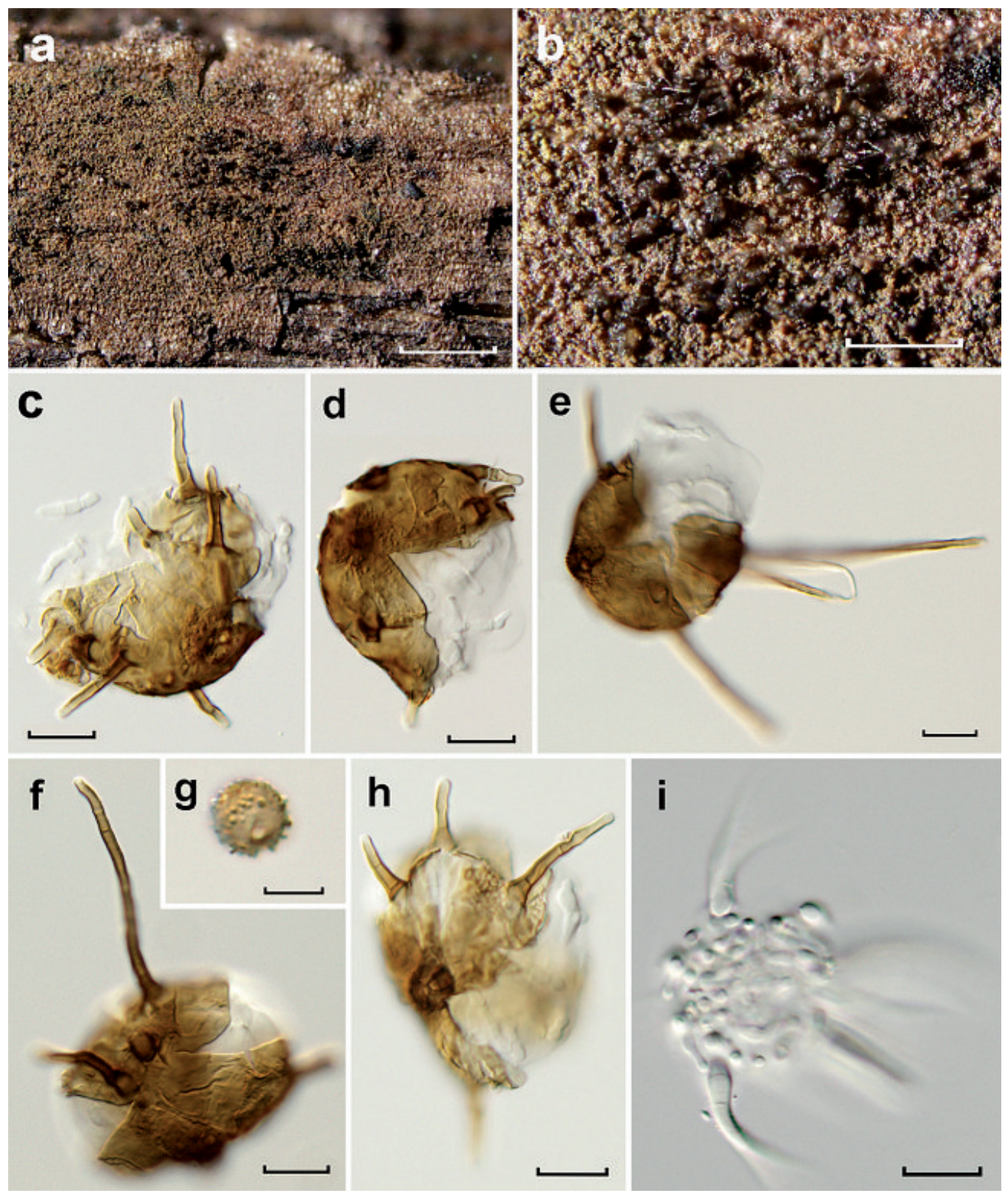

Fig. 4. Piricaudilium lobatum (PRM 842755, holotype). a-b. Colonies on natural substrate. c-f. Mature conidia with peel-like outer wall. g. Young conidium with verrucose surface. h. Detail of verrucose base. i. Bleached conidia showing internal hyphae. Scale bars: $a-b=500 \mu \mathrm{m}, c-j=20 \mu \mathrm{m}$.

observed as aberrant, multi-cellular masses with several lobes and spherical protrusions. They were also cheiroid or cheiroid-like in shape with widely divergent columns of cells or rarely closely appressed around the base and distally diverging or curving at the apical part of the columns. Appendages were often lacking and when present they were shorter and in less number compared with conidia on natural substrate or the type specimen with up to 15 of them and up to $140 \mu \mathrm{m}$ long (Subramanian, 1957). Thick-walled, often verrucose chlamydospore-like cells, terminal or intercalary on the hyphae, were formed on MEA. They were found to be conidiogenous and showed a single, inconspicuous pore-like locus per cell with conidium initials arising from them (Fig. 3f). Distinct but non-cicatrized conidiogenous cells were also found arising directly on the hyphae or intercalary 
between the chlamydospore-like cells of the mycelium. They were more or less similar in shape and disposition to the ones illustrated by Ellis (1976) on natural substrate and curiously, although very rarely, they were present in short chains of 2 or 3 with the apical cell showing an inconspicuous pore (Fig. 2c). Conidiophores were not observed on natural substrate or the isotype specimen and were rarely seen in our isolate. Nakagiri \& Ito (1995) also described several differences between their specimen on natural and artificial conditions similar to those observed in our strain. They included the presence of verrucose or tuberculate hyphae, irregularly shaped conidia surrounded by a thin membrane having short, 1-4 appendages only and absence of conidiophores when growing on CMA.

The placement of E. cochinensis within Tetraplosphaeriaceae as previously suggested by Tanaka et al. (2009) was confirmed by molecular data. It also supports the recognition of Ernakulamia as a distinct, well delimited taxon and its previous placements within other genera based on morphological characters (Subramanian, 1957; Ellis, 1976) were rejected. The genus Petrakia was recently emended and $P e$. echinata, its type species, was found to be a member of Melanommataceae, an unrelated family in Pleosporales (Jaklitsch \& Voglmayr, 2017). In the case of Piricauda, on the other hand, a representative specimen of $P$. paraguayensis from Brazil was found to belong to Capnodiales (da Silva et al., 2016) and therefore this genus is distantly related to Tetraplosphaeriaceae in Pleosporales. The remaining Piricauda species still lack DNA sequence data and their phylogenetic affinities are currently unknown although some taxa resembling Ernakulamia and sharing a palmicolous habitat e.g. P. longispora Mercado, Gené \& Guarro and P. mexicana Mercado, Heredia \& J. Mena (Mercado et al., 1997a, c) might be congeneric upon recollection and sequencing. In the absence of an ex-type culture of E. cochinensis to be included in the molecular analyses further evidence of relatedness was found in the presence of an internal conidial structure similarly to species of Polyplosphaeria, Quadricrura and Triplosphaeria. These and other genera were previously delimited among Tetraplosphaeriaceae based on molecular data and morphological differences of the anamorph and partly of the teleomorph (Tanaka et al., 2009, Ariyawansa et al., 2015). Our ITS-LSU phylogeny containing all currently sequenced genera of Tetraplosphaeriaceae including the newly added Ernakulamia strains (Fig. 1a) showed as well a high support for their delimitation based on molecular data and conidial morphology. A first lineage includes Polyplosphaeria, Ernakulamia and Quadricrura characterized by globose, appendiculate conidia. A second one includes Triplosphaeria with distoseptate conidia composed of three columns and a third lineage includes Tetraploa and Pseudotetraploa having both eu- and distoseptate, obpyriform conidia composed of four columns. Interestingly, S. longiappendiculata having subglobose, appendaged conidia forms a separate fourth lineage. Our placement of Shrungabeeja based on ITS-LSU sequence data is consistent with the analysis of SSU-LSU regions made by Ariyawansa et al. (2015) but differs from an ITS phylogeny presented in the same study where Shrungabeeja was placed as a basal clade to Triplosphaeria. Therefore the position of this genus should be revised using also protein-coding genes. Additionally, Shrungabeeja species are distinct in having macronematous, erect and cylindrical conidiophores bearing determinate or percurrent, lageniform conidiogenous cells (Rao \& Reddy, 1981; Zhang et al., 2009) in contrast with the remaining genera in Tetraplosphaeriaceae including Ernakulamia having reduced or absent conidiophores.

Interestingly, the Polyplosphaeria, Ernakulamia and Quadricrura lineage retrieved from the ITS-LSU phylogeny contains species with both septate (Po. thailandica, E. cochinensis, Figs. 2-3) and nonseptate conidia (Po. fusca, 
Quadricrura spp.) suggesting limited importance of this character for generic delimitation. Unfortunately, only Po. fusca has a known teleomorph which precludes comparison of further phenotypic characters that may show diagnostic differences among them. Tanaka et al. (2009) noted a morphological similarity between Quadricrura and Piricaudilium but did not provide clear delimiting characteristics among them. Based on examination of the holotype of Pi. lobatum, Quadricrura and Piricaudilium seem related and might be considered congeneric. Quadricrura species and Pi. lobatum both produce subglobose conidia with internal hyphal structure (Fig. 4i), external appendages and peel-like outer wall (Fig. 4c-h). This latter character was not mentioned by Holubová-Jechová (1988) in her original description but it was detected during our study of the type material and supports their affinity. The only clear demarcating difference between them is conidiogenesis that is holoblastic in Quadricrura (Tanaka, pers. com.) but monotretic in Piricaudilium (Holubová-Jechová, 1988). However, this characteristic needs revision because distinct pore-like structures are seen at the base of Quadricrura conidia (Tanaka et al., 2009 Figs. 14H, 15G) indicating tretic conidiogenesis rather than holoblastic. Molecular data are therefore necessary to confirm a putative phylogenetic placement of Piricaudilium among Tetraplosphaeriaceae and its affinity to Quadricrura. With the addition of Ernakulamia and possibly Piricaudilium to the family tretic conidium ontogeny becomes another diagnostic feature for its anamorphs besides the predominantly monoblastic conidiogenesis. This type of conidial formation is nevertheless quite common among the anamorph-rich Pleosporales (Zhang et al., 2009; 2012).

Acknowledgments. We are grateful to Markéta Šandová (PRM) and the curator of IMI for the loan of herbarium specimens in their care and Anita Tiller (MERCA) for hosting loans to G.D. at her institution. We thank also Tina A. Hofmann (UCH) for logistic support in Panama and Ivana Borovičková (Charles University) for molecular analyses. This study was supported by the Institutional Support for Science and Research program of the Ministry of Education, Youth and Sports of the Czech Republic. The Panamanian Ministry of Environment (MiAmbiente) is thanked for issuing collection and export permits (SE/APH-315, SE/AP-17-16, SEX/H-4-15 \& SEX/H-6-16). G.D. also acknowledges Magzoub Ismail and Kamash Ramanathan (EMlab P\&K) for lab support and provision of facilities.

\section{REFERENCES}

ARIYAWANSA H.A., HYDE K.D., JAYASIRI S.C., BUYCK B., KANDAWATTE W.T.C., CUI Y.Y., DAI D.Q., DAI Y.C., DARANAGAMA D.A., JAYAWARDENA R.S., LÜCKING R., GHOBAD-NEJHAD M., NISKANEN T., THAMBUGALA K.M., VOIGT K., ZHAO R.L., BOONMEE S., BAHKALI A.H., CHEN J., CUI B.K., DAYARATHNE M.C., DISSANAYAKE A.J., EKANAYAKA A.H., HASHIMOTO A., HONGSANAN S., JONES E.B.G., LARSSON E., LEWIS D., LI W.J., LI Q.R., LIU J.K., LUO Z.L., MAHARACHCHIKUMBURA S.S.N., MAPOOK A., MCKENZIE E.H.C., NORPHANPHOUN C., PANG K.L., PERERA R.H., PHOOKAMSAK R., PHUKHAMSAKDA C., RANDRIANJOHANY E., SENANAYAKE I.C., SINGTRIPOP C., SHANG Q., TANAKA K., TIAN Q., TIAN C.M., TIBPROMMA S., VERBEKEN A., ABDEL-WAHAB M.A., WANASINGHE D.N., WIJAYAWARDENE N.N., ZHANG J.F., ZHANG H., ABDEL-AZIZ F.A., ADAM Č IK S., AMMIRATI J.F., BULGAKOV T., CABRAL A.L., CALLAGHAN T.M., CALlAC P., CHANG C.H., COCA L.F., DALFORNO M., DOLLHOFER V., FLIEGEROVÁ K., GREINER K., GRIFFITH G.W., HO H.M., HOFSTETTER V., JEEWON R., KANG J.C., KIRK P.M., KYTÖVUORI I., LAWREY J.D., LI J.X.H., LIU Z.Y., ZHONG X.L., LIIMATAINEN K., LUMBSCH H.T., 
MATUMURA M., MONCADA B., NUANKAEW S., PARNMEN S., SANTIAGO M.D.A., SATO G., SOMMAI S., SONG Y., DE SOUZA C.A.F, DE SOUZA-MOTTA C.M., SU H.Y., SUETRONG S., WANG Y., WEI S.F., WEN T.C., SHEN H., YUAN H.S., ZHOU L.W., REBLOVA M., FOURNIER J., CAMPORESI E., LUANGSA-ARD J.J., TASANATHAI K., KHONSANIT A., THANAKITPIPATTANA D., SOMRITHIPOL S., DIEDERICH P., MILLANES A.M., COMMON R.S., STADLER S., YAN J.Y., LI X.H., LEE H.W., NGUYEN T.T.T., LEE H.B., BATTISTIN E., MARSICO O., VIZZINI A., VILA J., ERCOLE E., EBERHARDT U., SIMONINI G., WEN H.-A., CHEN X-H., MIETTINEN O., SPIRIN V. \& HERNAWATI, 2015 - Fungal diversity notes 111-252 - taxonomic and phylogenetic contributions to fungal taxa. Fungal Diversity 75: 27-274.

BHAT D. \& SUTTON B., 1985 - New and interesting hyphomycetes from Ethiopia. Transactions of the British Mycological Society 85: 107-122.

CAPDEET M. \& ROMERO A.I., 2010 - Fungi from palms in Argentina. 1. Mycotaxon 112: 339-355.

CYBERTRUFFLE'S ROBIGALIA, 2017 - Observations of Fungi and their associated organisms. www.cybertruffle.org.uk/robigalia/eng, Accession date - 5 April, 2017.

DA SILVA M., PINHO D.B., PEREIRA O.L., FERNANDES F.M. \& BARRETO R.W., 2016 - Naming potentially endangered parasites: foliicolous mycobiota of Dimorphandra wilsonii, a highly threatened Brazilian tree species. PLOS ONE 11(2):e0147895. doi:10.1371/journal. pone.0147895

DARRIBA D., TABOADA G.L., DOALLO R. \& POSADA D., 2012 — jModelTest 2: more models, new heuristics and parallel computing. Nature Methods 9: 772.

DELGADO G. \& MENA J., 2004 - Hifomicetos (Hongos Anamórficos) de la Reserva Ecológica "Alturas de Banao" (Cuba). Boletín de la Sociedad Micológica de Madrid 28: 115-124.

DOILOM M., DISSANAYAKE A.J., WANASINGHE D.N., BOONMEE S., LIU J.-K., BHAT D.J., TAYLOR J.E., BAHKALI A.H., MCKENZIE E.H.C. \& HYDE K.D., 2017 - Microfungi on Tectona grandis (teak) in Northern Thailand. Fungal Diversity 82: 107-182.

ELLIS M.B., 1976 - More dematiaceous Hyphomycetes. Commonwealth Mycological Institute, Kew.

FARR D.F. \& ROSSMAN A.Y., 2017 - Fungal Databases, U.S. National Fungus Collections, ARS, USDA. https://nt.ars-grin.gov/fungaldatabases/, Accession date — 5 April, 2017.

FARRIS J.S., KÄLLERSJÖ M., KLUGE A.G. \& BULT C., 1994 - Testing significance of incongruence. Cladistics 10: 315-319.

FRÖHLICH J. \& HYDE K.D., 2000 - Palm Microfungi. Fungal Diversity Research Series 3: 1-393.

FRÖHLICH J., HYDE K.D. \& PETRINI O., 2000 - Endophytic fungi associated with palms. Mycological Research 104: 1202-1212.

HERBIMI DATABASE, 2017 — http://www.herbimi.info/herbimi/searchname.htm, Accession date 5 April, 2017.

HIRAYAMA K. \& TANAKA K., 2011 - Taxonomic revision of Lophiostoma and Lophiotrema based on reevaluation of morphological characters and molecular analyses. Mycoscience 52: 401-412.

HOLUBOVÁ-JECHOVÁ V., 1988 — Studies on hyphomycetes from Cuba VIII. A new genus Piricaudilium and some species new for the territory of Cuba. Ceská Mykologie 42: 200-204.

HOLUBOVÁ-JECHOVÁ V. \& MERCADO A., 1986 - Studies on Hyphomycetes from Cuba IV. Dematiaceous Hyphomycetes from the Province Pinar del Rio. Ceská Mykologie 40: 142-164.

HOLUBOVÁ-JECHOVÁ V. \& MERCADO A., 1989 - Hyphomycetes from Loma de La Coca and some localities of La Habana and Matanzas provinces, Cuba. Acta Botánica Cubana 76: $1-15$.

HUGHES S.J., 1960 - Microfungi VI. Piricauda Bubák. Canadian Journal of Botany 38: 921-925.

HYDE K.D., TAYLOR J.E. \& FRÖHLICH J., 2000 — Genera of Ascomycetes from Palms. Fungal Diversity Research Series 2: 1-247.

HYDE K.D., HONGSANAN S., JEEWON R., BHAT D.J., MCKENZIE E.H.C., JONES E.B.G., PHOOKAMSAK R., ARIYAWANSA H.A., BOONMEE S., ZHAO Q., ABDEL-AZIZ F.A., ABDEL-WAHAB M.A., BANMAI S., CHOMNUNTI P., CUI B.-K., DARANAGAMA D.A., DAS K., DAYARATHNE M.C., DE SILVA N.I., DISSANAYAKE A.J., DOILOM M., EKANAYAKA A.H., GIBERTONI T.B., GÓES-NETO A., HUANG S.-K., JAYASIRI S.C., JAYAWARDENA R.S., KONTA S., LEE H.B., LI W.-J., LIN C.-G., LIU J.-K., LU Y.-Z., LUO Z.-L., MANAWASINGHE I.S., MANIMOHAN P., MAPOOK A, NISKANEN T., NORPHANPHOUN C., PAPIZADEH M., PERERA R.H., PHUKHAMSAKDA C., RICHTER C., DE A. SANTIAGO A.L.C.M., DRECHSLER-SANTOS E.R., SENANAYAKE I.C., TANAKA K., TENNAKOON T.M.D.S., THAMBUGALA K.M., TIAN Q., TIBPROMMA S., THONGBAI B., VIZZINI A., WANASINGHE D.N., WIJAYAWARDENE N.N., WU H.-X., YANG J., ZENG X.-Y., ZHANG H., ZHANG J.-F., 
BULGAKOV T.S., CAMPORESI E., BAHKALI A.H., AMOOZEGAR M.A., ARAUJONETA L.S., AMMIRATI J.F., BAGHELA A., BHATT R.P., BOJANTCHEV D., BUYCK B., DA SILVA G.A., DE LIMA C.L.F., DE OLIVEIRA R.J.V., DE SOUZA C.A.F., DAI Y.-C., DIMA B., DUONG T.T., ERCOLE E., MAFALDA-FREIRE F., GHOSH A., HASHIMOTO A., KAMOLHAN S., KANG J.-C., KARUNARATHNA S.C., KIRK P.M., KYTÖVUORI I., LANTIERI A., LIIMATAINEN K., LIU Z.-Y., LIU X.-Z., LÜCKING R., MEDARDI G., MORTIMER P.E., NGUYEN T.T.T., PROMPUTTHA I., RAJ K.N.A., RECK M.A., LUMYONG S., SHAHZADEH-FAZELI S.A., STADLER M., SOUDI M.R., SU H.-Y., TAKAHASHI T., TANGTHIRASUNUN N., UNIYAL P., WANG Y., WEN T.-C., XU J.-C., ZHANG Z.-K., ZHAO Y.-C., ZHOU J.-L. \& ZHU L., 2016 - Fungal diversity notes 367491: taxonomic and phylogenetic contributions to fungal taxa. Fungal Diversity 80: 1-270.

HYDE K.D., JONES E.B.G., LIU J.K., ARIYAWANSA H., BOEHM E., BOONMEE S., BRAUN U., CHOMNUNTI P., CROUS P.W., DAI D.Q., DIEDERICH P., DISSANAYAKE A., DOILOM M., DOVERI F., HONGSANAN S., JAYAWARDENA R., LAWREY J.D., LI Y.M., LIU Y.X., LÜCKING R., MONKAI J., MUGGIA L., NELSEN M.P., PANG K.L., PHOOKAMSAK R., SENANAYAKE I., SHEARER C.A., SUETRONG S., TANAKA K., THAMBUGALA K.M., WIJAYAWARDENE N.N., WIKEE S., WU H.X., ZHANG Y., AGUIRRE-HUDSON B., ALIAS S.A., APTROOT A., BAHKALI A.H., BEZERRA J.L., BHAT D.J., CAMPORESI E., CHUKEATIROTE E., GUEIDAN C., HAWKSWORTH D.L., HIRAYAMA K., HOOG S.D., KANG J.C., KNUDSEN K., LI W.J., LI X.H., LIU Z.Y., MAPOOK A., MCKENZIE E.H.C., MILLER A.N., MORTIMER P.E., PHILLIPS A.J.L., RAJA H.A., SCHEUER C., SCHUMM F., TAYLOR J.E., TIAN Q., TIBPROMMA S., WANASINGHE D.N., WANG Y., XU J.C., YAN J.Y., YACHAROEN S. \& ZHANG M., 2013 - Families of Dothideomycetes. Fungal Diversity 63: 1-313.

JAKLITSCH W.M. \& VOGLMAYR H., 2017 - Three former taxa of Cucurbitaria and considerations on Petrakia in the Melanommataceae. Sydowia 69: 81-95.

KRUYS A., ERIKSSON O.E. \& WEDIN M., 2006 - Phylogenetic relationships of coprophilous Pleosporales (Dothideomycetes, Ascomycota), and the classification of some bitunicate taxa of unknown position. Mycological Research 110: 527-536.

KRUYS A. \& WEDIN M., 2009 - Phylogenetic relationships and an assessment of traditionally used taxonomic characters in the Sporormiaceae (Pleosporales, Dothideomycetes, Ascomycota), utilising multi-gene phylogenies. Systematics and Biodiversity 7: 465-478.

LI G.J., HYDE K.D, ZHAO R.L., HONGSANAN S., ABDEL-AZIZ F.A., ABDEL-WAHAB M.A, ALVARADO P., ALVES-SILVA G., AMMIRATI J.F, ARIYAWANSA H.A, BAGHELA A., BAHKALI A.H, BEUG M., BHAT D.J., BOJANTCHEV D., BOONPRATUANG T., BULGAKOV T.S, CAMPORESI E., BORO M.C, CESKA O., CHAKRABORTY D., CHEN J.J., CHETHANA K.W.T., CHOMNUNTI P., CONSIGLIO G., CUI B.K., DAI D.Q., DAI Y.C., DARANAGAMA D.A., DAS K., DAYARATHNE M.C., DE CROP E., DE OLIVEIRA R.J.V., DE SOUZA C.A.F., DE SOUZA J.I., DENTINGER B.T.M., DISSANAYAKE A.J., DOILOM M., DRECHSLER-SANTOS E.R., GHOBAD-NEJHAD M., GILMORE S.P, GÓES-NETO A., GORCZAK M., HAITJEMA C.H, HAPUARACHCHI K.K., HASHIMOTO A., HE M.Q., HENSKE J.K, HIRAYAMA K., IRIBARREN M.J., JAYASIRI S.C, JAYAWARDENA R.S, JEON S.J., JERÔNIMO G.H, JESUS A.L, JONES E.B.G., KANG J.C., KARUNARATHNA S.C, KIRK P.M, KONTA S., KUHNERT E., LANGER E., LEE H.S., LEE H.B., LI W.J., LI X.H., LIIMATAINEN K., LIMA D.X., LIN C.G., LIU J.K., LIU X.Z., LIU Z.Y., LUANGSA-ARD J.J., LÜCKING R., LUMBSCH H.T., LUMYONG S., LEAÑO E.M., MARANO A.V., MATSUMURA M., MCKENZIE E.H.C, MONGKOLSAMRIT S., MORTIMER P.E., NGUYEN T.T.T., NISKANEN T., NORPHANPHOUN C., O’MALLEY M.A, PARNMEN S., PAWŁOWSKA J., PERERA R.H., PHOOKAMSAK R., PHUKHAMSAKDA C., PIRES-ZOTTARELLI C.L.A., RASPÉ O., RECK M.A., ROCHA S.C.O., DE SANTIAGO A.L.C.M.A., SENANAYAKE I.C., SETTI L., SHANG Q.J., SINGH S.K, SIR E.B., SOLOMON K.V., SONG J., SRIKITIKULCHAI P., STADLER M., SUETRONG S., TAKAHASHI H., TAKAHASHI T., TANAKA K., TANG L.P., THAMBUGALA K.M., THANAKITPIPATTANA D., THEODOROU M.K., THONGBAI B., THUMMARUKCHAROEN T., TIAN Q., TIBPROMMA S., VERBEKEN A., VIZZINI A., VLASÁK J., VOIGT K., WANASINGHE D.N, WANG Y., WEERAKOON G., WEN H.A., WEN T.C., WIJAYAWARDENE N.N, WONGKANOUN S., WRZOSEK M., XIAO Y.P., XU J.C., YAN J.Y., YANG J., DA YANG S., HU Y., ZHANG J.F., ZHAO J., ZHOU L.W., PERS̆OH D., PHILLIPS A.J.L. \& MAHARACHCHIKUMBURA S.S.N., 2016 — Fungal diversity notes 253-366: taxonomic and phylogenetic contributions to fungal taxa. Fungal Diversity 78: 1-237. 
MERCADO A., GENÉ J. \& GUARRO J., 1997a - Some Costa Rican hyphomycetes. II. Mycotaxon 64: 7-15.

MERCADO A., GONZÁLES G., MENA J. \& RODRÍGUEZ K., 1997b — Las palmas y su relación como sustratos de hongos microscópicos (Hifomicetos) en Cuba. Boletín de la Sociedad Micológica de Madrid 22: 33-44.

MERCADO A., HEREDIA G. \& MENA J., 1997c — Tropical hyphomycetes of Mexico I. New species of Hemicorynespora, Piricauda and Rhinocladium. Mycotaxon 63: 155-167.

MERCADO A., GUARRO J. \& HEREDIA G., 2005 - The hyphomycete genus Piricauda, with the description of a new species. Mycological Research 109: 723-728.

MYCOPORTAL, 2017 - http//:mycoportal.org/portal/index.php. Accession date - 17 April, 2017.

NAKAGIRI A. \& ITO T., 1995 - Some dematiaceous hyphomycetes on decomposing leaves of Satakentia liukiuensis from Ishigaki Island, Japan. IFO Research Communications 17: 75-98.

O’DONNELL K., 1993 - Fusarium and its near relatives. In: Reynolds D.R. \& Taylor J.W. (eds.), The fungal holomorph: mitotic, meiotic and pleomorphic speciation in fungal systematic. CAB International, Wallingford, pp. 225-233.

O’DONNELL K. \& CIGELNIK E., 1997 - Two divergent intragenomic rDNA ITS2 types within a monophyletic lineage of the fungus Fusarium are nonorthologous. Molecular Phylogenetics and Evolution 7:103-116.

RAO V.G. \& REDDY K.A., 1981 - Two new hyphomycetes. Indian Journal of Botany 4:108-114.

RONQUIST F., TESLENKO M., VAN DER MARK P., AYRES D.L., DARLING A., HÖHNA S., LARGET B., LIU L., SUCHARD M.A. \& HUELSENBECK J.P., 2012 - MrBayes 3.2: Efficient Bayesian phylogenetic inference and model choice across a large model space. Systematic Biology 61: 539-542

SCHOCH C.L., SUNG G.H., LÓPEZ-GIRÁLDEZ F., TOWNSEND J.P., MIADLIKOWSKA J., HOFSTETTER V., ROBBERTSE B., MATHENY P.B., KAUFF F., WANG Z., GUEIDAN C., ANDRIE R.M., TRIPPE K., CIUFETTI L.M., WYNNS A., FRAKER E., HODKINSON B.P., BONITO G,. GROENEWALD J.Z., ARZANLOU M., DE HOOG G.S., CROUS P.W., HEWITT D., PFISTER D.H., PETERSON K., GRYZENHOUT M., WINGFIELD M.J., APTROOT A., SUH S.O., BLACKWELL M., HILLIS D.M., GRIFFITH G.W., CASTLEBURY L.A., ROSSMAN A.Y., LUMBSCH H.T., LÜCKING R., BÜDEL B., RAUHUT A., DIEDERICH P., ERTZ D., GEISER D.M., HOSAKA K., INDERBITZIN P., KOHLMEYER J., VOLKMANN-KOHLMEYER B., MOSTERT L., O'DONNELL K., SIPMAN H., ROGERS J.D., SHOEMAKER R.A., SUGIYAMA J., SUMMERBELL R.C., UNTEREINER W., JOHNSTON P.R., STENROOS S., ZUCCARO A., DYER P.S., CRITTENDEN P.D., COLE M.S., HANSEN K., TRAPPE J.M., YAHR R., LUTZONI F. \& SPATAFORA J.W., 2009 - The Ascomycota Tree of Life: A phylum-wide phylogeny clarifies the origin and evolution of fundamental reproductive and ecological traits. Systematic Biology 58: 224-239.

STAMATAKIS A., HOOVER, P. \& ROUGEMONT J., 2008 - A Rapid Bootstrap Algorithm for the RAxML Web-Servers. Systematic Biology 75: 758-771.

SUBRAMANIAN C.V., 1957 - Two new species of Petrakia. Beihefte zur Sydowia 1: 14-15.

SUBRAMANIAN C.V., 1994 - Hyphomycetes from South East Asia - Novelties from Singapore and Malaysia. Kavaka 22/23: 52-76.

SWOFFORD D. L., 2002 - PAUP*. Phylogenetic analysis using parsimony (*and other methods). Version 4.0b10. Sinauer Associates, Sunderland.

TANAKA, T., HIRAYAMA K., YONEZAWA H., HATAKEYAMA S., HARADA Y., SANO T., SHIROUZU T. \& HOSOYA T., 2009 - Molecular taxonomy of bambusicolous fungi: Tetraplosphaeriaceae, a new pleosporalean family with Tetraploa-like anamorphs. Studies in Mycology 64: 175-209.

TAYLOR J.E. \& HYDE K.D., 2003 - Microfungi of tropical and temperate palms. Fungal Diversity Research Series 12: 1-459.

TIBPROMMA S., BHAT J.D., DOILOM M., LUMYONG S., NONTACHAIYAPOOM S., YANG J.B. \& HYDE K.D., 2016 - Three new Hermatomyces species (Lophiotremataceae) on Pandanus odorifer from Southern Thailand. Phytotaxa 275: 127-139.

TRAKUNYINGCHAROEN T., LOMBARD L., GROENEWALD J.Z., CHEEWANGKOON R., TOANUN C., ALFENAS A.C. \& CROUS P.W., 2014 - Mycoparasitic species of Sphaerellopsis, and allied lichenicolous and other genera. IMA Fungus 5: 391-414.

WHITTON S.R., MCKENZIE E.H.C. \& HYDE K.D., 2012 - Chapter 4 Anamorphic fungi associated with Pandanaceae In: Whitton S.R., McKenzie E.H.C. \& Hyde K.D. (eds.), Fungi associated with Pandanaceae. Fungal Diversity Research Series 21, pp. 125-353. 
WIJAYAWARDENE D.N.N., MCKENZIE E.H.C. \& HYDE K.D., 2012 - Towards incorporating anamorphic fungi in a natural classification - checklist and notes for 2011. Mycosphere 3: $157-228$.

ZHANG K., MA L.G. \& ZHANG X.G., 2009 - New species and records of Shrungabeeja from southern China. Mycologia 101: 573-578.

ZHANG Y., CROUS P.W., SCHOCH C.L. \& HYDE K.D., 2012 - Pleosporales. Fungal Diversity 53: $1-221$.

ZHANG Y., SCHOCH C.L., FOURNIER J., CROUS P.W., DE GRUYTER J., WOUDENBERG J.H., HIRAYAMA K., TANAKA K., POINTING S.B., SPATAFORA J.W. \& HYDE K.D., 2009 - Multi-locus phylogeny of Pleosporales: a taxonomic, ecological and evolutionary reevaluation. Studies in Mycology 64: 85-102. 
Declaration of author contributions to the publication / manuscript:

South Florida microfungi: a new species of Taeniolella (anamorphic Sordariomycetes) isolated from cabbage palm

Status: published

Name of journal: Nova Hedwigia 105 (1-2): 1-14, 2017.

Contributing authors:

Gregorio Delgado (GD)

Andrew N. Miller (AM)

What are the contributions of the doctoral candidate and his co-authors?

\section{(1) Concept and design}

Doctoral candidate GD: 100\%

(2) Conducting tests and experiments

Doctoral candidate GD: 100\% Carried out the field work

(3) Compilation of data sets and figures

Doctoral candidate GD: 80\% Obtained morphological, cultural and molecular data, generate figures

Co-author AM: 20\% Obtained molecular data

(4) Analysis and interpretation of data

Doctoral candidate GD: $80 \%$ Performed analysis and interpretations of the data Co-author AM: $20 \%$ Advised on analysis and interpretation of results

(5) Drafting of manuscript

Doctoral candidate GD: $80 \%$

Co-author AM: $20 \%$ 


\section{I hereby certify that the information above is correct.}

August 28th, 2019, Houston

Digitally signed by Gregorio

August 30th, 2019, Frankfurt am Main

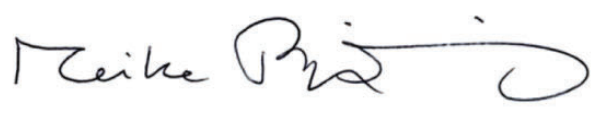

August 29th, 2019, Champaign 


\title{
South Florida microfungi: a new species of Taeniolella (anamorphic Sordariomycetes) isolated from cabbage palm
}

\author{
Gregorio Delgado ${ }^{1,2^{*}}$ and Andrew N. Miller ${ }^{3}$ \\ ${ }^{1}$ EMLab P\&K Houston, 6310 Rothway St., Houston, TX 77040, U.S.A. \\ 2 Department of Mycology, Institute of Ecology, Evolution and Diversity, Goethe \\ Universität Frankfurt, Max-von-Laue-Str. 13, 60438 Frankfurt am Main, Germany \\ ${ }^{3}$ Illinois Natural History Survey, University of Illinois, 1816 South Oak St., Champaign, \\ IL 61820, U.S.A.
}

With 2 figures

\begin{abstract}
Taeniolella sabalicola sp. nov., isolated from a petiole of a dead leaf of Sabal palmetto collected in south Florida, U.S.A., is described and illustrated based on morphological, cultural and molecular data. The fungus is characterized by forming slowly growing, black, restricted colonies on culture media and effuse colonies with abundant aerial mycelium on natural substrate after incubation, semi-macronematous or micronematous, long, unbranched conidiophores and clavate, ellipsoidal or cylindrical, smooth or verruculose, brown to blackish brown, multiseptate conidia with transverse, longitudinal and oblique septa, often surrounded by a mucilaginous sheath and usually in simple or branched acropetal chains. Phylogenetic analyses based on partial nuclear ribosomal large subunit (LSU) and internal transcribed spacer (ITS) sequence data also suggest the fungus is distinct from other Taeniolella species and possess affinities with members of Sordariomycetidae (Ascomycota) but its ordinal or familial position within the subclass remains uncertain. Molecular data also confirm that Taeniolella sensu lato is polyphyletic and show that $T$. sabalicola is unrelated to the generic type, T. exilis, recently placed in the family Kirschsteiniotheliaceae within the class Dothideomycetes.
\end{abstract}

Key words: lichenicolous, Peyronelia, phylogeny, saprobic, taxonomy.

\section{Introduction}

The genus Taeniolella S.Hughes, based on T. exilis (P.Karst.) S.Hughes as the type species, was first introduced by Hughes (1958) to accommodate fourteen anamorphs previously placed in several different genera and characterized by semi-macronematous, caespitose or scattered, usually short conidiophores, unbranched or sparingly branched

\footnotetext{
*Corresponding author: gdelgado@emlabpk.com 
near the base and bearing monoblastic, integrated, terminal, determinate, cylindrical or doliiform conidiogenous cells producing didymo- or phragmoconidia commonly in long, simple or branched acropetal chains that often secede with difficulty (Ellis 1971, Hawksworth 1979, Seifert et al. 2011). According to the MycoBank Database (www. mycobank.org) Taeniolella currently comprises 51 validly published names of which Seifert et al. (2011) accepted about 37 taxa. They range from saprobic species on wood, bark, litter, other fungi or submerged plant material as well as many lichenicolous taxa, the saprobic ones usually having multiseptate conidia and the lichenicolous ones only (0-)1(-2)-septa (Nash et al. 2004). Also two species, T. stilbospora (Corda) S.Hughes and T. exilis, have been reported as human pathogens causing cutaneous lesions in the face of a human patient and subcutaneous phaeohyphomycosis, respectively (de Hoog et al. 2000). The majority of them are known only from their asexual state but teleomorph connections have been established for a very few taeniolella-like anamorphs (Minter \& Holubová-Jechová 1981, Zelski et al. 2011). Taeniolella as currently circumscribed has been recognized as broadly defined (Gulis \& Marvanová 1999) and polyphyly has been previously suggested based on indirect molecular and taxonomic evidence (Summerell et al. 2006, Zelski et al. 2011, Réblová et al. 2016). Recently, based on mitochondrial and nuclear ribosomal DNA sequence data, the generic type species was placed in the family Kirschsteiniotheliaceae within the class Dothideomycetes (Ertz et al. 2016). Additionally, DNA of five novel or already described lichenicolous taxa was also sequenced and found to be restricted to the order Asterotexiales of the same class in a first comprehensive step toward resolving the highly polyphyletic status of the genus.

During studies of microfungi associated with dead leaves of cabbage palm trees collected in south Florida, a peculiar dematiaceous anamorph forming short acropetal chains of conidia was isolated following substrate incubation. Morphologically, the fungus showed a strong resemblance with $T$. phialosperma Ts. Watan., a species originally isolated from strawberry rhizosphere and paddy field soils in Japan (Watanabe 1992). Phylogenetic analyses of nuclear ribosomal DNA sequence data, however, revealed that they are not conspecific or even closely related and, along with micromorphological and cultural comparisons between this and other saprobic Taeniolella species, the Florida fungus is considered distinct and is described here as a new species.

\section{Materials and methods}

IsOLATION AND MORPHOLOGICAL STUDY: Samples of dead leaves of Sabal palmetto, the cabbage palm, were collected in forested areas of north Broward County, southeastern Florida, U.S.A, during the winter of 2014. They were first washed off under running tap water to remove debris and spores of fast-growing contaminants. Then they were cut in smaller pieces for incubation at room temperature in a plastic container lined with moist paper towels followed by periodical examinations until development of reproductive structures. Conidia were transferred aseptically to 2\% Malt Extract Agar (MEA: Healthlink, Jacksonville, Florida) and incubated at $25^{\circ} \mathrm{C}$ until sporulation was observed. Single-spore isolates were obtained according to Choi et al. (1999) and colonies originated from single conidia were subcultured on three different media: MEA, Potato Dextrose Agar (PDA) and Modified Cellulose Agar (MCA). Colony features were observed and measured on MEA and PDA after 28 days at $25^{\circ} \mathrm{C}$ for comparison with culture descriptions of the morphologically similar T. phialosperma (Watanabe 1992) but also on MCA after 2 months based on the slow growth in all media. Fungal structures from both natural substrate and cultures grown as above were mounted in 
lactophenol-cotton blue for microscopic observation. Minimum, maximum, 5th and 95th percentiles were calculated after measurement of each structure $(n=100)$ and outliers are shown in parentheses. The holotype specimen was air-dried and deposited in the Herbarium of the U.S. National Fungus Collections (BPI) along with semi-permanent slides and a dried culture. An isotype culture was also deposited at the Illinois Natural History Survey Fungarium (ILLS) and an ex-type culture is preserved in the Centraalbureau voor Schimmelcultures (CBS). A search for the type specimen of Peyronelia sirodesmioides in herbaria housing collections of R.Ciferri and R.Gonzalez-Fragoso (MA, L and W) was also conducted.

DNA EXTRACTION, PCR AMPLIFICATION AND SEQUENCING: A fungus isolate grown on MEA for 21 days at $25^{\circ} \mathrm{C}$ was sent to a sequencing facility, Laragen, Inc. (Culver City, California), where genomic DNA was extracted and the D1/D2 domains of the nuclear ribosomal 28S large subunit DNA (LSU nrDNA) were PCR amplified, purified and sequenced following the company's protocols for Fungal Identification Service (FunID http://laragen.com/laragen_micro_fungal.html) using primers NL1-NL4 (O'Donnell 1993). The returned LSU sequences were checked and assembled using CAP3 Sequence Assembly program (Huang \& Madan 1999) on the PRABI-Doua website (http://doua.prabi.fr/ software/cap3). In the case of the ITS region the genomic DNA was extracted from a culture using a DNeasy ${ }^{\circledR}$ Mini Plant extraction kit (Qiagen Inc., Valencia, California) following the manufacturer's protocols and detailed methods used for PCR amplification and sequencing followed Promputtha \& Miller (2010). ITS sequencing was then performed at the W.M.Keck Center at the University of Illinois Urbana-Champaign and the returned ITS sequences were assembled with Sequencher 5.1 (Gene Codes Corp, Ann Arbor, Michigan).

Phylogenetic analyses: The newly generated ITS and LSU nrDNA sequences were subjected to megablast searches in GenBank to first assess the phylogenetic position of T. sabalicola. The ITS sequence returned no close matches and therefore was not used for analysis. An LSU dataset was prepared including the closest matches and sequences of Taeniolella species belonging to the class Sordariomycetes retrieved from GenBank. They were subjected to megablast searches and closest hits or related taxa from previous phylogenies were also included (Crous et al. 2006, Réblová et al. 2012, 2016) along with representatives of Sordariomycetidae based on Réblová et al. (2015) and Untereiner et al. (2013). Two species of Xylaria (Xylariomycetidae) were used as outgroup. Sequences were aligned with MAFFT v. 7.245 (Katoh \& Standley 2013) on the online server using the automatically selected L-INS-i strategy (Katoh et al. 2005). Alignment was visually checked and ambiguously aligned regions were removed with Gblocks online v. 0.91b (Castresana 2000, Talavera $\&$ Castresana 2007) using the less stringent selection parameters. Phylogenetic relationships were inferred by Maximum Likelihood (ML) analysis performed in MEGA v. 6.06 (Tamura et al. 2013) and Bayesian Inference (BI) implemented in MrBayes v. 3.2.2 (Ronquist \& Huelsenbeck 2003, Ronquist et al. 2012). The best-fit substitution model as determined by MEGA using the corrected Akaike Information Criterion value was the General Time Reversible model with Gamma distributed rates plus invariant sites $(\mathrm{GTR}+\mathrm{G}+\mathrm{I})$ and was used for both $\mathrm{ML}$ and $\mathrm{BI}$. An initial BioNJ tree was automatically constructed and the Nearest-Neighbor-Interchange (NNI) algorithm was used as the ML heuristic method. Statistical support for internal branches was estimated by nonparametric bootstrapping (Felsenstein 1985) with 1000 replicates and bootstrap support (BS) $\geq 70 \%$ was considered significant (Hillis \& Bull 1993). Bayesian analysis consisted of two independent runs of four Markov Chain Monte Carlo chains starting from different random trees and 10 million generations each with trees sampled every 100th generation. Standard deviation of split frequencies $<0.01$ was set as a convergence diagnostic. The first $25 \%$ of trees were discarded as burn-in and a $50 \%$ majority rule consensus tree was constructed from the remaining trees to estimate posterior probabilities (BPP) for each node. Clades with $\mathrm{BPP} \geq 95 \%$ were considered statistically significant and highly supported (Alfaro et al. 2003). Trees were finally viewed and edited with MEGA or FigTree v1.4.2 (Rambaut 2009) and refined using Inkscape (inkscape.org).

\section{Results}

Sequences of the entire ITS and partial LSU nrDNA were obtained and deposited in GenBank. The final LSU alignment consisted of 1082 characters and 50 sequences 
representing 46 taxa including the outgroup. The ML analysis resulted in a single most likely tree (Fig. 1). The majority rule consensus tree of the 97,442 sampled trees resulting from the Bayesian analysis was nearly identical in topology (data not shown). Taeniolella sabalicola clusters in both trees with the only LSU sequence currently available of Ellisembia leonensis (M.B.Ellis) McKenzie on a single branch without significant BS support or BPP. They form an unsupported sister clade with members of Magnaporthales in the Sordariomycetes and group with species of Barbatosphaeria Réblová, Xylomelasma sordida Réblová and Xylochrysis lucida Réblová, V.Stepanek $\&$ R.K.Schumach., all non-stromatic perithecial ascomycetes, and the aero-aquatic fungus Cancellidium applanatum Tubaki, all incertae sedis within Sordariomycetidae. Molecular analyses also confirmed the polyphyletic status of Taeniolella at the subclass and ordinal levels with the genus split across two subclasses within Sordariomycetes: T. phialosperma and T. alta (Ehrenb.) S.Hughes were both placed in Sordariomycetidae within strongly supported clades belonging to the orders Sordariales (BS 99\%, BPP 99\%) and Diaporthales (BS 100\%, BPP 100\%), respectively. Taeniolella rudis (Sacc.) S.Hughes is placed on a long branch within the highly-supported Pleurotheciales clade (BS 100\%, BPP 100\%) in the subclass Hypocreomycetidae. This clade also includes the following accessions: Pleurothecium recurvatum (Morgan) Höhn. (三 Carpoligna pleurothecii F.A.Fernández \& Huhndorf) JQ429235 \& AF261070, Pleurotheciella rivularia Réblová, Seifert \& J.Fourn. JQ429232, P. centenaria Réblová, Seifert \& G.P.White JQ429234 and Sterigmatobotrys macrocarpa (Corda) S.Hughes GU017317 \& GU017316.

\section{Taxonomy}

Taeniolella sabalicola G.Delgado \& A.N.Mill., sp. nov.

Fig. $2 \mathrm{~A}-\mathrm{H}$

MycoBank MB 818075

Colonies on natural substrate effuse, black, forming a cottony, dense, gray aerial mycelium after incubation in moist chamber. MYcelium partly immersed and partly superficial, composed of smooth or finely roughened, septate, cylindrical or inflated, subhyaline to light brown or brown, branched hyphae, 2-4(-7) $\mu$ m wide. CONIDIOPHORES semi-macronematous or micronematous, mononematous, arising terminally or laterally from the hyphae, solitary or caespitose, erect or ascending, straight or flexuous, cylindrical, unbranched, septate, smooth or finely roughened, light brown to brown, up to $530 \mu \mathrm{m}$ long, 2-3(-5) $\mu \mathrm{m}$ wide. ConidiogenOus CELLS monoblastic, integrated, terminal, determinate, cylindrical or subcylindrical, sometimes inflated or doliiform, $5-11(-15) \times 2.5-6 \mu \mathrm{m}$, often arising directly on the hyphae. Conidia holoblastic, acrogenous, narrowly clavate to clavate or long clavate, ellipsoidal, narrowly cylindrical, cylindrical to subcylindrical or long cylindrical, straight or flexuous, euseptate, with 4-23(-29) transverse septa, 0-4 longitudinal septa and 0-3 oblique septa, sometimes slightly constricted at 1-2 transverse septa, smooth or verruculose, brown to blackish brown, sometimes reddish brown, often partially surrounded by a subhyaline mucilaginous sheath, solitary or catenate and forming simple, acropetal chains of 2-3(-5) conidia or branching laterally, each branch producing also short conidial 


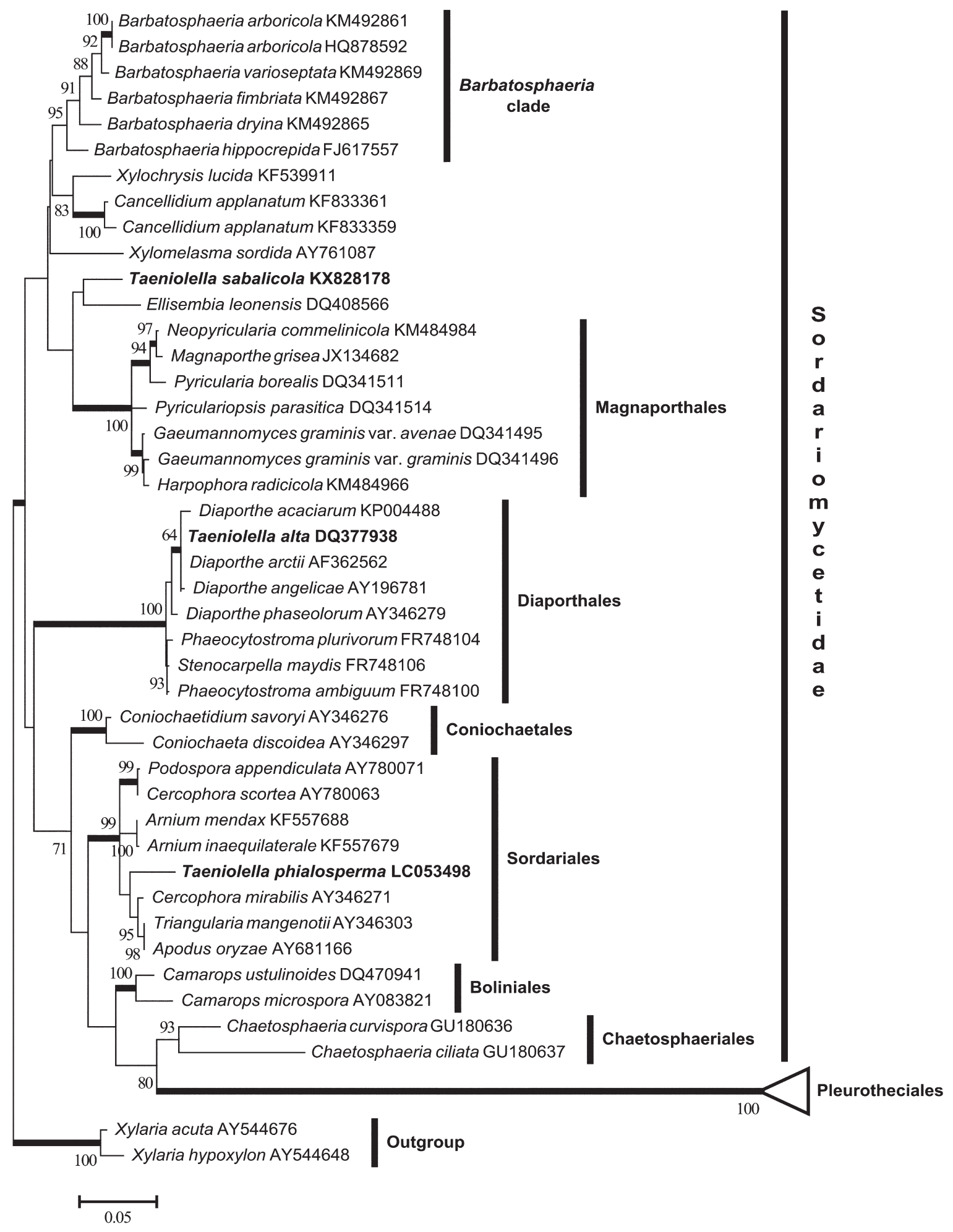

Fig. 1. Phylogenetic tree inferred from ML analysis ( $\ln \mathrm{L}=-6487.27)$ of selected LSU sequences belonging to Sordariomycetes showing the phylogenetic position of T. sabalicola within the class. Other Taeniolella species are marked in bold. The Pleurotheciales clade including T. rudis occurred on a long branch and was collapsed for space reasons. Bootstrap support values $\geq 70 \%$ are shown at the nodes and Bayesian posterior probabilities $\geq 95 \%$ are indicated by thickened branches. 

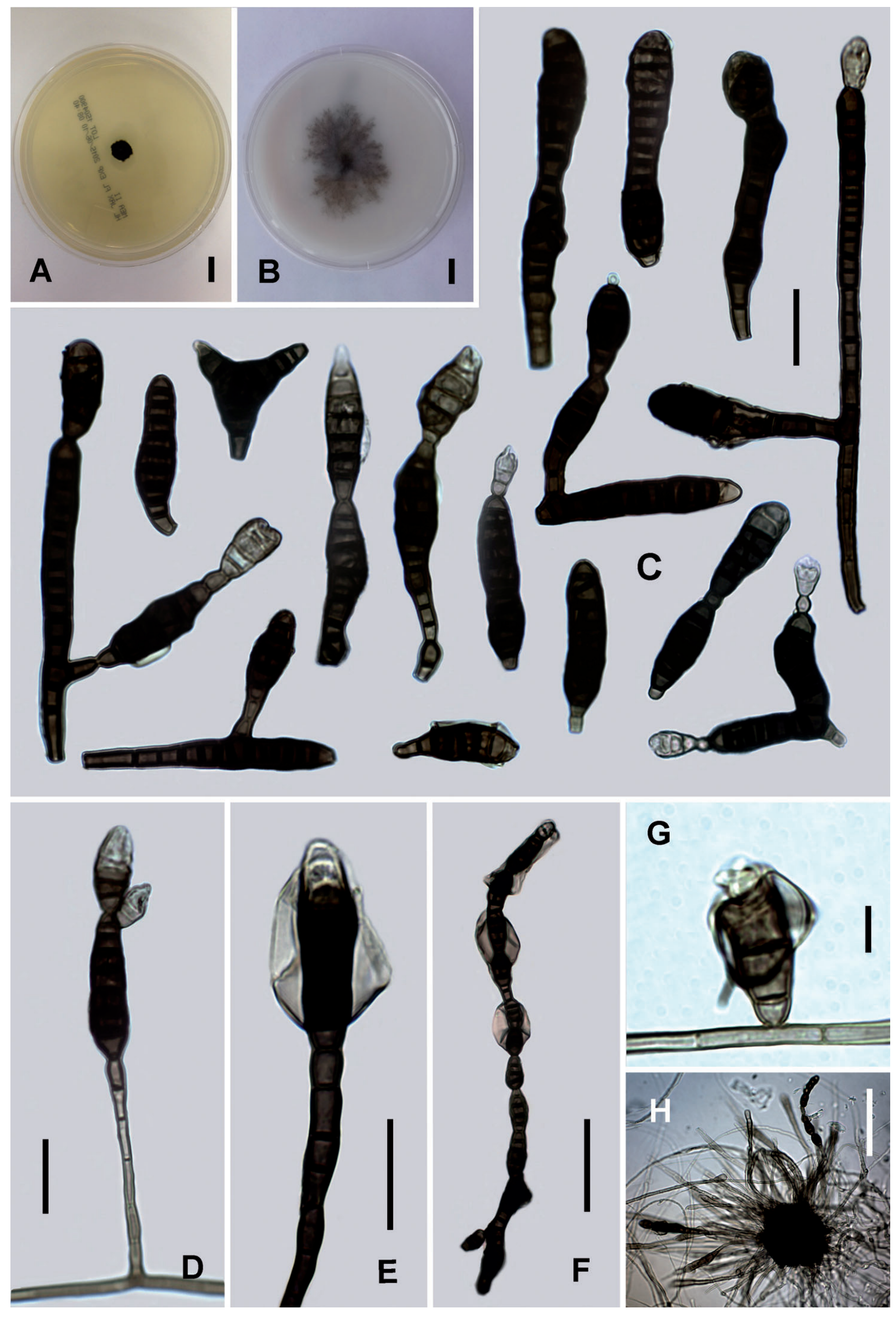
chains, occasionally also bifurcating 1-2 times, 31-164(-185) × 6-11(-14) $\mu$ m; apex often rounded, truncate or spathulate and paler, base truncate. TELEOMORPH unknown.

CoLONIES on MEA slowly growing, reaching 6-11 mm diam. after $28 \mathrm{~d}$ at $25^{\circ} \mathrm{C}$, black, compact, raised at center 1-3 mm, sometimes slightly sulcate, often with a small amount of gray aerial mycelium in the center, margin entire, submerged and cracking the medium or more or less irregular and diffuse, reverse black. CoLONIES on PDA similar to MEA, slow growing, reaching 9-11 mm diam. after $28 \mathrm{~d}$ at $25^{\circ} \mathrm{C}$, black, circular, flat or slightly raising in the center, also with a small amount of gray or black aerial mycelium, margin diffuse, reverse black. CoLONIES on MCA reaching 25-48 mm diam. after $2 \mathrm{mo}$ at $25^{\circ} \mathrm{C}$, irregular, loosely cottony, gray, reverse not visible. CONIDIOPHORES similar to those on natural substrate, subhyaline to light brown or brown, up to $190 \mu \mathrm{m}$ long on MEA and PDA, up to $780 \mu \mathrm{m}$ long on MCA, 1-3(-4) $\mu \mathrm{m}$ wide. ConIDIA also similar to those on natural substrate, brown to dark brown on MEA and PDA, brown to blackish brown on MCA, 21-128(-140) $\times 5-11(-14) \mu \mathrm{m},(3-) 6-21(-25)$ transverse septa, $0-2$ longitudinal septa, $0-1(-3)$ oblique septa, forming longer chains of up to 10 conidia, also surrounded by a subhyaline to brown mucilaginous sheath more often as an spherical blob up to $45 \mu \mathrm{m}$ diam. Sclerotial bodies produced on MEA and MCA cultures 2 mo or older, consisting of compact masses of hyphae, spherical, light brown to blackish brown, 36-103 $\mu \mathrm{m}$ diam.

Eтyмоlogy: Latin, sabalicola, referring to the host genus Sabal where the fungus was isolated.

Specimen examined: United States, Florida, Broward Co., Fort Lauderdale, 26 $12^{\prime} 20.5^{\prime \prime} \mathrm{N}$ 8009'50.6"W, $2.9 \mathrm{~m}$ asl., on petiole of dead leaf of Sabal palmetto (Walter) Lodd. ex Schult. \& Schult., 25 January 2014, leg. J.M.Perez, holotype (BPI 892972A), isotype (ILLS 80642), ex-holotype strain (CBS 140346), ex-holotype sequences (ITS KX828179, LSU KX828178).

\section{Discussion}

Taeniolella sabalicola fits well within the current broad generic concept of Taeniolella in having semi-macronematous or micronematous, unbranched conidiophores, monoblastic, determinate conidiogenous cells and phragmoconidia forming short, branched acropetal chains. Morphological and molecular data clearly support it as a new and distinct taxon within the genus. On the natural substrate the immersed mycelium is composed of thick-walled, brown hyphae with inflated cells up to $7 \mu \mathrm{m}$ wide but the aerial hyphae are cylindrical, thinner and light brown to brown. Conidiophores on the substrate surface are short and frequently caespitose but after incubation and the subsequent formation of aerial mycelium over the fungus colonies they are very long,

Fig. 2. Taeniolella sabalicola (holotype). A. Colony on MEA after 28 days incubation at $25^{\circ} \mathrm{C}$. B. Colony on MCA after 2 months incubation at $25^{\circ} \mathrm{C}$. C. Conidia on natural substrate. D. Conidiophore, conidiogenous cell and conidia in chain on natural substrate. E. Detail of a conidium surrounded by a mucilaginous sheath on MCA. F. Conidia in long chain on MEA. G. Young conidium born on the hyphae. H. Sclerotial body and conidia on MCA. Scale bars A, B = 1 cm, C, D, E = $20 \mu \mathrm{m}, \mathrm{F}$, $\mathrm{H}=50 \mu \mathrm{m}, \mathrm{G}=5 \mu \mathrm{m}$. 
erect, developing solitarily and arising laterally or terminally from the aerial hyphae. Similarly, conidiophores developed in culture on the colony surface or from immersed hyphae were comparatively shorter than those developed from the aerial mycelium, especially in MCA where the colony was cottony, with abundant aerial mycelium and very long conidiophores. On MEA and PDA colonies were restricted and compact. Terminal conidiophores are often formed gradually at the tip of the hyphae, becoming darker and thicker-walled until a long, narrowly cylindrical conidium is formed, the basal part of it is usually hard to distinguish from the remaining conidiophore.

Conidia on natural substrate are usually in short chains of two or three, rarely five, but in artificial media chains were longer and composed of up to 10 conidia, usually shorter in length when in long chains. Nevertheless, constrictions along the conidia are not distinct enough to distinguish whether they separate different conidia or are merely constrictions within a conidium. Slender, subhyaline to light brown cells sometimes appeared between conidia, or some cells are wider and darker along the conidial length that could be interpreted as a different conidium in the chain, especially on MEA. Conidia can branch even in early developmental stages on one side and sometimes bifurcate later once or twice, each branch being able to produce a new conidium or a small conidiogenous cell that also produces a new conidium. The apex or the conidial body or both are often surrounded by a mucilaginous sheath that in culture media often turns into a distinctive mucoid sphere, brown and stiff in appearance when conidia arise from the aerial mycelium or the colony surface, probably due to desiccation. A chain consisting of a few conidia can have up to three of these blobs (Fig. 2 F) or even a single conidium can have two of them. Conidiogenous cells can arise directly on the aerial hyphae and produce short, sessile conidia or the conidia can often arise directly on the hyphae as well. In general the fungus behaves more or less similarly under natural and artificial conditions but sometimes subhyaline, two to five or conglomerates of several, more or less spherical cells were formed at the apex of conidia immersed or developed right on top of the medium surface as an apparent artifact of culture growth not seen on natural substrate. Brown to dark brown sclerotial bodies comprising densely packed hyphal masses were also found immersed in old cultures and surrounded by short, few-celled, mostly clavate, subhyaline to light-brown or brown conidia (Fig. $2 \mathrm{H}$ ).

Among saprobic species of Taeniolella with multiseptate conidia, T. sabalicola morphologically resembles T. phialosperma (Watanabe 1992, Matsushima \& Matsushima 1995) in having semi-macronematous, long conidiophores and brown to dark brown, clavate, ellipsoidal or cylindrical, relatively large conidia in chains of similar number that can be simple or branched and are often completely or partially surrounded by a mucilaginous sheath. This is a thermotolerant fungus known so far from soils across eastern Asia and with affinities to the Sordariales (Liang et al. 2011, Réblová et al. 2016). Ertz et al. (2016) proposed its exclusion from Taeniolella based on unusual morphological features and its phylogenetic position unrelated to the generic type species. An LSU sequence (LC053498) derived from an ex-type culture of T. phialosperma (FFPRI TW 73-466) grouped distantly from T. sabalicola despite their morphological similarities. Taeniolella phialosperma also differs in having larger conidia (35-315 × 9-26 $\mu \mathrm{m})$ with up to 32-transverse septa, very rarely a longitudinal 
septum and the presence of a phialophora-like synanamorph with simple or branched, often verticillate conidiophores, phialides with a conspicuous collarette and hyaline or subhyaline, globose, smooth, 1-celled conidia. Its colonies on PDA are also different, dark yellowish green at first, later becoming dark gray in color, often covered with a golden yellow aerial mycelium and reaching $48-55 \mathrm{~mm}$ after 28 days at $25{ }^{\circ} \mathrm{C}$ (Watanabe 1992).

In our phylogeny the closest relative of T. sabalicola was Ellisembia leonensis (Ellis 1958, McKenzie 1995, Wu \& Zhuang 2005), a morphologically different sporidesmiumlike anamorph of uncertain placement within the class (Shenoy et al. 2006) with macronematous conidiophores that proliferate percurrently up to three times and solitary, fusiform, 9-17-distoseptate conidia. The poorly supported relationship between these two taxa and with members of Magnaporthaceae as well as other Sordariomycetidae incertae sedis may require a more extensive taxon sampling and the use of additional molecular markers to further resolve their phylogenetic relationships. The remaining two Taeniolella species used for analysis, T. alta and T. rudis, did not show a close relationship with $T$. sabalicola but grouped within two other strongly supported clades in Sordariomycetidae and Hypocreomycetidae, respectively. Taeniolella alta showed affinities with members of Diaporthales as previously seen in a peripheral study aiming to resolve phylogenetic lineages within the family Botryosphaeriaceae (Crous et al. 2006). Ertz et al. (2016) recently questioned the reliability of that sequence because the source culture failed to sporulate and the morphological features of T. alta strongly differ from those of diaporthaceous fungi. Consequently, further specimens will be necessary to clarify the phylogenetic placement of this species. Taeniolella rudis, on the other hand, nested in a fully supported clade with Sterigmatobotrys macrocarpa as previously seen in phylogenetic studies including both taxa (Réblová et al. 2012, 2016). This is a dematiaceous hyphomycete with macronematous conidiophores terminating in penicillate heads and hyaline, 2-3-septate conidia which has repeatedly been reported as the synanamorph of T. rudis (Hughes 1980b, Gareth-Jones et al. 2002). They grouped together with members of Pleurothecium Höhn. and Pleurotheciella Réblová, Seifert \& J.Fourn. within the recently established order Pleurotheciales belonging to Hypocreomycetidae (Réblová et al. 2016). Both of these genera include holomorphic ascomycete taxa whose perithecial, chaetosphaeria-like teleomorphs are morphologically similar to the recently discovered teleomorph of $S$. macrocarpa (Réblová \& Seifert 2011). Ertz et al. (2016) transferred T. rudis to Sterigmatobotrys based on similar results and its distant phylogenetic position from $T$. exilis, the type species of Taeniolella, but retained it as distinct from $S$. macrocarpa due to morphological differences. Although a MycoBank number is available for the name $S$. rudis, the combination was not publicly released at the moment of submitting this paper and, therefore, was not used here.

Additionally, Taeniolella stilbospora (Corda) S.Hughes (Ellis 1971, Melnik 2000) is also morphologically comparable to T. sabalicola in having caespitose conidiophores on natural substrate and long, cylindrical, straight or flexuous, brown, smooth, up to 24-septate conidia similar in size and rounded at the apex, some conidial cells producing one or two lateral branches in culture (de Hoog et al. 2000). No LSU sequence of $T$. stilbospora is currently available in GenBank but megablast searches of ITS and SSU 
sequences annotated under that name, AY843127 and AY843258, respectively, reveal that $T$. stilbospora has phylogenetic affinities with members of Dothideomycetes. Summerell et al. (2006) placed it within Botryosphaeriaceae based on the ITS sequence mentioned above and therefore, despite their morphological similarities, this species is phylogenetically distant from T. sabalicola. Similarly, T. typhoides Gulis \& Marvanová, known from submerged decaying leaves of Nuphar lutea (L.) Smith in Belarus (Gulis \& Marvanová 1999), also has lateral or terminal, simple, sometimes extremely long conidiophores, cylindrical, rounded at the apex, multiseptate conidia in short acropetal chains that can arise directly from the hyphae and produce sclerotial bodies similar in size on MEA after several months of incubation under water. Shearer et al. (2009) revealed that $T$. typhoides is related with members of Lindgomycetaceae, a family of freshwater ascomycetes in the Pleosporales (Dothideomycetes), and therefore is unrelated to T. sabalicola in the Sordariomycetes. Additionally, conidia are longer and more septate in culture and natural substrate, having a length up to $470 \mu \mathrm{m}$ and up to 60 septa in the latter, and rarely possess oblique septa.

Moreover, a tentative placement of $T$. sabalicola in Peyronelia Cif. \& Gonz.Frag. was also considered based on the strong similarity with the anamorph of Glyphium leptothecium (Earle) B.Sutton [三 G. corrugatum (Ellis) Goree] and to a lesser extent with anamorphic G. schizosporum (Maire) H.Zogg (Sutton 1970) and G. grisonense Math. (Mathiassen 1993). The three species of Glyphium with a peyronelia-like anamorph possess ascospores that disarticulate into part-spores before maturity while still within the ascus. They were traditionally included in Mytilinidiaceae (Mytilinidiales, Dothideomycetes) but were recently placed in Patellariales based on multigene sequence data analyses (Boehm et al. 2015). Sutton (1970) tentatively assigned their anamorphs to the genus Peyronelia based on a comparable morphology with the type species, P. sirodesmioides Cif. \& Gonz.Frag. (Ciferri \& GonzalezFragoso 1927, Hughes 1958), and the acropetal development of conidia at a moment when different morphs of a pleomorphic fungus were allowed formal separate names, a practice not allowed today under the provisions of the current code (McNeill et al. 2012). They form long, multiseptate, irregularly verruculose conidia in acropetal chains similar in size, shape and color to T. sabalicola, even the distinction between individual conidia in the chains is difficult. The conidia of G. leptothecium usually have one or two longitudinal or oblique septa and occur in branched chains, while those of G. schizosporium and G. grisonense are in unbranched chains with none or occasionally a longitudinal septum (Sutton 1970, Mathiassen 1993, Boehm et al. 2015). However, the disparate phylogenetic affinities between them and T. sabalicola and the obscure status of the members of Peyronelia precluded placement in this genus despite their close morphological resemblance. Attempts to locate the type specimen of $P$. sirodesmioides in different herbaria were unsuccessful and it is probably lost.

The polyphyletic status of Taeniolella was previously realized (Summerell et al. 2006, Zelski et al. 2011, Réblová et al. 2016) based on accumulated evidence from molecular studies of different taxonomic groups including the few saprobic species with available DNA sequence data (Crous et al. 2006, Shearer et al. 2009, Liang et al. 2011, Réblová et al. 2012), or inferred from distantly related ascomycetous fungi with taeniolella-like anamorphs (Minter \& Holubová-Jechová 1981, Wijayawardene 
et al. 2012, Zelski et al. 2011). Some species were previously transferred to or synonymized with members of other genera e.g. Anavirga B.Sutton (Kirk 1983), Cladophialophora Borelli (de Hoog et al. 1995), Corynespora Güssow (Heuchert \& Braun 2006), Polydesmus Mont. (Shoemaker \& Hambleton 2001) and Taeniolina M.B.Ellis (Kirk 1981) but the genus still remained heterogeneous. Recently Ertz et al. (2016), in a phylogenetic reassessment of the genus with emphasis on lichenicolous taxa, confirmed that Taeniolella is strongly polyphyletic with its members scattered throughout different classes (i.e. Sordariomycetes and Dothideomycetes). Taeniolella exilis, the type species, was recovered as a member of the family Kirschsteiniotheliaceae within Dothideomycetes, and five other lichenicolous taxa were found to be confined to the order Asterotexiales in the Dothideomycetes. Based on the rather preliminary knowledge about the phylogenetic relationships among members of the genus and the lack of molecular data for the majority of taxa, they refrained to propose new generic changes and preferred to provisionally retain Taeniolella in a broad sense until more data becomes available, a criterion followed here as well to accommodate T. sabalicola.

\section{Acknowledgments}

We would like to thank Bettina Heuchert (Martin-Luther-Universität Halle-Wittenberg) for serving as a pre-submission reviewer, José M.Pérez (University of Florida, U.S.A.) for collecting the source material for this work, Sayaka Ban (NBRC, Japan) for kindly depositing the ITS-LSU sequences from the ex-type strain of T. phialosperma in GenBank and G.Mathiassen (TROM, Norway) for providing relevant literature. We are grateful to the curators of MA, W and $\mathrm{L}$ for searching the type specimen of $P$. sirodesmioides in their collections. Kamash Ramanathan and Malcolm Moody (EMLab P\&K) are acknowledged for the provision of laboratory facilities and financial support.

\section{References}

ALFARO, M.E., S. ZOLLER \& F. LUTZONI 2003: Bayes or Bootstrap? A simulation study comparing the performance of Bayesian Markov Chain Monte Carlo sampling and bootstrapping in assessing phylogenetic confidence. - Mol. Biol. Evol. 20: 255-266.

BOEHM, E.W., G. MARSON, G.H. MATHIASSEN, A. GARDIENNET \& C.L. SCHOCH 2015: An overview of the genus Glyphium and its phylogenetic placement in Patellariales. - Mycologia 107: 607-618.

CASTRESANA, J. 2000: Selection of conserved blocks from multiple alignments for their use in phylogenetic analysis. - Mol. Biol. Evol. 17: 540-552.

CHOI, Y.W., K.D. HYDE \& W.H. HO 1999: Single spore isolation of fungi. - Fungal Divers. 3: 29-38.

CIFERRI, R. \& R. GONZALEZ-FRAGOSO 1927: Hongos parasitos y saprofitos de la Republica Dominicana (12.a Serie). - Bol. R. Soc. Esp. Hist. Nat. 27: 323-334.

CROUS, P.W., B. SLIPPERS, M.J. WINGFIELD, J. RHEEDER, W.F.O. MARASAS et al. 2006: Phylogenetic lineages in the Botryosphaeriaceae. - Stud. Mycol. 55: 235-253.

DE HOOG, G.S., J. GUARRO, J. GENE \& M.J. FIGUERAS 2000: Atlas of Clinical Fungi. $2^{\text {nd }}$ ed. - Centraalbureau voor Schimmelcultures, Utrecht/Universitat Rovira i Virgili, Reus.

DE HOOG, G.S., E. GUÉHO, F. MASCLAUX, A.H.G. GERRITS VAN DEN ENDE, K.J. KWONCHUNG et al. 1995: Nutritional physiology and taxonomy of human-pathogenic CladosporiumXylohypha species. - J. Med. Vet. Mycol. 33: 339-347. 
ELLIS, M.B. 1958: Clasterosporium and some allied Dematiaceae-Phragmosporae I. - Mycol. Pap. 70: $1-89$.

ELLIS, M.B. 1971: Dematiaceous Hyphomycetes. - Commonwealth Mycological Institute, Kew.

ERTZ, D., B. HEUCHERT, U. BRAUN, C.E. FREEBURY, R.S. COMMON et al. 2016: Contribution to the phylogeny and taxonomy of the genus Taeniolella, with a focus on lichenicolous taxa. - Fungal Biology, doi: 10.1016/j.funbio.2016.05.008. In press, corrected proof.

FELSENSTEIN, J. 1985: Confidence limits on phylogenies: an approach using the bootstrap. Evolution 39: 783-791.

GARETH-JONES, E.B., R.A. EATON \& S. SOMRITHIPOL 2002: Taeniolella rudis and Taeniolella longissima sp. nov. with secondary sympodioconidia from freshwater habitats. - Mycoscience 43: 201-206.

GULIS, V. \& L. MARVANOVÁ 1999: Three new scolecosporous hyphomycetes from waters in Belarus. - Mycotaxon 72: 237-250.

HAWKSWORTH, D.L. 1979: The lichenicolous hyphomycetes. - Bull. Brit. Mus. Nat. Hist. Bot. 6: $183-300$.

HEUCHERT, B. \& U. BRAUN 2006: On some dematiaceous lichenicolous hyphomycetes. -Herzogia 19: $11-21$.

HILLIS, D.M. \& J.J. BULL 1993: An empirical test of bootstrapping as a method for assessing confidence in phylogenetic analysis. - Syst. Biol. 42: 182-192.

HUANG, X. \& A. MADAN 1999: CAP3: A DNA sequence assembly program. - Genome Res. 9: 868-877.

HUGHES, S.J. 1958: Revisiones hyphomycetum aliquot cum appendice de nominibus rejiciendis. - Can. J. Bot. 36: 727-836.

HUGHES, S.J. 1980b: Taeniolella rudis. - Fungi Canadenses 185: 1-2.

KATOH, K. \& D.M. STANDLEY 2013: MAFFT Multiple Sequence Alignment Software Version 7: Improvements in Performance and Usability. - Mol. Biol. Evol. 30: 772-780.

KATOH, K., K. KUMA, H. TOH \& T. MIYATA 2005: MAFFT version 5: improvement in accuracy of multiple sequence alignment. - Nucleic Acids Res. 33: 511-518.

KIRK, P.M. 1981: New or interesting microfungi I. Dematiaceous hyphomycetes from Devon. Trans. Br. mycol. Soc. 76: 71-87.

KIRK, P.M. 1983: New or interesting microfungi X. Hyphomycetes on Laurus nobilis leaf litter.Mycotaxon 18: 259-298.

LIANG, Y., F. WANG, A.N. LI \& D.C. LI 2011: Thermotolerant fungi and their phylogenetic analyses based on rDNA-ITS sequences. - Mycosystema 30: 542-550.

MATSUSHIMA, K. \& T. MATSUSHIMA 1995: Fragmenta Mycologica-I. - Mat. Mycol. Mem. 8: $45-54$.

MATHIASSEN, G. 1993: Corticolous and lignicolous Pyrenomycetes s. lat. (Ascomycetes) on Salix along a mid-Scandinavian transect. - Sommerfeltia 20: 1-180.

MCNEILL, J., F.R. BARRIE, W.R. BUCK, V. DEMOULIN, W. GREUTER et al. (eds.) 2012: International Code of Nomenclature for algae, fungi, and plants (Melbourne Code) adopted by the Eighteenth International Botanical Congress Melbourne, Australia, July 2011. http://www.iapt-taxon. org/nomen/main.php Last accessed September 2015.

MCKENZIE, E.H.C. 1995: Dematiaceous hyphomycetes on Pandanaceae. 5. Sporidesmium sensu lato. - Mycotaxon 56: 9-29. 
MELNIK, V.A. 2000: Definitorium fungorum Rossiae. Classis Hyphomycetes. Fasc. 1. Fam. Dematiaceae. - Nauka, St. Petersburg.

MINTER, D.W. \& V. HOLUBOVÁ-JECHOVÁ 1981: New or interesting hyphomycetes on decaying pine litter from Czechoslovakia. - Folia Geobot. Phytotaxon. 16: 195-217.

NASH, T.H., B.D. RYAN, P. DIEDERICH, C. GRIES \& F. BUNGARTZ (eds.) 2004: Lichen Flora of the Greater Sonoran Desert Region. Volume II. - Lichens Unlimited, Tempe.

O'DONNELL, K. 1993. Fusarium and its near relatives. - In: REYNOLDS D.R. \& J.W. TAYLOR (eds.): The fungal holomorph: mitotic, meiotic and pleomorphic speciation in fungal systematic, pp. 225-233. - CAB International, Wallingford.

PROMPUTTHA, I. \& A.N. MILLER 2010: Three new species of Acanthostigma (Tubeufiaceae, Dothideomycetes) from Great Smoky Mountains National Park. - Mycologia 102: 574-587.

RAMBAUT, A. 2009: FigTree v1.4: Tree Figure Drawing Tool. http://tree.bio.ed.ac.uk/software/ figtree/

RÉBLOVÁ, M., K. RÉBLOVÁ \& V. ŠTĚPÁNEK 2015: Molecular systematics of Barbatosphaeria (Sordariomycetes): multigene phylogeny and secondary ITS structure. - Persoonia 35: 21-38.

RÉBLOVÁ, M. \& K.A. SEIFERT 2011: Discovery of the teleomorph of the hyphomycete, Sterigmatobotrys macrocarpa, and epitypification of the genus to holomorphic status. - Stud. Mycol. 68: 193-202.

RÉBLOVÁ, M., K.A. SEIFERT, J. FOURNIER \& V. STEPÁNEK 2012: Phylogenetic classification of Pleurothecium and Pleurotheciella gen. nov. and its dactylaria-like anamorph (Sordariomycetes) based on nuclear ribosomal and protein-coding genes. - Mycologia 104: 1299-1314.

RÉBLOVÁ M., K.A. SEIFERT, J. FOURNIER \& V. STEPÁNEK 2016: Newly recognised lineages of perithecial ascomycetes: the new orders Conioscyphales and Pleurotheciales. - Persoonia 37: 57-81.

RONQUIST, F. \& J.P. HUELSENBECK 2003: MrBayes 3: Bayesian phylogenetic inference under mixed models. - Bioinformatics 19: 1572-1574.

RONQUIST, F., M. TESLENKO, P. VAN DER MARK, D.L. AYRES, A. DARLING et al. 2012: MrBayes 3.2: Efficient Bayesian phylogenetic inference and model choice across a large model space. - Syst. Biol. 61: 539-542.

SEIFERT, K., G. MORGAN-JONES, W. GAMS \& B. KENDRICK 2011: The genera of hyphomycetes. - CBS-KNAW Fungal Biodiversity Centre, Utrecht.

SHEARER, C.A., H.A. RAJA, A.N. MILLER, P. NELSON, K. TANAKA et al. 2009: The molecular phylogeny of freshwater Dothidiomycetes - Stud. Mycol. 64: 145-153.

SHENOY, B.D., R. JEEWON, W.P. WU, D.J. BHAT \& K.D. HYDE 2006: Ribosomal and RPB2 DNA sequence analyses suggest that Sporidesmium and morphologically similar genera are polyphyletic. - Mycol. Res. 110: 916-928.

SHOEMAKER, R.A. \& S. HAMBLETON 2001: "Helminthosporium" asterinum, Polydesmus elegans, Imimyces, and allies. - Can. J. Bot. 79: 592-599.

SUMMERELL, B.A., J.Z. GROENEWALD, A. CARNEGIE, R.C. SUMMERBELL \& P.W. CROUS 2006: Eucalyptus microfungi known from culture. 2. Alysidiella, Fusculina and Phlogicylindrium genera nova, with notes on some other poorly known taxa. - Fungal Divers. 23: 323-350.

SUTTON, B.C. 1970: Glyphium leptothecium (Earle) comb. nov., G. schizosporum (Maire) Zogg, and their imperfect states. - Trans. Br. mycol. Soc. 54: 255-264.

TALAVERA, G. \& J. CASTRESANA 2007: Improvement of phylogenies after removing divergent and ambiguously aligned blocks from protein sequence alignments. - Syst. Biol. 56: 564-577. 
TAMURA, K., G. STECHER, D. PETERSON, A. FILIPSKI \& S. KUMAR 2013: MEGA6: Molecular Evolutionary Genetics Analysis version 6.0. - Mol. Biol. Evol. 30: 2725-2729.

UNTEREINER, W.A., M. BOGALE, A. CARTER, H.W. BUD PLATT, S.Å. HANSON et al. 2013: Molecular phylogeny of Boliniales (Sordariomycetes) with an assessment of the systematics of Apiorhynchostoma, Endoxyla and Pseudovalsaria. - Mycologia 105: 564-588.

WATANABE, T. 1992: Taeniolella phialosperma sp. nov. from Japan. - Mycologia 84: 478-483.

WIJAYAWARDENE, D.N.N., E.H.C. MCKENZIE \& K.D. HYDE 2012: Towards incorporating anamorphic fungi in a natural classification - checklist and notes for 2011. - Mycosphere 3: 157-228.

WU, W.P. \& W. ZHUANG 2005: Sporidesmium, Endophragmiella and related genera from China. - Fungal Diversity Press, Hong Kong.

ZELSKI, S.E., H.A. RAJA, A.N. MILLER \& C.A SHEARER 2011: Chaetorostrum quincemilensis, gen. et sp. nov., a new freshwater ascomycete and its Taeniolella-like anamorph from Peru. Mycosphere 2: 593-600. 
Declaration of author contributions to the publication / manuscript:

South Florida microfungi: Castanedospora, a new genus to accommodate Sporidesmium pachyanthicola (Capnodiales, Ascomycota)

Status: published

Name of journal: Cryptogamie, Mycologie 39 (1): 109-127, 2018.

Contributing authors:

Gregorio Delgado (GD)

Andrew N. Miller (AM)

Meike Piepenbring (MP)

What are the contributions of the doctoral candidate and his co-authors?

(1) Concept and design

Doctoral candidate GD: $100 \%$

(2) Conducting tests and experiments

Doctoral candidate GD: $100 \%$ Carried out the field work

(3) Compilation of data sets and figures

Doctoral candidate GD: $70 \%$ Obtained morphological and cultural data, generated figures \& drawing

Co-author AM: 20\% Obtained molecular data, MP: 10\% Advised on drawing

(4) Analysis and interpretation of data

Doctoral candidate GD: $80 \%$ Performed analysis and interpretations of the data Co-authors AM: 10\%, MP: 10\% Advised on analysis and interpretation of results

(5) Drafting of manuscript

Doctoral candidate GD: $80 \%$

Co-authors AM: 10\%, MP: 10\% 
I hereby certify that the information above is correct.

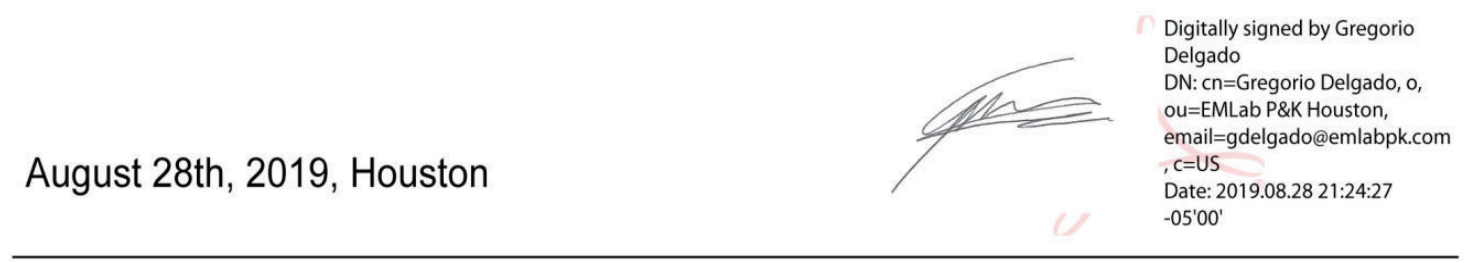

Date and place

Signature doctoral candidate

August 30th, 2019, Frankfurt am Main

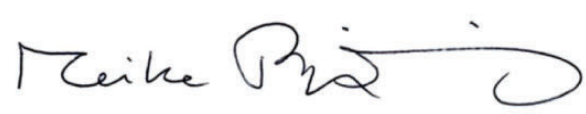

Date and place

Signature supervisor

August 29th, 2019, Champaign

Andrew N. Miller Miller
Date: 2019.08.29 09:12:14-05'00'

Date and place

Signature supervisor 


\title{
South Florida microfungi: Castanedospora, a new genus to accommodate Sporidesmium pachyanthicola (Capnodiales, Ascomycota)
}

\author{
Gregorio DELGADO ${ }^{a, b^{*}}$, Andrew N. MILLER ${ }^{c}$ \& Meike PIEPENBRING ${ }^{b}$ \\ ${ }^{a}$ EMLab P\&K Houston, \\ 10900 Brittmoore Park Drive Suite G, Houston, TX 77041, USA \\ ${ }^{b}$ Department of Mycology, Institute of Ecology, Evolution and Diversity, \\ Goethe Universität Frankfurt, Max-von-Laue-Str. 13, \\ 60438 Frankfurt am Main, Germany \\ 'Illinois Natural History Survey, University of Illinois, \\ 1816 South Oak Street, Champaign, IL 61820, USA
}

\begin{abstract}
The taxonomic status and phylogenetic placement of Sporidesmium pachyanthicola in Capnodiales (Dothideomycetes) are revisited based on a specimen collected on the petiole of a dead leaf of Sabal palmetto in south Florida, U.S.A. New evidence inferred from phylogenetic analyses of nuclear ribosomal DNA sequence data together with a broad taxon sampling at family level suggest that the fungus is a member of Extremaceae and therefore its previous placement within the broadly defined Teratosphaeriaceae was not supported. A new genus Castanedospora is introduced to accommodate this species on the basis of its distinct morphology and phylogenetic position distant from Sporidesmiaceae sensu stricto in Sordariomycetes. The holotype material from Cuba was found to be exhausted and the Florida specimen, which agrees well with the original description, is selected as epitype. The fungus produced considerably long cylindrical to narrowly obclavate conidia in culture strongly resembling those of Sporidesmajora pennsylvaniensis, another sporidesmium-like, capnodiaceous anamorph. However, phylogenetic analyses show that they are not congeneric and the latter belongs to the family Phaeothecoidiellaceae.
\end{abstract}

\section{Anamorphic / palmicolous / phylogeny / saprobic}

\section{INTRODUCTION}

The generic concept of Sporidesmium Link and its segregated genera based on morphological features such as conidial septation, presence or absence of conidiophores and the pattern of extension of the conidiogenous cells (Subramanian, 1992; Hernández \& Sutton, 1997; Seifert et al., 2011) was early recognized to be diagnostically valuable but schematic and phylogenetically unsound (Reblová, 1999). Shenoy et al. (2006) conducted the first comprehensive molecular study of

\footnotetext{
* Corresponding author: gdelgado@emlabpk.com
} 
sporidesmium-like taxa revealing that they are polyphyletic and belong to the ascomycete classes Dothideomycetes and Sordariomycetes while the phenotypic characters used to delimit sporidesmium-like genera were not phylogenetically significant. More recently, considerable progress has been made in clarifying their systematic position with the resurrection of the family Sporidesmiaceae Fr., typified by the genus Sporidesmium, for a distinct monophyletic clade incertae sedis within Sordariomycetes (Su et al., 2016). This clade contains eight Sporidesmium species morphologically similar to $S$. ehrenbergii M.B. Ellis, the generic lectotype. Neither this species nor the original generic type, S. atrum Link (Ellis, 1958; Hughes, 1979), were included in the phylogenetic analyses of the family due to the absence of an ex-lectotype strain or a type material, respectively. These authors treated Ellisembia Subram. as a synonym of Sporidesmium based on molecular data and introduced the family Distoseptisporaceae K.D. Hyde \& McKenzie, typified by Distoseptispora K.D. Hyde, McKenzie \& Maharachch., to accommodate ellisembia-like taxa with relatively short conidiophores and long cylindrical, distoseptate conidia that clustered outside Sporidesmiaceae. They also erected Pseudosporidesmium K.D. Hyde \& McKenzie to accomodate S. knawiae Crous (Crous, 2008) based on its distinct morphology and phylogenetic placement within the subclass Xylariomycetidae in the Sordariomycetes. This taxon was recently placed in its own family Pseudosporidesmiaceae Crous along with a second species and Repetophragma inflatum (Berk. \& Ravenel) W.P. Wu (Crous et al., 2017). Hyde et al. (2016) and Yang et al. (2017) further described several Sporidesmium and Distoseptispora species within their respective families. Zhang et al. (2017) collected the first sexual morph of Sporidesmium, S. thailandense W. Dong, H. Zhang \& K.D. Hyde, on submerged wood in Thailand. The fungus produces immersed ascomata with an erumpent neck and long cylindrical, unitunicate asci containing 8 fusiform, 3 -septate, obliquely uniseriate ascospores. It did not exhibit an associated anamorph but clustered within Sporidesmiaceae with high support. Two monotypic, sporidesmiumlike genera named Sporidesmioides J.F. Li, R. Phookamsak \& K.D. Hyde and Pseudostanjehughesia J. Yang \& K.D. Hyde (Li et al., 2016; Yang et al., 2017) were introduced within Torulaceae (Pleosporales, Dothideomycetes) and incertae sedis within the subclass Diaporthomycetidae (Sordariomycetes), respectively. The taxonomic and phylogenetic status of further taxa such as $S$. australiense M.B. Ellis and $S$. tropicale M.B. Ellis were clarified by these authors based on multi-gene sequence data. Finally, estimation of divergence times for taxa within Ascomycota and particularly for Sordariomycetes using molecular clock methods led Hyde et al. (2017) to suggest that Sporidesmiaceae and its sister family Papulosaceae might be upgraded to ordinal status under the name Sporidesmiales.

Taxonomic and biodiversity studies on saprobic microfungi associated with dead plant debris in south Florida revealed several new or poorly studied sporidesmium-like taxa (Delgado, 2008, 2009, 2010, 2013, 2014). One of them is S. pachyanthicola R.F. Castañeda \& W.B. Kendr., first described from dead leaves of Pachyanthus poiretii Griseb. in neighboring Cuba (Castañeda \& Kendrick, 1990). The fungus is characterized by a simple sporidesmium-like morphology consisting of long narrowly obclavate or long cylindrical, mutiseptate conidia with truncate bases and short conidiophores without percurrent extensions. Florida collections were made on rachides and petioles of dead leaves of Sabal palmetto, the cabbage palm, and on unidentified dead bark (Delgado, 2009). The fungus has also been reported on dead branches of Eucalyptus sp. from subtropical China (Wu \& Zhuang, 2005) and recently on dead bamboo stems from Nicaragua (Delgado \& Koukol, 2016). Shenoy et al. (2006) first assessed the phylogenetic relationships of 
S. pachyanthicola based on a strain (HKUCC 10835) obtained from the Chinese specimen mentioned above but without details on the isolate's morphology or growth characteristics. Using LSU sequence data they found that the fungus belongs to Dothideomycetes where it grouped in a highly supported clade with a few members of the families Mycosphaerellaceae and Capnodiaceae. Subsequently, this single LSU sequence was included in studies of dothideomycetous or capnodiaceous fungi using a more extensive taxon sampling or to design specific primers for amplification of the LSU locus (Ma et al., 2016). These studies eventually refined the phylogenetic position of $S$. pachyanthicola. The fungus was further placed in Teratosphaeriaceae, a large family segregated from the polyphyletic Mycosphaerellaceae (Crous et al., 2007), within a moderately to highly supported clade together with Staninwardia suttonii Crous \& Summerell and Pseudoramichloridium brasilianum (Arzanlou \& Crous) Cheew. \& Crous (Arzanlou et al., 2007; Yang et al., 2010). It was placed also in a poorly supported group together with Neohortaea acidophila (Hölker, Bend, Pracht, Tetsch, Tob. Müll., M. Höfer \& de Hoog) Quaedvl. \& Crous within Teratosphaeriaceae (Crous et al., 2009b). More recently, Hernández et al. (2017) placed it within Capnodiales incertae sedis sister to Catenulostroma species in Teratosphaeriaceae without statistical support and based on a limited taxon sampling at family level.

While isolating microfungi from samples collected in south Florida, S. pachyanthicola was recovered again and successfully cultivated on agar medium. In the present paper the current generic status of the fungus in Sporidesmium and its phylogenetic position in Capnodiales are reassessed in the light of new morphological, cultural and molecular evidence, based on a strain other than the one employed by Shenoy et al. (2006). Additionally, a hypothetical relationship of this species with Sporidesmajora pennsylvaniensis Batzer \& Crous, a morphologically similar sporidesmium-like anamorph in Capnodiales (Yang et al., 2010), was tested using molecular data.

\section{MATERIALS AND METHODS}

\section{Morphological and cultural study}

Dead leaves of Sabal palmetto were first washed off under running tap water and cut in smaller pieces for incubation at room temperature in a plastic container followed by periodical observations. The strain of $S$. pachyanthicola studied here was recovered around colonies of another fungus isolated under these conditions and growing on a 2\% Malt Extract Agar (MEA) plate after seven days at $25^{\circ} \mathrm{C}$. Once detected it was transferred aseptically to another MEA plate and incubated under similar conditions until sporulation was observed. Single-spore isolates were subsequently obtained following Choi et al. (1999). Colonies were subcultured on MEA and Potato Dextrose Agar (PDA) and descriptions are based on one month old cultures. The voucher specimen source of the isolate was reexamined to confirm the presence of the fungus on natural substrate. Fungal structures from both in vitro and in vivo conditions were mounted in lactophenol cotton blue and examined under an Olympus BX45 compound microscope. Minimum, maximum, 5th and 95th percentile values were calculated based on $\mathrm{n}=50$ measurements of each structure at $1000 \times$ magnification and outliers are given 
in parentheses. Line drawings were made using a drawing tube (Carl Zeiss, Oberkochen, Germany). Epitype and isoepitype specimens in the form of semipermanent slides and dried cultures were deposited in the Herbarium of the U.S. National Fungus Collections (BPI) and the Illinois Natural History Survey Fungarium (ILLS), respectively. An ex-epitype living culture is maintained in the Westerdijk Fungal Biodiversity Institute (CBS). Fungal and host plant names are cited throughout the text following Index Fungorum or the International Plant Names Index (www. ipni.org), respectively. Herbaria or culture collection acronyms are cited according to Index Herbariorum (http://sweetgum.nybg.org/science/ih/).

\section{DNA extraction, PCR amplification, and sequencing}

Genomic DNA was extracted from a 2-week old fungal isolate grown on MEA using a DNeasy ${ }^{\circledR}$ Mini Plant extraction kit (Qiagen Inc., Valencia, CA) according to the manufacturer's instructions. Subsequent methods on PCR amplification and Sanger sequencing were carried out according to Promputtha \& Miller (2010). The complete internal transcribed spacer (ITS) region and partial nuclear ribosomal large subunit (LSU) were amplified in separate reactions using the primer sets ITS1F-ITS4 and LROR-LR6, respectively (Vilgalys \& Hester, 1990; White et al., 1990; Gardes \& Bruns, 1993; Rehner \& Samuels, 1995). PCR products were sequenced using these primers along with LR3 and LR3R on an Applied Biosystems 3730XL high-throughput capillary sequencer (Applied Biosystems, Foster City, CA) at the W. M. Keck Center of the University of Illinois UrbanaChampaign. Consensus ITS and LSU sequences were assembled with Sequencher 5.1 (Gene Codes Corp., Ann Arbor, Michigan) and deposited in GenBank.

\section{Taxon sampling and phylogenetic analyses}

An ITS-LSU concatenated dataset including closest hits from megablast searches of the newly generated sequences of $S$. pachyanthicola in GenBank was prepared for analysis. The available LSU sequence DQ408557 belonging to the Chinese strain HKUCC 10835 was retrieved and added to the dataset. Additional sequences from related capnodiaceous families used in previous phylogenetic studies (Crous et al., 2007, 2009b; Quaedvlieg et al., 2014) were also included (Table 1). To test the hypothesis whether S. pachyanthicola shares phylogenetic affinities with the morphologically similar Sporidesmajora pennsylvaniensis, sequences from this and related taxa (Yang et al., 2010; Hongsanan et al., 2017) were downloaded and incorporated in the dataset. Cladosporium macrocarpum (Cladosporiaceae, Capnodiales) was used as outgroup. Sequences from each region were aligned separately using MAFFT v7.310 (Katoh et al., 2002; Katoh \& Standley, 2013) on the online server which automatically selected the FFT-NS-i strategy for both datasets. Alignments were visually examined, manually edited and concatenated in MEGA v6.06 (Tamura et al., 2013). Both maximum likelihood (ML) and Bayesian inference (BI) approaches were employed to reconstruct phylogenetic relationships among taxa. ML analysis was conducted using RAxML v8.2.10 (Stamatakis, 2014) implemented on the CIPRES Science Gateway server (Miller et al. 2010) and employing the GTRGAMMA model. Branch support values (BS) were estimated using the rapid bootstrapping algorithm with 1000 replicates and clades with $\mathrm{BS} \geq$ $70 \%$ were considered well supported (Hillis \& Bull, 1993). jModeltest 2.1.10 v20160303 (Darriba et al., 2012), also on the CIPRES Gateway, was used to obtain 


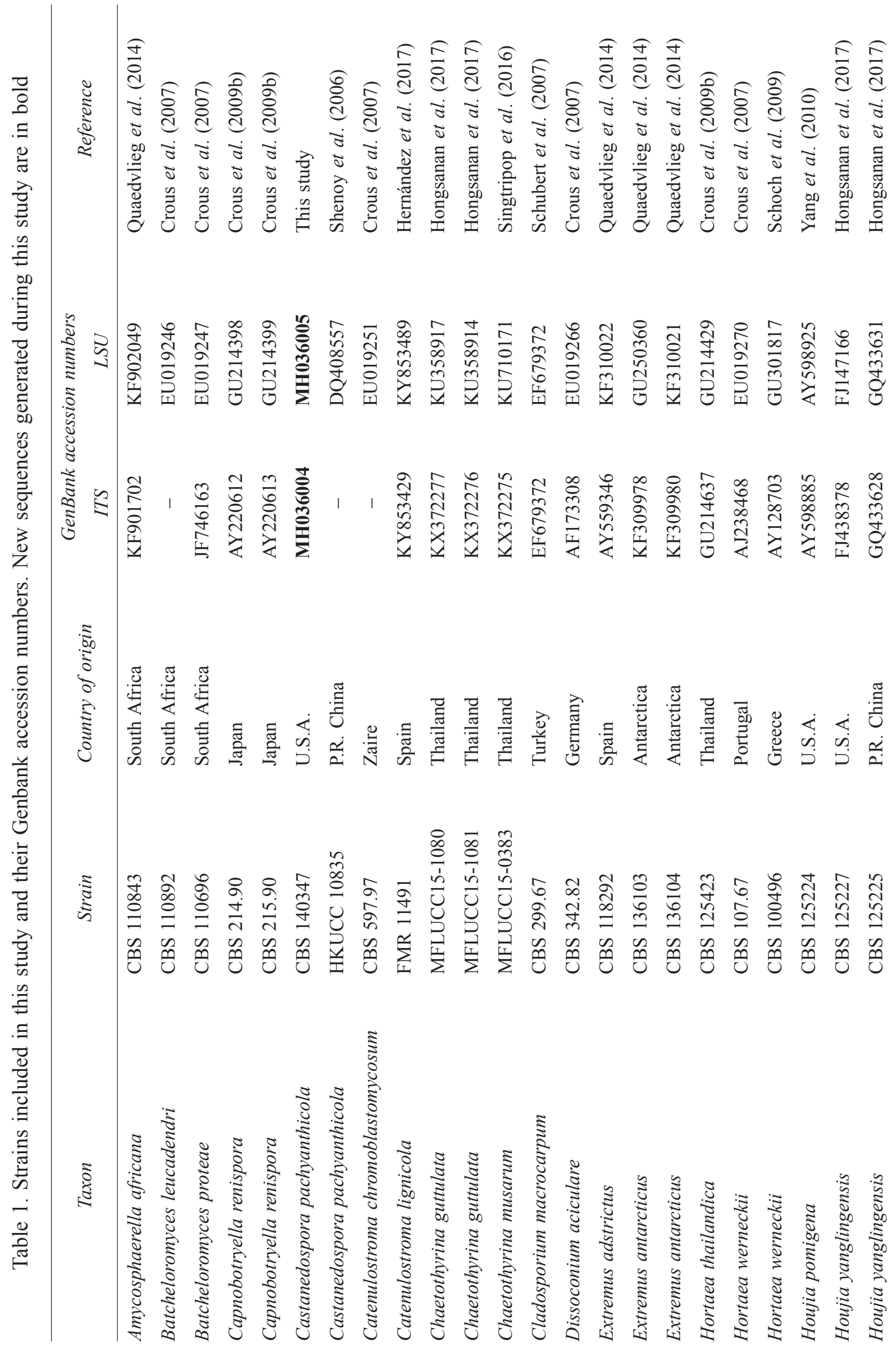




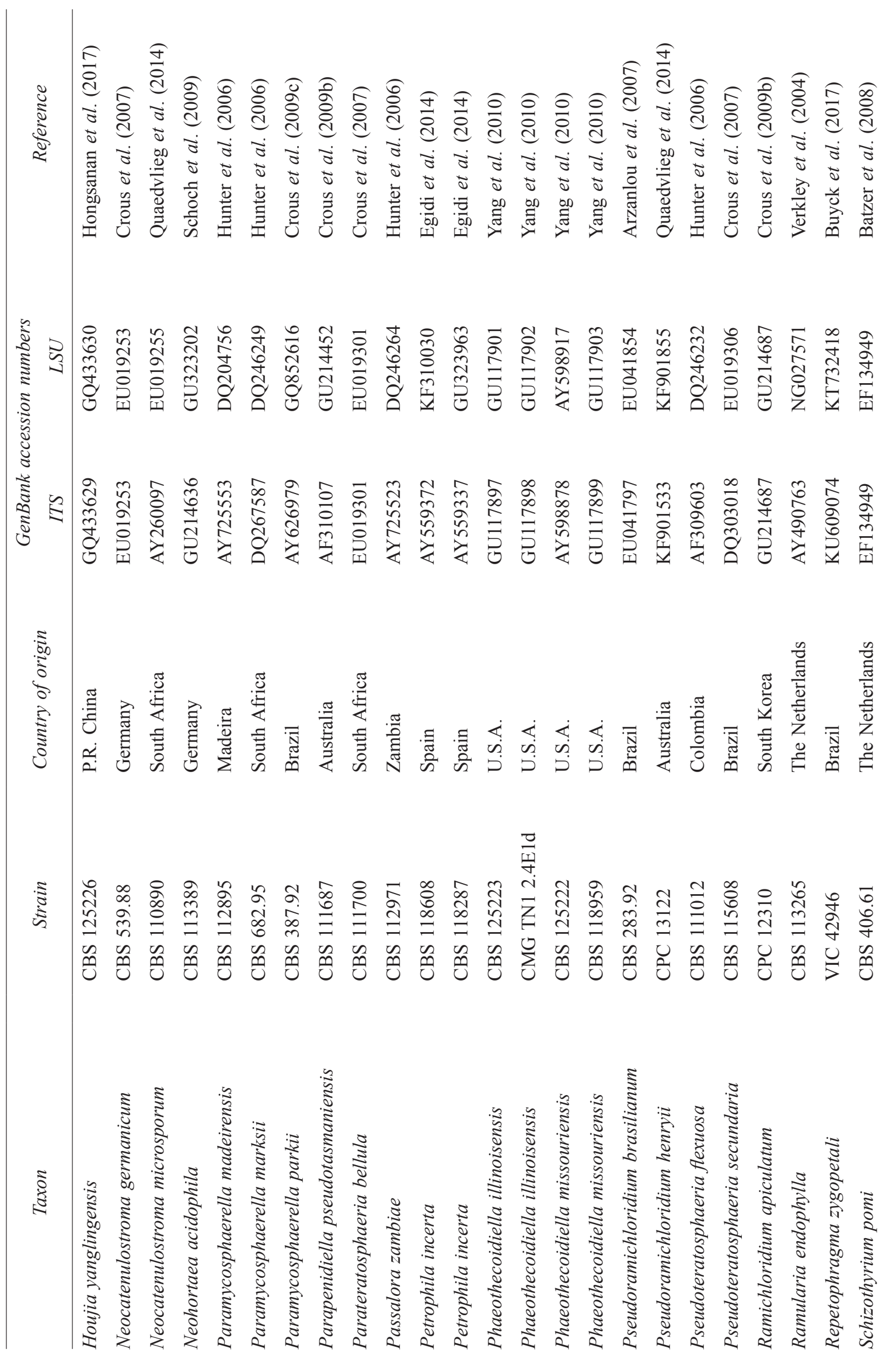




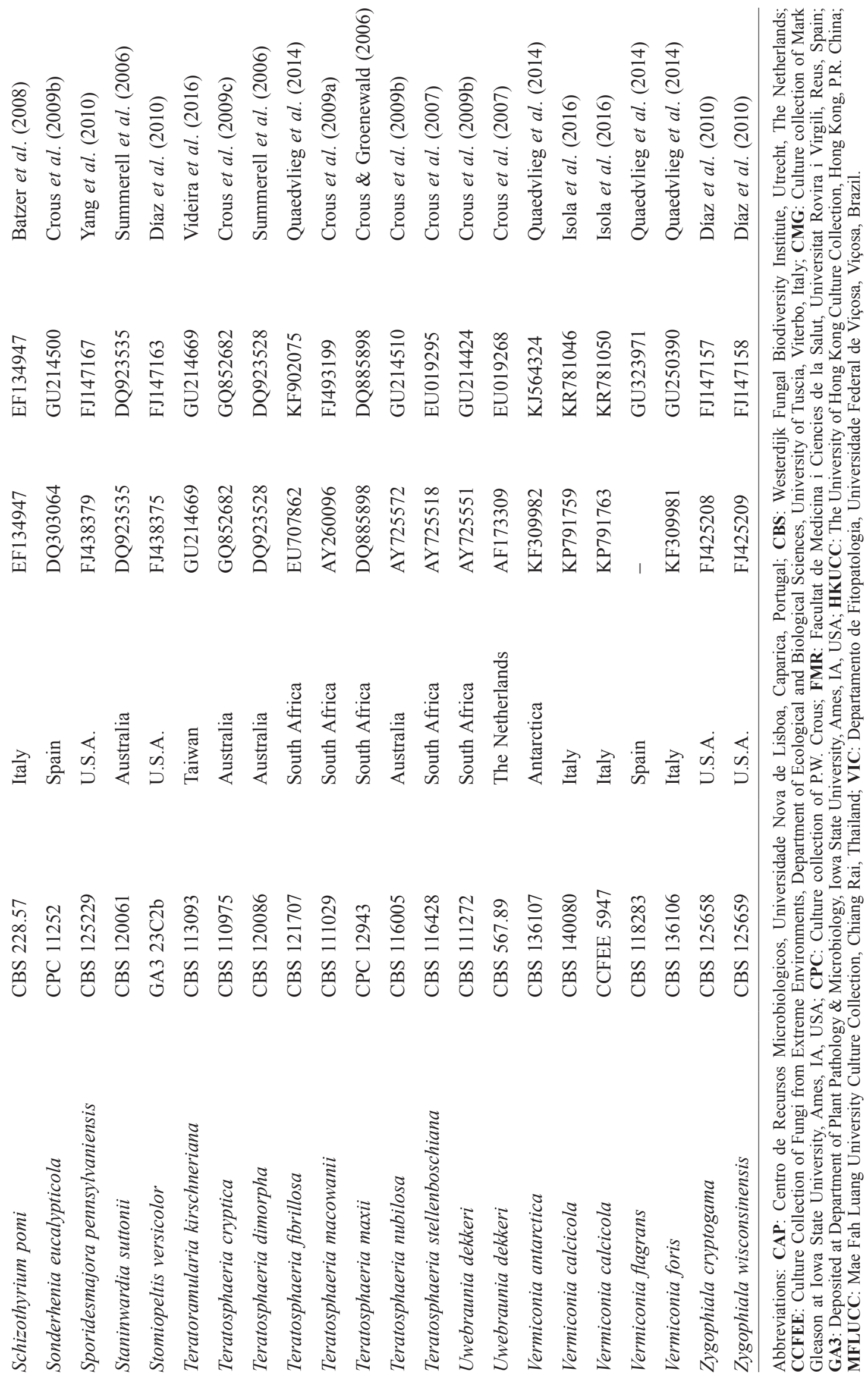


the best fitting substitution model for BI analysis which choose $\mathrm{GTR}+\mathrm{I}+\mathrm{G}$ using the Akaike Information Criterion. Bayesian inference was performed with MrBayes v3.2.6 (Ronquist \& Huelsenbeck, 2003; Ronquist et al., 2012) and consisted of two independent runs of 10 million generations with four Markov Chain Monte Carlo chains set to stop when standard deviation of split frequencies decreased below 0.01 and trees sampled every 100th generation. The first $25 \%$ of trees were removed as burn-in and Bayesian posterior probabilities (BPP) for each node were estimated from the $50 \%$ majority rule consensus of the remaining trees. Convergence of runs was further diagnosed in Tracer v1.6.0 (Rambaut et al., 2014) and clades receiving $\mathrm{BPP} \geq 95 \%$ were considered statistically significant (Alfaro et al., 2003). Trees were viewed in FigTree v1.4.2. (Rambaut, 2009) and edited in MEGA or Inkscape (inkscape.org).

\section{RESULTS}

\section{Phylogenetic analyses}

The newly obtained LSU sequence from the Florida strain of S. pachyanthicola CBS 140347 was 278 bp longer than the one retrieved online from strain HKUCC 10835 isolated in China. They were 99.5\% identical when comparing their overlapping region of $823 \mathrm{bp}$ and differed only by $3 \mathrm{bp}$ and 1 gap. An ITS sequence from the Chinese strain was not available for comparison. The final ITS-LSU dataset consisted of 69 sequences representing 56 taxa including the outgroup and 1974 nucleotide characters, 635 from the ITS alignment and 1339 from the LSU alignment. The RaxML and BI phylogenies were identical in topology and the best-scoring ML tree from the RaxML analysis is shown in Fig. 1. Effective Sample Size values of all relevant parameters were $>200$ as verified in Tracer indicating adequate sampling of the posterior distribution (Drummond et al., 2006; Drummond \& Rambaut, 2009). The backbone of the tree representing the order Capnodiales was strongly supported in the Bayesian analysis (1.0 BPP) but without BS support. Clades corresponding to the different capnodiaceous families included in the analyses were recovered as monophyletic with high support in both trees except Teratosphaeriaceae, similar to previous phylogenetic studies (Crous et al., 2009b; Yang et al., 2010; Quaedvlieg et al., 2014). Both strains of S. pachyanthicola clustered with maximum support (100\% BS, 1.0 BPP). They were sister to Neohortaea acidophila CBS 113389 also with high support (99\% BS, 1.0 BPP). The three strains occurred within a highly supported monophyletic clade (99\% BS, $1.0 \mathrm{BPP})$ formed by members of the family Extremaceae and including the type genus and species Extremus adstrictus (Egidi \& Onofri) Quaedvlieg \& Crous. Sporidesmajora pennsylvaniensis CBS 125229 grouped with high support (99\% BS, 1.0 BPP) with species of another sporidesmium-like genus, Houjia G.Y. Sun \& Crous, represented by $H$. pomigena Batzer \& Crous and $H$. yanglingensis G.Y. Sun \& Crous. They occurred within a monophyletic clade with maximum support (100\% BS, $1.0 \mathrm{BPP})$ representing the family Phaeothecoidiellaceae K.D. Hyde \& Hongsanan and including Phaeothecoidiella missouriensis Batzer \& Crous, its type genus and species. 


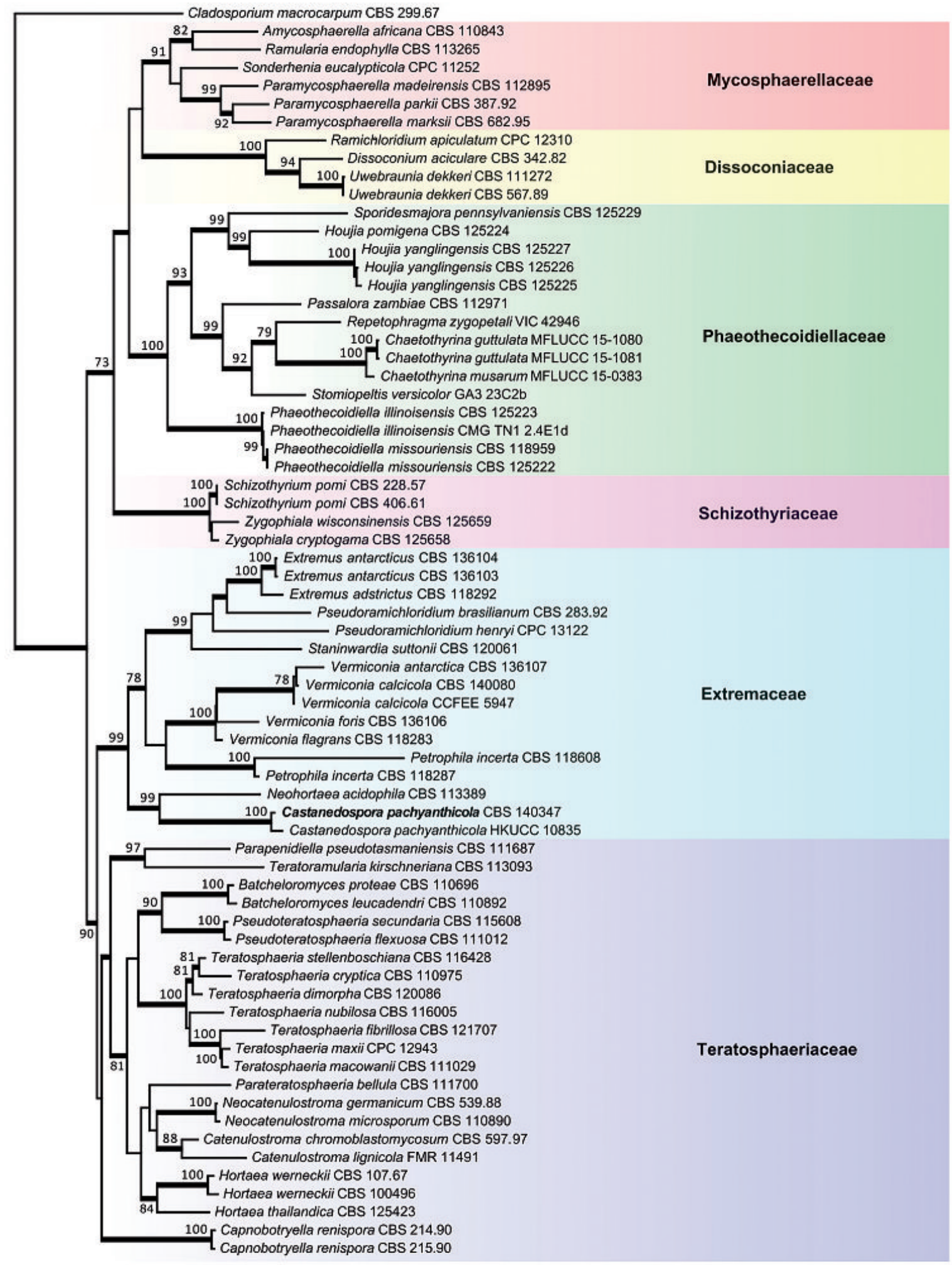

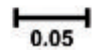

Fig. 1. RaxML phylogenetic tree (ML likelihood $=-18908.58$ ) constructed from a concatenated ITSLSU dataset of 69 sequences belonging to selected families in Capnodiales showing the placement of Castanedospora pachyanthicola. The name of the new strain obtained during this work is highlighted in bold. Numbers above branches represent ML bootstrap support values $\geq 70 \%$ and thickened branches indicate posterior probabilities $\geq 0.95 \%$. 


\section{Taxonomy}

Castanedospora G. Delgado \& A.N. Mill., gen. nov.

MycoBank: MB 824583

Hyphomycetous. Colonies with mycelium partly superficial, partly immersed, composed of branched, septate, pale brown to brown, smooth or finely verruculose hyphae. Conidiophores macronematous, mononematous, simple, cylindrical, smooth, brown, septate, without percurrent extensions. Conidiogenous cells monoblastic, integrated, terminal, cylindrical or doliiform, determinate, brown, apex truncate. Conidia long narrowly obclavate or subcylindrical, attenuated toward the apex, straight or flexuous, multiseptate, pale brown to brown, smooth, apex rounded, basal cell conico-truncate.

Type species: Castanedospora pachyanthicola (R.F. Castañeda \& W.B. Kendr.) G. Delgado \& A.N. Mill.

Etymology: Named in honor of Dr. Rafael F. Castañeda-Ruiz, Cuban mycologist who first described this fungus and who has extensively contributed to the study of tropical hyphomycetes.

Castanedospora pachyanthicola (R.F. Castañeda \& W.B. Kendr.) G. Delgado \& A.N. Mill. comb. nov.

MycoBank: MB 824584

Basionym: Sporidesmium pachyanthicola R.F. Castañeda \& W.B. Kendr., Univ. Waterloo Biol. Ser. 33: 45, 1990.

Colonies growing saprotrophically on natural substrate, inconspicuous, hairy. Mycelium partly superficial, partly immersed, composed of branched, septate, smooth, pale brown to brown hyphae, $1.5-2 \mu \mathrm{m}$ wide. Conidiophores macronematous, mononematous, cylindrical or subcylindrical, straight or flexuous, simple, smooth, brown, 1-7-septate, (8) 10-26 (37) $\times 3.5-5 \mu \mathrm{m}$, often slightly bulbous at their base and up to $6 \mu \mathrm{m}$ wide, without percurrent extensions. Conidiogenous cells monoblastic, integrated, terminal, cylindrical, determinate, brown, 5-7 $\times 3-4 \mu \mathrm{m}$, apex truncate. Conidia narrowly obclavate or subcylindrical, attenuated toward the apex, straight or flexuous, 9-33-euseptate, rarely constricted at one septum, pale brown to brown becoming subhyaline or hyaline towards the apex, smooth, (36) 43-162 (188) × 3-5 $\mu \mathrm{m}$, apex rounded, 1.5-2 $\mu \mathrm{m}$ wide, basal cell conico-truncate. Teleomorph unknown.

Colonies on MEA slow growing, reaching 13-18 mm diam. after one month at $25^{\circ} \mathrm{C}$, circular, gray, felty, raised $2-3 \mathrm{~mm}$, margin entire, reverse black. Colonies on PDA similar to MEA, slow growing, reaching 17-19 mm diam. after one month at $25^{\circ} \mathrm{C}$, sporulation late, starting after two months on both MEA and PDA. Mycelium composed of subhyaline to pale brown, septate, branched, smooth or finely verruculose hyphae, 1.5-3 (4) $\mu \mathrm{m}$ wide. Conidiophores similar to those on natural substrate, solitary or in groups of two, terminal or intercalary on the hyphae, when terminal macro-, semimacro- or micronematous, brown, paler when terminal, 1-8-septate, straight or sometimes flexuous, smooth or verrucose at the base, slightly constricted at septa, (6) 10-45 (60) $\times$ 3-6 $\mu \mathrm{m}$. Conidiogenous cells doliiform or cylindrical, often terminal on the hyphae and narrowly cylindrical or subcylindrical, 5-8 $\times 3-4 \mathrm{~mm}$, apex truncate, $2-3 \mu \mathrm{m}$ wide. Conidia long narrowly obclavate to long cylindrical, pale brown, (13) 31-200 (219) septate, (146) 172-825 (942) $\mu \mathrm{m}$ long, 2-5 (6) $\mu \mathrm{m}$ wide, $2-2.5 \mu \mathrm{m}$ wide at the apex, rarely slightly constricted at one 
Fig. 2. Castanedospora pachyanthicola (from epitype). Hyphae, conidiophores, conidiogenous cells and conidia on MEA. Scale bar $=30 \mu \mathrm{m}$.

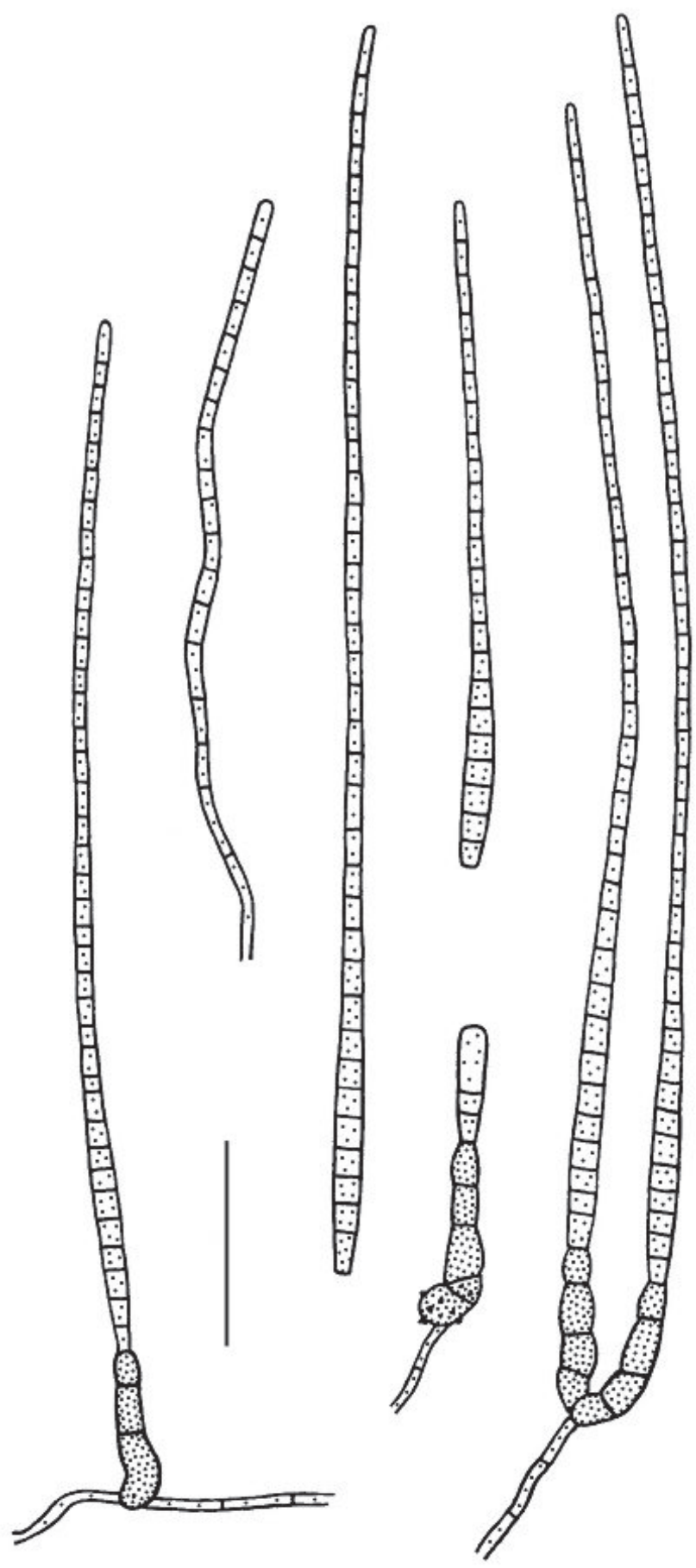

septum, some cells swollen, 0-3-septate and 4.5-6 $\mu \mathrm{m}$ wide, basal cell cylindrical or conico-truncate.

Typification: Holotype of S. pachyanthicola: Cuba, Pinar del Rio, Viñales, on dead leaves of Pachyanthus poiretii, leg. R.F. Castañeda, 27 March 1989, INIFAT C89/138. Epitype designated here: United States, Florida, Broward Co., Fort Lauderdale, $26^{\circ} 12^{\prime} 20.5^{\prime} \mathrm{N} 80^{\circ} 09^{\prime} 50.6^{\prime \prime} \mathrm{W}, 2.9 \mathrm{~m}$ asl., on petiole of dead leaf of Sa. palmetto (Walter) Lodd. ex Schult. \& Schult. (Arecaceae), 25 January 2014, leg. J.M. Pérez (BPI 892972B; isoepitype ILLS 80801; ex-epitype strain CBS 140347; ex-epitype sequences: ITS MH036004, LSU MH036005). 


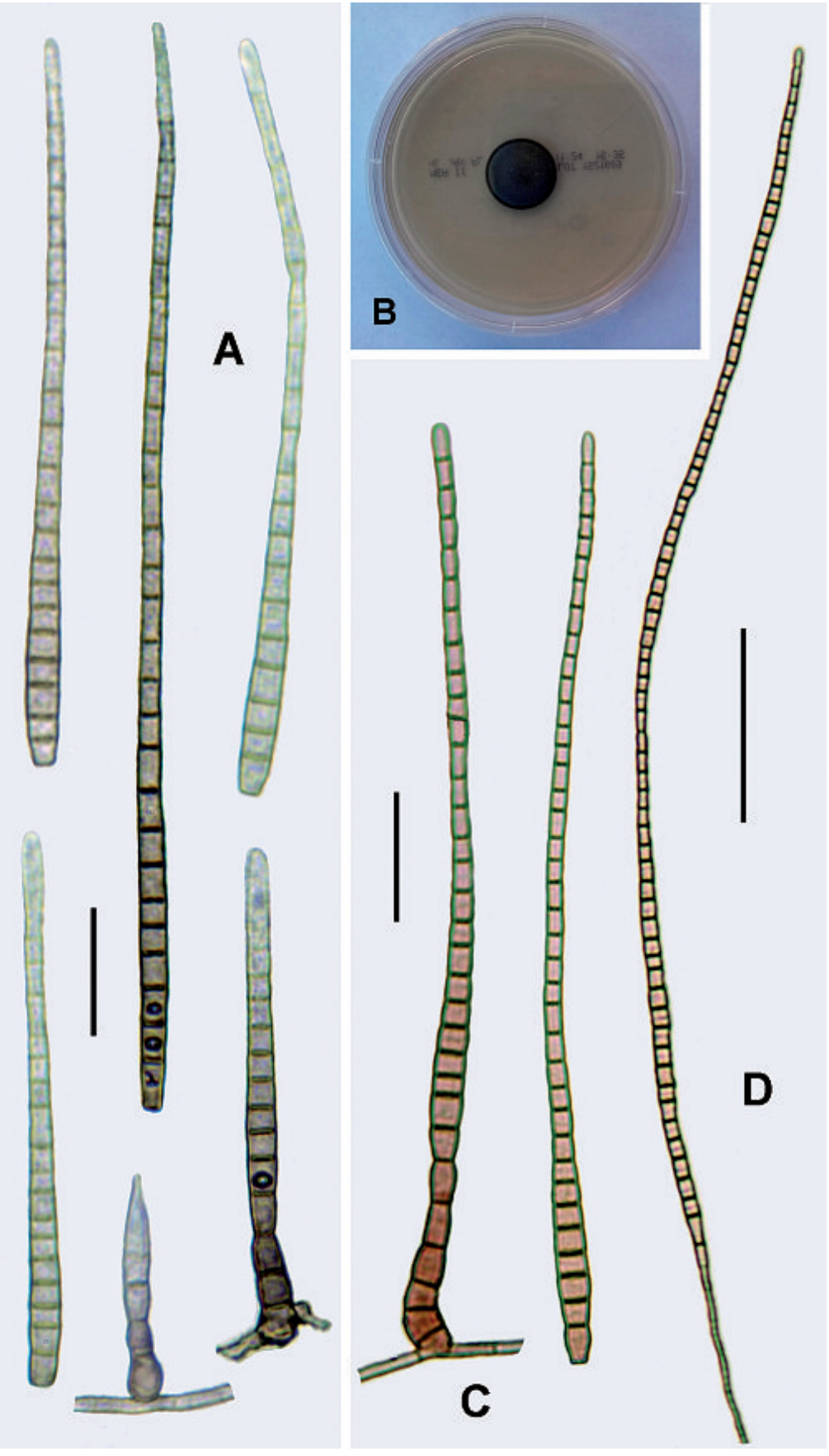

Fig. 3. Castanedospora pachyanthicola (from epitype). A. Conidiophores and conidia on natural substrate. B. Colony on MEA after one month at $25^{\circ} \mathrm{C}$. C. Conidiophore and conidia on MEA. D. Terminal conidium on the hyphae. Scale bars: A, $\mathrm{C}=20 \mu \mathrm{m}, \mathrm{D}=50 \mu \mathrm{m}$.

Notes: The holotype specimen from Cuba (Castañeda \& Kendrick, 1990) has slightly longer conidiophores $(30-75 \mu \mathrm{m})$ and shorter conidia $(50-140 \mu \mathrm{m})$ compared with the material studied here on natural substrate. Other specimens previously described from identical palm tree species in Florida (Delgado, 2009) are morphologically similar to the present collection. The Chinese specimen WU 1595 (Wu \& Zhuang, 2005) and the source of strain HKUCC 10835 (Shenoy et al., 2006) has shorter conidiophores $(20-40 \mu \mathrm{m})$ and shorter conidia $(35-90 \mu \mathrm{m})$. Specimens collected in Nicaragua possessed shorter conidiophores $(14-32 \mu \mathrm{m})$ and the shortest conidia of all $(24-57 \mu \mathrm{m})$ with fewer, 5-12 septa in each conidium (Delgado \& Koukol, 2016). 


\section{DISCUSSION}

The morphological study of the specimen of S. pachyanthicola from Florida shows that its characteristics agree well with the protologue of the species despite some minor differences in conidiophore and conidial length. These morphological differences may be attributed to intraspecific variability. The holotype material from Cuba no longer contains conidial structures and the only available microscope slide preparation is lost (Castañeda, pers. comm.). There is no preserved ex-type living culture and therefore the species $S$. pachyanthicola is epitypified with the specimen collected in Florida. On artificial media, the strain CBS 140347 obtained from this specimen often produced conidia reaching more than $900 \mu \mathrm{m}$ long and having up to 219 septa (Fig. 3D) being considerably longer than conidia on natural substrate. Unfortunately, morphological data are not available for the other existing strain of the fungus, HKUCC 10835, which was not available upon request precluding comparison of morphology and growth characteristics between the two isolates. Such differences in conidiophore and conidial length are apparently not uncommon among sporidesmium-like fungi when growing in artificial conditions. Matsushima (1993) commented on the highly variable length of conidia in Repetophragma filisporum (Matsush.) R.F. Castañeda, McKenzie \& K.D. Hyde (三 S. filisporum Matsush.), shorter on natural substrate $(27-70 \mu \mathrm{m})$ but longer when growing on a piece of steam-sterilized banana leaf on Corn Meal Agar (50-300 $\mu \mathrm{m})$. Yang et al. (2017) attributed the significant differences in conidial length among specimens of Distoseptispora multiseptata J. Yang \& K.D. Hyde to the length of incubation. Conidia of the holotype specimen reached up to $380 \mu \mathrm{m}$ in length while conidia of a second collection measured up to $700 \mu \mathrm{m}$ in length. According to $\mathrm{Wu} \& \mathrm{Zhuang}$ (2005) most sporidesmium-like taxa can be cultured on Potato Dextrose Agar. However, they are largely underrepresented in international culture collections and only until recently their cultural characteristics started to be recorded on a regular basis with the advent of molecular studies in the group preceded by isolation on agar media. As a result, the taxonomic value of morphological differences between growth under natural and artificial conditions, if any, is still unclear.

Recently, the family Sporidesmiaceae was resurrected in Sordariomycetes for a clade containing several sporidesmium-like taxa morphologically resembling S. ehrenbergii, the lectotype species of the genus (Su et al., 2016). This was a major step toward clarifying phylogenetic relationships within the large and polyphyletic genus Sporidesmium and its allies. The concept, however, is still a working hypothesis in need of testing pending the availability of fresh collections or isolates of $S$. ehrenbergii, and therefore the phylogeny of the genus still remains unsettled (Crous et al., 2017). Nevertheless, the taxonomic status of phylogenetically distant taxa previously placed in Sporidesmium such as S. pachyanthicola (Castañeda \& Kendrick, 1990) can be reassessed now with more confidence. Castanedospora is introduced as a new monotypic genus to accommodate this taxon based on a freshly collected specimen and new morphological, cultural and molecular data. Our phylogenetic analyses confirmed its previously known placement within Capnodiales (Dothideomycetes) (Shenoy et al., 2006), distant from Sporidesmiaceae sensu stricto in Sordariomycetes. They also revealed additional evidence to support its familial position outside the broadly defined Teratosphaeriaceae and within the related Extremaceae. Quaedvlieg et al. (2014) introduced Extremaceae to accommodate teratosphaeriaceous asexual fungi known to occur in extreme habitats such as rocks surfaces or within rocks in the Mediterranean region or Antarctica (Ruibal et al., 
2009). Current family members are morphologically and ecologically highly diverse being filamentous or yeast-like and ranging from lichenicolous, epiphyllous, and acidophilic or occurring as endophytes, plant pathogens or saprobes. The latter taxa include Pseudoramichloridium brasilianum, isolated from forest soil in Brazil (Arzanlou et al., 2007), or P. henryi, isolated from leaf spots of Corymbia henryi (S.T. Blake) K.D. Hill \& L.A.S. Johnson in Australia (Cheewangkoon et al., 2009), and now C. pachyanthicola recorded on miscellaneous plant debris. The family diagnosis included so far sympodially proliferating conidiogenous cells with or without a terminal rachis that can be subdenticulate and conidia rarely with 1-2 transverse septa (Quaedvlieg et al., 2014). With the addition of Castanedospora, this concept is expanded to incorporate monoblastic, determinate conidiogenesis and simple, multiseptate conidia. In the present ITS-LSU phylogeny the closest relative of C. pachyanthicola was Neohortaea acidophila (三 Hortaea acidophila Hölker, Bend, Pracht, Tetsch, Tob. Müll., M. Höfer \& de Hoog), an extremophilic black yeast isolated from an extract of lignite rock containing humic and fulvic acids at pH 0.6 (Hölker et al., 2004). Quaedvlieg et al. (2014) introduced Neohortaea to accommodate this acidophilic species in a genus morphologically similar but phylogenetically distinct from Hortaea $(H$.$) Nishim. \& Miyaji in Teratosphaeriaceae.$ Surprisingly, the taxon was not included in their extensive multigene trees and its position was left inconclusive. Our phylogeny, on the other hand, supports its placement in Extremaceae distant from other Hortaea species in Teratosphaeriacae such as $H$. werneckii (Horta) Nishim. \& Miyaji, the generic type, and $H$. thailandica Crous \& K.D. Hyde (Fig. 1). Crous et al. (2009b) also showed a close relationship between $N$. acidophila and $C$. pachyanthicola in a single gene analysis using LSU sequence data. Their different morphologies and contrasting ecologies are consistent with the diversity shown in Extremaceae, but additional taxon sampling of family members together with other phylogenetic markers are needed to clarify their intriguing relationship.

A possible affinity between Castanedospora and Sporidesmajora was not supported in our analyses despite their morphological resemblance in culture and phylogenetic placement in Capnodiales. This monotypic sporidesmium-like genus, typified by Sp. pennsylvaniensis, was first isolated from the sooty blotch and flyspeck (SBFS) disease complex on apple in the state of Pennsylvania, U.S.A (Yang et al., 2010). It is characterized by forming long narrowly obclavate, multiseptate conidia when grown on culture media that can reach up to $350 \mu \mathrm{m}$ on oatmeal agar. Our family-level phylogeny clearly shows that Castanedospora and Sporidesmajora are not congeneric but phylogenetically distant with the latter belonging to Phaeothecoidiellaceae (Hongsanan et al. 2017). This capnodiaceous family was recently introduced for a well-supported clade tentatively named 'Micropeltidaceae' by Yang et al. (2010) including Sporidesmajora. It is based on the genus Phaeothecoidiella Batzer \& Crous whose two species produce pigmented endoconidia that resemble phragmospores covered by a prominent mucilaginous sheath inside hyphae. Sporidesmajora is closely related with Houjia (Seifert et al., 2011), another sporidesmium-like but morphologically different genus, within Phaeothecoidiellaceae. Its two species are characterized by conidiophores reduced to conidiogenous cells and short, broadly ellipsoid to subcylindrical or obclavate, transversely and obliquely septate conidia tapering to a cuneiform basal cell possessing a truncate hilum. The family also includes morphologically disparate epiphytic species producing small, flattened thyriothecial ascomata associated with SBFS diseases of economic fruits such as mango and banana e.g. Chaetothyrina Theiss (Singtripop et al., 2016; Hongsanan et al., 2017). Recently, Buyck et al. (2017) described Repetophragma 
zygopetali O.L. Pereira, Meir. Silva \& R.F. Castañeda as belonging to the 'Micropeltidaceae' clade mentioned above. In our phylogeny this taxon is actually a member of Phaeothecoidiellaceae (Fig. 1) suggesting that the sporidesmium-like morphology, although still poorly sampled at the ordinal level, might be rather widespread within Capnodiales.

Acknowledgments. Special thanks are due to Rafael F. Castañeda-Ruiz (INIFAT, Cuba) and Scott Redhead (DAOM) for searching the holotype of S. pachyanthicola in their collections and clarifying the typification status of the specimen studied here. José M. Pérez (University of Florida) is also thanked for collecting the specimen source of this work. Michael Manning and Kamash Ramanathan (EMLab P\&K) are acknowledged for provision of laboratory facilities.

\section{REFERENCES}

ALFARO M.E., ZOLLER S. \& LUTZONI F., 2003 — Bayes or bootstrap? A simulation study comparing the performance of Bayesian Markov chain Monte Carlo sampling and bootstrapping in assessing phylogenetic confidence. Molecular Biology and Evolution 20: 255-266.

ARZANLOU M., GROENEWALD J.Z., GAMS W., BRAUN U., SHIN H.-D \& CROUS P.W., 2007 - Phylogenetic and morphotaxonomic revision of Ramichloridium and allied genera. Studies in Mycology 58: 57-93.

BATZER J.C, ARIAS M.M., HARRINGTON T.C., GLEASON M.L., GROENEWALD J.Z. \& CROUS P.W., 2008 - Four species of Zygophiala (Schizothyriaceae, Capnodiales) are associated with the sooty blotch and flyspeck complex on apple. Mycologia 100: 246-258.

BUYCK B., DUHEM B., DAS K., JAYAWARDENA R.S., NIVEIRO N., PEREIRA O.L., PRASHER I.B., ADHIKARI S., ALBERTÓ E.O., BULGAKOV T.S., CASTAÑEDARUIZ R.F., HEMBROM M.E., HYDE K.D., LEWIS D.P., MICHLIG A., NUYTINCK J., PARIHAR A., POPOFF O.F., RAMIREZ N.A., DA SILVA M., VERMA R.K. \& HOFSTETTER V., 2017 - Fungal Biodiversity Profiles 21-30. Cryptogamie, Mycologie 38: 101-146.

CASTAÑEDA R.F. \& KENDRICK B., 1990 - Conidial fungi from Cuba: II. University of Waterloo Biology Series 33: 1-62.

CHEEWANGKOON R., GROENEWALD J.Z., SUMMERELL B.A., HYDE K.D., TO-ANUN C., CROUS P.W., 2009 - Myrtaceae, a cache of fungal biodiversity. Persoonia 23: 55-85.

CHOI Y.W., HYDE K.D. \& HO W.H., 1999 - Single spore isolation of fungi. Fungal Diversity 3: 29-38.

CROUS P.W., 2008 - Sporidesmium knawiae Crous, sp. nov. Fungal Planet 29: 1-2.

CROUS P.W., BRAUN U. \& GROENEWALD J.Z., 2007 - Mycosphaerella is polyphyletic. Studies in Mycology 58: 1-32.

CROUS P.W. \& GROENEWALD J.Z., 2006 - Mycosphaerella maxii. Fungal Planet 6: 1-2.

CROUS P.W., GROENEWALD J.Z., SUMMERELL B.A., WINGFIELD B.D. \& WINGFIELD M.J., 2009a - Co-occurring species of Teratosphaeria on Eucalyptus. Persoonia 22: 38-48.

CROUS P.W., SCHOCH C.L., HYDE K.D., WOOD A.R., GUEIDAN C., DE HOOG G.S. \& GROENEWALD J.Z., 2009b — Phylogenetic lineages in the Capnodiales. Studies in Mycology 64: 17-47.

CROUS P.W., SUMMERELL B.A., CARNEGIE A.J., WINGFIELD M.J., HUNTER G.C., BURGESS T.I., ANDJIC V., BARBER P.A. \& GROENEWALD J.Z., 2009c — Unravelling Mycosphaerella: do you believe in genera? Persoonia 23: 99-118.

CROUS P.W., WINGFIELD M.J., BURGESS T.I., CARNEGIE A.J., HARDY G.E.ST.J., SMITH D., SUMMERELL B.A., CANO-LIRA J.F., GUARRO J., HOUBRAKEN J., LOMBARD L., MARTÍN M.P., SANDOVAL-DENIS M., ALEXANDROVA A.V., BARNES C.W., BASEIA I.G., BEZERRA J.D.P., GUARNACCIA V., MAY T.W., HERNÁNDEZ M., STCHIGEL A.M., MILLER A.N., ORDOÑEZ M.E., ABREU V.P., ACCIOLY T., AGNELlO C., AGUSTIN-COLMÁN A., ALBUQUERQUE C.C., ALFREDO D.S., ALVARADO P., ARAÚJO-MAGALHÃES G.R., ARAUZO S., ATKINSON T., BARILI A., BARRETO R.W., BEZERRA J.L., CABRAL T.S., CAMELLO-RODRÍGUEZ F., 
CRUZ R.H.S.F., DANIËLS, P.P., DA SILVA B.D.B., DE ALMEIDA D.A.C., DE CARVALHOJÚNIOR A.A., DECOCK C.A., DELGAT L., DENMAN S., DIMITROV R.A., EDWARDS J., FEDOSOVA A.G., FERREIRA R.J., FIRMINO A.L., FLORES J.A., GARCÍA D., GENÉ J., GIRALDO A., GÓIS J.S., GOMES A.A.M., GONÇALVES C.M., GOULIAMOVA D.E., GROENEWALD M., GUÉORGUIEV B.V., GUEVARA-SUAREZ M., GUSMÃO L.F.P., HOSAKA K., HUBKA V., HUHNDORF S.M., JADAN M., JURJEVIĆ Ž., KRAAK B., KUČERA V., KUMAR T.K.A., KUŠAN I., LACERDA S.R., LAMLERTTHON S., LISBOA W.S., LOIZIDES M., LUANGSA-ARD J.J., LYSKOVÁ P., MAC CORMACK W.P., MACEDO D.M., MACHADO A.R., MALYSHEVA E.F., MARINHO P., MATOČEC N., MEIJER M., MEŠIĆ A., MONGKOLSAMRIT S., MOREIRA K.A., MOROZOVA O.V., NAIR K.U., NAKAMURA N., NOISRIPOOM W., OLARIAGA I., OLIVEIRA R.J.V., PAIVA L.M., PAWAR P., PEREIRA O.L., PETERSON S.W., PRIETO M., RODRÍGUEZANDRADE E., ROJO DE BLAS C., ROY M., SANTOS E.S., SHARMA R., SILVA G.A., SOUZA-MOTTA C.M., TAKEUCHI-KANEKO Y., TANAKA C., THAKUR A., SMITH M.TH., TKALČEC Z., VALENZUELA-LOPEZ N., VAN DER KLEIJ P., VERBEKEN A., VIANA M.G., WANG X.W. \& GROENEWALD J.Z., 2017 — Fungal Planet description sheets: 625-715. Persoonia 39: 270-467.

DARRIBA D., TABOADA G.L., DOALLO R. \& POSADA D., 2012 — jModelTest 2: more models, new heuristics and parallel computing. Nature Methods 9: 772.

DELGADO G., 2008 - South Florida microfungi: a new species of Stanjehughesia (hyphomycetes) from Sabal palm. Mycotaxon 103: 229-234.

DELGADO G., 2009 — South Florida microfungi: Veramycella bispora, a new palmicolous anamorphic genus and species, with some new records for the continental USA. Mycotaxon 107: 357-373.

DELGADO G., 2010 - South Florida microfungi: Kalamarospora multiflagellata gen. et sp. nov. (hyphomycetes), with additional new records from USA. Mycotaxon 114: 231-246.

DELGADO G., 2013 — South Florida microfungi: a new species of Ellisembia (hyphomycetes) with new records from the U.S.A. Mycotaxon 123: 445-450.

DELGADO G., 2014 - South Florida microfungi: Linkosia longirostrata, a new hyphomycete on paurotis palm. Mycotaxon 129: 41-46.

DELGADO G. \& KOUKOL O., 2016 - Microfungi from Nicaragua in a historical collection kept at the herbarium of the Charles University in Prague. Cryptogamie, Mycologie 37: 15-36.

DÍAZ M.M., BATZER, J.C., HARRINGTON T.C., WONG A.W., BOST S.C., COOLEY D.R., ELLIS M.A., HARTMAN J.R., ROSENBERGER D.A., SUNDIN G.W., SUTTON T.B., TRAVIS J.W., WHEELER M.J., YODER K.S. \& GLEASON M.L., 2010 — Diversity and biogeography of sooty blotch and flyspeck fungi on apple in the eastern and midwestern United States. Phytopathology 100: 345-355.

DRUMMOND A.J., HO S.Y.W, PHILLIPS M.J. \& RAMBAUT A., 2006 - Relaxed phylogenetics and dating with confidence. PLoS Biology 4(5): e88. doi: 10.1371/journal.pbio.0040088

DRUMMOND A.J. \& RAMBAUT A., 2009 - 18 - Bayesian evolutionary analysis by sampling trees. In: LEMEY P., SALEMI M. \& VANDAMME A.M. (eds) The Phylogenetic Handbook: A practical approach to phylogenetic analysis and hypothesis testing, $2^{\text {nd }}$ Edition. Cambridge University Press, Cambridge, pp 564-591.

EGIDI E., DE HOOG G.S., ISOLA D., ONOFRI S., QUAEDVLIEG W., DE VRIES M., VERKLEY G.J.M., STIELOW J.B., ZUCCONI L. \& SELBMANN L., 2014 — Phylogeny and taxonomy of meristematic rock-inhabiting black fungi in the Dothideomycetes based on multi-locus phylogenies. Fungal Diversity 65: 127-165.

ELLIS M.B., 1958 - Clasterosporium and some allied Dematiaceae-Phragmosporae. I. Mycological Papers 7: 1-89.

GARDES M. \& BRUNS T.D., 1993 - ITS primers with enhanced specificity for basidiomycetes application to the identification of mycorrhizae and rusts. Molecular Ecology 2: 113-118.

HERNÁNDEZ A. \& SUTTON B.C., 1997 - Imimyces and Linkosia, two genera segregated from Sporidesmium sensu lato, and redescription of Polydesmus. Mycological Research 101: 201-209.

HERNÁNDEZ M., GENÉ J., CASTAÑEDA R.F., MENA J., CROUS P.W. \& GUARRO J., 2017 Phylogeny of saprobic microfungi from Southern Europe. Studies in Mycology 86: 53-97.

HILLIS D.M. \& BULL J.J., 1993 - An empirical test of bootstrapping as a method for assessing confidence in phylogenetic analysis. Systematic Biology 42: 182-192.

HÖLKER U., BEND J., PRACHT R., TETSCH L., MÜLLER T., HÖFER M. \& DE HOOG G.S., 2004 - Hortaea acidophila, a new acid-tolerant black yeast from lignite. Antonie van Leeuwenhoek 86: 287-294. 
HONGSANAN S., ZHAO R.L. \& HYDE K.D., 2017 - A new species of Chaetothyrina on branches of mango, and introducing Phaeothecoidiellaceae fam. nov. Mycosphere 8: 137-146.

HUGHES S.J., 1979 - Relocation of species of Endophragmia auct. with notes on relevant generic names. New Zealand Journal of Botany 17: 139-188.

HUNTER G.C., WINGFIELD B.D., CROUS P.W. \& WINGFIELD M.J., 2006 - A multi-gene phylogeny for species of Mycosphaerella occurring on Eucalyptus leaves. Studies in Mycology 55: 147-161.

HYDE K.D., HONGSANAN S., JEEWON R., BHAT D.J., MCKENZIE E.H.C., JONES E.B.G., PHOOKAMSAK R., ARIYAWANSA H.A., BOONMEE S., ZHAO Q., ABDEL-AZIZ F.A., ABDEL-WAHAB M.A., BANMAI S., CHOMNUNTI P., CUI B.K., DARANAGAMA D.A., DAS K., DAYARATHNE M.C., DE SILVA N.I., DISSANAYAKE A.J., DOILOM M., EHANAYAKA A.H., GIBERTONI T.B., GÓES-NETO A., HUANG S.K., JAYASIRI S.C., JAYAWARDENA R.S., KONTA S., LEE H.B., LI W.J., LIN C.G., LIU J.K., LU Y.Z., LUO Z.L., MANAWASINGHE I.S., MANIMOHAN P., MAPOOK A., NISKANEN T., NORPHANPHOUN C., PAPIZADEH M., PERERA R.H., PHUKHAMSAKDA C., RICHTER C., SANTIAGO A.L.C.M.D.A., DRECHSLER-SANTOS E.R., SENANAYAKE I.C., TANAKA K., TENNAKOON T.M.D.S., THAMBUGALA K.M., TIAN Q., TIBPROMMA S., THONGBAI B., VIZZINI A., WANASINGHE D.N., WIJAYAWARDENE N.N., WU H.X., YANG J., ZENG X.Y., ZHANG H., ZHANG J.F., BULGAKOV T.S., CAMPORESI E., BAHKALI A.H., AMOOZEGAR M.A., ARAUJONETA L.S., AMMIRATI J.F., BAGHELA A., BHATT R.P., BOJANTCHEV D., BUYCK B., DE SILVA G.A., DE LIMA C.L.F., DE OLIVEIRA R.J.V., DE SOUZA C.A.F., DAI Y.C., DIMA B., DUONG T.T., ERCOLE E., MAFALDA-FREIRE F., GHOSH A., HASHIMOTO A., KAMOLHAN S., KANG J.C., KARUNARATHNA S.C., KIRK P.M., KYTÖVUORI I., LANTIERI A., LIIMATAINEN K., LIU Z.Y., LIU X.Z., LÜCKING R., MEDARDI G., MORTIMER P.E., NGUYEN T.T.T., PROMPUTTHA I., RAJ K.N.A., RECK M.A., LUMYONG S., SHAHZADEH-FAZELI S.A., STADLER M., SOUDI M.R., SU H.Y., TAKAHASHI T., TANGTHIRASUNUN N., UNIYAL P., WANG Y., WEN T.C., XU J.C., ZHANG Z.K., ZHAO Y.C., ZHOU J.L. \& ZHU L., 2016 - Fungal diversity notes 367-490: taxonomic and phylogenetic contributions to fungal taxa. Fungal Diversity 80: 1-270.

HYDE K.D., MAHARACHCHIKUMBURA S.S.N., HONGSANAN S., SAMARAKOON M.C., LÜCKING R., PEM D., HARISHCHANDRA D., JEEWON R., ZHAO R.-L., XU J.-C., LIU J.-K., AL-SADI A.M., BAHKALI A.H. \& ELGORBAN A.M., 2017 — The ranking of fungi: a tribute to David L. Hawksworth on his 70th birthday. Fungal Diversity 84: 1-23.

ISOLA D., ZUCCONI L., ONOFRI S., CANEVA G., DE HOOG G.S. \& SELBMANN L., 2016 Extremotolerant rock inhabiting black fungi from Italian monumental sites. Fungal Diversity 76: 75-96.

KATOH K., MISAWA K., KUMA K. \& MIYATA T., 2002 - MAFFT: a novel method for rapid multiple sequence alignment based on fast Fourier transform. Nucleic Acids Research 30: 3059-3066.

KATOH K. \& STANDLEY D.M., 2013 - MAFFT Multiple Sequence Alignment Software version 7: Improvements in performance and usability. Molecular Biology and Evolution 30: 772-780.

LI JF., BHAT D.J., PHOOKAMSAK R., MAPOOK A., LUMYONG S. \& HYDE K.D., 2016 Sporidesmioides thailandica gen. et sp. nov. (Dothideomycetes) from northern Thailand. Mycological Progress 15: 1169-1178.

MA Y.R., XIA J.W., GAO J.M., LI Z. \& ZHANG X.G., 2016 - Anacacumisporium, a new genus based on morphology and molecular analyses from Hainan, China. Cryptogamie, Mycologie 37: 45-59.

MATSUSHIMA T., 1993 - Matsushima Mycological Memoirs No. 7: 1-75.

MILLER M.A., PFEIFFER W. \& SCHWARTZ T., 2010 - Creating the CIPRES Science Gateway for inference of large phylogenetic trees. In: Proceedings of the Gateway Computing Environments Workshop (GCE), 14 Nov. 2010, New Orleans, pp. 1-8.

PROMPUTTHA I. \& MILLER A.N., 2010 - Three new species of Acanthostigma (Tubeufiaceae, Dothideomycetes) from Great Smoky Mountains National Park. Mycologia 102: 574-587.

QUAEDVLIEG W., BINDER M., GROENEWALD J.Z., SUMMERELL B.A., CARNEGIE A.J., BURGESS T.I. \& CROUS P.W., 2014 — Introducing the Consolidated Species Concept to resolve species in the Teratosphaeriaceae. Persoonia 33: 1-40.

RAMBAUT A., 2009 - FigTree v1.4: tree figure drawing tool. Available at http://tree.bio.ed.ac.uk/ software/figtree/

RAMBAUT A., SUCHARD M.A., XIE D. \& DRUMMOND A.J., 2014 - Tracer v1.6. Available at http://tree.bio.ed.ac.uk/software/tracer/ 
REBLOVÁ M., 1999 - Studies in Chaetosphaeria sensu lato III. Umbrinosphaeria gen. nov. and Miyoshiella with Sporidesmium anamorphs. Mycotaxon 71: 13-43.

REHNER S.A. \& SAMUELS G.J., 1995 - Molecular systematics of the Hypocreales: a teleomorph gene phylogeny and the status of their anamorphs. Canadian Journal of Botany 73(S1): 816-823.

RONQUIST F. \& HUELSENBECK J.P., 2003 - MrBayes 3: Bayesian phylogenetic inference under mixed models. Bioinformatics 19: 1572-1574.

RONQUIST F., TESLENKO M., VAN DER MARK P., AYRES D.L., DARLING A., HONNA S., LARGET B., LIU L., SUCHARD M.A. \& HUELSENBECK J.P., 2012 — MrBayes 3.2: Efficient Bayesian phylogenetic inference and model choice across a large model space. Systematic Biology 61: 539-542.

RUIBAL C., GUEIDAN C., SELBMANN L., GORBUSHINAA.A., CROUS P.W., GROENEWALD J.Z., MUGGIA L., GRUBE M., ISOLA D., SCHOCH C.L., STALEY J.T., LUTZONI F. \& DE HOOG G.S., 2009 - Phylogeny of rock-inhabiting fungi related to Dothideomycetes. Studies in Mycology 64: 123-133.

SCHOCH C.L., CROUS P.W., GROENEWALD J.Z., BOEHM E.W.A., BURGESS T.I., DE GRUYTER J., DE HOOG G.S., DIXON L.J., GRUBE M., GUEIDAN C., HARADA Y., HATAKEYAMA S., HIRAYAMA K., HOSOYA T., HUHNDORF S.M., HYDE K.D., JONES E.B.G., KOHLMEYER J., KRUYS Å., LI Y.M., LÜCKING R., LUMBSCH H.T., MARVANOVÁ L., MBATCHOU J.S., MCVAY A.H., MILLER A.N., MUGAMBI G.K., MUGGIA L., NELSEN M.P., NELSON P., OWENSBY C.A., PHILLIPS A.J.L., PHONGPAICHIT S., POINTING S.B., PUJADE-RENAUD V., RAJA H.A., RIVASPLATA E., ROBBERTSE B., RUIBAL C., SAKAYAROJ J., SANO T., SELBMANN L., SHEARER C.A., SHIROUZU T., SLIPPERS B., SUETRONG S., TANAKA K., VOLKMANN-KOHLMEYER B., WINGFIELD M.J., WOOD A.R., WOUDENBERG J.H.C., YONEZAWA H., ZHANG Y. \& SPATAFORA J.W., 2009 - A class-wide phylogenetic assessment of Dothideomycetes. Studies in Mycology 64: 1-15.

SCHUBERT K., GROENEWALD, J.Z., BRAUN U., DIJKSTERHUIS J., STARINK M.S., HILL C.F., ZALAR P., DE HOOG G.S. \& CROUS P.W., 2007 — Biodiversity in the Cladosporium herbarum complex (Davidiellaceae, Capnodiales), with standardization of methods for Cladosporium taxonomy and diagnostics. Studies in Mycology 58: 105-156.

SEIFERT K., MORGAN-JONES G., GAMS W. \& KENDRICK B., 2011 - The genera of hyphomycetes. CBS-KNAW Fungal Biodiversity Centre, Utrecht.

SHENOY B.D., JEEWON R., WU W.P., BHAT D.J. \& HYDE K.D., 2006 - Ribosomal and RPB2 DNA sequence analyses suggest that Sporidesmium and morphologically similar genera are polyphyletic. Mycological Research 110: 916-928.

SINGTRIPOP C., HONGSANAN, S., LI J., INDEEWARI DE SILVA N., PHILLIPS A.J.L., JONES E.B.G., BAHKALI A.H. \& HYDE K.D., 2016 - Chaetothyrina mangiferae sp. nov., a new species of Chaetothyrina. Phytotaxa 255: 21-33.

STAMATAKIS A., 2014 - RAxML version 8: a tool for phylogenetic analysis and post-analysis of large phylogenies. Bioinformatics 30: 1312-1313.

SU H.Y, HYDE K.D., MAHARACHCHIKUMBURA S.S., ARIYAWANSA H.A., LUO Z., PROMPUTTHA I., TIAN Q., LIN C., SHANG Q., ZHAO Y., CHAI H., LIU X., BAHKALI A.H., BHAT J.D., MCKENZIE E.H.C. \& ZHOU D., 2016 - The families Distoseptisporaceae fam. nov., Kirschsteiniotheliaceae, Sporormiaceae and Torulaceae, with new species from freshwater in Yunnan Province, China. Fungal Diversity 80: 375-409.

SUBRAMANIAN CV., 1992 - A reassessment of Sporidesmium (Hyphomycetes) and some related taxa. Proceedings of the Indian Academy of Sciences (Plant Sciences) B58: 179-190.

SUMMERELL B.A., GROENEWALD J.Z., CARNEGIE A., SUMMERBELL R.C. \& CROUS P.W., 2006 - Eucalyptus microfungi known from culture. 2. Alysidiella, Fusculina and Phlogicylindrium genera nova, with notes on some other poorly known taxa. Fungal Diversity 23: $323-350$.

TAMURA K., STECHER G., PETERSON D., FILIPSKI A. \& KUMAR S., 2013 — MEGA6: Molecular Evolutionary Genetics Analysis version 6.0. Molecular Biology and Evolution 30: 2725 2729.

VERKLEY G.J.M., CROUS P.W., GROENEWALD J.Z., BRAUN U. \& APTROOT A., 2004 Mycosphaerella punctiformis revisited: morphology, phylogeny, and epitypification of the type species of the genus Mycosphaerella (Dothideales, Ascomycota). Mycological Research 108: 1271-1282.

VIDEIRA S.I.R., GROENEWALD J.Z., BRAUN U., SHIN H.D. \& CROUS P.W., 2016 - All that glitters is not Ramularia. Studies in Mycology 83: 49-163. 
VILGALYS R. \& HESTER M., 1990 - Rapid identification and mapping of enzymatically amplified ribosomal DNA from several Crytococcus species. Journal of Bacteriology 172: 4238-4246.

WHITE T.J., BRUNS T., LEE S.B. \& TAYLOR J.W., 1990 - Amplification and direct sequencing of fungal ribosomal RNA genes for phylogenetics. In: Innis M.A., Gelfand D.H., Sninsky J.J. \& White T.J. (eds), PCR protocols: a guide to methods and application. Academic Press, San Diego, pp. 315-322.

WU W.P. \& ZHUANG W., 2005 - Sporidesmium, Endophragmiella and related genera from China. Fungal Diversity Press, Hong Kong.

YANG H.L., SUN G.Y., BATZER J.C., CROUS P.W., GROENEWALD J.Z. \& GLEASON M.L., 2010 - Novel fungal genera and species associated with the sooty blotch and flyspeck complex on apple in China and the USA. Persoonia 24: 29-37.

YANG J., MAHARACHCHIKUMBURA S.S.N., LIU JK., HYDE K.D., JONES E.B.G., AL-SADI A.M. \& LIU Z.-Y., 2017 - Pseudostanjehughesia aquitropica gen. et sp. nov. and Sporidesmium sensu lato species from freshwater habitats. Mycological Progress: 1-26. https://doi. org/10.1007/s11557-017-1339-4

ZHANG H., DONG W., HYDE K.D., MAHARACHCHIKUMBURA S.S.N., HONGSANAN S., BHAT D.J., AL-SADI A.M. \& ZHANG D., 2017 — Towards a natural classification of Annulatascaceae-like taxa: introducing Atractosporales ord. nov. and six new families. Fungal Diversity 85: 75-110. 
Declaration of author contributions to the publication / manuscript:

Panama, a hot spot for Hermatomyces (Hermatomycetaceae, Pleosporales) with five new species, and a critical synopsis of the genus

Status: published

Name of journal: IMA FUNGUS 9(1): 107-141, 2018.

Contributing authors:

Ondřej Koukol (OK)

Gregorio Delgado (GD)

Tina A. Hofmann (TH)

Meike Piepenbring (MP)

What are the contributions of the doctoral candidate and his co-authors?

(1) Concept and design

Doctoral candidate GD: Not involved in concept \& design

Co-author OK: $100 \%$

(2) Conducting tests and experiments

Doctoral candidate GD: Not involved in field work

Co-authors OK: $80 \%$, TH: $20 \%$ Carried out the field work

(3) Compilation of data sets and figures

Doctoral candidate GD: 30\% Obtained morphological and cultural data

Co-author OK: 70\% Obtained morphological, cultural and molecular data, generated figures and drawings

\section{(4) Analysis and interpretation of data}

Doctoral candidate GD: $30 \%$ Performed interpretations of the data

Co-authors OK: $60 \%$ Performed analysis and interpretations of data, TH: 5\%, MP:

$5 \%$ Advised on interpretation of results 


\section{(5) Drafting of manuscript}

Doctoral candidate GD: $50 \%$

Co-authors OK: $40 \%$, TH: 5\%, MP: $5 \%$

\section{I hereby certify that the information above is correct.}

August 28th, 2019, Houston

Digitally signed by Gregorio

$\mathrm{DN}: \mathrm{Cn}=$ Gregorio Delgado, $\mathrm{o}$

ou=EMLab P\&K Houston,

email=gdelgado@emlabpk.com,

$\mathrm{c}=$ US

Date: 2019.08 .28 21:25:30 -05'00

Date and place

Signature doctoral candidate

August 30th, 2019, Frankfurt am Main

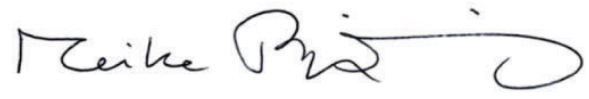

Date and place

Signature supervisor

\begin{tabular}{l} 
Andrew N. Miller $\begin{array}{l}\text { Digitally signed by } \\
\text { Andrew N. Miller } \\
\text { Date: 2019.08.29 } \\
09: 12: 58-05^{\prime} 00^{\prime}\end{array}$ \\
\hline
\end{tabular}

Date and place

Signature supervisor

August $21^{\text {st }} 2019$, Praha

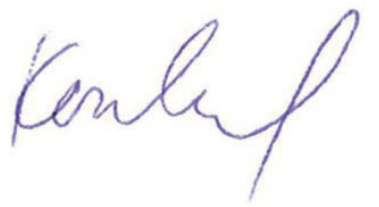

Date and place

Signature corresponding author 


\title{
Panama, a hot spot for Hermatomyces (Hermatomycetaceae, Pleosporales) with five new species, and a critical synopsis of the genus
}

\author{
Ondřej Koukol ${ }^{1}$, Gregorio Delgado ${ }^{2,3}$, Tina A. Hofmann ${ }^{4}$, and Meike Piepenbring ${ }^{3}$
}

${ }^{1}$ Department of Botany, Faculty of Science, Charles University, Benátská 2, CZ-128 01 Praha 2, Czech Republic; corresponding author e-mail: ondrej.koukol@natur.cuni.cz

2EMLab P\&K Houston, 10900 Brittmoore Park Dr. Suite G, Houston, TX 77041, USA

${ }^{3}$ Department of Mycology, Institute of Ecology, Evolution and Diversity, Goethe Universität Frankfurt, Max-von-Laue-Str. 13, 60438 Frankfurt am Main, Germany

${ }^{4}$ Centro de Investigaciones Micológicas (CIMi), Herbarium UCH, Autonomous University of Chiriquí (UNACHI), 0427, David, Chiriquí, Panama

Abstract: Five new species belonging to Hermatomyces (Hermatomycetaceae, Pleosporales) are described based on morphological investigations of specimens collected on rotten twigs and stems of various plants in Panama as well as phylogenetic analyses of sequence data of nuclear ribosomal and protein coding genes (EF1- $\alpha$, RPB2, $\beta$-TUB). The new species are described as: Hermatomyces bifurcatus, $H$. constrictus, $H$. megasporus, $H$. sphaericoides, and $H$. verrucosus spp. nov. Previously described species such as $H$. sphaericus and $H$. tucumanensis were identified among the studied specimens. The new combination, $H$. reticulatus, is made for Subicularium reticulatum based on examination of the holotype and fresh collections. Hermatomyces subiculosus, originally described from Thailand, is reduced to synonymy with $H$. reticulatus; $H$. tectonae is synonymized under $H$. sphaericus based on morphological and molecular evidence; and $H$. chiangmaiensis and $H$. thailandicus are considered later synonyms of $H$. krabiensis and $H$. indicus, respectively. The type material of Scyphostroma mirum was found to be conspecific with $H$. tucumanensis and, therefore, the generic name Hermatomyces should be conserved or protected against the older name Scyphostroma and the binomial $H$. tucumanensis against $S$. mirum. Sixteen species of Hermatomyces are recognized, their distinctive characteristics are highlighted in line drawings and a key is provided for their identification. The peculiar morphology and consistent phylogeny of new and previously known Hermatomyces species supports the recognition of the recently introduced monotypic family Hermatomycetaceae as a well delimited monophyletic taxon within the order Pleosporales.
Key words: Dothideomycetes lowland tropical forest Neotropical fungi new taxa

Article info: Submitted: 22 February 2018; Accepted: 12 May 2018; Published: 22 May 2018.

\section{INTRODUCTION}

The genus Hermatomyces accommodates asexual fungi growing saprotrophicallyon dead planttissueand producing two types of multicellular conidia in nest-like, velvety sporodochia composed of melanized and sterile hyphae surrounding a fertile sporulating area (Ellis 1971). The two types of conidia usually recognized are the lenticular, muriform ones, with subhyaline to pale brown peripheral cells surrounding dark brown to black central cells, and the cylindrical ones (also referred to as paraphyses, setae or turbinate conidia), when present are composed of 1-4 columns of several (2-11) hyaline, thin-walled cells, sometimes with cell walls unevenly melanized. Speggazini (1911) first introduced the generic name, with $H$. tucumanensis as the type species, based on material collected in Argentina. In his original description he recognized only one type of conidia, the almost globose parenchymatic lenticular conidia, and interpreted the cylindrical ones as conidiophores. Later, this species was recorded from Ghana and Sierra Leone (Hughes 1953),
Cuba (Mercado 1984), Peru (Matsushima 1993), Taiwan (Chang 1995), USA (Delgado 2013), and India (Pratibha et al. 2012, Prasher \& Singh 2015) on dead leaves or wood of a wide range of plant species. Hughes (1953) also introduced the combination $H$. sphaericus for a hermatomyces-like fungus originally described as Stemphylium sphaericum with only lenticular conidia. Subsequently, four additional species were described based on morphology: $H$. dimorphus from India (Rao \& de Hoog 1986), H. amphisporus from México (Castañeda \& Heredia 2000), H. uniseriatus from Brazil (Leăo et al. 2013), and $H$. indicus from India (Prasher \& Sushma 2014).

In recent years, several species with one or two types of conidia (previously referred to as monomorphic or dimorphic, respectively) have been described from Thailand and China and further characterized using molecular sequence data. The first sequences of Hermatomyces obtained by Doilom et al. (2016) suggested a placement of the genus within Lophiotremataceae (Pleosporales). Those authors also described two further species, $H$. tectonae and $H$. thailandicus.

\section{๑) 2018 International Mycological Association}

You are free to share - to copy, distribute and transmit the work, under the following conditions:

Attribution: $\quad$ You must attribute the work in the manner specified by the author or licensor (but not in any way that suggests that they endorse you or your use of the work).

Non-commercial: You may not use this work for commercial purposes.

No derivative works: You may not alter, transform, or build upon this work.

For any reuse or distribution, you must make clear to others the license terms of this work, which can be found at http://creativecommons.org/licenses/by-nc-nd/3.0/legalcode. Any of the above conditions can be waived if you get permission from the copyright holder. Nothing in this license impairs or restricts the author's moral rights. 


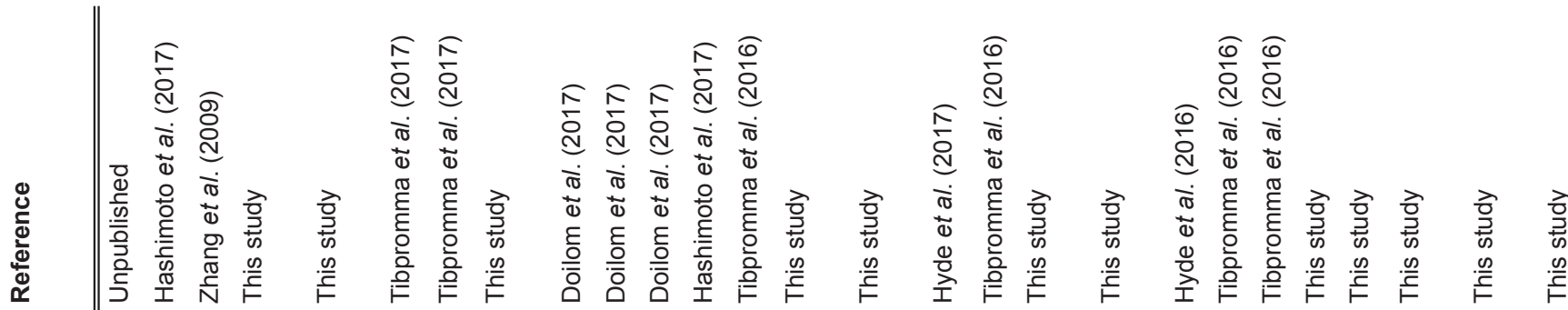

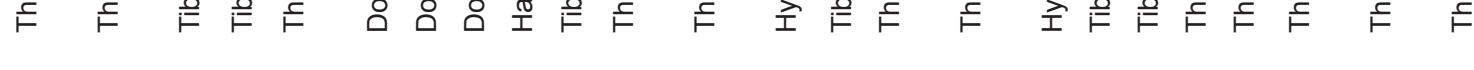

$\stackrel{2}{2}$

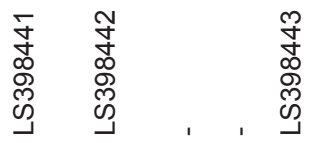

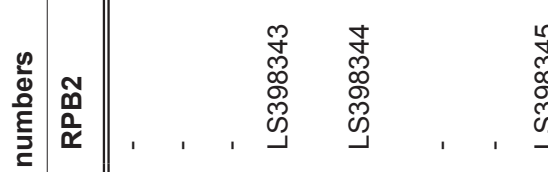

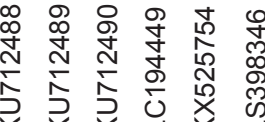

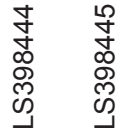

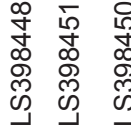

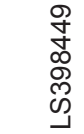

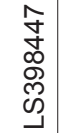

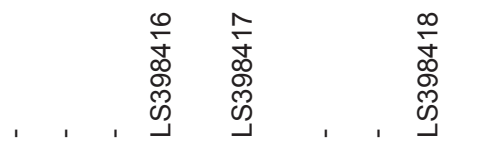

总

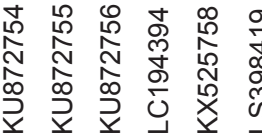

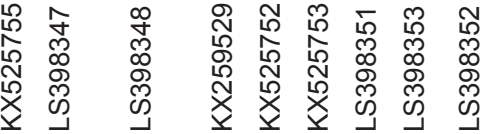

怘

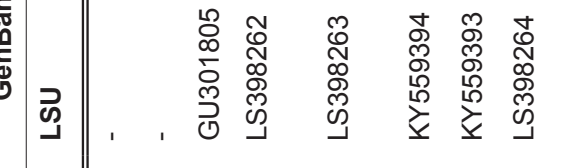

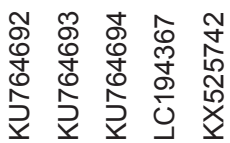

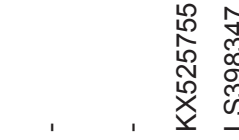

กิ

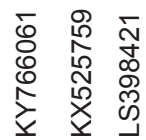

袋

సิํำ

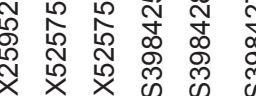

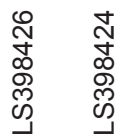

פ

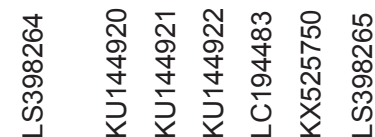

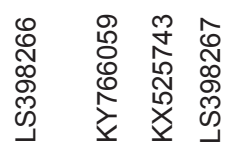

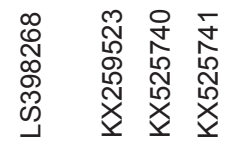

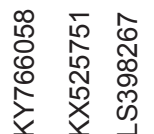

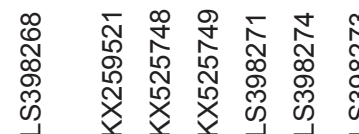

న్ల

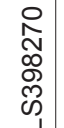

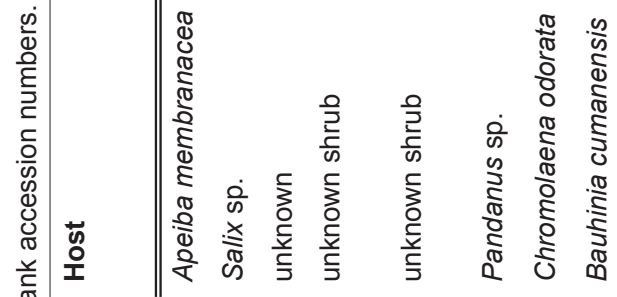

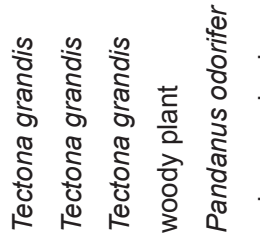

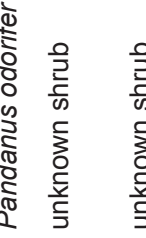

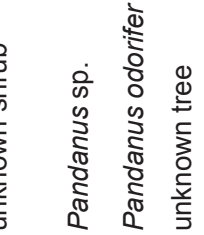

离

㐫

눈

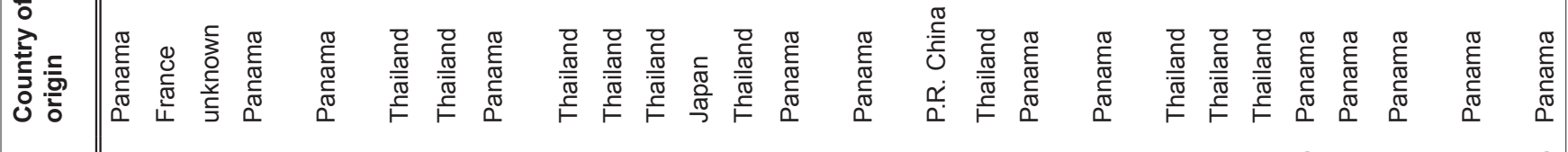

E

这

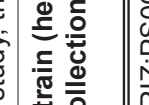

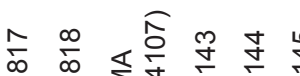

$\frac{d}{i}$

엉

$\sum_{0}$

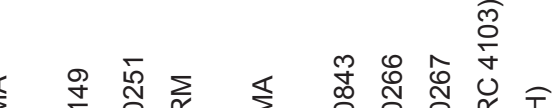

สิ

旁 娄
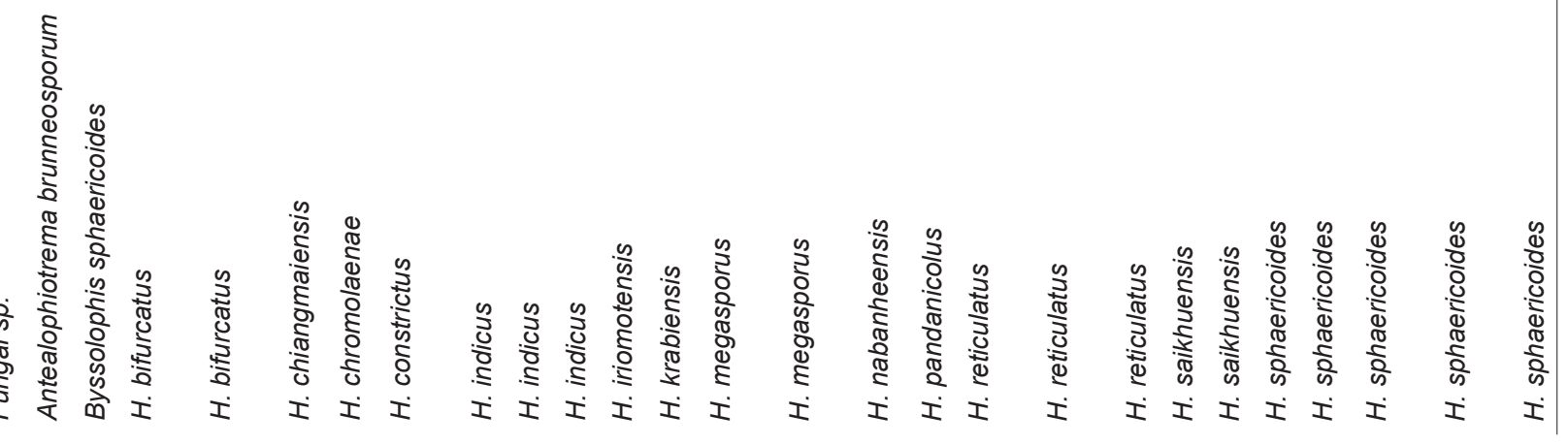


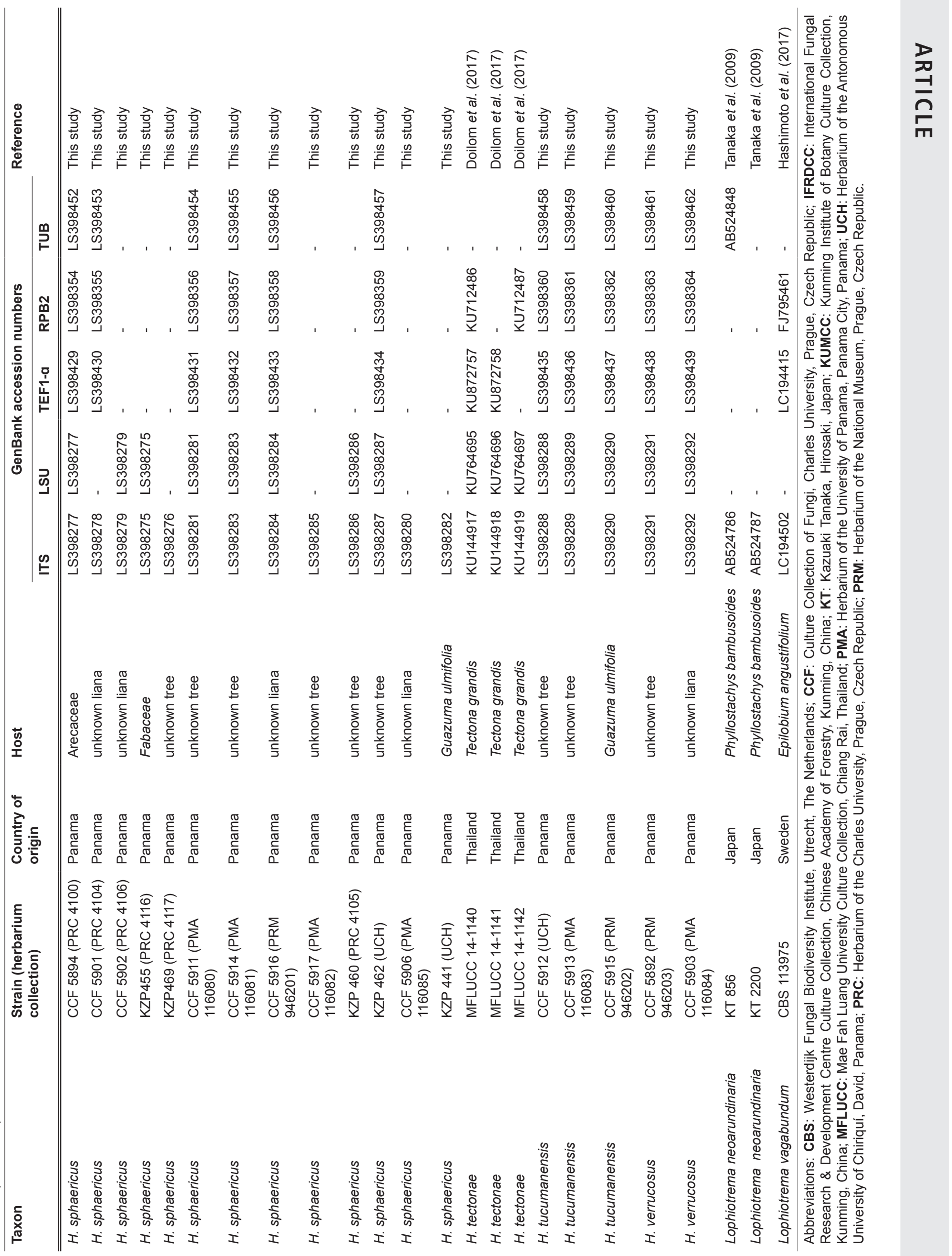


Additionally, other species, notably $H$. chiangmaiensis, $H$. chromolaenae, $H$. krabiensis, $H$. pandanicola, $H$. saikhuensis, and $H$. subiculosus, have been described from single isolates obtained from rotten plant material (Hyde et al. 2016, Tibpromma et al. 2016, 2017). Hyde et al. (2016) synonymized Scyphostroma mirum (Starbäck 1899) with Subicularium reticulatum (Farr \& Goos 1989) and combined them into $H$. mirum. More recently, the family Hermatomycetaceae was validated and reintroduced to accommodate the single genus Hermatomyces and two other species, $H$. iriomotensis and $H$. nabanheensis, described from Japan and China, respectively (Hashimoto et al. 2017, Hyde et al. 2017).

Some Hermatomyces species, such as $H$. sphaericus or $H$. tucumanensis, are apparently pantropical and quite common, while others are locally restricted and known so far only from the type or very few localities. Species introduced during the pre-molecular era were described based on distinct morphological features, but in contrast the taxonomic novelties introduced in recent years seem to lack thorough phenotypic analyses and descriptions. The plant species on which they occur and the areas of origin were emphasized for all recently described Hermatomyces species together with results of molecular analyses and minute differences in morphology (Doilom et al. 2016, Tibpromma et al. 2016).

In the course of surveys of saprobic microfungi conducted in Panama, numerous collections of Hermatomyces were made on a variety of plant debris. Due to its position along the Central American isthmus, Panama is a representative region of the Neotropics that has been relatively well explored in terms of its fungal biodiversity (Piepenbring 2006, 2007) but where hermatomyces-like fungi were previously unknown. The aim of this study is to provide an in-depth overview of the species of this genus based on morphological and molecular data obtained from freshly collected material as well as herbarium specimens. Information on known distribution areas and substrates are compiled and revised in order to elucidate their importance for species delimitation.

\section{MATERIALS AND METHODS}

\section{Specimens and morphological studies}

Specimens were collected during fieldwork carried out in the provinces of Chiriquí and Bocas del Toro, western Panama, in July 2016 and 2017. Rotten twigs and stems of various plant species showing Hermatomyces colonies were recognized in the field with a hand lens ( $\times 16$ magnification) and further observed under a dissecting microscope for morphological examination and isolation into pure culture. Lenticular conidia from colonies were first picked up using a sterile needle and placed on malt extract agar (MEA) or potato carrot agar (PCA). Further transfers and cultivation were also performed on PCA and potate dextrose agar (PDA) at room temperature $\left(23-25{ }^{\circ} \mathrm{C}\right)$. To induce sporulation, selected isolates were also grown on water agar with sterile wooden toothpicks. Sometimes, sporodochia of different morphotypes were found close to each other on the same substrate. In such cases the sporodochia used for isolation in culture were marked and preparations for light microscopy were then made from these and nearby conidiomata. Conidia were mounted in water, Melzer's reagent, lactic acid or lacto-cotton blue and examined using differential interference contrast on an Olympus BX-51 (Olympus, Tokyo) with a digital camera Olympus DP72 (Olympus, Tokyo). Colonies on the natural substrates were measured under a calibrated Olympus SZ61 stereomicroscope. Microscopic measurements are reported as the mean \pm standard deviation of values resulting from 50 measurements of structures mounted in the same reagents. Measurements were analysed using one-way ANOVA with nonparametric Kruskal-Wallis test in PAST v2.07 (Hammer et al. 2001). Holotype specimens are deposited in PMA (University of Panama Herbarium, Panama) and paratypes in $\mathrm{UCH}$ (Autonomous University of Chiriquí Herbarium, Panama) and PRM (Herbarium of the Prague National Museum, Czech Republic). Non-type specimens were deposited in PRC (Herbarium of the Charles University, Prague, Czech Republic). Further specimens were borrowed from the US National Fungus Collection (BPI), Royal Botanic Gardens Kew (K(M)-IMI), and PRM for comparison and observation of conidial structures.

\section{SEM microscopy}

Scanning electron microscopy was performed on a JEOL6380 LV microscope (JEOL, Tokyo). Pieces of colonies (3 $\times 3 \mathrm{~mm}$ ) from the natural substrate were fixed in osmium tetroxide vapors for $2 \mathrm{w}$ at $5-10{ }^{\circ} \mathrm{C}$ and gold-coated in BalTec SCD 050 sputter coater (Bal-Tec, Balzers, Liechtenstein). The specimens were observed with a spot size of 38-45 $\mu \mathrm{m}$ and accelerating voltage of $20-25 \mathrm{kV}$.

\section{DNA extraction, PCR amplification and sequencing}

DNA was extracted from 2-week old cultures grown on MEA using a Zymo Research Fungal/Bacterial Kit (Zymo Research, Orange, CA). Nuclear rDNA containing the ITS1$5.8 S-I T S 2$ and the highly variable D1/D2 domains of the $28 \mathrm{~S}$ regions, subsequently referred here to a ITS and LSU, was amplified with primer sets ITS1F/NL4 (White et al. 1990, O'Donnell 1993). Three fragments of protein-coding markers

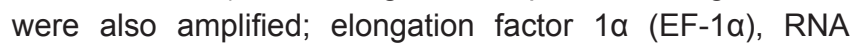
polymerase II second largest subunit (RPB2) and $\beta$-tubulin ( $\beta$-TUB). The EF-1 $\alpha$ fragment was amplified with primer set 983F/2218R (Rehner \& Buckley 2005), RPB2 with RPB25F/fRPB2-7cR (Liu et al. 1999), and $\beta$-TUB with T1/T22 (O'Donnell \& Cigelnik 1997). The PCR products were viewed by electrophoresis on $1 \%(\mathrm{w} / \mathrm{v})$ TAE agarose gel stained with ethidium bromide. The PCR products were purified with the Gel/PCR DNA Fragments Extraction Kit (Geneaid Biotech, Bade City, Taiwan). Both strands of the PCR fragments were sequenced with the primers used for amplification at the Sequencing Laboratory of the OMICS Core Facility, BIOCEV (Vestec, Czech Republic). The widely used 18S rDNA region (Tibpromma et al. 2016, Hashimoto et al. 2017) was not amplified because of limited variability; all available Hermatomyces sequences from GenBank were found to differ only in three indels.

\section{Taxon sampling and phylogenetic analyses}

The closest hits and sequences from Hermatomyces species were selected from previous phylogenetic studies (Doilom et 
Table 2. Characteristics of alignments of studied gene regions and the models adopted for Bayesian analyses.

\begin{tabular}{|c|c|c|c|c|c|}
\hline DNA region & \#sequences & \#nucleotide sites & \#parsimony informative & \#variable & Model (BIC criterion) \\
\hline ITS & 47 & 467 & 102 & 135 & TIM2ef+G \\
\hline LSU & 37 & 513 & 25 & 43 & TrNef+I \\
\hline RPB2 & 43 & 1011 & 211 & 273 & $\mathrm{TrNef}+\mathrm{G}$ \\
\hline EF1- $\alpha$ & 45 & 872 & 121 & 165 & $\operatorname{TrN}+\mathrm{I}+\mathrm{G}$ \\
\hline$\beta$-TUB & 25 & 615 & 112 & 205 & TrNef+I \\
\hline
\end{tabular}

al. 2016, Hyde et al. 2016, Tibpromma et al. 2016, Hashimoto et al. 2017, Hyde et al. 2017) and used to build datasets. Details of strains and sequences used are listed in Table 1. Five separate datasets (ITS, LSU, EF1- $\alpha$, RPB2, $\beta$-TUB) were assembled and aligned using MAFFT algorithms implemented in Geneious v. 6.1 .5 (Biomatters, Auckland) and manually edited in the same software. The best-fit substitution model for each gene was determined using the Bayesian information criterion in jModeltest v. 2.1.5 (Darriba et al. 2012) and the selected models for the ITS, LSU, EF1- $\alpha$, RPB2 and $\beta$-TUB regions including number of variable and parsimony positions are summarized in Table 2. The five datasets were tested for combinability by using the partition homogeneity test (Farris et al. 1994) implemented in PAUP* v. $4.0 b 10$ (Swofford 2002), which showed that there was significant incongruence among the datasets. Phylogenetic analyses were performed by Bayesian inference using MrBayes v. 3.2 (Ronquist et al. 2012) and Maximum likelihood (ML) running on the RAxML Web Server v. 7.7.1 (Stamatakis et al. 2008). For Bayesian analyses, two independent runs of 4-6 M generations were run sampling every 100th generation. The first $25 \%$ of samples were discarded as burn-in and the remaining trees were used to compute a $50 \%$ majority rule consensus tree with posterior probabilities (PP) as Bayesian branch support. The average standard deviation of split frequencies estimating convergence reached the level of $0.003-0.006$ at the end of analyses. The GTRCAT approximation implemented in the $\mathrm{ML}$ analysis and nonparametric bootstrapping (BS) with 1000 replicates were used for branch support.

Bayesian species tree analyses were performed with *BEAST v. 2.4.8 (Bouckaert et al. 2014), which uses multilocus data to simultaneously co-estimate gene trees embedded within a species tree under a coalescent model. Although *BEAST does not require that each gene alignment contains the same number of sequences, only 44 samples represented by at least three regions were included. The mapping of each sample to the appropriate species was based on singlegene phylogenies. BEAUTi v. 2.4.8 (Bouckaert et al. 2014) was used to create the XML-formatted input files for *BEAST using the Gamma category count with shape and proportion of invariant sites obtained from jModeltest. Site models, clock models and trees were unlinked for all regions. Relaxed log normal molecular clock model with birth-death model and gamma-distributed population sizes for the species-tree prior and a piecewise linear population size model with a constant root were selected with default values used for remaining priors. The analysis was run for $50 \mathrm{M}$ generations sampling every 5000th generation. Convergence and effective sample size (EES) were assessed for each parameter using Tracer v. 1.5 (Rambaut \& Drummond 2009). Since the ESS of all parameters was above 200 , the first $20 \%$ of trees were discarded as burn-in. A maximum clade credibility tree with the $95 \%$ highest probability density was produced by using TreeAnnotator version v. 2.4.8 (Bouckaert et al. 2014) and visualized in FigTree (http://tree.bio.ed.ac.uk/software/ figtree). DensiTree v. 2.4.8 (Bouckaert et al. 2014) was used to visualize the posterior distribution of the species trees.

\section{RESULTS}

Five DNA regions (ITS, LSU, EF1- $\alpha$, RPB2, $\beta$-TUB) were sequenced in 30 specimens belonging to eight species of Hermatomyces. A good congruence between morphological features and segregation of respective sequences into clades was generally found (Fig. 1). Numerous collections belonging to $H$. sphaericus with just the lenticular conidium type grouped within a well-supported clade together with sequences attributed to $H$. chromolaenae (only in the LSU tree), $H$. pandanicola (except in the EF1- $\alpha$ tree), and $H$. saikhuensis and $H$. tectonae having one or both conidium types. Two collections tentatively identified as $H$. subiculosus (CCF 5893 and CCF 5905) formed a well-supported clade together with sequence data from the type collection of this species. The remaining single conidium type collections differing in size and wall ornamentation of their lenticular conidia grouped into two distinct clades, and described here as $H$. sphaericoides and $H$. verrucosus. Three collections with both conidium types were identified as $H$. tucumanensis and together formed a well-supported clade in all phylogenies. Two collections with unusually large conidia of both types that do not differ from $H$. subiculosus with just one conidium type in their rDNA sequence data but were clearly distinct based on their coding genes are described as $H$. megasporus. Four collections with both conidium types formed two distinct and unrelated clades and are described as $H$. bifurcatus and $H$. constrictus. The majority of these clades were highly supported in the consensus species tree retrieved from the Bayesian analysis of the multilocus dataset (Fig. 2), although conflicts in some clades (most distinct at $H$. bifurcatus and $H$. nabanheensis) indicated that these genes have undergone incomplete lineage sorting. 
ITS

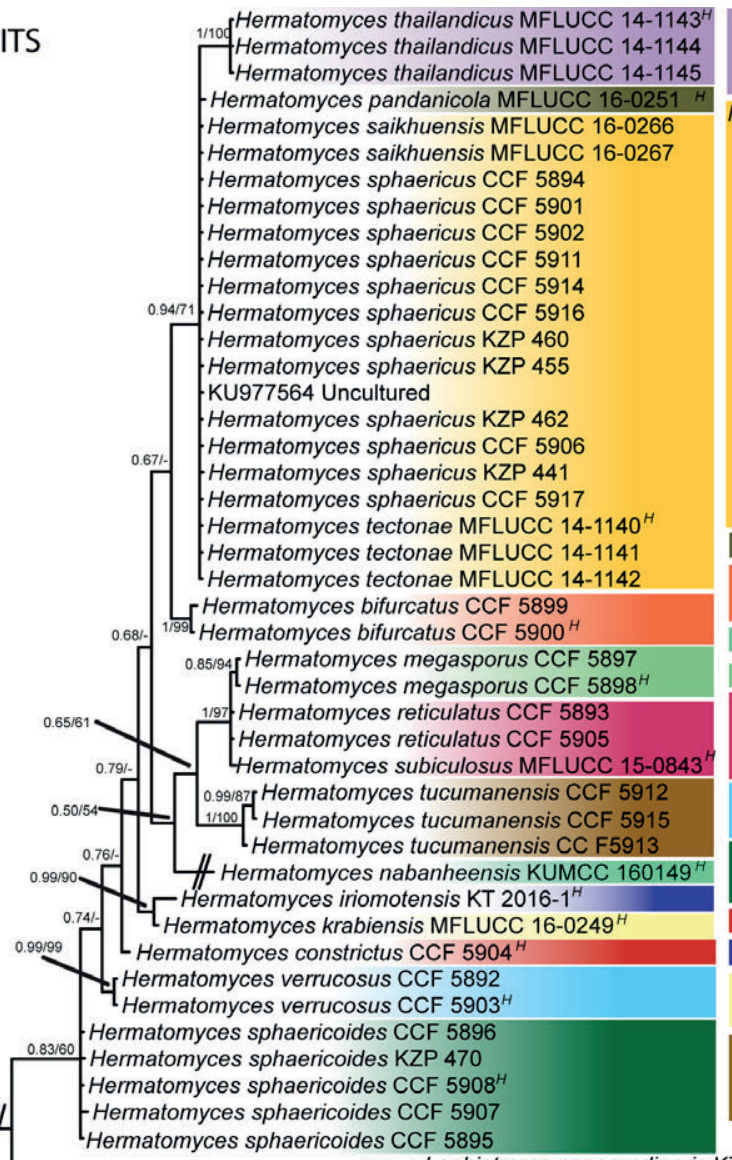

$1 / 100 \begin{aligned} & \text { Hermatomyces thailandicus MFLUCC 14-1143 } \\ & \text { Hermatomyces thailandicus MFLUCC 14-1144 }\end{aligned}$ Hermatomyces thailandicus MFLUCC 14-1145 Hermatomyces saikhuensis MFLUCC 16-0266 Hermatomyces saikhuensis MFLUCC 16-0267 Hermatomyces sphaericus CCF 5894 Hermatomyces sphaericus CCF 5901 Hermatomyces sphaericus CCF 5902 Hermatomyces sphaericus CCF 5906 e MFLUCC 14-1141 Hermatomyces tectonae MFLUCC 14-1142 Hermatomyces megasporus CCF 5897 Hermatomyces megasporus CCF 5898 matomyces reticulatus CCF 5893

Tetomyces reticulatus CCF 5905 87 Hermatomyces tucumanensis CCF 5912 Hermatomyces tucumanensis CCF 59 1/100 Lophiotrema neoarundinaria KT 2200 Lophiotrema neoarundinaria KT 856

Hermatomyces thailandicus MFLUCC 14-1143 Hermatomyces thailandicus MFLUCC 14-1144 Hermatomyces thailandicus MFLUCC 14-1145 Hermatomyces chromolaenae MFLUCC 16-2818 ${ }^{H}$ Hermatomyces tectonae MFLUCC $14-1140^{\mathrm{H}}$ Hermatomyces tectonae MFLUCC 14-1141 Hermatomyces tectonae MFLUCC 14-1142 Hermatomyces sphaericus CCF 5894 Hermatomyces sphaericus KZP 460 Hermatomyces sphaericus KZP 462 Hermatomyces sphaericus CCF 5914 Hermatomyces sphaericus CCF 5916 Hermatomyces sphaericus CCF 5902 Hermatomyces sphaericus CCF 5911 Hermatomyces sphaericus KZP 455 Hermatomyces saikhuensis MFLUCC 16-0266Hermatomyces saikhuensis MFLUCC 16-0267Hermetomyces pandanicola MFLUCC $16-0251^{\mathrm{H}}$ Hermatomyces bifurcatus CCF 5899 Hermatomyces bifurcatus CCF $5900^{\mathrm{H}}$ Hermatomyces nabanheensis KUMCC $160149^{\prime}$ and proposed synonymies: H. indicus $=H$. thailandicus

H. sphaericus $=H$. chromolaenae $=H$. saikhuensis $=H$. tectonae

H. pandanicola

H. bifurcatus

H. nabanheensis

H. megasporus

H. reticulatus $=H$. subiculosus

H. verrucosus

H. sphaericoides

H. constrictus

H. iriomotensis

H. krabiensis

$=H$. chiangmaiensis

H. tucumanensis

Hermatomyces megasporus CCF $5898^{\mathrm{H}}-0.821$. Hermatomyces reticulatus CCF 5893 Hermatomyces reticulatus CCF 5905 Hermatomyces subiculosus MFLUCC $15-0843^{\mathrm{H}}$ Hermatomyces verrucosus CCF $589277^{0.98 / 81}$ Hermatomyces verrucosus CCF $\left.5903^{H}\right]^{0.998}$

Hermatomyces sphaericoides CCF $5908^{\mathrm{H}}$ Hermatomyces sphaericoides CCF 5895 Hermatomyces constrictus CCF $5904^{\mathrm{H}}$

Hermatomyces iriomotensis KT 2016-1 Hermatomyces krabiensis MFLUCC $16-0249^{\mathrm{H}}$ Hermatomyces chiangmaiensis MFLUCC $16-2817^{\mathrm{H}}$

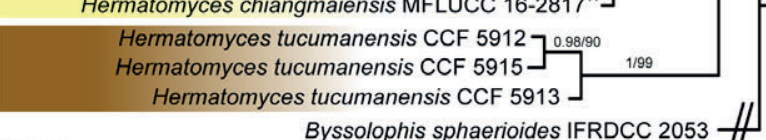
Byssolophis sphaerioides IFRDCC 2053 \#

\#Antealophiotrema brunneosporum CBS 123095
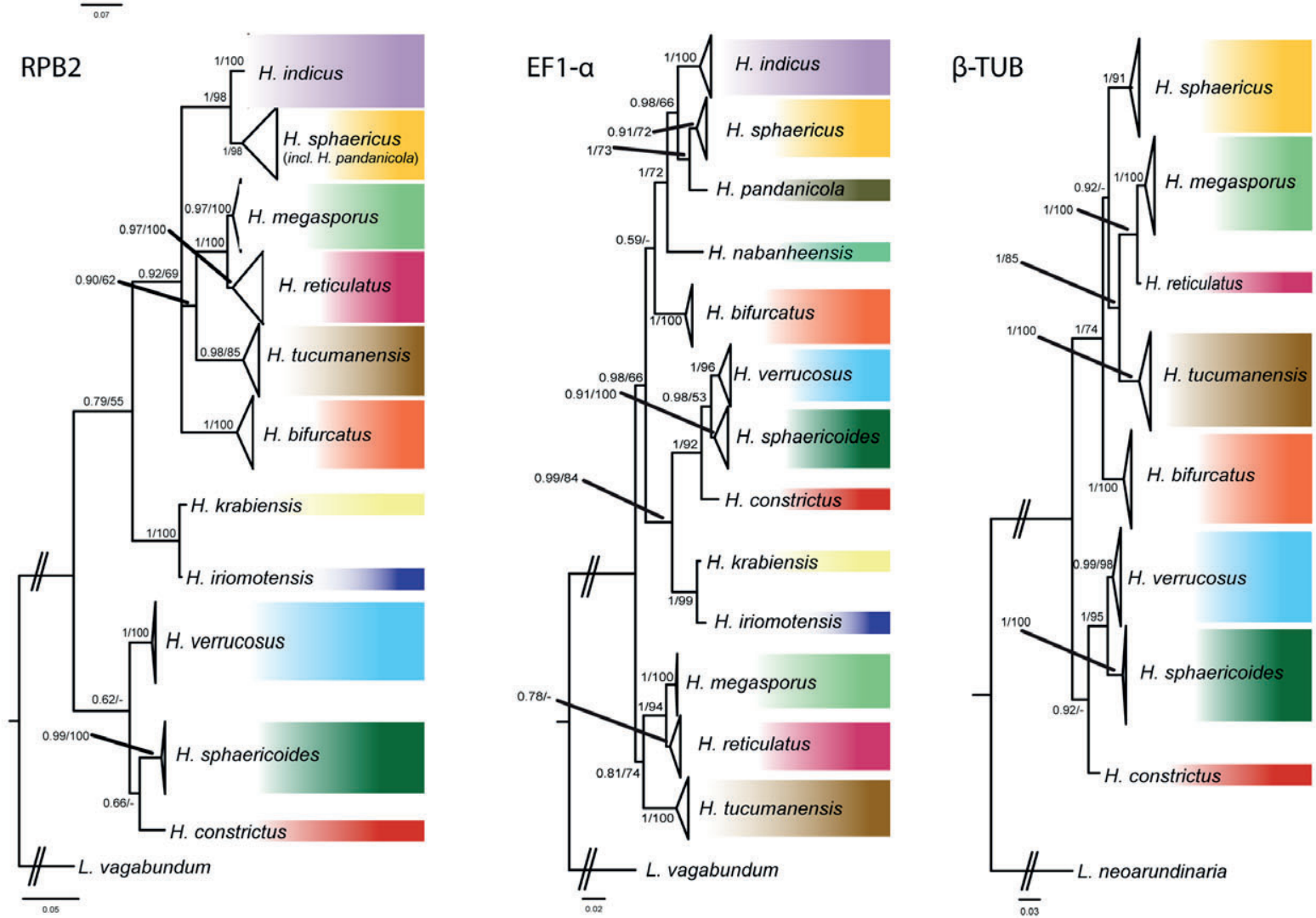

Fig. 1. Phylogenetic trees inferred from Bayesian and ML analyses of the genus Hermatomyces based on ITS, LSU, RPB2, EF1- $\alpha$ and $\beta$-TUB and including five newly described Hermatomyces taxa. Numbers above branches represent PP>0.5 and ML bootstrap support values BS $>90 \%$. Ex-type living cultures are indicated by superscript letter: $\mathrm{H}$ - holotype. 
A

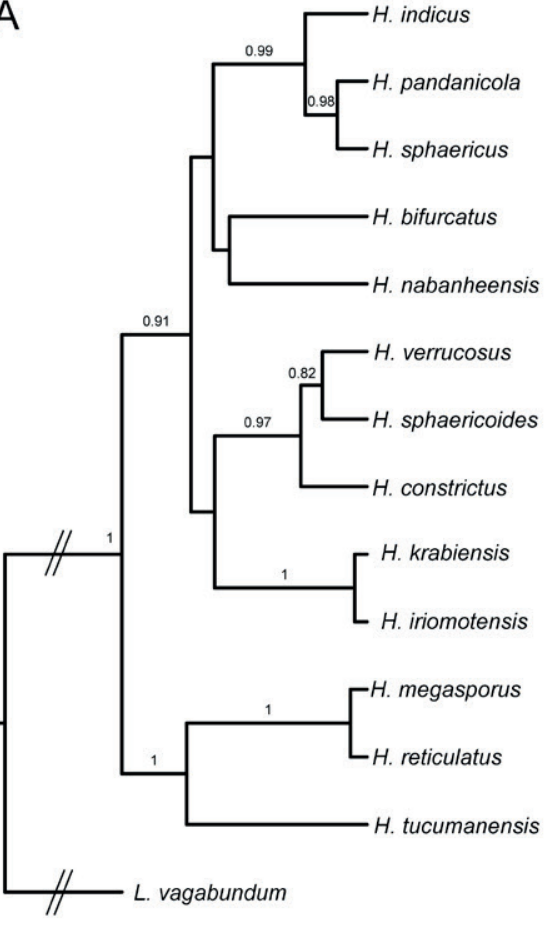

B

Fig. 2. Species trees from Bayesian analysis of combined dataset of ITS, LSU, RPB2, EF1- $\alpha$ and $\beta-T U B$. A. Consensus topology resulting from the *BEAST analysis. Numbers above branches represent PP>0.5. B. Vizualization of 8000 trees with green lines representing the most likely topologies obtained from DensiTree.

\section{TAXONOMY}

Hermatomyces Speg., Anal. Mus. nac. B. Aires, ser. 3 13: 445 (1911).

Type species: Hermatomyces tucumanensis Speg. 1911.

Classification: Hermatomycetaceae, Pleosporales, Dothideomycetes

Notes: The family Hermatomycetaceae was recently reintroduced and validly published by Hashimoto et al. (2017). Although the family is currently monotypic, similarly to several other families among Pleosporales, its delimitation seems to be well justified. Liu et al. (2017) analyzed divergence times of all clades within Dothideomycetes treated as families or orders and found good support for the majority of them. In the phylogeny presented by Hashimoto et al. (2017), the Hermatomycetaceae clade rooted comparably deep to the closely related Anteagloniaceae and Lophiotremataceae suggesting similar divergence times.

Hermatomyces bifurcatus Koukol \& G. Delgado, sp. nov. MycoBank MB824244

(Figs 4, 13A, D, G, J, 16B)

Etymology: bifurcates, referring to the furcate shape of cylindrical conidia.

Diagnosis: Differs from other species of Hermatomyces with two conidium types in the cylindrical conidia with two bifurcating columns of cells, each arising from a bulbous basal cell and ending in a verrucose and pigmented apical cell.

Type: Panama: Chiriquí Province: Boquete, Bajo Mono, pipeline trail, along tourist path, $8^{\circ} 49^{\prime} 40.22^{\prime \prime} \mathrm{N}, 82^{\circ} 29^{\prime} 26.11^{\prime \prime} \mathrm{W}$, 1720 m a.s.I., on dry rotten twig of a shrub, 9 Jul 2017, O. Koukol KZP353 (PMA 116075 - holotype; CCF 5900 - exholotype culture).

Description: Colonies on the natural substrate forming sporodochial conidiomata, superficial, scattered, more or less circular or oval, mostly non-subiculate, gray-black, consisting of an orbicular, blackish gray, flattened outer zone sometimes with a poorly developed subiculum and a black, glistening, granulose sporulating centre, 300-500 $\mu \mathrm{m}$ diam. Mycelium mostly superficial, composed of a loose or compact network of repent, branched, septate, smooth, locally thick-walled, pale brown to brown hyphae, 3-4 $\mu$ m wide; subicular hyphae short, ascending, irregularly geniculate or flexuous, densely packed, anastomosing. Conidiophores micronematous or semimacronematous, mononematous, cylindrical, erect, subhyaline or pale brown, smooth or finely verruculose, up to $27 \mu \mathrm{m}$ long, 2-4 $\mu \mathrm{m}$ wide, often corresponding to conidiogenous cells. Conidiogenous cells monoblastic, integrated, terminal, determinate, subhyaline to pale brown or brown, cylindrical or slightly subulate, often arising directly on the superficial mycelium and closely packed together at the fertile centre, sphaerical, subsphaerical or ampulliform, 4-6 $\times$ 3-4 $\mu \mathrm{m}$. Conidia of two types, solitary, dry; lenticular conidia muriform, smooth, broadly ellipsoidal in front view, central 

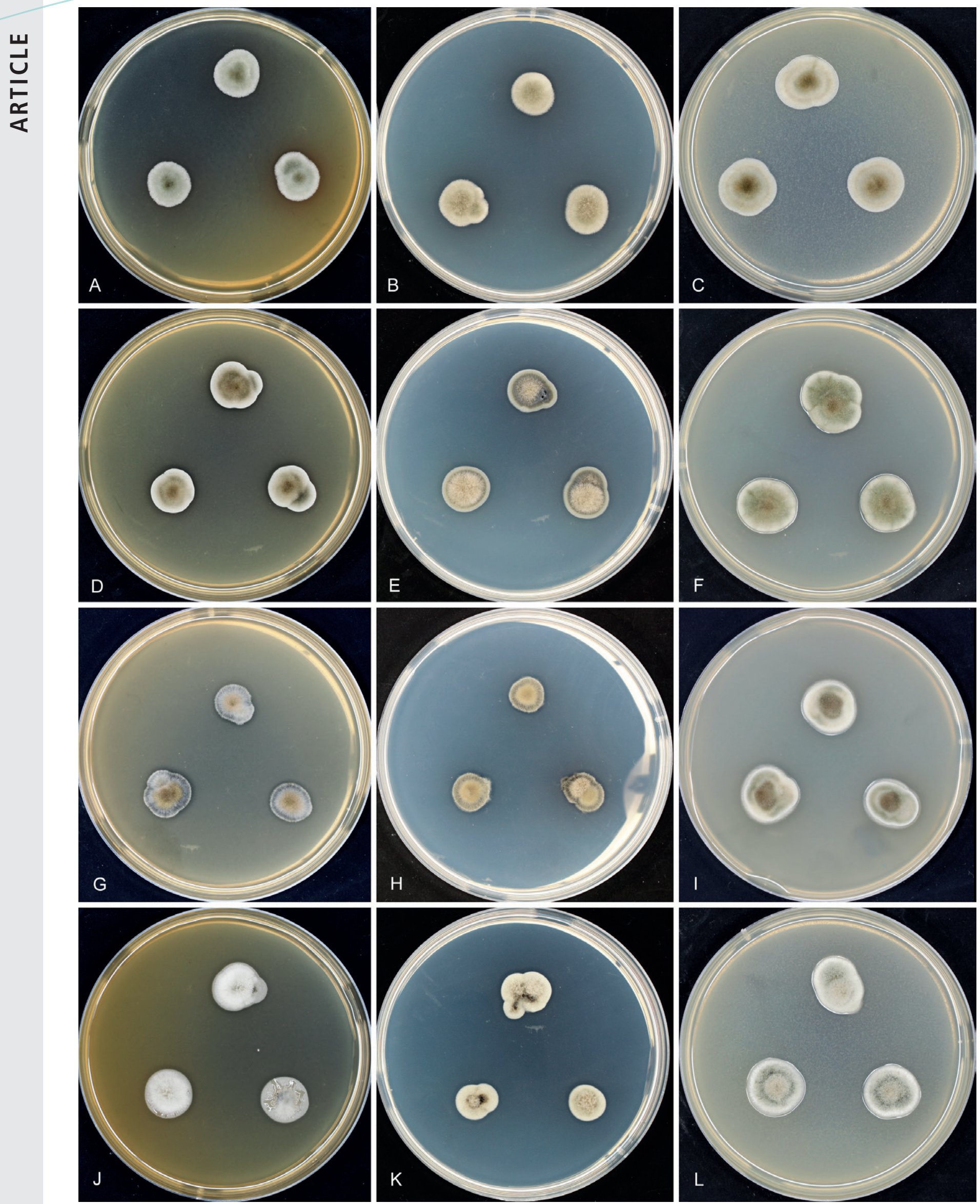

Fig. 3. Morphology of Hermatomyces colonies in culture. A-C. H. bifurcatus (CCF 5899). D-F. H. constrictus (CCF 5904). G-I. H. megasporus (CCF 5898). J-L. H. reticulatus (CCF 5893). M-O. H. sphaericoides (CCF 5908). P-R. H. sphaericus (CCF 5894). S-U. H. tucumanensis (CCF 5913). V-X. H. verrucosus (CCF 5903). All after $7 \mathrm{~d}$ growth at $25^{\circ} \mathrm{C}$ on MEA, PCA or PDA (from left to right). 


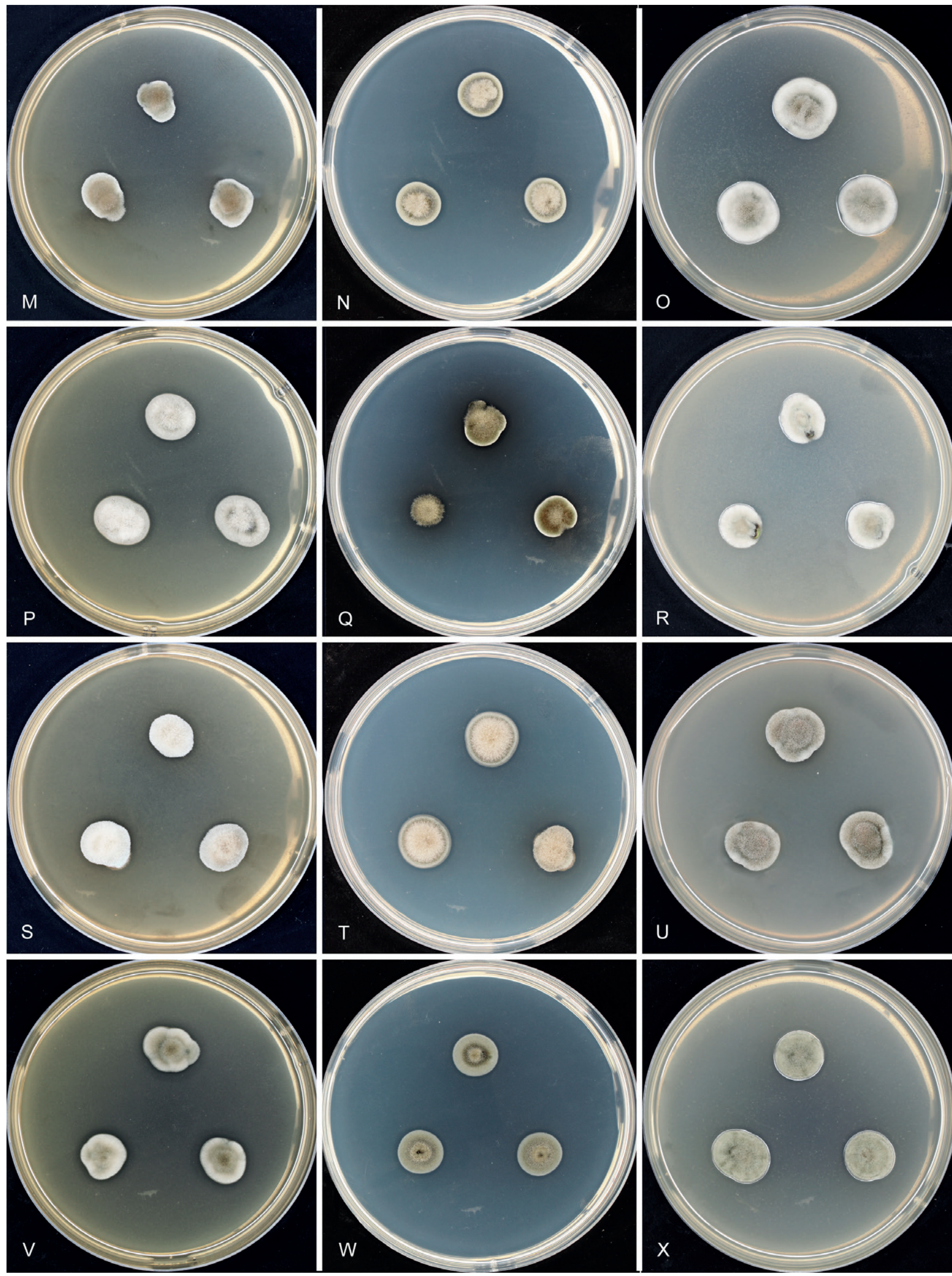

Fig. 3. (Continued). 

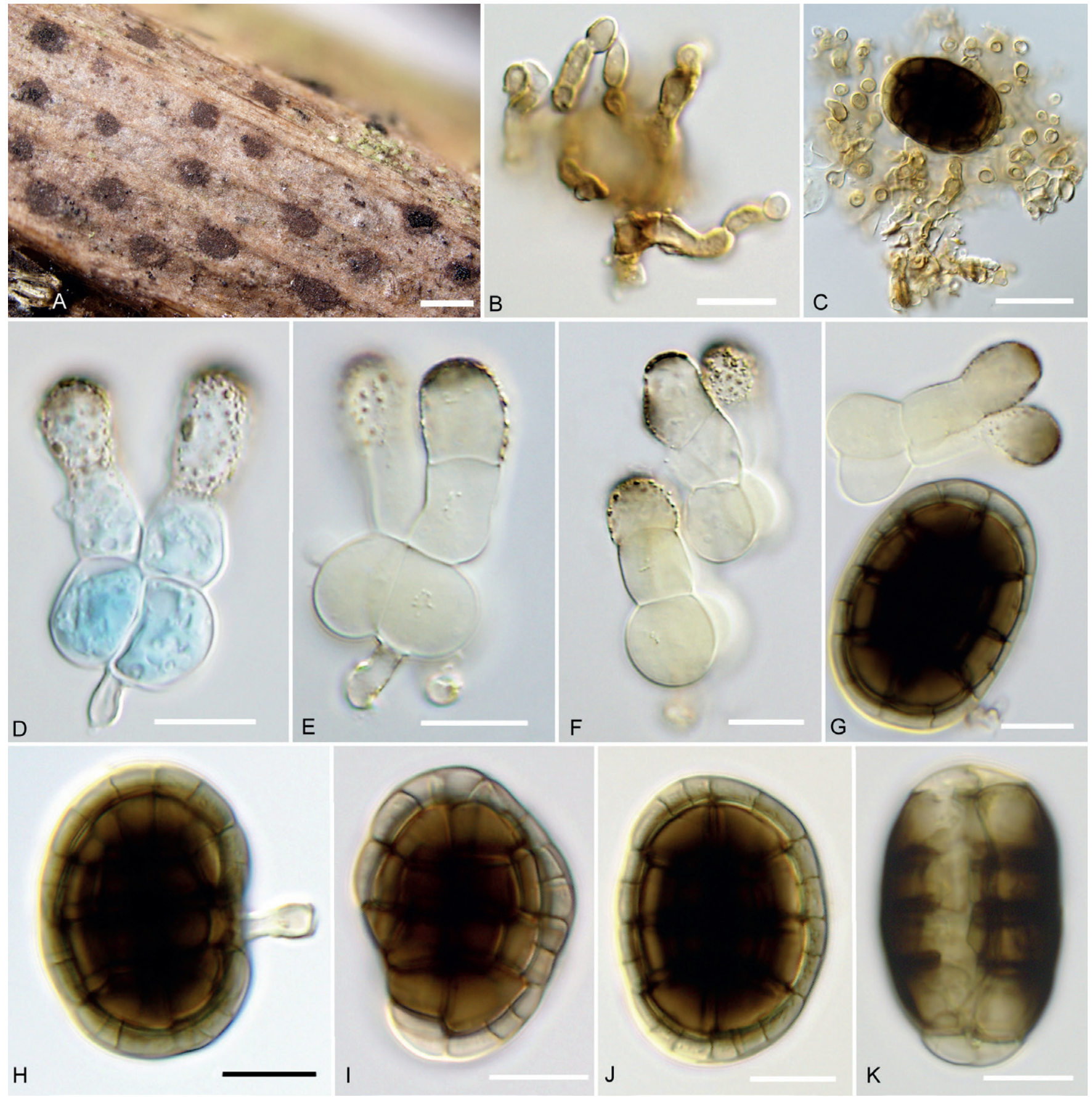

Fig. 4. Hermatomyces bifurcatus (PMA 116075 - holotype). A. Colonies on the natural substrate. B. Subicular hyphae. C. Conidiogenous cells and young lenticular conidium. D-F. Cylindrical conidia (stained with lacto-cotton blue at D). G. Cylindrical and lenticular conidium. H-K. Lenticular conidia. Bar A = 500 $\mu \mathrm{m}, \mathrm{B}-\mathrm{K}=10 \mu \mathrm{m}$.

cells brown or dark brown to blackish brown, peripheral cells subhyaline to pale brown, forming a wide and distinct ring, ellipsoidal to narrowly oblong or oblong in side view where two distinct adpressed halves can be recognized, each half seen laterally as a row of 4-7 cells, end cells subhyaline to pale brown, middle cells dark brown or blackish brown, (24-) 30-36.5(-41) × (18-)21.5-26(-28) $\mu \mathrm{m}, 14-20.5 \mu \mathrm{m}$ thick, $\mathrm{L} / \mathrm{W}=1.42$; cylindrical conidia bifurcated, straight or flexuous, septate, constricted at the septa, (18-)26-33.5(-36) $\mu \mathrm{m}$ long, consisting of two columns of 3 cells, very rarely 2-celled, basal cells bulbous, globose or subglobose, smooth, hyaline, tightly appressed together, 9-14 × 13-18.5 $\mu \mathrm{m}$, middle and apical cells diverging, doliiform, cylindrical or subcylindrical, apical cells clavate or doliiform, verrucose, subhyaline or pale brown, apex rounded and dark brown or blackish brown, 7-16 × 7-12 $\mu \mathrm{m}$. Sexual morph unknown.

Cultures (Fig. 3A-C): Colonies moderately slow growing, reaching on MEA and $P C A$ 14-16 mm diam, and on PDA 12-13 mm after $7 \mathrm{~d}$ at $25^{\circ} \mathrm{C}$. No sporulation observed after $4 \mathrm{~m}$ at $25^{\circ} \mathrm{C}$.

Notes: Hermatomyces bifurcatus can be distinguished from other species with two conidium types in having colonies with 
a poorly developed subiculum and cylindrical conidia with two bifurcating columns of cells each one arising from separate but tightly appressed, bulbous basal cells. The remaining cells diverge upwards and each column ends in a verrucose and pigmented apical cell. A similar ornamentation of the apical cell is present in $H$. uniseriatus (Leão et al. 2013) with lenticular conidia almost identical in size, 27-36 $\mu \mathrm{m}$ diameter and 15.5-24 $\mu \mathrm{m}$ thick, but currently without available DNA sequence data. Cylindrical conidia of $H$. uniseriatus, however, differ in consistently having only a single column of 3-4 cells and lacking a pigmented apex. Hermatomyces iriomotensis (Hashimoto et al. 2017) also shows some resemblance in the overall shape and length of its cylindrical conidia, 20.5-33 $\mu \mathrm{m}$ long and with two slightly diverging columns ending in pigmented cells. Its conidia, however, may consist of two but also of a single column of cells. They are larger in number of septa and cells, the apical ones are smooth while the basal cells are not distinctly bulbous as in $H$. bifurcatus. Phylogenetically, both species are distantly related in all analyses. Together with $H$. tucumanensis, $H$. bifurcatus has the most ellipsoidal conidia known in the genus (Fig. 18).

Additional material examined: Panama: Chiriquí Province: Boquete, Bajo Mono, pipeline trail, along tourist path, $8^{\circ} 49^{\prime} 40.22$ 'N $82^{\circ} 29^{\prime} 26.11^{\prime \prime W}, 1720 \mathrm{~m}$ a.s.l., on dry rotten twig of a shrub, 9 Jul. 2017, O. Koukol KZP352 (PRM 946196; CCF 5899-living culture).

\section{Hermatomyces constrictus Koukol \& G. Delgado, sp. nov. \\ MycoBank MB824245}

(Figs 5, 13B, E, H, K, 16C)

Etymology: constrictus, referring to the distinctly constricted septa of the two-celled cylindrical conidia.

Diagnosis: Differs from other species of Hermatomyces with two conidium types in the presence of two-celled cylindrical conidia that are distinctly constricted at the central or eccentric septum.

Type: Panama: Chiriquí Province: west of Los Algarrobos, path through pastures along Majagua river, $8^{\circ} 29^{\prime} 47.82^{\prime \prime} \mathrm{N}$, $82^{\circ} 26^{\prime} 19.721^{\prime \prime} \mathrm{W}, 110 \mathrm{~m}$ a.s.l., on rotten stem of Bauhinia cumanensis (Fabaceae), 14 Jul. 2017, O. Koukol KZP408 (PMA 116076 - holotype; CCF 5904 - ex-type living culture; PRC 4107 - isotype).

Description: Colonies on the natural substrate forming sporodochial, subiculate conidiomata, superficial, scattered, circular or oval, rarely confluent, brown-black, consisting of a velvety, dense, thick, annular, brown sterile mycelial outer zone enclosing a whitish black, glistening, abundantly sporulating centre, circular or oval, with the cylindrical conidia distinct among the lenticular ones, 300-500 $\mu \mathrm{m}$ diam. Mycelium superficial, composed of a compact network of repent, branched, septate, smooth or finely verruculose, pale brown to brown hyphae, 2-4 $\mu \mathrm{m}$ wide; subicular hyphae branched, septate, verrucose to strongly verrucose, locally verruculose or finely verruculose, pale brown to brown, erect, flexuous, undulate or irregularly geniculate, ascending, branching and rarely anastomosing to form a moderately dense network. Conidiophores micronematous, mononematous, cylindrical, hyaline, smooth, up to $21 \times 1.5-3 \mu \mathrm{m}$, often corresponding to conidiogenous cells. Conidiogenous cells monoblastic, integrated, terminal, determinate, often arising directly on the superficial mycelium and closely packed together at the fertile centre, sphaerical, subsphaerical or ampulliform, pale brown to brown, smooth, 4-7 $\times 3.5-5 \mu \mathrm{m}$. Conidia of two types, solitary, dry; lenticular conidia muriform, smooth, disc-shaped, broadly ellipsoidal or rarely subglobose in front view, central cells brown to blackish brown or black, peripheral cells hyaline to subhyaline, forming a wide and distinct ring, slightly constricted at the septa or not, ellipsoidal in side view where two distinct adpressed halves can be recognized, each half seen laterally as a row of 6-7 cells, end cells subhyaline, middle cells blackish brown to black, (22-)25.5-29.5(-32) × 19-23.5(-27.5) $\mu \mathrm{m}$, 14.5-19 $\mu \mathrm{m}$ thick, L/W = 1.29; cylindrical conidia 2-celled, symmetrical or asymmetrical, the upper cell smaller with a central or eccentric septum, distinctly constricted at the septum, guttulate, smooth, straight or flexuous, 37-57 $\mu \mathrm{m}$ long, upper and lower cells long ellipsoidal, ellipsoidal, long ovoid, obclavate, obpyriform or sometimes broadly ovoid, often curved, lower cells (20-)24-30.5(-37) × 12-17 $\mu \mathrm{m}$, upper cells (16-)20-26(-30) × 8-14 $\mu \mathrm{m}$, apex more or less rounded or slightly flattened, often slightly attenuated and dark brown or black. Sexual morph unknown.

Cultures (Fig. 3D-F): Colonies moderately slow growing reaching on MEA 12-13 $\mathrm{mm}$ diam, on PCA 14-16 mm, and on PDA $14-16 \mathrm{~mm}$ after $7 \mathrm{~d}$ at $25{ }^{\circ} \mathrm{C}$. No sporulation observed after $4 \mathrm{~m}$ at $25^{\circ} \mathrm{C}$.

Notes: Hermatomyces constrictus is unique among the species with two conidium types in having two-celled cylindrical conidia distinctly constricted at the central or eccentric septum. Hughes (1953) described and depicted similarly shaped cylindrical conidia from K(M)-IMI 39940(e) collected in Ghana that were later redrawn by Ellis (1971). They called them "paraphyses" or "setae" and wrongly considered them to belong to $H$. tucumanensis. That specimen is tentatively identified here as $H$. cf. constrictus but differs in having two but also three-celled conidia, slightly or not constricted at the septa and smaller in size reaching up to $45 \mu \mathrm{m}$ in length. The upper cells are cylindrical or subcylindrical to broadly ellipsoidal and often widened at the melanized, slightly rounded apex or dumbbell-shaped to use Ellis's words. This is in contrast to $H$. constrictus where the upper cells are often attenuated at the apex. Therefore, the specimen from Ghana most probably represents a different species.

Additional material examined: Panama: Chiriquí Province: Boquete, Bajo Mono, pipe line trail, $8^{\circ} 49^{\prime} 40.22^{\prime \prime} \mathrm{N} 82^{\circ} 29^{\prime} 26.11^{\prime \prime} \mathrm{W}, 1720 \mathrm{~m}$ a.s.I., on dry rotten twig of unknown tree, 9 Jul. 2017, O. Koukol KZP343 (PRC 4097); Los Algarrobos, path to Majagua river, $8^{\circ} 29^{\prime} 13.86^{\prime \prime} \mathrm{N}$ $82^{\circ} 26^{\prime 2} 2.881^{\prime \prime W}, 105 \mathrm{~m}$ a.s.l., on rotten twig of liana, $8 \mathrm{Jul}$. 2017, O. Koukol KZP328 (PRM 946197). 

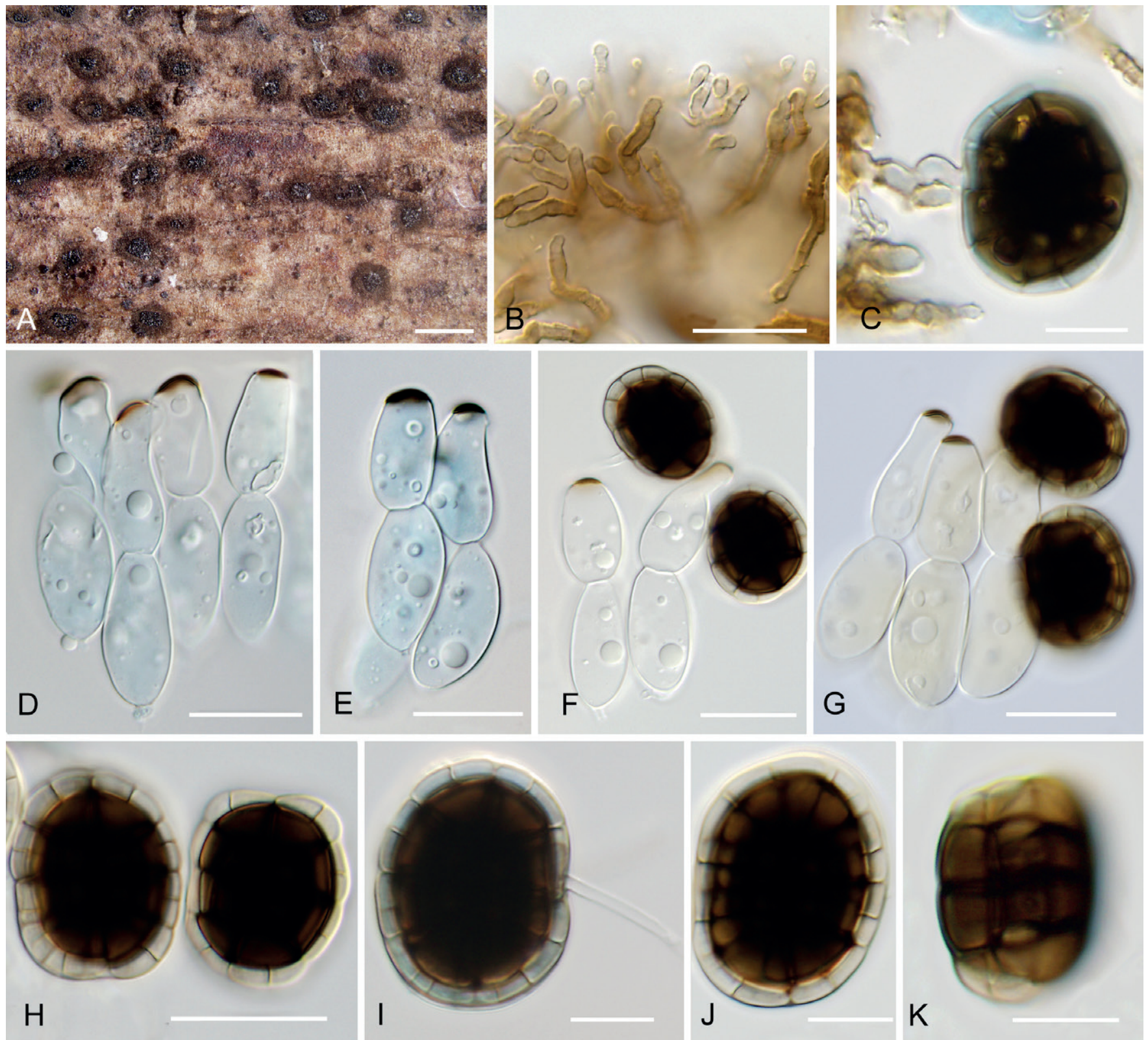

Fig. 5. Hermatomyces constrictus (PMA 116076 - holotype). A. Colonies on the natural substrate. B. Subicular hyphae. C. Young lenticular conidium attached to conidiophore (stained with lacto-cotton blue). D-E. Cylindrical conidia (stained with lacto-cotton blue). F-G. Cylindrical and lenticular conidia. $\mathbf{H}, \mathbf{J}-\mathbf{K}$. Lenticular conidia. I. Mature lenticular conidium attached to conidiophore (stained with lacto-cotton blue). Bar $\mathrm{A}$ $=500 \mu \mathrm{m}, \mathrm{B}-\mathrm{G}, \mathrm{I}-\mathrm{K}=10 \mu \mathrm{m}, \mathrm{H}=20 \mu \mathrm{m}$.

Hermatomyces megasporus Koukol \& G. Delgado, sp. nov.

MycoBank MB824246

(Figs 6, 13C, F, I, L, 16H)

Etymology: megaspores, referring to the largest cylindrical conidia known in Hermatomyces.

Diagnosis: Distinguished from other species of Hermatomyces by the larger size of the conidia and from the morphologically close $\mathrm{H}$. dimorphus in having cylindrical conidia consisting of two columns each of (5-)6-7(-10) swollen cells, appressed together but sometimes separated or rarely diverging, with apical and subapical cells laterally or apically pigmented and sometimes forming short, lateral columns around the middle or basal portions of the conidia.

Type: Panama: Chiriquí Province: Boquete, Bajo Mono, pipe line trail, close to the waterfall, $8^{\circ} 49^{\prime} 34.90 " \mathrm{~N}, 82^{\circ} 29^{\prime} 54.46^{\prime \prime} \mathrm{W}$, $1840 \mathrm{~m}$ a.s.l., on dry rotten twig of unknown shrub, $9 \mathrm{Jul}$. 2017, O. Koukol KZP351 (PMA 116077 - holotype; CCF 5898 - ex-holotype living culture).

Description: Colonies on the natural substrate forming sporodochial, subiculate conidiomata, superficial, scattered when young, crowded and confluent when older, more or less circular, oval or lobed, dark gray-black, consisting of a well-developed, velvety, dense, thick, annular, dark gray, 


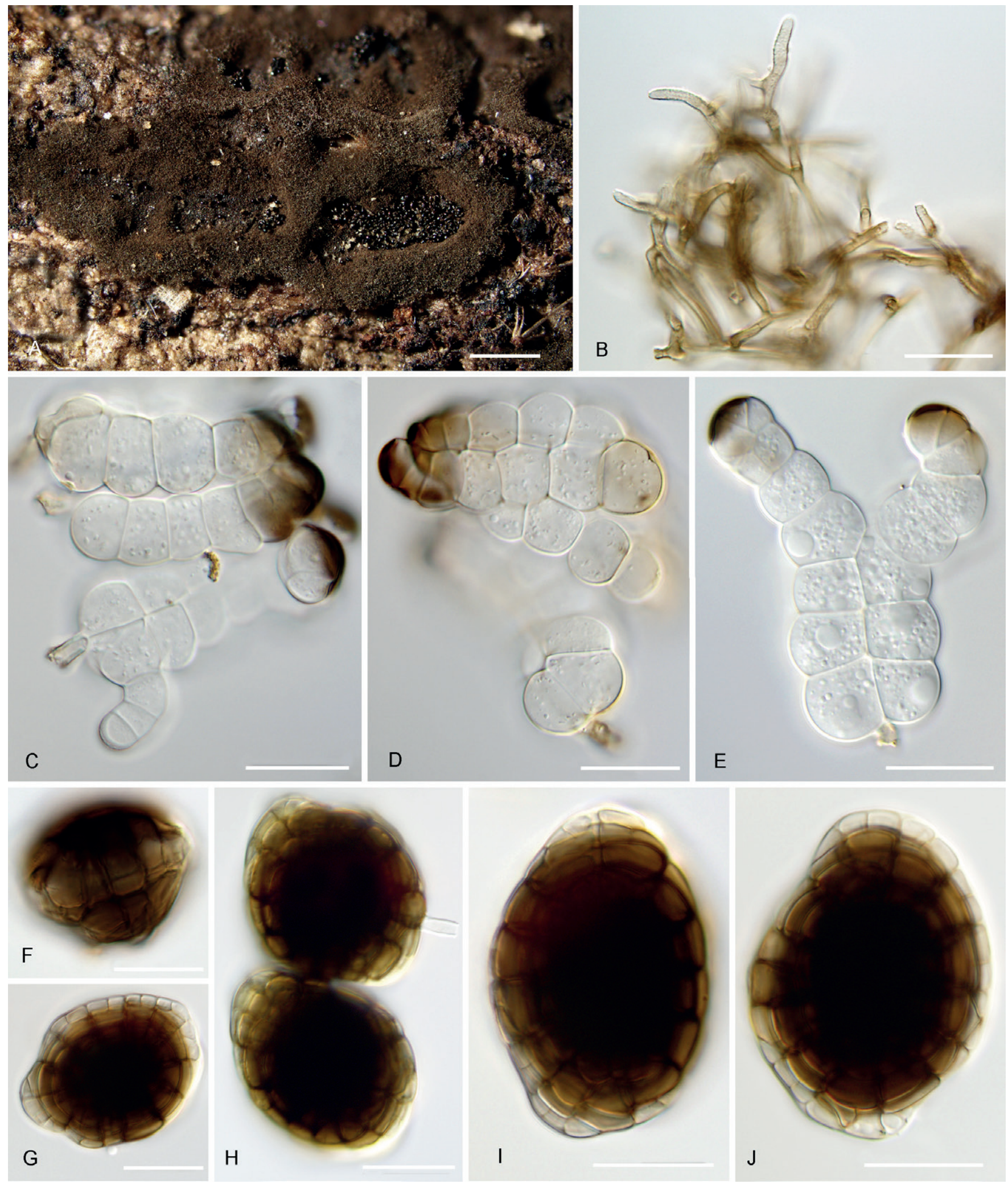

Fig. 6. Hermatomyces megasporus (PMA 116077 - holotype). A. Colonies on the natural substrate showing well-developed subiculum. B. Subicular hyphae. C-E. Cylindrical conidia. F-J. Lenticular conidia. Bar A $=500 \mu \mathrm{m}, \mathrm{B}-\mathrm{J}=20 \mu \mathrm{m}$.

sterile mycelial outer zone enclosing a black or whitish black, glistening, granulose sporulating centre spotted with white cylindrical conidia, circular, oval or lobed by confluence, forming large patches 5-6 mm long when confluent; young colonies consisting only of black lenticular conidia closely packed in a dome-like centre that remain together when disturbed and are surrounded by an orbicular, blackish and flattened outer zone; subicular hyphae and cylindrical conidia apparently develop later. Mycelium superficial composed of a compact network of repent, branched, septate, smooth or verrucose, locally thick-walled, brown hyphae, 2-4 $\mu \mathrm{m}$ wide; subicular hyphae undulate, irregularly geniculate or flexuous, 
pale brown to brown, smooth or finely verruculose to locally verruculose, verrucose or spinulose, thin or locally thick walled, branching and anastomosing forming a moderately dense network. Conidiophores micronematous, mononematous, cylindrical or slightly subulate, hyaline to pale brown, smooth or finely verruculose to verrucose, up to $20 \times 2-4.5 \mu \mathrm{m}$, often corresponding to the conidiogenous cells. Conidiogenous cells monoblastic, integrated, terminal, determinate, subhyaline to pale brown or brown, cylindrical, often arising directly on the superficial mycelium and closely packed together in the fertile centre, sphaerical, subsphaerical or ampulliform, smooth or finely verruculose, $4-7 \times 3-5 \mu \mathrm{m}$. Conidia of two types, solitary, dry; lenticular conidia muriform, smooth, broadly ellipsoidal, ellipsoidal or disc-shaped in front view, rarely subsphaerical, central cells brown to blackish brown or black, peripheral cells pale brown to brown or hyaline, forming a wide and distinct ring $3-5 \mu \mathrm{m}$ wide, constricted at the septa, broadly ellipsoidal in side view where two distinct adpressed halves can be recognized, each half seen laterally as a row of 8-10 cells, end cells pale brown, middle cells blackish brown or black, often slightly attenuated at both round ends, (45-)49-56(-59) $\times(31-)$ 37-46 $\mu \mathrm{m}, 27-30 \mu \mathrm{m}$ thick, L/W = 1.30; cylindrical conidia straight or flexuous, septate, smooth, subhyaline, (37-) 49.5-60.5(67-) × 18-28(-32) $\mu \mathrm{m}$, consisting of two columns of (5-)6-7(-10) swollen cells each, usually appressed together but sometimes separated or rarely diverging, each column with 5-7 transverse septa, 10-19 $\mu \mathrm{m}$ at the widest part, constricted at the septa, often with 0-3 longitudinal or 0-2 oblique septa delimiting smaller cells toward the apex, apical and subapical cells straight, curved or bent to one side, laterally or apically pigmented brown to blackish brown, often a lateral cells is formed and delimited by a longitudinal or oblique septum at the subapical level, protruding and pigmented or not, sometimes short, curved, single columns up to four cells are formed laterally at the middle or basal cells, apical cell rounded or flattened, (9-)14-24(-28) $\mu \mathrm{m}$ wide, basal cells 12-19 $\mu \mathrm{m}$ wide. Sexual morph unknown.

Cultures (Fig. 3G-1): Colonies moderately slow growing reaching on MEA 10-14 $\mathrm{mm}$ diam, on PCA 10-12 mm, and on PDA $17-18 \mathrm{~mm}$ after $7 \mathrm{~d}$ at $25^{\circ} \mathrm{C}$. No sporulation observed after $4 \mathrm{~m}$ at $25^{\circ} \mathrm{C}$.

Notes: Hermatomyces megasporus is a morphologically remarkable species with large lenticular conidia and the largest cylindrical conidia among all currently recognized species of the genus. It is comparable to $H$. dimorphus (Rao \& de Hoog 1986) in conidial morphology and septation, with cylindrical conidia having transverse, longitudinal and oblique septa in both species. The two species differ, however, in the size and number of columns and cells, with $H$. dimorphus having smaller cylindrical conidia, 15-40 × 10-15 $\mu \mathrm{m}$, and four columns, each of seven cells. It also lacks the short, lateral columns of cells sometimes formed around the middle or basal portions of the conidia. Pigmentation usually occurs along a central column or between two opposite columns in side view, and extends beyond the middle of the conidia instead of apically or subapically as in $H$. megasporus. The lenticular conidia, however, are similar in size, reaching 35-55 $\mu \mathrm{m}$ diam in $H$. dimorphus but narrower in side view being only
15-20 $\mu \mathrm{m}$ thick. Compared to other known Hermatomyces species, both $H$. megasporus and $H$. dimorphus show a similar trend in a substantial increase in the number of cells connected with their decrease in size.

Additional material examined: Panama: Chiriquí Province: Boquete, Bajo Mono, pipe line trail, $8^{\circ} 49^{\prime} 40.22^{\prime \prime} \mathrm{N} 82^{\circ} 29^{\prime} 26.11^{\prime \prime} \mathrm{W}, 1720 \mathrm{~m}$ a.s.I., on rotten twig of unknown shrub, 19 Jul. 2016, O. Koukol KZP300 (PRM 946198, CCF 5897-living culture).

Hermatomyces reticulatus (M.L. Farr \& Goos.) Koukol \& G. Delgado, comb. nov.

MycoBank MB824247

(Figs 7, 14A, D, G, J, 17A)

Basionym: Subicularium reticulatum M.L. Farr \& Goos, Mem. N. Y. bot. Gdn. 49: 66 (1989)

Synonym: Hermatomyces subiculosus C.G. Lin et al., Fungal Diversity 80: 73 (2016); as 'subiculosa'.

Type: Venezuela: Miranda State: Parque Nacional Guatopo, road between Santa Teresa and Los Alpes, on wood, 29 Jun1971, K.P. Dumont, J.H. Haines \& C. Blanco (BPI 1100692 - holotype).

Description: Colonies on the natural substrate in the form of sporodochial, subiculate conidiomata, superficial, scattered or crowded and confluent, more or less circular, oval or lobed, brown-black, consisting of a well-developed, velvety, dense, thick, annular, grayish brown sterile mycelial outer zone enclosing a black, glistening, abundantly sporulating granulose centre, circular, oval or lobed by confluence, where conidia are compactly appressed, though easily liberated when touched, 250-750 $\mu \mathrm{m}$ diam when single, forming large patches on the substrate 4-6 mm long when confluent. Mycelium superficial, composed of a compact network of repent, branched, septate, smooth or verruculose, locally thick walled, brown to dark brown hyphae, 2-4.5 $\mu \mathrm{m}$ wide, subicular hyphae septate, branched, flexuous, undulate or irregularly geniculate, pale brown to brown, finely verruculose to locally smooth or verrucose, profusely branching, curving and anastomosing forming a dense network. Conidiophores micronematous or semimacronematous, mononematous, cylindrical, smooth or finely verruculose, pale brown, up to 13 $\mu \mathrm{m}$ long, 4-5 $\mu \mathrm{m}$ wide, often corresponding to conidiogenous cells. Conidiogenous cells monoblastic, integrated, terminal, cylindrical, determinate, subhyaline to pale brown, often arising directly on the superficial mycelium and closely packed together at the fertile centre, sphaerical, subsphaerical or ampulliform, 5-9 × 3-5 $\mu \mathrm{m}$. Conidia of one type, globose, subglobose, broadly ellipsoidal, oblong or somewhat irregular in front view, ellipsoidal or narrowly oblong to oblong in side view where two distinct adpressed halves can be recognized, each half seen laterally as a row of 5-9 cells, sometimes with a deep constriction between halves, end cells and cells along the constriction often pale brown, muriform, with transverse, longitudinal and oblique septa, 4-celled (rarely 3-celled), subhyaline to pale brown and verruculose when young, dark brown to blackish brown and verrucose at maturity, (29.5-) $3-40(-45) \times 25-34(-41) \mu \mathrm{m}, 22-30 \mu \mathrm{m}$ thick, L/W = 1.20. Sexual morph unknown. 

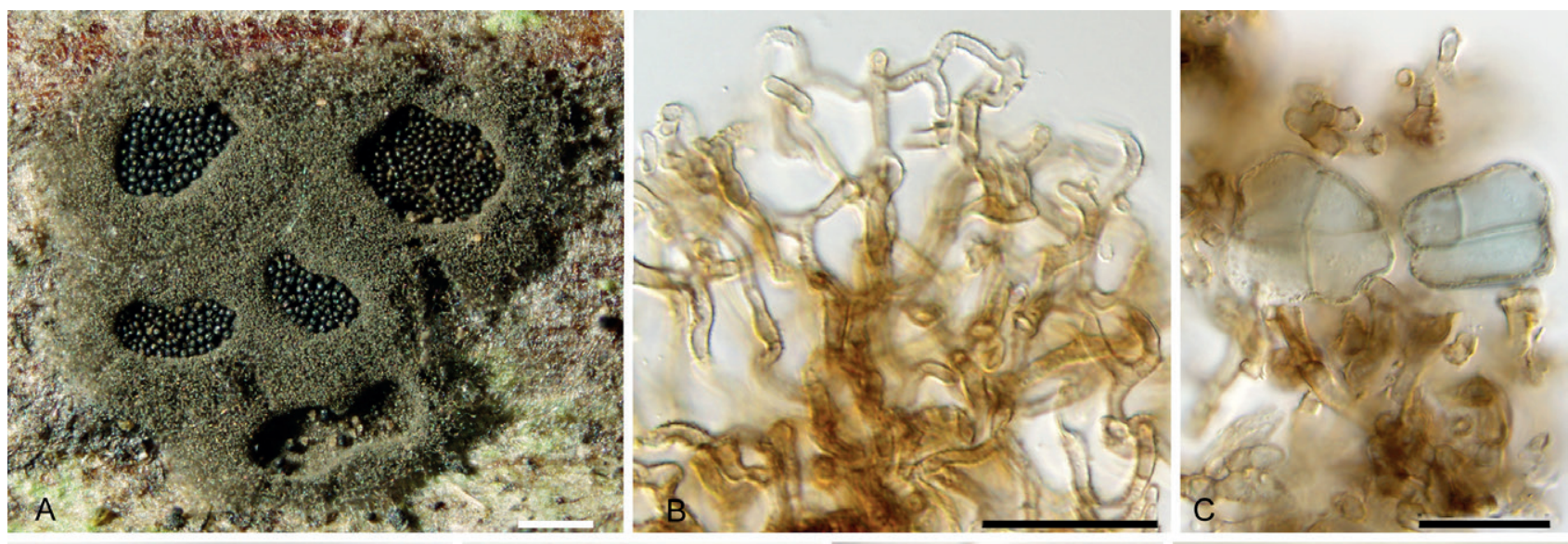

D
$\frac{1}{n}$
ㅍ

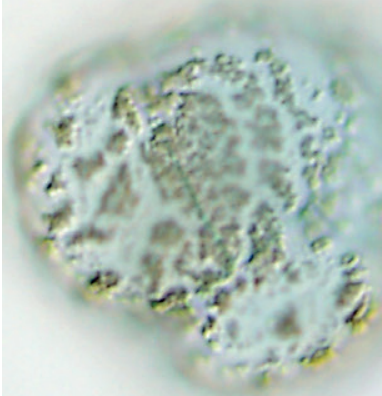

D

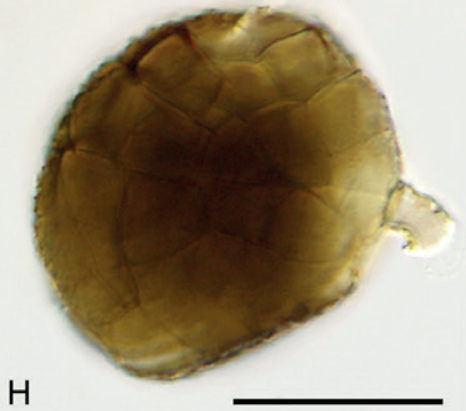

H

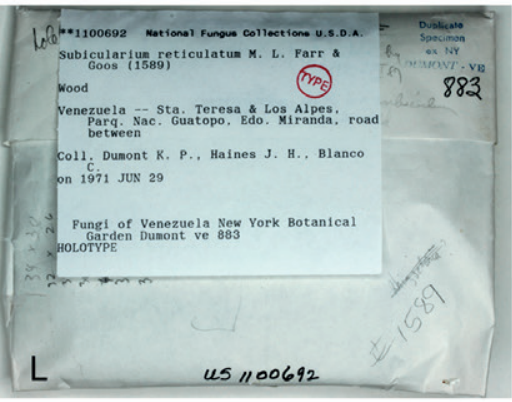

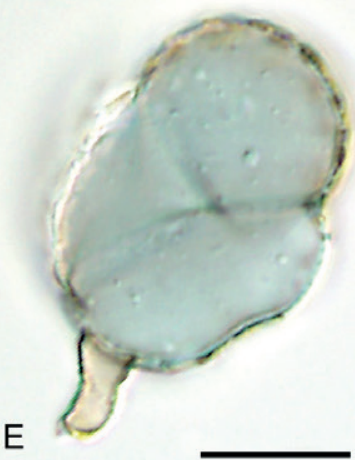

E

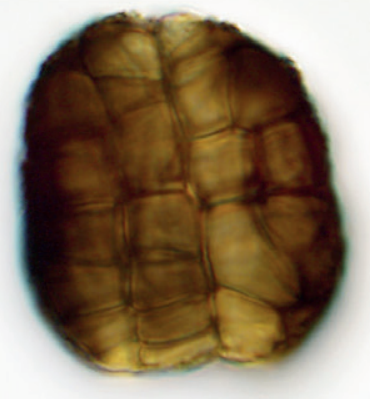

I

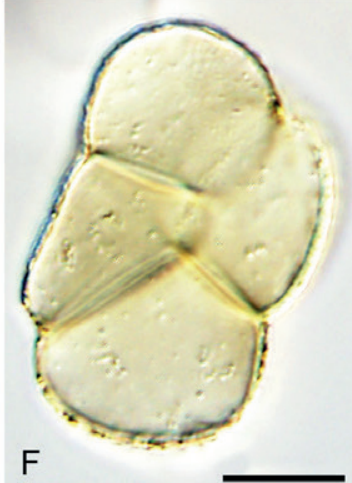

F
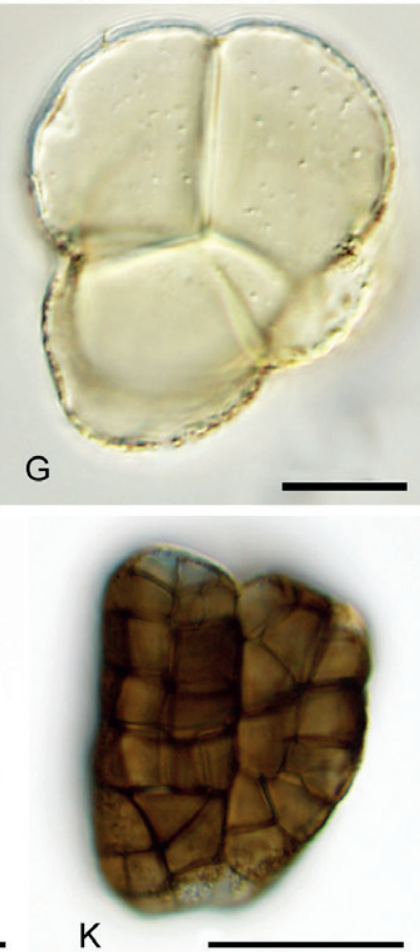

J
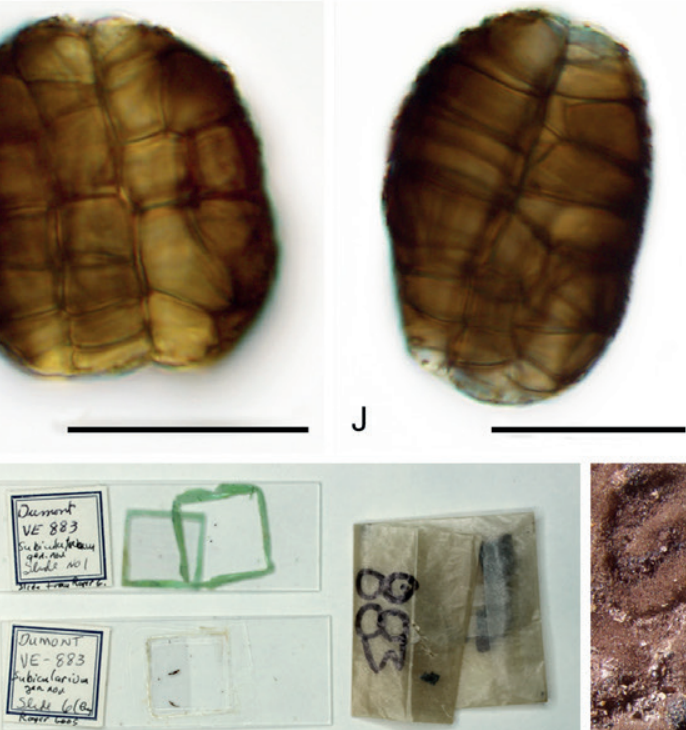

M
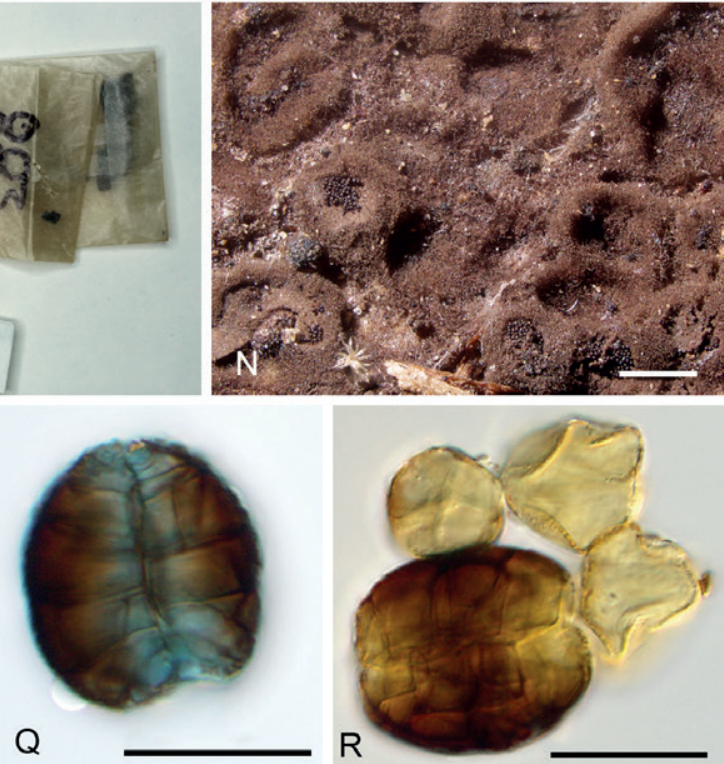

R
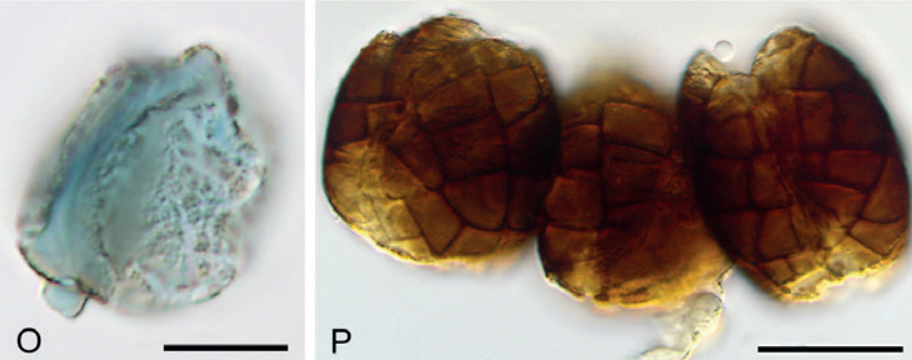

Fig. 7. Hermatomyces reticulatus (PMA 116078-holotype). A. Colonies on the natural substrate showing well-developed subiculum. B. Subicular hyphae. C-G. Young lenticular conidia (stained with lacto-cotton blue at C-E). H-K. Mature lenticular conidia. L-M. Envelope and content of the holotype of Subicularium reticulatum (BPI 1100692). N. Colonies on the natural substrate. O. Young conidium (stained with lacto-cotton blue). P-R. Mature conidia (stained with lacto-cotton blue at $\mathrm{Q}$ ). $\mathrm{Bar} A=500 \mu \mathrm{m}, \mathrm{B}-\mathrm{G}=10 \mu \mathrm{m}, \mathrm{H}-\mathrm{K}=20 \mu \mathrm{m}, \mathrm{N}=500 \mu \mathrm{m}, \mathrm{O}=10 \mu \mathrm{m}, \mathrm{P}-\mathrm{R}=20 \mu \mathrm{m}$. 
Cultures (Fig. 3J-L): Colonies moderately slow growing reaching on MEA 14-15 mm diam, on PCA 10-12 mm, and on PDA $12-13 \mathrm{~mm}$ after $7 \mathrm{~d}$ at $25{ }^{\circ} \mathrm{C}$. No sporulation observed after $4 \mathrm{~m}$ at $25^{\circ} \mathrm{C}$.

Notes: The presence of lobed lenticular conidia that are 4-celled when young, verrucose, dark brown and variably shaped at maturity with numerous oblique septa and lacking the paler ring of peripheral cells, makes $H$. reticulatus distinct from other species of Hermatomyces with one conidium type. Another distinct feature is the formation of a very compact layer of conidia in the sporulating centre of the colony caused by the irregular shape of the conidia (Fig. 14G). This species was first described by Farr \& Goos (1989) from a piece of wood in Venezuela as S. reticulatum. A re-examination of the holotype (BPI 1100692) revealed a fungus morphologically identical to our collections from Panama in the shape and septation of the conidia, particularly the presence of longitudinal and oblique septa (Fig. 60-R). Conidia are also similar in size having 28-35 $\mu \mathrm{m}$ long and 26-32 $\mu \mathrm{m}$ wide.

Molecular sequence data retrieved from the Panama collections clustered in all phylogenies with ex-type sequences of $H$. subiculosus described by Hyde et al. (2016) from decaying wood in Thailand, but their phenotypic characteristics were slightly different. Conidia in the holotype are smaller, 15-35 $\mu \mathrm{m}$ long and 18-30 $\mu \mathrm{m}$ wide at the broadest part (Hyde et al. 2016), but considering their identical sequences, this phenotypic difference can be attributed to intraspecific variability. Hyde et al. (2016) suggested the monotypic Subicularium to be a later synonym of Hermatomyces and also considered S. reticulatum a later synonym of Scyphostroma mirum. Based on our morphological study of the holotype of Subicularium reticulatum and the results of molecular analyses, we make the new combination $H$. reticulatus and reduce $H$. subiculosus to synonymy.

Additional material examined: Panama: Chiriquí Province: west of Los Algarrobos, path through pastures along Majagua river, $8^{\circ} 29^{\prime} 47.82^{\prime \prime} \mathrm{N} 82^{\circ} 26^{\prime} 19.721^{\prime \prime} \mathrm{W}, 110 \mathrm{~m}$ a.s.l., on rotten twig of unknown tree, 8 Jul. 2016, O. Koukol KZP191 (PRM 946199; CCF 5893 - living culture); ibid., on dry rotten twig of unknown tree, $14 \mathrm{Jul}$, 2017, O. Koukol KZP409 (PMA 116078; CCF 5905 - living culture); ibid. on wet rotten liana, 14 Jul, 2017, O. Koukol KZP414 (PRC 4098; CCF 5910 - living culture).

\section{Hermatomyces sphaericoides Koukol \& G. Delgado, sp. nov. \\ MycoBank MB824248}

(Figs 8, 14B, E, H, K, 17B)

Etymology: sphaericoides, recalling $H$. sphaericus, to which it is morphologically similar.

Diagnosis: Differs from the morphologically close $H$. sphaericus in the consistently dark brown to blackish brown, finely verruculose lenticular conidia, ellipsoidal in side view and with an inconspicuous or narrow outer ring of peripheral cells.
Type: Panama: Chiriquí Province: west of Los Algarrobos, path through pastures along Majagua river, $8^{\circ} 29^{\prime} 47.82^{\prime \prime} \mathrm{N}$ $82^{\circ} 26^{\prime} 19.721^{\prime \prime} \mathrm{W}, 110 \mathrm{~m}$ a.s.l., on dry rotten twig of unknown tree, 14 Jul. 2017, O. Koukol KZP412 (PMA 116079 holotype; CCF 5908 - ex-holotype living culture).

Description: Colonies on the natural substrate forming sporodochial, subiculate conidiomata, superficial, more or less circular, oval or lobed, scattered or crowded and confluent, dark gray-black, consisting of a velvety, dense, thick, annular, dark gray, sterile mycelial outer zone enclosing a black, glistening, flattened, abundantly sporulating granulose centre, circular, oval or lobed by confluence, where conidia are easily liberated when touched, 400-700 $\mu \mathrm{m}$ diam when solitary, up to $1500 \mu \mathrm{m}$ long when confluent. Mycelium superficial, composed of a compact network of repent, branched, septate, smooth, pale brown or brown hyphae, 1.5-3.5 $\mu \mathrm{m}$ wide, subicular hyphae septate, pale brown, brown in mass, branched, mostly smooth but locally verrucose or sometimes finely verruculose, flexuous, undulate or strongly geniculate, branching and anastomosing to form a dense network. Conidiophores inconspicuous, rarely seen, up to $14 \mu \mathrm{m}$ long and $3.5 \mu \mathrm{m}$ wide, often corresponding to conidiogenous cells. Conidiogenous cells monoblastic, determinate, arising directly on the superficial mycelium and closely packed together at the fertile centre, sphaerical, subsphaerical, ellipsoidal or ampulliform, pale brown, smooth or finely verruculose, 3-7 $\times 2-5 \mu \mathrm{m}$. Conidia of one type, solitary, dry, lenticular, globose, subglobose, broadly ellipsoidal or rarely disc-shaped in front view, muriform, sometimes slightly constricted at the septa, finely verruculose, central cells dark brown to blackish brown, peripheral cells narrow and brown, rarely pale brown, ellipsoidal or oblong in side view where two distinct adpressed halves can be recognized, each half seen laterally as a row of 5-7 cells, end cells pale brown to brown, middle cells dark brown to blackish brown, with a narrow, sometimes deep constriction between them, (20.5-) 24.5-28(-31) × (20-)23-26(-29) $\mu \mathrm{m},(15-) 19-25 \mu \mathrm{m}$ thick, $\mathrm{L} / \mathrm{W}=1.08, \mathrm{~L} / \mathrm{T}=1.26$. Sexual morph unknown.

Cultures (Fig. 3M-O): Colonies moderately slow growing reaching on MEA 12-13 mm diam, on PCA 14-16 mm, and on PDA $14-16 \mathrm{~mm}$ after $7 \mathrm{~d}$ at $25^{\circ} \mathrm{C}$. Sporulation on PDA late, within $4 \mathrm{~m}$ at $25^{\circ} \mathrm{C}$ and observed only in one (KZP470) out of five strains. Lenticular conidia (22.5-)24.5-28(-30) $\times$ 22.5-26.5(-29) $\mu \mathrm{m}$ and 19-23 $\mu \mathrm{m}$ thick.

Notes: Hermatomyces sphaericoides is hardly distinguishable from $H$. sphaericus on morphological grounds, as indicated by the specific epithet. The two species are, however, phylogenetically distinct and collections of both taxa grouped distantly in all phylogenies (Figs 1-2). Morphologically, in contrast to $H$. sphaericus, the conidia of $H$. sphaericoides are consistently dark brown to blackish brown and finely verruculose with the outer ring of peripheral cells inconspicuous or narrow and brown, sometimes only slightly constricted at the septa. Further differences can be found in side view where conidia of $H$. sphaericoides tend to be more ellipsoidal $(\mathrm{L} / \mathrm{T}=1.26)$ compared to broadly ellipsoidal in $H$. sphaericus $(\mathrm{L} / \mathrm{T}=1.22)$ although this difference was not 


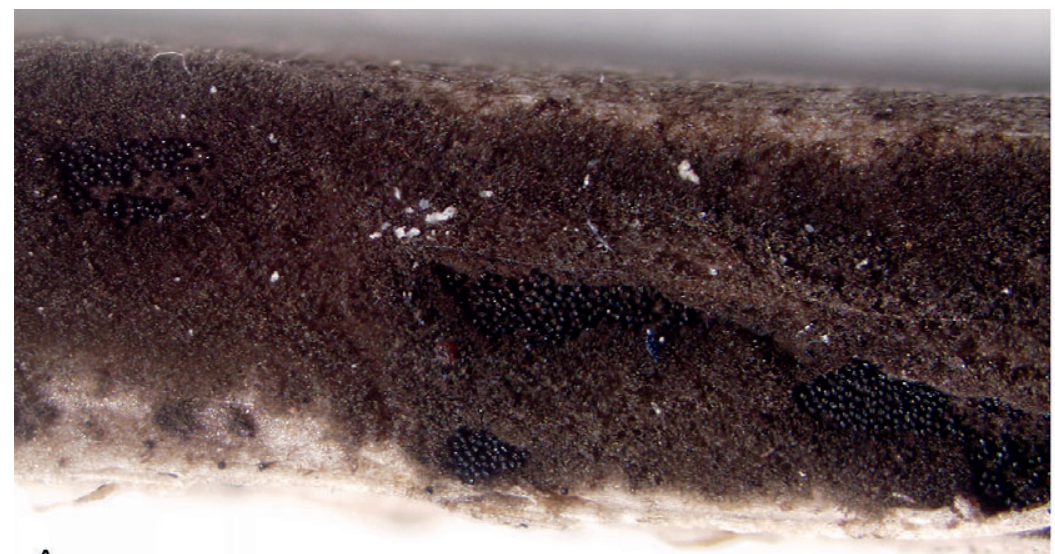

A
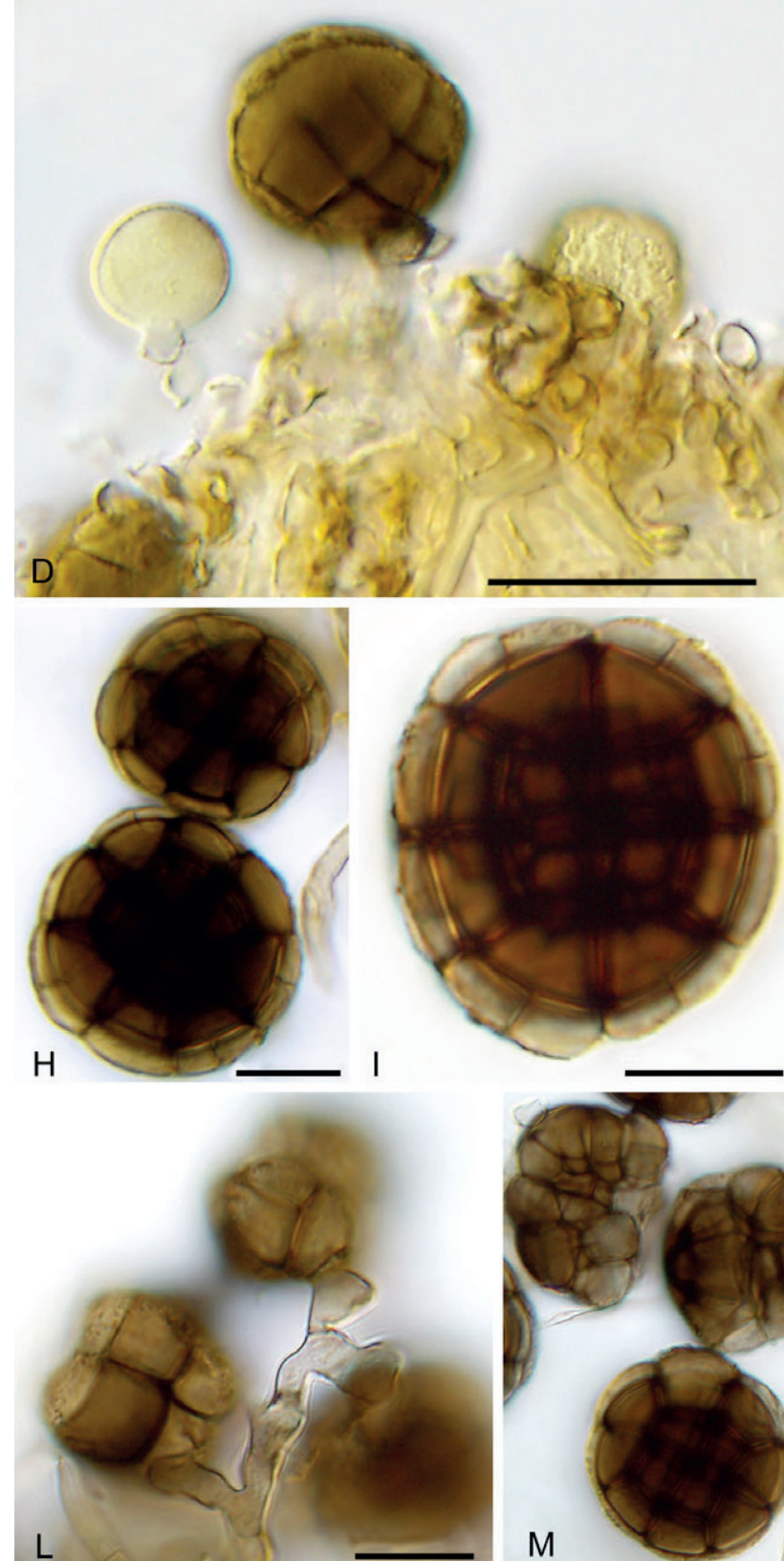
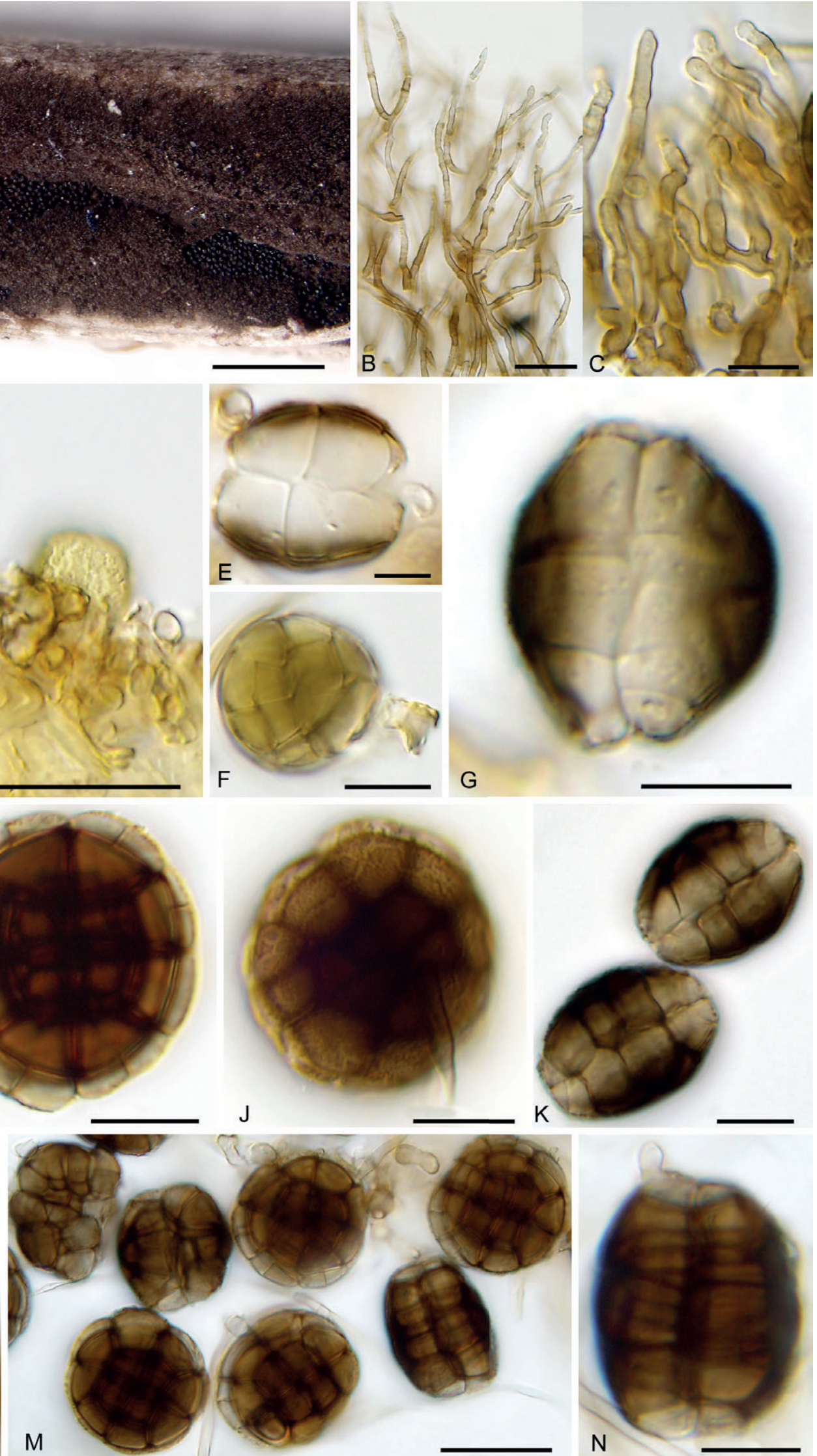

Fig. 8. Hermatomyces sphaericoides (PMA 116079 - holotype) A. Colonies on the natural substrate. B-C. Subicular hyphae. D. Conidiogenous cells and young conidia. E-G. Young conidia. H-K. Mature conidia. L-N. Conidia on PDA. Bar A = 500 $\mu \mathrm{m}, \mathrm{B}=20 \mu \mathrm{m}, \mathrm{C}-\mathrm{L}=10 \mu \mathrm{m}, \mathrm{M}=20$ $\mu \mathrm{m}, \mathrm{N}=10 \mu \mathrm{m}$. 
significant. Subicular hyphae are mostly smooth or sparingly verrucose, less compact and forming a dark gray subiculum around the fertile centre but combinations of some of these features were similarly found in $\mathrm{H}$. sphaericus specimens.

Additional material examined: Panama: Chiriquí Province: west of Los Algarrobos, path through pastures along Majagua river, $8^{\circ} 29^{\prime} 47.82^{\prime \prime} \mathrm{N} 82^{\circ} 26^{\prime} 19.721^{\prime \prime} \mathrm{W}, 110 \mathrm{~m}$ a.s.l., on dry rotten twig of unknown tree, 14 Jul. 2017, O. Koukol KZP411 (PRM 946200; CCF 5907 - living culture); Los Algarrobos, path to Majagua river, $8^{\circ} 29^{\prime} 13.86^{\prime \prime} \mathrm{N} 82^{\circ} 26^{\prime} 2.881^{\prime \prime} \mathrm{W}, 105 \mathrm{~m}$ a.s.l., on rotten leaf of Astrocaryum standleyanum (Arecaceae), 8 Jul. 2017, O. Koukol KZP320 (PRC 4102; CCF 5895- living culture); ibid., on rotten petiole of unknown liana leaf, 8 Jul. 2017, O. Koukol KZP326 (PRC 4103; CCF 5896- living culture); Bocas del Toro Province: along the road between Almirante and Rambála, 9¹0'1.79"N 82 18'57.27'W, $201 \mathrm{~m}$ a.s.l., on dry rotten stem of unknown liana, 22 Jul. 2017, O. Koukol KZP470 (UCH).

\section{Hermatomyces sphaericus (Sacc.) S. Hughes,} Mycol. Pap. 50: 100 (1953).

(Figs 9, 10, 14C, F, I, L, 17C)

Basionym: Stemphylium sphaericum Sacc., Atti Accad. Sci. Ven.-Trent.-Istr. 10: 86 (1917).

Synonyms: Hermatomyces chromolaenae Jin F. Li et al., Index Fungorum 342: 1 (2017).

Hermatomyces saikhuensis Tibpromma et al., Phytotaxa 275: 134 (2016).

Hermatomyces tectonae Doilom et al., Fungal Div. 82: 117 (2016).

Type: Philipines: Laguna: Los Baňos, on decorticated braches of Barleria cristata (Acanthaceae). Dec. 1915, C. F. Baker [Fungi Malayana no. 395] (K(M) IMI 37763 - holotype).

Description: Colonies on the natural substrate in the form of sporodochial, subiculate conidiomata, superficial, more or less circular, oval or lobed, scattered or crowded and confluent, brown-black or gray-black, consisting of a velvety, dense, thick, annular, brown or gray, sterile mycelial outer zone enclosing a black, glistening, abundantly sporulating granulose centre, circular, oval or lobed by confluence where conidia are easily liberated when touched, 300-800 $\mu \mathrm{m}$ diam when solitary, up to $1600 \mu \mathrm{m}$ long when confluent. Mycelium superficial, composed of a tightly compact network of repent, branched, septate, smooth or finely verruculose, locally thick-walled, brown hyphae, 2-4 $\mu \mathrm{m}$ wide, subicular hyphae flexuous, undulate, strongly or irregularly geniculate, subhyaline or pale brown to brown, branched, smooth, finely verruculose or locally verrucose, branching and anastomosing to form a dense network. Conidiophores micronematous, mononematous, cylindrical or forked once, subhyaline or pale brown, up to 15 long and 2-4 $\mu \mathrm{m}$ wide, often corresponding to conidiogenous cells. Conidiogenous cells monoblastic, integrated, terminal, cylindrical, determinate, subhyaline to pale brown, smooth or finely verruculose, often arising directly on the superficial mycelium and closely packed together at the fertile centre, sphaerical, subsphaerical or ampulliform, $4-10 \times 3-4 \mu \mathrm{m}$. Conidia of one type, solitary, dry, lenticular, globose, subglobose, disc-shaped or broadly ellipsoidal in front view, muriform, smooth or verruculose, central cells brown, dark brown to blackish brown, sometimes all cells brown and muriform septation visible, outer ring of peripheral cells narrow or wide, pale brown to brown, often constricted at septa, broadly ellipsoidal or oblong in side view where two distinct adpressed halves can be recognized, each half seen laterally as a row of 4-7 cells, end cells subhyaline to pale brown, middle cells brown to blackish brown, with a narrow, sometimes deep constriction between them, (21-)24-29($32.5) \times(18-) 21-27(-31.5) \mu \mathrm{m}, 16-23.5(-28) \mu \mathrm{m}$ thick, L/W $=1.08, \mathrm{~L} / \mathrm{T}=1.22$.

Cultures (Fig. 3P-R): Colonies moderately slow growing reaching on MEA 13-17 $\mathrm{mm}$ diam, on PCA12-16 mm, and on PDA 12-16 mm after $7 \mathrm{~d}$ at $25^{\circ} \mathrm{C}$. Sporulation on PDA late within $4 \mathrm{~m}$ at $25^{\circ} \mathrm{C}$ and observed only in one (CCF 5911) of 12 strains. Lenticular conidia (24.5-)26.5-30(-31.5) × 22.5$29 \mu \mathrm{m}$ and (18.5-)21-25.5 $\mu \mathrm{m}$ thick.

Notes: Hermatomyces sphaericus was the first species with one conidium type transferred into the genus (Hughes 1953). Our numerous collections match well with the type collection (K(M)-IMI 37763) and Hughes' description based on his specimens from bark of Albizia gummifera (Mimosaceae), Averhoa carambola (Oxalidaceae), Theobroma cacao (Sterculidaceae), and rachides of leaves of Elais guineensis (Arecaceae) collected in Ghana. He described the lenticular conidia as $26-31 \times 25-30 \mu \mathrm{m}$ and $20-25 \mu \mathrm{m}$ thick. Other specimens described in the literature are reported as having similar or slightly smaller conidia. Holubová-Jechová \& Mercado (1986) reported conidia as $24-28.8 \times 24-27 \mu \mathrm{m}$ and 16.6-21 $\mu \mathrm{m}$ thick for a specimen collected on a dead branch from Cuba (PRM 838101) and revised in this study, while Heredia et al. (1997) described conidia as 24-29 × 24$30 \mu \mathrm{m}$ and $15-21 \mu \mathrm{m}$ thick for specimens collected on fallen twigs and branches of angiosperms and on a palm petiole in Mexico. Zhang et al. (2009) provided conidial dimensions of 23-29 × 22-26 $\mu \mathrm{m}$ for specimens collected on a dead branch of Rauvolfia vomitoria (Apocynaceae) and dead wood of Tectona grandis (Lamiaceae) in China. Mel'nik (2000) reported conidia $26-31 \times 25-30 \mu \mathrm{m}$ and $25-30 \mu \mathrm{m}$ thick for a specimen collected on dry thin branches of Larix sibirica (Pinaceae) in Russia, which is, however, questionable, because it represents the only record outside the tropics.

Examination and comparison of the specimens from Panama revealed morphological variability in other features, e.g. the subiculum in PRC 4100 was brown and composed of strongly geniculate, brown, smooth or finely verruculose hyphae forming compact masses, while the subiculum in PRC 4105 was gray and composed of subhyaline to pale brown, irregularly geniculate, undulate and loose hyphae with some degree of ornamentation, finely verruculose to locally verruculose. Conidial ornamentation was mainly verruculose throughout Panamanian specimens. Re-examination of PRM 838101 from Cuba also revealed the presence of verruculose conidia. Surprisingly, this feature has been rarely mentioned in descriptions of $H$. sphaericus and wall ornamentation, if smooth or not, has often been overlooked for both conidia and subicular hyphae. The only exceptions were Hughes (1953), who described subicular hyphae as smooth, and Zhang 

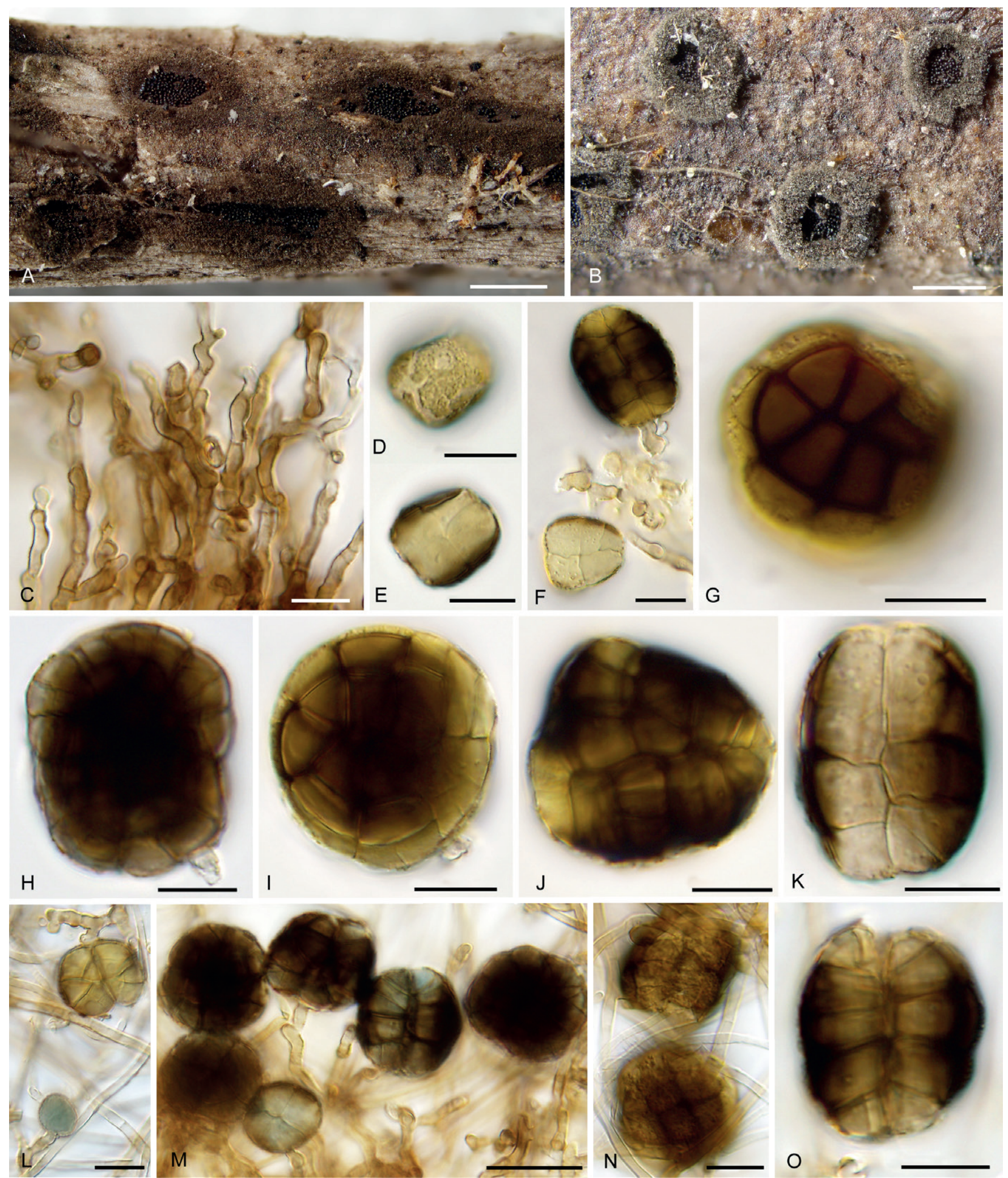

Fig. 9. Hermatomyces sphaericus (PMA 116080) A-B. Colonies on the natural substrate showing morphological variability. C. Subicular hyphae. D-G. Young conidia. H-K. Mature conidia. L. Young conidia on PDA (stained with lacto-cotton blue at L-M). M-O. Mature conidia on PDA. Bar A-B $=500 \mu \mathrm{m}, \mathrm{C}-\mathrm{L}=10 \mu \mathrm{m}, \mathrm{M}=20 \mu \mathrm{m}, \mathrm{N}-\mathrm{O}=10 \mu \mathrm{m}$.

et al. (2009) who mentioned smooth conidia. Indeed, the conidia in permanent slides of the holotype (Fig. 10B-D) are either smooth or inconspicuously verruculose. Sporulation in culture media, on the other hand, was rare with only one of 12 isolates able to produce conidia after $4 \mathrm{~m}$ of incubation.
In contrast, Zhang et al. (2009) reported sporulation of two strains after 6-10 d when grown on PDA at $24-25^{\circ} \mathrm{C}$ in the only reference to cultural data available so far for $H$. sphaericus. These examples, based on several collections of different origins, show that $H$. sphaericus is a plurivorous, 


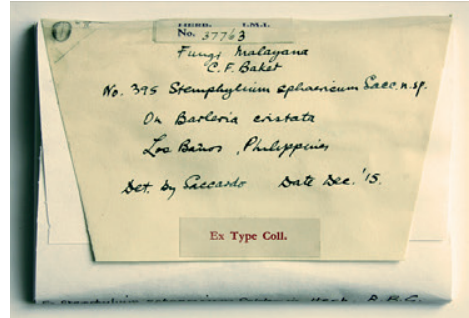

A

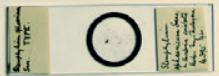

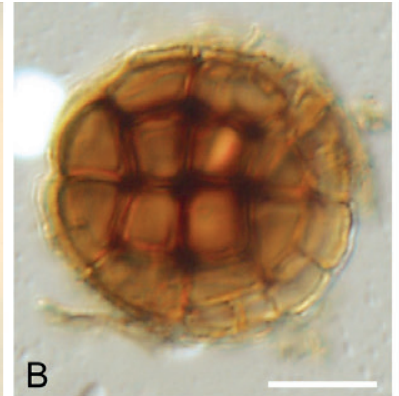
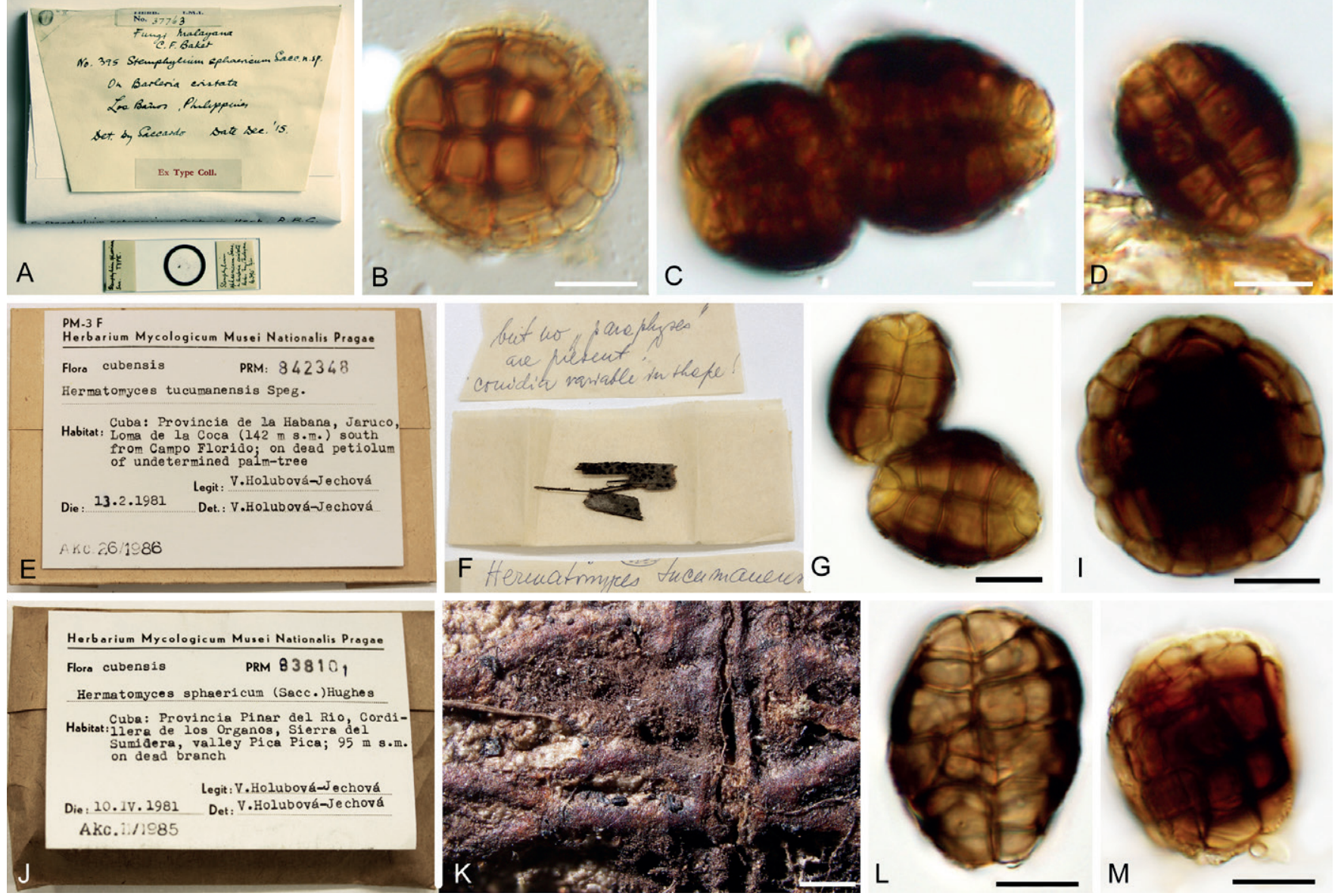

Fig. 10. Revised fungarium collections of Hermatomyces sphaericus A. Envelope of the holotype of Stemphylium sphaericum (K(M) IMI 37763). B-D. Mature conidia. E. Envelope of collection PRM 842348. F. Content of the envelope including remarks on morphology. G-I. Mature conidia. J. Envelope of collection PRM 838101. K. Colony on the substrate. L-M. Mature conidia. Bar B-D = $10 \mu \mathrm{m}, \mathrm{G}-\mathrm{I}=10 \mu \mathrm{m}, \mathrm{K}=500 \mu \mathrm{m}, \mathrm{L}-\mathrm{M}=$ $10 \mu \mathrm{m}$.

morphologically variable species whose morphology may depend either on environmental or cultural conditions, the plant species on which the fungus is growing and possibly also to the age of the colony.

Hermatomyces sphaericus has been further recorded on the dead rachis and petiole of Archontophoenix alexandrae from Hong Kong and Singapore (Taylor \& Hyde 2003), on dead leaves of Chamaedorea sp. (both Arecaceae) and plant debris from Mexico (Heredia \& Mercado 1998, Becerra et al. 2007), on branches and leaf litter of Shorea sp. (Dipterocarpaceae) in Indonesia (Harahap 2013), on dead branches and wood of Syzygium jambos (Myrtaceae) and Pisonia aculeata (Nyctaginaceae), respectively, from Cuba (Delgado et al. 2002, Mercado et al. 2002) and on submerged twigs and twigs in bird nests from Brazil (Barbosa \& Gusmão 2011, Conceição \& Marques 2015). It is considered the most widespread species in the genus (Hashimoto et al. 2017) with a pantropical distribution. However, in the absence of available voucher specimens or molecular data, the distribution of $H$. sphaericus in all the countries mentioned in the literature cannot be confirmed. In view of the high morphological similarity with $H$. sphaericoides and in the absence of reference molecular data, we consider $H$. sphaericus to be the widespread species while $H$. sphaericoides is currently known only from Panama.
In this context, two recently described species with one conidium type, $H$. saikhuensis and $H$. chromolaenae, represent $H$. sphaericus based on morphological and molecular data and are considered conspecific here. They were described based on single isolates collected on dead leaves of Pandanus odorifer (Pandanaceae) and a dead stem of Chromolaena odorata (Asteraceae) (Tibpromma et al. 2016, 2017), respectively, in Thailand. The phenotypic differences, mainly smaller lenticular conidia, 14-21.5 × 11$19 \mu \mathrm{m}$ for $H$. saikhuensis and 9-10.5 × 10-11.5 $\mu \mathrm{m}$ for $H$. chromolaenae, may be attributed to intraspecific variability. The sequences originating from ex-type cultures of these taxa clustered in all our phylogenies with the numerous sequences belonging to our specimens of $H$. sphaericus (Fig. 1). Although Tibpromma et al. (2017) observed some segregation in their phylogenies this should be considered artificial and a sequencing error. When available sequences from GenBank were clustered with our dataset, the only variability was found for LSU sequences on their flanking regions in an area where all other sequences are conserved.

Additional material examined: Panama: Chiriquí Province: Los Algarrobos, path to Majagua river, $8^{\circ} 29^{\prime} 13.86^{\prime \prime} \mathrm{N} 82^{\circ} 26^{\prime} 2.881^{\prime \prime} \mathrm{W}, 105$ m a.s.I., on heavily rotten leaf of Arecaceae, 12 Jul. 2016, P. Zehnálek KZP241 (PRC 4100; CCF - living culture); David, UNACHI, Botanical 
Garden, along San Cristobal river, $8^{\circ} 26^{\prime} 3.49^{\prime \prime} \mathrm{N} 82^{\circ} 27^{\prime} 8.802$ 'W, $45 \mathrm{~m}$ a.s.I., on dry rotten stem of unknown liana, 11 Jul 2017, L. Janošík KZP375 (PRC 4104; CCF 5902- living culture); ibid., on dry rotten stem of unknown liana, 11 Jul. 2017, L. Janošík KZP376 (PRC 4106; CCF 5902- living culture); ibid., on dry rotten hanging twig of Guazuma ulmifolia (Malvaceae), 19 Jul. 2017, O. Koukol KZP441 (UCH); west of Los Algarrobos, path through pastures along Majagua river, $8^{\circ} 29^{\prime} 47.82^{\prime \prime} \mathrm{N} 82^{\circ} 26^{\prime} 19.721^{\prime \prime} \mathrm{W}, 110 \mathrm{~m}$ a.s.l., on wet rotten stem of unknown liana, 14 Jul. 2017, O. Koukol KZP410 (PMA 116085; CCF 5906- living culture); ibid., on dry rotten twig of unknown tree, 14 Jul. 2017, O. Koukol KZP415 (PMA 116080; CCF 5911- living cultur); Boquete, Lago La Estrella, 843'44.09”N 82²3'2.465”W, 977 $\mathrm{m}$ a.s.l., on dry rotten hanging twig of unknown tree, $19 \mathrm{Jul}$. 2017, $\mathrm{O}$. Koukol KZP445 (PMA 116081; CCF 5914- living cultur); Bocas del Toro Province: Changuinola, dirty road close to the old railway bridge, $9^{\circ} 24^{\prime} 21.85^{\prime \prime} \mathrm{N} 82^{\circ} 31^{\prime} 12.24$ "W, $18 \mathrm{~m}$ a.s.l., dry rotten hanging twig of unknown Fabaceae, 20 Jul. 2017, O. Koukol KZP455 (PRC 4116); along the road between Almirante and Changuinola, $9^{\circ} 21^{\prime} 57.54$ " $\mathrm{N}$ $82^{\circ} 28^{\prime} 33.29$ "W, $135 \mathrm{~m}$ a.s.l., on dry rotten hanging twig of unknown tree, 21 Jul. 2017, O. Koukol KZP457 (PRC 4108; CCF 5916- living culture); ibid., on dry rotten hanging unknown liana, 21 Jul. 2017, O. Koukol KZP458 (PRM 946201); along the road between Almirante and Changuinola, $9^{\circ} 20^{\prime} 46.66^{\prime \prime} \mathrm{N} 82^{\circ} 28^{\prime} 23.24^{\prime \prime} \mathrm{W}, 128 \mathrm{~m}$ a.s.l., on dry rotten hanging twig of unknown tree, $21 \mathrm{Jul}$. 2017, O. Koukol KZP459 (PMA 116082; CCF 5917- living culture); ibid., on dry rotten hanging twig of unknown tree, 21 Jul. 2017, O. Koukol KZP460 (PRC 4105); along the road between Almirante and Changuinola, $9^{\circ} 18^{\prime} 51.75^{\prime \prime} \mathrm{N}$ $82^{\circ} 27^{\prime} 0.47^{\prime \prime} \mathrm{W}, 52 \mathrm{~m}$ a.s.l., on dry rotten hanging twig of unknown tree, 21 Jul. 2017, O. Koukol KZP462 (UCH); along the road between Almirante and Rambála, 9`12'9.65”N 82²0'48.80”W, 36 m a.s.l., dry rotten hanging twig of unknown tree, 22 Jul. 2017, O. Koukol KZP469 (PRC 4117). - Cuba: La Habana Province: Jaruco, Loma de la Coca, south of Campo Florido, on dead petiole of an undetermined palm tree (Arecaceae), 13 Feb. 1981, V. Holubová-Jechová (PRM 842348; as H. tucumanensis); Pinar del Rio, Sierra de Sumidero, Pica Pica valley, on dead branch, 10 Apr. 1981, V. Holubová-Jechová (PRM 838101).

Hermatomyces tucumanensis Speg., Anal. Mus. nac. B. Aires, ser. 3 13: 446 (1911).

(Figs 11, 15A, C, E, G, 16K)

Description: Colonies on the natural substrate in the form of sporodochial, subiculate conidiomata, superficial, more or less circular, oval or lobed, scattered or crowded and confluent, gray-black, consisting of a velvety, dense, thick, annular, gray, sterile mycelial outer zone enclosing a black or whitish black, glistening, abundantly sporulating granulose centre, circular, oval or lobed by confluence where cylindrical conidia are seen among the lenticular ones and are easily liberated when touched, 250-500 $\mu \mathrm{m}$ diam when solitary, up to $900 \mu \mathrm{m}$ long when confluent. Mycelium superficial, composed of a loose or compact network of repent, branched, septate, anastomosing, smooth or finely verruculose, locally verruculose or verrucose, thin or thick walled, pale brown to brown hyphae, 2-4 $\mu \mathrm{m}$ wide; subicular hyphae ascending, branched, septate, verruculose or verrucose, pale brown to brown, erect, flexuous, undulate or irregularly geniculate, branching and rarely anastomosing to form a moderately dense network. Conidiophores micronematous, mononematous, cylindrical, hyaline to pale brown, smooth, up to $12 \times 3-4 \mu \mathrm{m}$, often corresponding to conidiogenous cells. Conidiogenous cells monoblastic, integrated, terminal, determinate, often arising directly on the superficial mycelium and closely packed together at the fertile centre, subsphaerical, ovoid or ampulliform, pale brown to brown, smooth, 4-8 × 3-5 $\mu \mathrm{m}$. Conidia of two types, solitary, dry; lenticular conidia muriform, smooth, ellipsoidal in front view, central cells mostly black or dark brown to blackish brown, peripheral cells hyaline to subhyaline, forming a distinct but often incomplete ring up to $4 \mu \mathrm{m}$ wide, slightly constricted at the septa or not, narrowly oblong in side view with the two halves not readily recognizable, each half seen laterally as a row of $6-7$ cells, end cells hyaline to subhyaline, middle cells dark brown to blackish brown, (22-)27-35 × 18-25 $\mu \mathrm{m}, 12-17 \mu \mathrm{m}$ thick, $\mathrm{L} / \mathrm{W}=1.38$; cylindrical conidia straight or slightly flexuous, septate, smooth, subcylindrical or obclavate, consisting of two columns of 3-6 cells each arising from one or two basal cells, each column with 3-5 transverse septa and sometimes with $0-1$ oblique septa delimiting smaller cells toward the apex, hyaline, with a distinct dark brown pigmentation running from the top downwards and narrowing to a point close to the basal cell(s), apex rounded and widened, (21-)23-26(-28.5) × 7-14 $\mu \mathrm{m}$. Sexual morph unknown.

Cultures (Fig. 3S-U): Colonies moderately slow growing reaching on MEA 12-13 $\mathrm{mm}$ diam, on PCA 14-16 mm, and on PDA $14-16 \mathrm{~mm}$ after $7 \mathrm{~d}$ at $25^{\circ} \mathrm{C}$. No sporulation observed after $4 \mathrm{~m}$ at $25^{\circ} \mathrm{C}$.

Notes: Spegazzini (1911) described H. tucumanensis, the generic type, from a rotten branch of Smilax campestris (Smilacaceae) and Celtis sp. (Cannabaceae) in Argentina. It is evident from his fig. 65 that he considered the cylindrical conidia to be conidiophores ("sporophores"), bearing two melanized beaks with hanging lenticular conidia. This misinterpretation might have been caused by the limited quality of the optical equipment available at the time but also both types of conidia may give that impression when seen appressed together. Our three specimens match well the protologue of $H$. tucumanensis in the overall shape of conidia, but our measurements are smaller compared to those of Spegazzini (1911). He recorded lenticular conidia 35-40 × $30 \mu \mathrm{m}$ and 15-20 $\mu \mathrm{m}$ thick and "sporophores" (cylindrical conidia) $20-40 \mu \mathrm{m}$ long with a similar thickness of 10-15 $\mu \mathrm{m}$. Leão et al. (2013) examined what they considered to be the holotype of $H$. tucumanensis (LPS15823) and also described larger conidia, the lenticular conidia being 31-42 × 14-16 $\mu \mathrm{m}$ and the cylindrical ones with two columns of $2-3$ cells each and 31-46 × 17-28 $\mu \mathrm{m}$. In view of similar differences between specimens of other taxa such as $H$. reticulatus, we suggest to consider them as the result of intraspecific variability.

Numerous collectors after Spegazzini subsequently recorded " $H$. tucumanensis" but descriptions in the literature and our study of available specimens suggest that the name became rather an "umbrella" species and was largely attributed to numerous morphologically different two conidium type and one conidium type species recorded in various countries and on diverse hosts. Hughes (1953) mentioned collections 

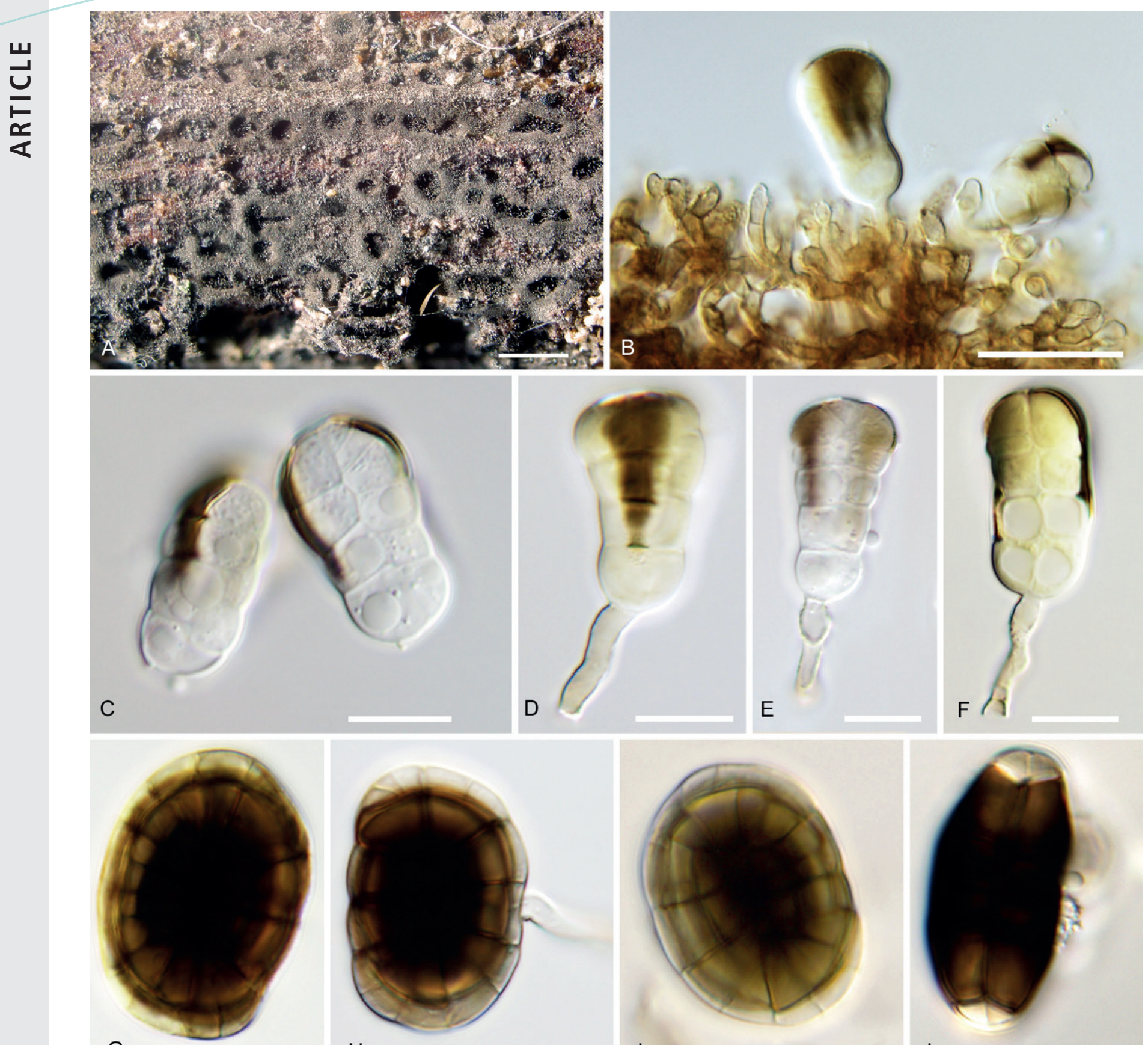

G
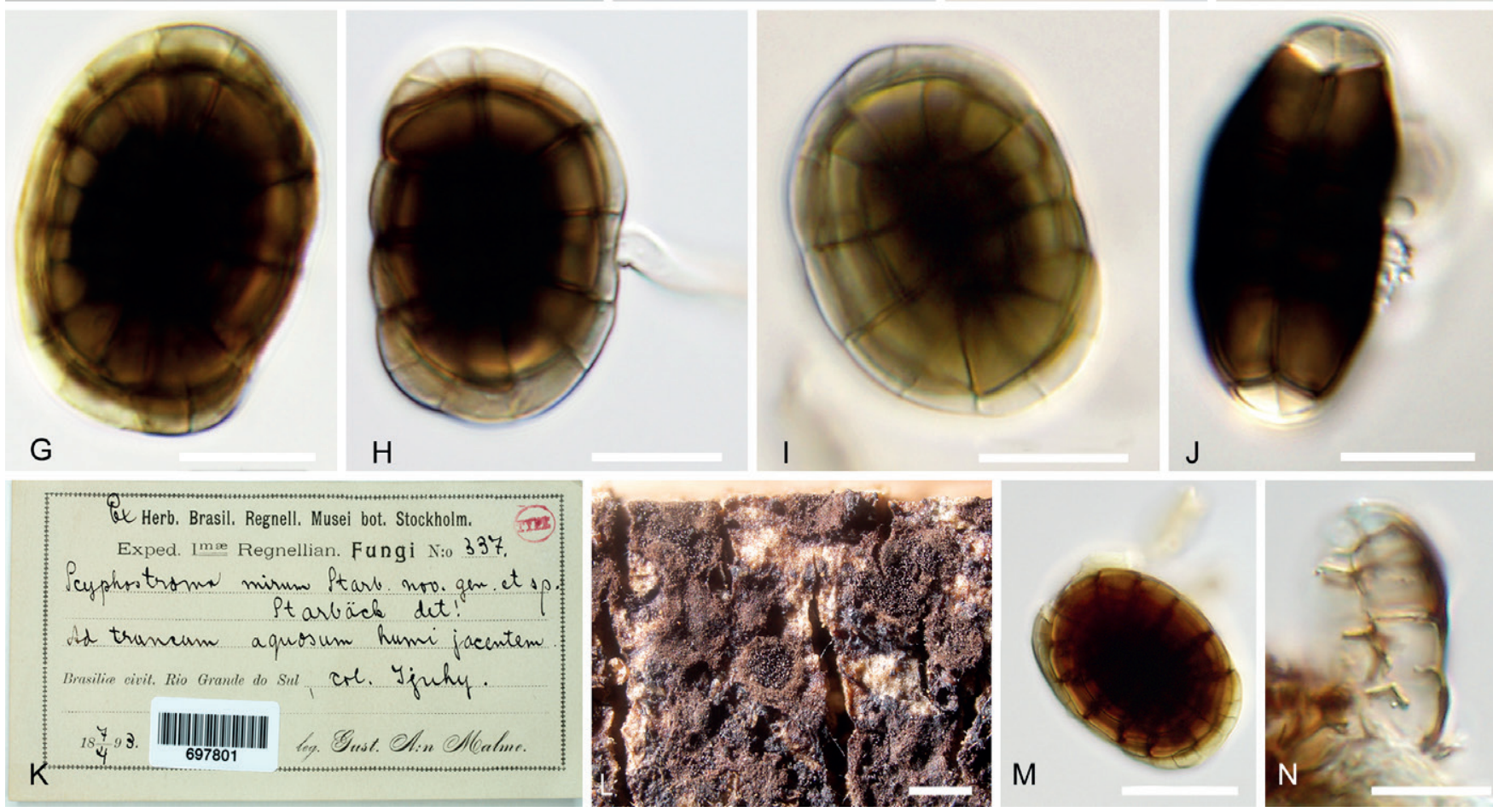

Fig. 11. Hermatomyces tucumanensis (PMA 116083) A. Colonies on the natural substrate. B. Conidiogenous cells, young conidia and subicular hyphae. C. Young cylindrical conidia. D-F. Cylindrical conidia with still attached conidiogenous cell and conidiophore. G-J. Lenticular conidia. K. Envelope and content of the holotype of Scyphostroma mirum (BPI 697801). L. Colonies on the natural substrate. M. Lenticular conidium. N. Fragment of cylindrical conidium. Bar $A=500 \mu \mathrm{m}, B-C=20 \mu \mathrm{m}, D-J=10 \mu \mathrm{m}, \mathrm{L}=500 \mu \mathrm{m}, \mathrm{M}-\mathrm{N}=10 \mu \mathrm{m}$. 
of " $H$. tucumanensis" from dead branches of Averrhoa carambola, Alchornea cordifolia (Euphorbiaceae), Coffea liberica (Rubiaceae), and Elaeidis guineensis (Arecaceae) from Ghana and Sierra Leone. His species concept, based on examination of the type material from Argentina along with material in $\mathrm{K}(\mathrm{M})-\mathrm{IMI}$, was much broader than that of Spegazzini's. Hughes (1953) depicted one specimen with 2-3-celled cylindrical conidia in one column and another morphologically different specimen with six-celled cylindrical conidia in two columns, both with apical pigmentation. In our opinion the specimens studied and illustrated by Hughes (fig. 43) belong to at least two different species, but not to $H$. tucumanensis. Further records are also questionable in the absence of morphological details. Mercado (1984) examined a specimen on the dead trunk of an unidentified tree in Cuba and described only lenticular conidia, but the picture also shows cylindrical conidia with 2-5 darker apical cells resembling $H$. amphisporus. Similarly, another collection from Cuba and revised in our study (PRM 842348) turned out to belong to $H$. sphaericus (Fig. 10). Matsushima (1993) reported " $H$. tucumanensis" from decaying petioles of a palm tree and a twig of a broad-leaved tree in Peru with 4-6-celled cylindrical conidia composed of globose, hyaline cells. His specimen is obviously not conspecific with $H$. tucumanensis and he most probably referred to a distinct, yet undescribed species of Hermatomyces. Delgado (2013) reported a specimen on rachides of dead leaves of Acoelorrhaphe wrightii (Arecaceae) in Florida without depicting cylindrical conidia. Unpublished morphological data along with unedited pictures were revised within the scope of this study and the Florida specimen seems to represent $H$. amphisporus. Prasher \& Singh (2015) recorded a collection under the name " $H$. tucumanensis" from a branch in litter and bark of Mangifera indica (Anacardiaceae) in India. They mentioned "elliptical to almost round", smooth lenticular conidia 30-40 $\times 20-28 \mu \mathrm{m}$ long and $13.5-15 \mu \mathrm{m}$ thick. Cylindrical conidia were not described and the lenticular conidia in Fig. $1 \mathrm{C}$ match well those of $H$. reticulatus, particularly by the presence of a distinct constriction between halves, comparable dimensions and apparently verruculose wall ornamentation. Chang (1995) recorded a specimen on unknown decaying twigs from a stream in Taiwan having cylindrical conidia with two columns of 3-4 cells each and darkly pigmented apical cells which based on pigmentation and conidial shape does not seem to be conspecific with $H$. tucumanensis either. Finally, Castañeda \& Heredia (2000) and Prasher \& Sushma (2014) considered $H$. tucumanensis monomorphic following Ellis (1971) who described cylindrical conidia as 'setae'. Therefore, the currently known distribution of $H$. tucumanensis must be considered with caution and based on our revision is limited to the Neotropics.

We were unable as a part of this study to re-examine the type material of this species in LPS, which comprises two packets, both of them from one of the two original hosts. One of these collections appears to require selection as a lectotype, for which a sequenced epitype could then be designated. However, we prefer to leave this pending for a future note as we consider it unwise to make a choice without a critical examination of the Spegazzini material.
Material examined: Panama: Chiriquí Province: David, UNACHI, Botanical Garden, along San Cristobal river, $8^{\circ} 26^{\prime} 3.49^{\prime \prime} \mathrm{N}$ $82^{\circ} 27^{\prime} 8.802$ 'W, $45 \mathrm{~m}$ a.s.l., on dry rotten twig of unknown tree, 19 Jul. 2017, O. Koukol KZP443 (UCH; CCF 5912- living culture); ibid. on dry rotten hanging twig of Guazuma ulmifolia, 19 Jul. 2017, O. Koukol KZP444 (PMA 116083; CCF 5913- living culture); ibid., on dry rotten hanging twig of unknown tree, 19 Jul. 2017, O. Koukol KZP453 (PRM 946202; CCF 5915- living culture).

\section{Hermatomyces verrucosus Koukol \& G. Delgado, sp. nov.}

MycoBank MB824249

(Figs 12, 15B, D, F, H, 17D)

Etymology: verrucosus, referring to the verrucose surface of the lenticular conidia.

Diagnosis: Differs from other species of Hermatomyces with one conidium type in having distinctly verrucose lenticular conidia and subicular hyphae.

Type: Panama: Chiriquí Province: David, UNACHI, Botanical Garden, along San Cristobal river, $8^{\circ} 26^{\prime} 3.49^{\prime \prime} \mathrm{N}$, $82^{\circ} 27^{\prime} 8.802^{\prime \prime} \mathrm{W}, 45 \mathrm{~m}$ a.s.I., on dry rotten stem of unknown liana, 11 Jul. 2017, L. Janošík KZP377 (PMA 116084 holotype; CCF 5903 - ex-type living culture).

Description: Colonies on the natural substrate forming sporodochial, subiculate conidiomata, superficial, more or less circular or oval, scattered or crowded and confluent, brown-black, consisting of a velvety, annular, compact, dark brown, sterile mycelial outer zone enclosing a black, glistening sporulating centre, circular, oval or lobed by confluence, where conidia are easily liberated when touched, 250-700 $\mu \mathrm{m}$ diam when solitary, up to $1500 \mu \mathrm{m}$ long when confluent. Mycelium superficial composed of compact network of repent, branched, septate, smooth or verruculose, pale brown to brown hyphae, 2-4 $\mu \mathrm{m}$ wide; subicular hyphae septate, branched, flexuous, undulate or irregularly geniculate once or few times, pale brown to brown, finely verruculose or finely spinulose to verruculose or locally verrucose, branching and anastomosing to form a dense network. Conidiophores micronematous, mononematous, cylindrical or slightly subulate, subhyaline to pale brown, smooth or finely verruculose, $6-10 \times 2-4 \mu \mathrm{m}$, often corresponding to conidiogenous cells. Conidiogenous cells monoblastic, integrated, terminal, determinate, often arising directly on the superficial mycelium and closely packed together at the fertile centre, sphaerical, subsphaerical or ampulliform, pale brown to brown, smooth or finely verruculose, $4-8 \times 2-5 \mu \mathrm{m}$. Conidia of one type, lenticular, globose, subglobose or disc-shaped in front view, sometimes somewhat irregular, solitary, dry, muriform, constricted at the septa or not, verrucose, central cells brown to dark brown or blackish brown to black, peripheral cells pale brown to brown, wide but sometimes narrow, broadly ellipsoidal to oblong in side view where two distinct adpressed halves can be recognized, each half seen laterally as a row of 4-7 cells, end cells subhyaline to pale brown, middle cells brown to blackish brown, 23-30(-39) $\times$ 21-29.5 $\mu \mathrm{m}, 14-22 \mu \mathrm{m}$ thick, L/W $=1.12$. Sexual morph unknown. 

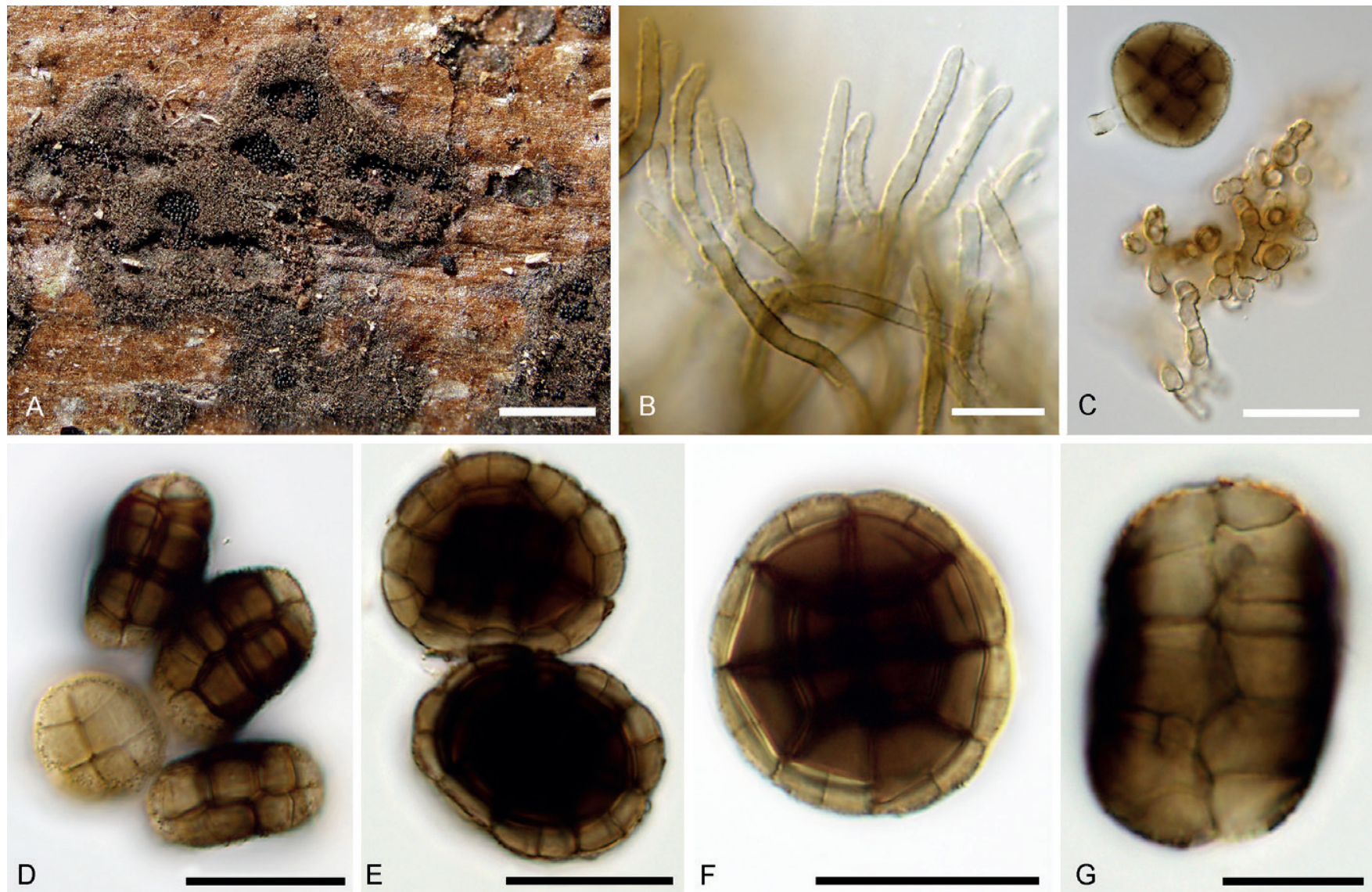

Fig. 12. Hermatomyces verrucosus (PMA 116084 - holotype) A. Colonies on the natural substrate. B. Subicular hyphae. C. Basal hyphae with young conidium. D-G. Mature conidia. Bar $A=500 \mu \mathrm{m}, \mathrm{B}-\mathrm{E}=10 \mu \mathrm{m}, \mathrm{F}=20 \mu \mathrm{m}, \mathrm{G}=10 \mu \mathrm{m}$.

Cultures (Fig. 3V-X): Colonies moderately slow growing reaching on MEA 12-13 $\mathrm{mm}$ diam, on PCA $12 \mathrm{~mm}$, and on PDA $13-15 \mathrm{~mm}$ after $7 \mathrm{~d}$ at $25^{\circ} \mathrm{C}$. No sporulation observed after $4 \mathrm{~m}$ at $25^{\circ} \mathrm{C}$

Notes: Hermatomyces verrucosus is morphologically close to $H$. sphaericus and $H$. sphaericoides, both with similarly shaped conidia and ornamented walls. Its conidia, however, are distinctly verrucose and wall ornamentation is more conspicuous on the wider ring of paler peripheral cells when seen in front view. Subicular hyphae are distinctly verruculose including sometimes a finely spinulose or locally verrucose ornamentation and less geniculate, more undulate or flexuous in appearance. Moreover, $H$. verrucosus formed a separate clade with high support in all phylogenies distant from these other two monomorphic taxa (Fig. 1) despite the morphological similarities between them.

Additional material examined: Panama: Chiriquí Province: Boquete Bajo Mono, pipe line trail, 849'40.22"N 82²9'26.11"W, 1720 m a.s.I., on dry rotten twig of unknown tree, 9 Jul. 2017, O. Koukol KZP506 (PRC 4101); David, UNACHI, Botanical Garden, along San Cristobal river, $8^{\circ} 26^{\prime} 3.49^{\prime \prime} \mathrm{N} 82^{\circ} 27^{\prime} 8.802^{\prime \prime} \mathrm{W}, 45 \mathrm{~m}$ a.s.l., on twigs in the litter of unknown tree, 6 Jul. 2016, O. Koukol KZP171 (PRM 946203; CCF 5892 - living culture).

\section{Overview of other Hermatomyces species}

Hermatomyces amphisporus R.F. Castañeda \& Heredia, Cryptog. Mycol. 21: 223 (2000).

(Fig. 16A)

Notes: Castañeda \& Heredia (2000) described this species with two conidum types on a decaying branch of Cyathea sp. and on setae of an undetermined fungus from Mexico. The cylindrical conidia are distinct in being turbinate to pyriform, with four short columns of 6-11 cells usually arising from a single basal cell and widening to a bulbous, leprous and graybrown apex. Hermatomyces pandanicola (Tibpromma et al. 2016), has morphologically similar cylindrical conidia with turbinate, dark brown apical cells and short columns arising from a common basal cell but conidia of both types are smaller than those in $H$. amphisporus. DNA sequence data of $H$. amphisporus are still unavailable. but it is accepted here based on the distinct morphology and unusual habitat. This fungus is also reported from decaying branches in a further locality in Mexico (Martínez et al. 2014) and from Vietnam (Mel'nik et al. 2013). This species might have a wider distribution range if other closely resembling specimens in the literature identified as $H$. tucumanensis are considered (Mercado 1984, Delgado 2013). 

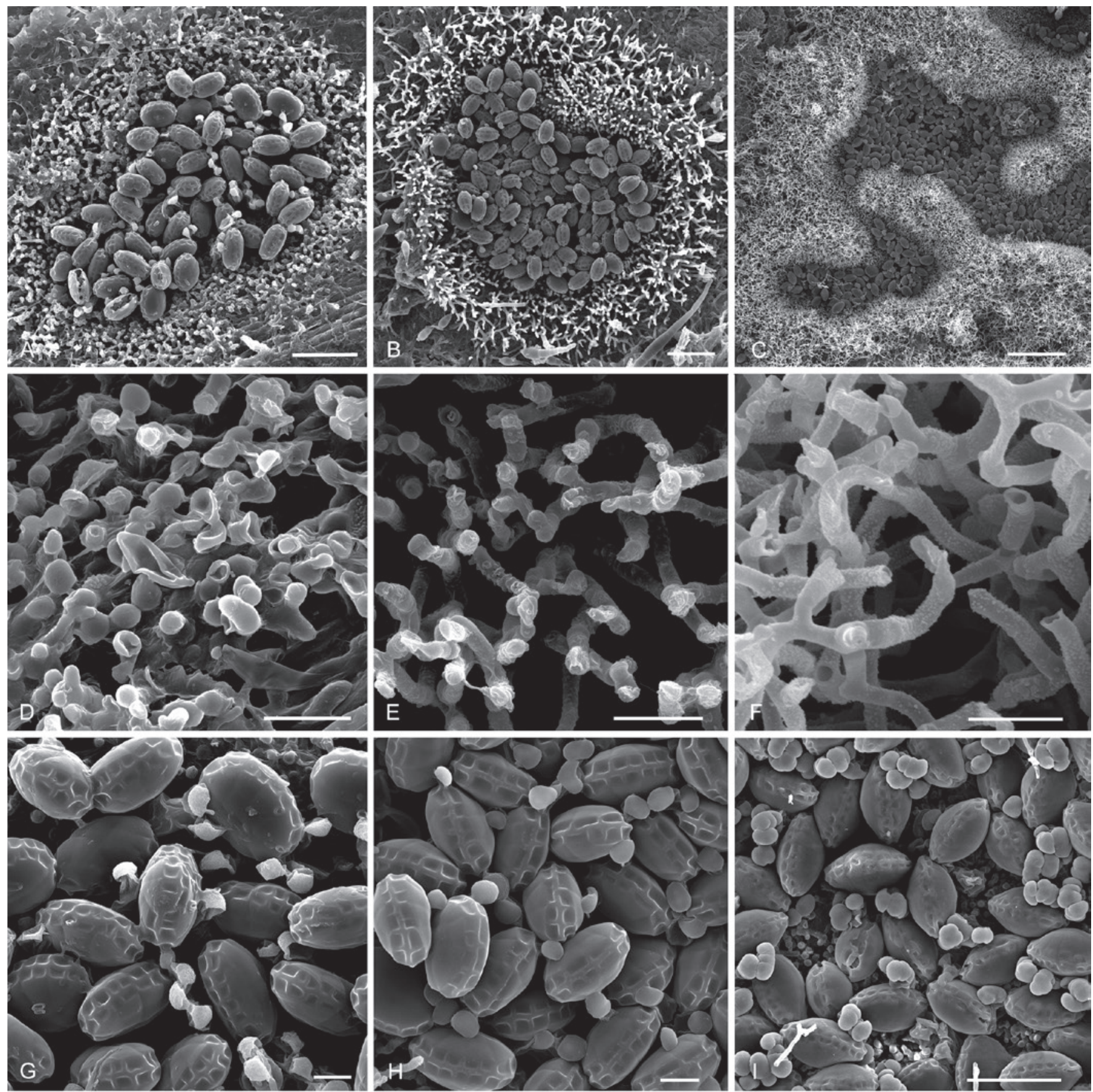

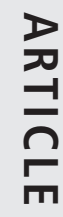
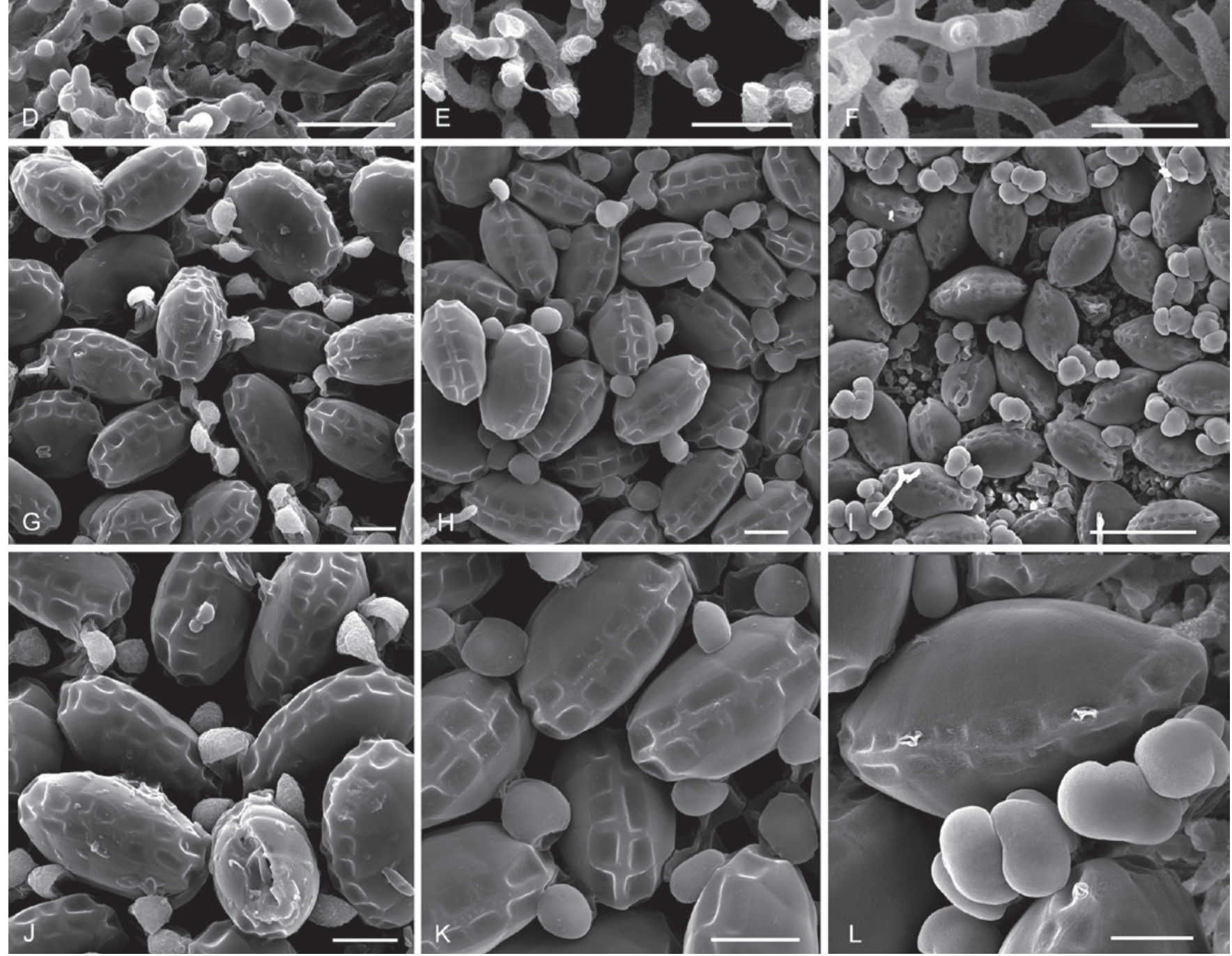

Fig. 13. Hermatomyces species as seen by scanning electron microscope. A, D, G, J. H. bifurcatus (PRM 946196). B, E, H, K. H. constrictus (PRC 4107). C, F, I, L.. H. megasporus (PMA 116077 - holotype). Colony on the substrate, subicular hyphae, conidia, detail of conidia (from top to bottom). Bar $A-B=50 \mu \mathrm{m}, C=200 \mu \mathrm{m}, \mathrm{D}-\mathrm{L}=10 \mu \mathrm{m}$. 

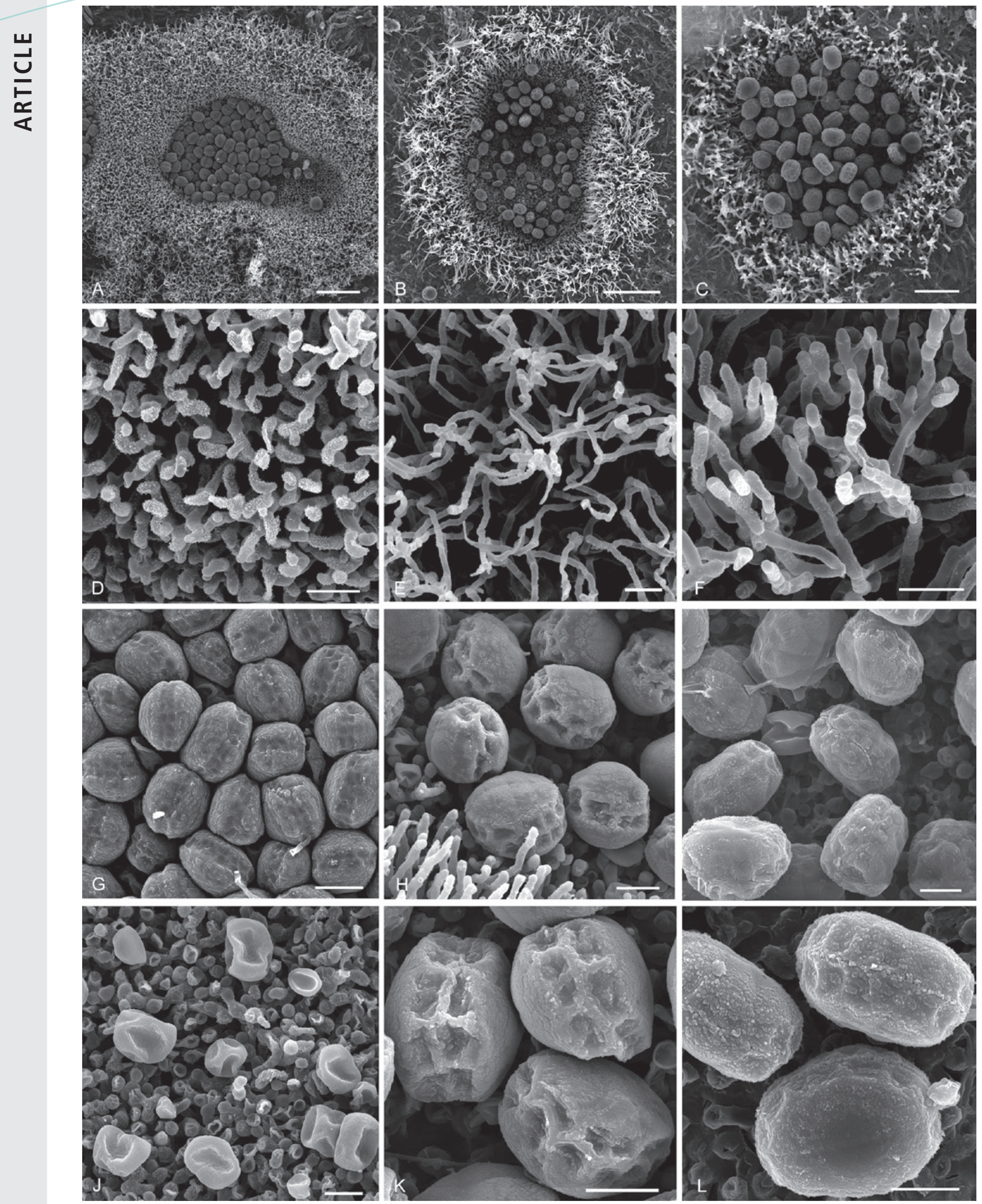

Fig. 14. Hermatomyces species as seen by scanning electron microscope. A, D, G, J. H. reticulatus (PMA 116078). B, E, H, K. H. sphaericoides (PMA 116079 - holotype). C, F, I, L. H. sphaericus (PRC 4106) (from left to right). Colony on the substrate, subicular hyphae, conidia, detail of conidia (from top to bottom). Bar A-B $=50 \mu \mathrm{m}, \mathrm{C}=200 \mu \mathrm{m}, \mathrm{D}-\mathrm{L}=10 \mu \mathrm{m}$. 

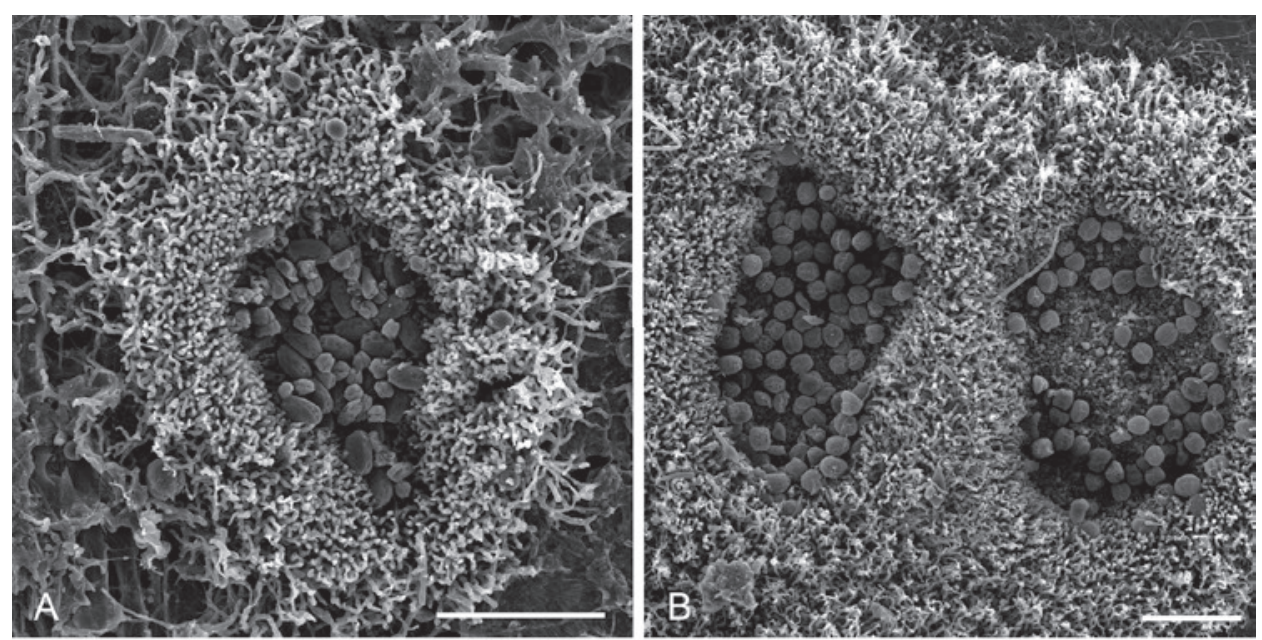

D
$\frac{1}{n}$
ㅍ
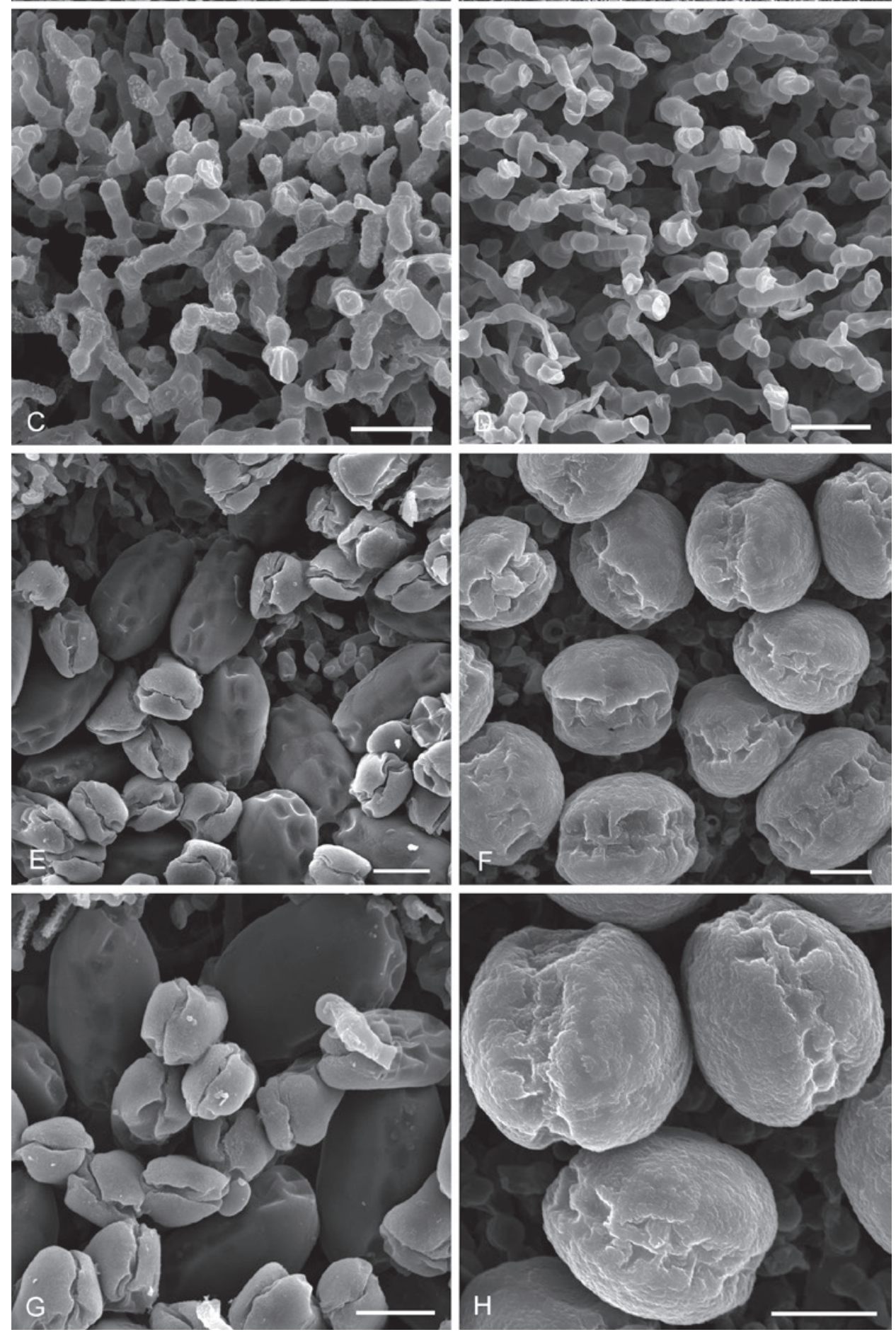

Fig. 15. Hermatomyces species as seen by scanning electron microscope. A, C, E, G. H. tucumanensis (PMA 116083). B, D, F, H. H. verrucosus (PRM 946203) (from left to right). Colony on the substrate, subicular hyphae, conidia, detail of conidia (from top to bottom). Bar A-B $=50 \mu \mathrm{m}$, $C=200 \mu \mathrm{m}, \mathrm{D}-\mathrm{L}=10 \mu \mathrm{m}$. 

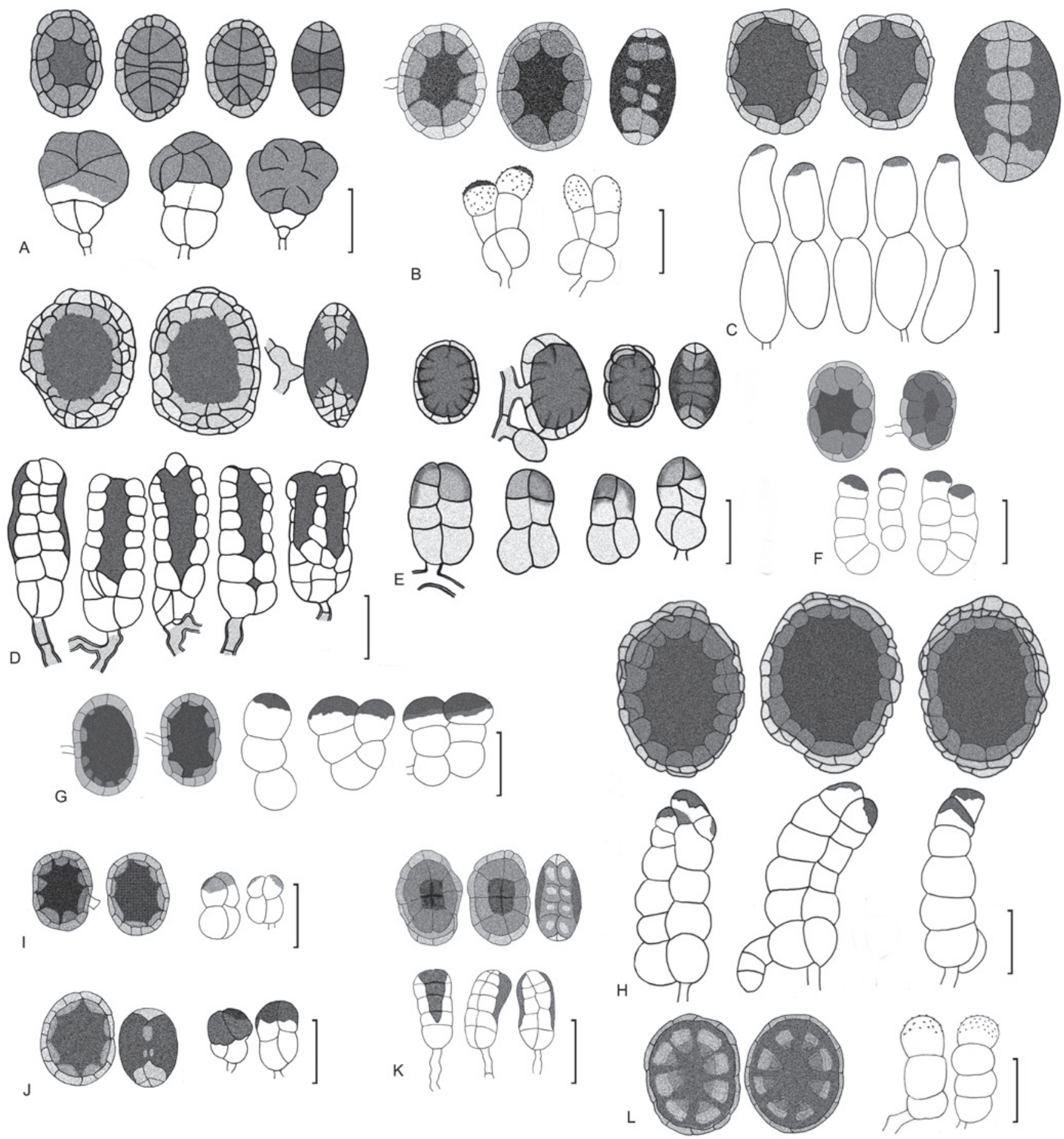

Fig. 16. Species of Hermatomyces with two conidium types, visual guide. A. H. amphisporus. B. H. bifurcatus. C. H. constrictus. D. H. dimorphus. E. H. indicus. F. H. iriomotensis. G. H. krabiensis. H. H. megasporus. I. H. nabanheensis. J. H. pandanicola. K. H. tucumanensis. L. H. uniseriatus. Bar $=20 \mu \mathrm{m}$.

Hermatomyces dimorphus V. Rao \& de Hoog, Stud. Mycol. 28: 35 (1986). (Fig. 16D)

Notes: Rao \& de Hoog (1986) described this species with two condium types from unidentified twigs in Karnataka, India, and so far it is known only from the type locality. The fungus is unique in having the most complex cylindrical conidia among known Hermatomyces species, which were termed 'paraphyses' in the protologue. These condia are composed of four vertical rows of seven cells each with septa in different orientations and a peculiar pigmentation pattern along a central or two columns and extending beyond the middle of the conidia. Although molecular data are not available for $H$. dimorphus, it is accepted here based on the conspicuous morphological features. 
Hermatomyces indicus Prasher \& Sushma, Nova Hedwigia 94: 552 (2014)

Synonym: Hermatomyces thailandicus Doilom et al., Fungal Div. 82: 121 (2016); as "thailandica".

(Fig. 16E)

Notes: Prasher \& Sushma (2014) provided a detailed description of $H$. indicus, which has both condium types, based on a specimen collected on a dead petiole of Phoenix rupicola (Arecaceae) in India and referred to the cylindrical type as 'turbinate' conidia. Doilom et al. (2016) ignored the morphologically close $H$. indicus when introducing $H$. thailandicus, probably due to the absence of molecular data available for this species. They differentiated $H$. thailandicus from another taxon, $H$. tectonae, based on polymorphic nucleotide comparisons, size of conidiophores, and both types of conidia, together with colony features. However, the dimensions, shape and apical pigmentation of the cylindrical conidia, as well as the dimensions of the lenticular conidia of $H$. thailandicus, completely overlap with those of $H$. indicus. Moreover, the only apparent difference inferred from Table 4 in Doilom et al. (2016) is the number of cells in the cylindrical conidia, probably arising from a misunderstanding of the description in Prasher \& Sushma (2014) where the total number of cells is given. Therefore, $H$. thailandicus is considered conspecific with $H$. indicus and reduced to synonymy.

Hermatomyces iriomotensis A. Hashim. \& Kaz. Tanaka, Persoonia 39: 58 (2017).

(Fig. 16F)

Notes: Hashimoto et al. (2017) described H. iriomotensis, with two conidium types, based on a combination of phenotypic and molecular data from dead twigs of a woody plant in Japan. The lenticular conidia with an inconspicuous ring composed of minute peripheral cells and 4-8-celled cylindrical conidia with cells arranged in 1-2 columns represent a unique set of morphological features. Molecular data show a close relationship with another species with both conidium types, H. krabiensis (Figs 1-2) but their separation is justified on the basis of the different morphology of their cylindrical conidia.

Hermatomyces krabiensis Tibpromma et al., Phytotaxa 275: 132 (2016).

(Fig. 16G)

Synonym: Hermatomyces chiangmaiensis J.F. Li et al., Index Fungorum 342: 45 (2017).

Notes: The only available sequence of $H$. chiangmaiensis (LSU rDNA, GenBank KY559394) showed $100 \%$ similarity with that of $H$. krabiensis when an evidently artificial flanking region was trimmed (see also note to $H$. chromolaenae). The two taxa also share an identical habitat, on dead leaves of Pandanus sp. in Thailand, and have similar cylindrical conidia with two columns of 2-3 rectangular to globose cells constricted at the septa and arising from a common basal cell. fig. $29 \mathrm{e}$ of the protologue of $\mathrm{H}$. chiangmaiensis (Tibpromma et al. 2017) shows a cylindrical conidium with turbinate, darkened apical cells identical to those of $H$. krabiensis
(Tibpromma et al. 2016). Because no other sequence was available for comparison the differences observed in phenotypic characteristics, such as the smaller lenticular conidia and cylindrical conidia having up to 3-4 columns of cells in the latter, must be considered intraspecific variability. Therefore, $H$. chiangmaiensis is reduced here to synonymy based on morphological and molecular evidence.

Hermatomyces mirum (Starbäck) C.G. Lin et al., Fungal Div. 80: 69 (2016).

Basionym: Scyphostroma mirum Starbäck, Bih. K. svenska VetenskAkad. Handl., Afd. 3 25: 24 (1899).

Type: Brazil: Rio Grande do Sul: on dead trunk, 4 Jul. 1893, G. O. A. Malme (BPI 697801 - holotype).

Notes: Examination of the holotype of Scyphostroma mirum showed this to be conspecific with $H$. tucumanensis (Fig. $11 \mathrm{~K}-\mathrm{N})$. Lenticular conidia were well preserved and had the same morphology as those of $H$. tucumanensis with measurements close to Spegazzini's at 32-42 × 27.5-32 $\mu \mathrm{m}$. The cylindrical conidia were mostly collapsed or broken, but the characteristic two parallel columns of cells and apical melanization were still evident (Fig.11 N). According to Hyde et al. (2016), the monotypic genus Scyphostroma was "wrongly described in the literature and has never been referred to any taxonomic discourses of the genus complex", which is however not a reason for omitting this name as the earliest validly published name for Hermatomyces. Therefore, the widely used generic name Hermatomyces should be conserved or protected against the older Scyphostroma and the binomial $H$. tucumanensis should be conserved or protected against $S$. mirum.

Hermatomyces nabanheensis Tibpromma et al., Fungal Div. 87: 39 (2017).

(Fig. 16I)

Notes: Hermatomyces nabanheensis was collected on dead leaves of Pandanus sp. in China (Hyde et al. 2017). Overall, it shows some phenotypic similarity with $H$. pandanicola, which has both conidium types, but is phylogenetically distinct. When sequences of $H$. nabanheensis were included in our dataset, they showed a different placement each time (Fig. 1) and this was most evident in the species tree (Fig. 2). Based on morphological and molecular evidence this is accepted as a distinct species.

\section{Hermatomyces pandanicola Tibpromma et al., Phytotaxa 275: 134 (2016).} (Fig. 16J)

Notes: Sequences of $H$. pandanicola did not show a stable phylogenetic placement in our analyses. Based on both nuclear ribosomal DNA regions and the RPB2 gene, the species was placed inside the $H$. sphaericus clade but together they formed a clade separate from these sequences in the EF1- $\alpha$ phylogeny. Considering that this species possesses the two types of conidia but clustered with $H$. sphaericus which has a single type, it could perhaps be a 
hybrid species or the sequences of ITS, LSU nrDNA and RPB2 deposited in GenBank by Tibpromma et al. (2016) do not belong to this taxon. Additional collections are needed to confirm its position and status.

Hermatomyces tectonae Doilom et al., Fungal Div. 82: 119 (2016).

Notes: In our opinion, $H$. tectonae should be considered of uncertain application because its description is ambiguous, being based on a mixture of $H$. sphaericus and $H$. indicus. The protologue (Doilom et al. 2016: 16) mentions two conidium types, but in our phylogenies the sequences of $H$. tectonae from the holotype and paratype specimens consistently clustered with sequences of $H$. sphaericus with a single conidium type. Moreover, Doilom et al. (2016: Fig. 6) depicts two different types of lenticular conidia; Fig. 6D shows globose or subglobose conidia not flattened in lateral view, while Figs $6 \mathrm{G}-\mathrm{J}$ show oval, distinctly flattened, ellipsoidal or broadly ellipsoidal conidia mixed with cylindrical conidia similar to those of $H$. indicus. Therefore, $H$. tectonae is synonymized here under $H$. sphaericus. Records of $H$. tectonae in Japan by Hashimoto et al. (2017) must also be attributed to $H$. sphaericus.

Hermatomyces uniseriatus S.M. Leão \& Gusmão, Nova Hedwigia 96: 482 (2013). (Fig. 16L)

Notes: Leão et al. (2013) described this species from rotten bark collected in Brazil. The cylindrical conidia of $H$. uniseriatus consistently have a single column of 3-4 cells with a verrucose, hyaline to pale brown apical cell lacking distinct, darker pigmentation. Without available molecular data, the phylogenetic placement of this species is currently unknown, but we consider it distinct in the genus based on morphological evidence.
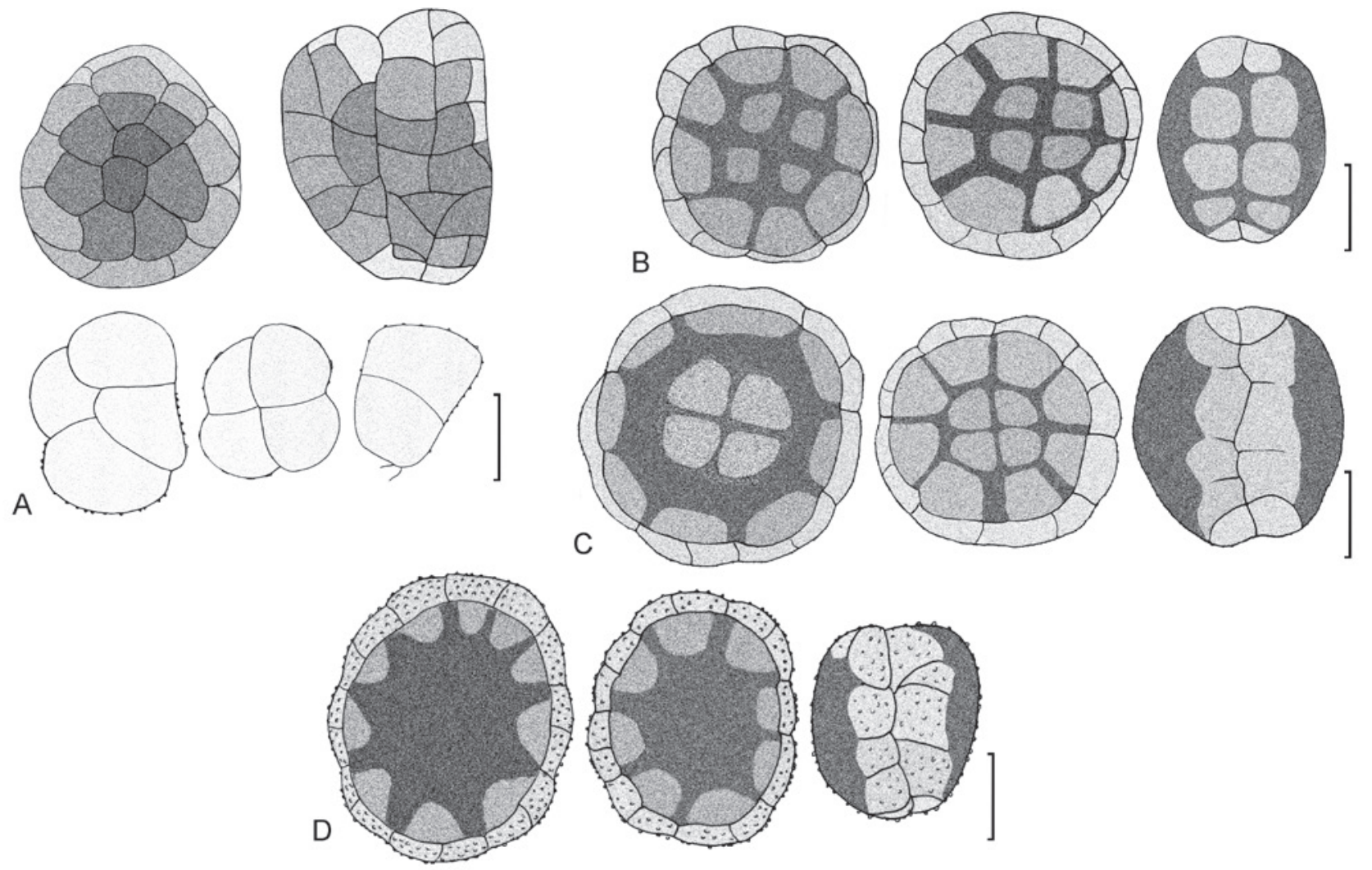

Fig. 17. Species of Hermatomyces with one conidium type, visual guide. A. H. reticulatus. B. H. sphaericoides. C. H. sphaericus. D. H. verrucosus. Bar $=20 \mu \mathrm{m}$.

\section{Key to the species of Hermatomyces}

2 (1) Lenticular conidia with transverse, longitudinal and oblique septa, verrucose when young 
3 (2) Conidial ornamentation distinctly verrucose ......

4 (3) Conidia (15-)19-25 $\mu \mathrm{m}$ thick, L/T $=1.26$

H. sphaericoides

Conidia 16-23.5(-28) $\mu \mathrm{m}$ thick, $\mathrm{L} / \mathrm{T}=1.22$

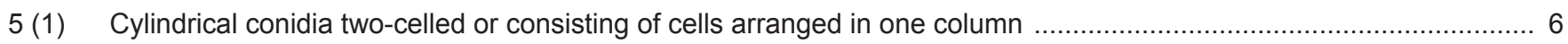

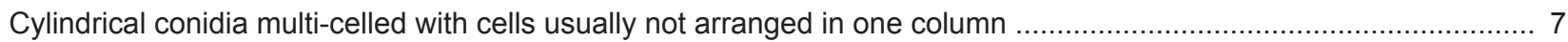

6 (5) Cylindrical conidia two-celled, constricted at the septa .......................................................... H. constrictus

Cylindrical conidia with cells arranged in one column, apical cell verrucose .................................... H. uniseriatus

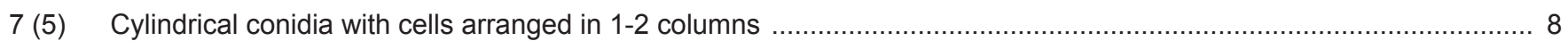

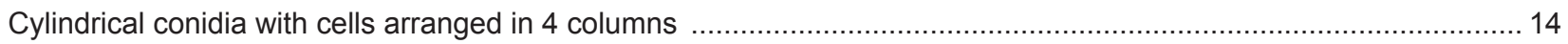

8 (7) ylindrical conidia with apical cells verrucose, subhyaline or pale brown .............................................. H. bifurcatus

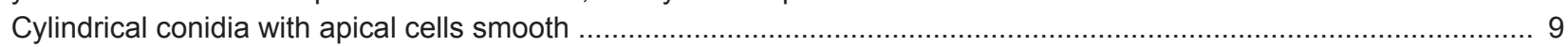

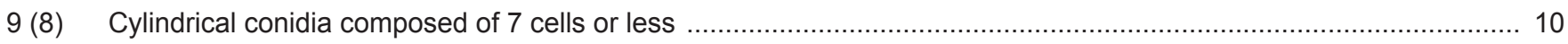

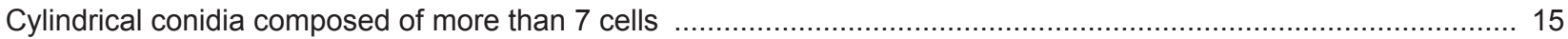

10 (9) Lenticular conidia with peripheral cells constricted at the septa ...................................................................11

Lenticular conidia with peripheral cells not constricted at the septa ........................................................ 12

11 (10) Lenticular conidia $>30 \mu \mathrm{m}$ in length, cylindrical conidia without swollen lower cells ............................. H. iriomotensis Lenticular conidia $24.5-32.5 \mu \mathrm{m}$ in length, cylindrical conidia with swollen lower cells

12 (10) Cylindrical conidia 9-12 $\mu \mathrm{m}$ wide at the broadest part

H. pandanicola

Cylindrical conidia wider

13 (12) Cylindrical conidia 22.5-35.5 $\mu \mathrm{m}$ in length

H. indicus

Cylindrical conidia 15.5-27 $\mu \mathrm{m}$ in length

H. nabanheensis

14 (7) Cylindrical conidia 30-38 $\times 20-26 \mu \mathrm{m}$, with bulbous, gray-brown apex

H. amphisporus Cylindrical conidia 15-40 × 10-15 $\mu \mathrm{m}$, with pigmentation in vertical strands between two opposite columns

H. dimorphus

15 (9) Cylindrical conidia with apical cells laterally or apically pigmented brown to blackish brown

H. megasporus Cylindrical conidia with dark brown pigmentation running from the top downwards and narrowing to a point close to the basal cell(s)

H. tucumanensis

\section{DISCUSSION}

This is the first comprehensive study of Hermatomyces in the Neotropics, based on phenotypic and molecular data of freshly collected specimens from Panama, and also including a revision of selected herbarium specimens. The occurrence of Hermatomyces species in the Neotropics was previously limiteds to the description of three species, including the generic type (Spegazzini 1911, Castañeda \& Heredia 2000, Leão et al. 2013) and scattered records of the common $H$. sphaericus in a few countries (HolubováJechová \& Mercado 1986). The high diversity discovered in Panama and represented by five morphologically and phylogenetically distinct new species is comparable with the one observed in south-east Asia (Hyde et al. 2017). Other previously known taxa, such as $H$. reticulatus, $H$. sphaericus, and $H$. tucumanensis, are reported for the first time from Panama based on complete specimen data. The number of species collected in a single country, eight of the 16 currently recognized taxa, may suggest that this area represents a diversity hot-spot of the genus. Hermatomyces species seem to occur with the same frequency in both the Neotropics and the Palaeotropics, and several species, such as $H$. indicus and $H$. sphaericus, were shown to have wider distribution areas than previously thought. Collection efforts in neighboring countries targeting these conspicuous hyphomycetes might reveal further novelties in Hermatomyces and expand our understanding of their interspecific relationships.

The phylogenetic placement of $H$. tucumanensis, the generic type, was assessed for the first time using molecular data and based on three representative specimens. Its position supports the monophyly of the genus as a well delimited taxon within Pleosporales (Hashimoto et al. 2017). This is the first time that phylogenetic relationships have been assessed for the most common $H$. sphaericus, the currently available sequences in GenBank (KU999956, 
KX033549, KX033518, KX036229, Y.-R. Ma, unpubl.) are erroneous and belong to a taxon outside Hermatomyces (Delgado et al. 2017). Our phylogenies retrieved from five loci yielded incongruent topologies but the same specimens always clustered together (Fig. 1). Bayesian analysis of the multilocus dataset (Fig. 2) revealed substantial evidence of incomplete lineage sorting in the evolution of Hermatomyces. Less possibly, the incongruent topologies of several species, notably $H$. bifurcatus, $H$. nabanheensis or $H$. pandanicola, indicate hybridization events because sexual morphs of Hermatomyces species have not yet been found.

When Hashimoto et al. (2017) introduced the new family name Hermatomycetaceae, the sporodochial conidiomata and two conidium types were considered the most distinctive family features. The presence of a hyphal subiculum is rare in Pleosporales, and when present is usually restricted to a more or less extensive, sometimes inconspicuous, mycelial growth under the ascomata or conidiomata, or even surrounding them (Zhang et al. 2012, Jaklitsch et al. 2018) but never reaching the degree of organization seen in Hermatomyces.

Colony architecture followed a very similar pattern in all new or previously described taxa despite some obvious differences, which might be useful in species level delimitation especially among taxa with both conidium types. Hermatomyces bifurcatus, for example, produces sporodochia with an inconspicuous subiculum and an almost flattened outer zone (Fig. 4A), while those of $H$. megasporus have a dense and well-developed subiculum of distinct height (Fig. 6A). However, differences in size or colour among specimens of the single conidium type species $H$. sphaericus (Fig.9A-B) might be mainly due to ecological factors. The morphology of the subicular hyphae, particularly their appearance and wall ornamentation, was also more or less typical of each species, but differences in roughness or degree of geniculation were seen even within the same subiculum; this suggests variation due to age since the more ornamented or geniculate hyphae might be older. In contrast, the bottom of the fertile colony centre is more uniform among the species and is covered with a network of repent and brown hyphae where micronematous or semimacronematous conidiophores arise and are intermixed with subsphaerical or ampulliform conidiogenous cells closely packed together. These conidiogenous cells are apparently most related to the production of lenticular conidia, but both conidium types were found emerging from short conidiophores.

Cultures isolated from Panamanian specimens (Fig. 3) rarely sporulated and conidia were only seen in a very few strains of taxa with a single conidium type, such as $H$. sphaericus (Fig. 9L-O) or H. sphaericoides (Fig. 8L-N). This is consistent with previously described species which failed to sporulate even after extended incubation periods (Tibpromma et al. 2016, Hashimoto et al. 2017) and seems to be a regular tendency of Hermatomyces isolates. Matsushima (1993) was the only one who reported production of both types of conidia on Corn Meal agar for a putative new species misidentified as $H$. tucumanensis.

In the past, members of the genus have been regularly recorded during mycological surveys carried out in tropical regions, but variability in morphology was often disregarded and collections were frequently identified as $H$. tucumanensis even though cylindrical conidia were not observed. This excessively conservative approach contrasts with the recent inflation in the number of newly described Hermatomyces species and reflects the opposite extreme of non-critical hunt for new species without serious consideration of currently recognized species (Doilom et al. 2016, Tibpromma et al. 2016). Importance given to molecular analyses with improperly edited sequences easily resulted in artifacts and misleading conclusions about phylogenetic affinities and taxonomic novelties. Based on our results, five new species are described, but seven species are synonymized, which is unusual considering that the ratio between the number of species recognized after versus before the study is 0.94 (16 vs. 17) and lower than studies on comparably large genera (Hawksworth \& Lücking 2017). We propose for future studies aimed at Hermatomyces that descriptions of new species based on single specimens or isolates should be made only if distinct morphological characteristics are present (Hashimoto et al. 2017). In the particular case of taxa with one conidium type, reliable identification should be done only by including molecular sequence data. The ITS region seems to be a good barcode for resolution at species level in this genus, but the addition of sequence data from other coding regions is recommended. The use of rather conservative LSU as a sole marker (Tibpromma et al. 2017) should be avoided, as is the widespread use of SSU, and especially in the description of taxonomic novelties due to the extremely low variability of this region.

Our findings of several collections of the same Hermatomyces species from largely unrelated plant species (monocotyledons vs. dicotyledons) indicates that substrate identity has limited taxonomic value in this case and Hermatomyces species are more restricted by the physical condition of the substrate. The most commonly observed substrates in Panama were found to be heavily rotten hanging stems of lianas or twigs of various shrubs and trees while still attached to the tree or hanging also on the lianas. This aerial position allows the substrate to be drier than similar material in litter, which seems to be an important feature in the development of Hermatomyces species. Although such a substrate may be found in various ecosystems, the distribution of Hermatomyces species seems to be limited by elevation and climate. In our study, they were most frequently found in seasonal lowland tropical forest (at 45-100 m a.s.l.; UNACHI Botanical Garden and Los Algarrobos, with six species) and in elevations of about $1700 \mathrm{~m}$ (Boquete, Bajo Mono, with four species) but not above $1900 \mathrm{~m}$ where forests are humid throughout the year and despite numerous surveys performed at such localities. Interestingly, the permanently humid Atlantic site was less rich in both the diversity and frequency of occurrence of the colonies with only two species. Targeted sampling also showed that Hermatomyces colonies may be quite frequent, and virtually every second twig in the seasonal lowland forest at the Pacific site carried them. Sometimes, up to three species co-occurred on the same twig, only several centimetres apart. These results contrast with those of previous studies where Hermatomyces species were found on humid plant material or even on material immersed in water (Chang 1995, Barbosa \& Gusmão 2011). The main pathway of dispersal of Hermatomyces species 


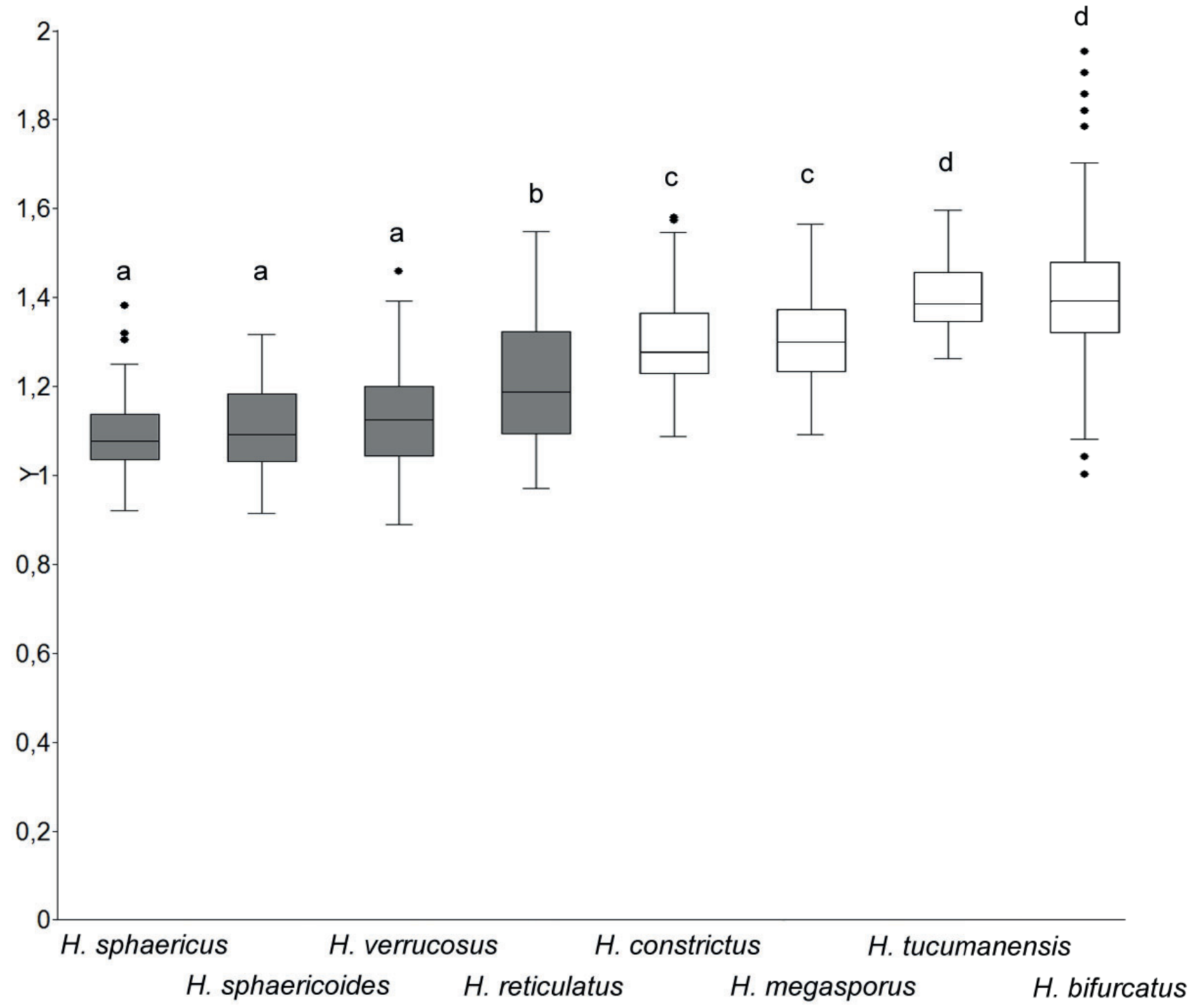

Fig. 18. Mean length/width ratios of lenticular conidia of Hermatomyces species collected in Panama. Species with one conidium type are indicated by gray boxes. Letters above the boxes indicate significant differences $(\mathrm{P}<0.05)$ obtained from non-parametric Kruskal-Wallis comparison.

remains questionable. Their large, multicellular conidia do not suggest effective dispersal by wind and the dispersion by raindrops and bark flow seems more probable. The presence of sequence KU977564 originating from an unidentified endophyte isolated from seeds of Apeiba membranacea (Malvaceae) in the $H$. sphaericus clade (Fig. 1) indicates that $H$. sphaericus may have an endophytic phase.

Based on our multiple phylogenies, we did not find any clear pattern in evolution of one and two conidium type Hermatomyces species. The similarity of young lobed conidia of $H$. reticulatus to the cylindrical conidia of $H$. bifurcatus, and that both types of conidia are born as globose, blown ends of the conidiogenous cells, may suggest a potential common origin of these two types of conidium. Intuitively, it might be expected that monomorphic species would be ancestral, but this situation was not apparent in any phylogeny. In most cases (Fig. 1), species with two conidium types are found at the base of the phylogenetic trees. Therefore, we assume that the two-type state is ancestral in Hermatomyces. We also found no evolutionary trend in the complexity of cylindrical conidia, although the morphology of lenticular conidia showed a pattern between the two groups of species. All species with one type have verruculose to verrucose conidia which are almost circular in front view (L/W 1) compared to smooth conidia of broadly ellipsoidal to ellipsoidal conidia of those with two types (L/W > 1.2, Fig. 18). Rao \& de Hoog (1986) assumed that the conidia differed in their ecological roles. The perpendicular position of the cylindrical conidia in the colony suggests they serve as a kind of protection or cushion to the lenticular conidia. Indeed, only the germination of lenticular conidia has been observed (Doilom et al. 2016), and the capacity of cylindrical conidia to germinate has not been proved. Even if cylindrical conidia function only as support to the lenticular conidia and do not contribute to dispersal, we recommend the maintenance of the term conidium in both cases to avoid further confusion. 


\section{ACKNOWLEDGMENTS}

We are grateful to Markéta Šandová (PRM), Shannon Dominick (BPI) and Lee Davis $(K(M))$ for the loan of specimens in their care. We also thank Ivana Borovičková for technical assistance in obtaining the molecular data, and Alena Kubátová for preparation of specimens for electron microscopy, as well as Orlando Cáceres, Lukáš Janošík and Petr Zehnálek for assistance in the field. This study was supported by Institutional Support for Science and Research of the Ministry of Education, Youth and Sports of the Czech Republic. G.D. also acknowledges Magzoub Ismail, Michael Manning and Kamash Ramanathan (EMlab P\&K) for provision of laboratory facilities. The Environmental Ministry of Panama (MiAmbiente) is thanked for issuing the collection and export permits (SE/APH-3-15, SE/AP-1716, SEX/H-4-15 \& SEX/H-6-16).

\section{REFERENCES}

Barbosa FR, Gusmão LFP (2011) Conidial fungi from semi-arid Caatinga Biome of Brazil Rare freshwater hyphomycetes and other new records. Mycosphere 2: 475-485.

Becerra Cl, Heredia G, Arias RM (2007) Contribución al conocimiento de los hongos anamorfos saprobios del Estado de Tabasco II. Revista Mexicana de Micologia 24: 39-53.

Bouckaert R, Heled J, Kühnert D, Vaughan T, Wu C-H, et al. (2014) BEAST 2: A Software Platform for Bayesian Evolutionary Analysis. PLoS Computational Biology 10: e1003537.

Castañeda RF, Heredia G (2000) Two new dematiaceous hyphomycetes on Cyathea from Mexico. Cryptogamie, Mycologie 21: 221-228.

Chang HS (1995) Notes on Taiwan dematiaceous hyphomycetes, some species of the genera Exserticlava, Craspedodidymum and Hermatomyces. Botanical Bulletin of Academia Sinica 36 : 243-246.

Conceição LB, Marques MFO (2015) A preliminary study on the occurrence of microscopic asexual fungi associated with bird nests in Brazilian semi-arid. Mycosphere 6: 274-279.

Darriba D, Taboada GL, Doallo R, Posada D (2012) jModelTest 2: more models, new heuristics and parallel computing. Nature Methods 9: 772.

Delgado G (2013) South Florida microfungi: a new species of Ellisembia (hyphomycetes) with new records from the U.S.A. Mycotaxon 123: 445-450.

Delgado G, Mena J, Calduch M, Decock C (2002) Hyphomycetes (hongos mitospóricos) del área protegida Mil Cumbres, Cuba occidental. Cryptogamie, Mycologie 23: 277-293.

Delgado G, Koukol O, Cáceres O, Piepenbring M (2017) The phylogenetic placement of Ernakulamia cochinensis within Pleosporales (Dothideomycetes, Ascomycota). Cryptogamie, Mycologie 38: 435-451.

Doilom M, Dissanayake AJ, Wanasinghe DN, Boonmee S, Liu JK, et al. (2016) Microfungi on Tectona grandis (teak) in Northern Thailand. Fungal Diversity 39: 1-76.

Ellis MB (1971) Dematiaceous Hyphomycetes. Kew: Commonwealth Mycological Institute.

Farr ML, Goos RD (1989) Subicularium reticulatum gen. et sp. nov., an unusual fungus from Venezuela. Memoirs of the New York Botanical Garden 49: 66-69.

Farris JS, Källersjö M, Kluge AG, Bult C (1994) Testing significance of incongruence. Cladistics 10: 315-319.

Hammer $\varnothing$, Harper DAT, Ryan PD (2001) PAST: Paleontological Statistics Software Package for Education and Data Analysis. Palaeontologia Electronica 4: 1-9.

Harahap I (2013) Community structure of sporulating fungi on decaying litter of Shorea spp. at Dramaga Research Forest, Bogor. MSc thesis, Bogor Agricultural University, Indonesia [in Indonesian].

Hashimoto A, Matsumura M, Hirayama K, Tanaka K (2017) Revision of Lophiotremataceae (Pleosporales, Dothideomycetes): Aquasubmersaceae, Cryptocoryneaceae, and Hermatomycetaceae fam. nov. Persoonia 39: 51-73.

Hawksworth DL, Lücking R (2017) Fungal diversity revisited: 2.2 to 3.8 million species. Microbiology Spectrum 5: FUNK-0052-2016.

Heredia G, Mena J, Mercado A, Reyes M (1997) Tropical hyphomycetes of Mexico. II. Some species from the Tropical Biology Station “Los Tuxtlas", Veracruz, Mexico. Mycotaxon 64: 203-223.

Heredia G, Mercado A (1998) Tropical hyphomycetes of Mexico. III. Some species from the Calakmul Biosphere Reserve, Campeche. Mycotaxon 68: 137-143.

Holubová-Jechová V, Mercado A (1986) Studies on Hyphomycetes from Cuba IV. Dematiaceous Hyphomycetes from the Province Pinar del Rio. Česká Mykologie 40: 142-164.

Hughes SJ (1953) Fungi from the Gold Coast. II. Mycological Papers 50: $1-104$

Hyde KD, Hongsanan S, Jeewon R, Bhat DJ, McKenzie EHC, et al. (2016) Fungal diversity notes 367-490: taxonomic and phylogenetic contributions to fungal taxa. Fungal Diversity $\mathbf{8 0}$ : $1-270$.

Hyde KD, Norphanphoun C, Abreu VP, Bazzicalupo A, Chethana KWT, et al. (2017) Fungal diversity notes 603-708: taxonomic and phylogenetic notes on genera and species. Fungal Diversity 87: $1-235$

Jaklitsch WM, Checa J, Blanco MN, Olariaga I, Tello S, et al. (2018) A preliminary account of the Cucurbitariaceae. Studies in Mycology 90: 71-118.

Leão SM, Gusmão LFP, Castañeda RF (2013) Conidial fungi from the semi-arid Caatinga biome of Brazil. Three new species and new records. Nova Hedwigia 96: 479-494.

Liu JK, Hyde KD, Jeewon R, Phillips AJL, et al. (2017) Ranking higher taxa using divergence times: a case study in Dothideomycetes. Fungal Diversity 84: 75-99.

Liu YJ, Whelen S, Hall B D (1999) Phylogenetic relationships among ascomycetes: evidence from an RNA polymerse II subunit. Molecular Biology and Evolution 16: 1799-1808.

Martínez K, Heredia G, Rosique E, Cappello S (2014) Hongos anamorfos asociados a restos vegetales del Parque Estatal "Agua Blanca", Macuspana, Tabasco, México. Acta Botánica Mexicana 107: 99-119.

Matsushima T (1993) Matsushima Mycological Memoirs 7: 1-75.

Mel'nik VA (2000) Definitorium fungorum Rossiae Classis Hyphomycetes. Fasc. 1. Fam. Dematiaceae. St Petersburg: Nauka.

Mel'nik VA, Novozhilov YK, Popov ES, Alexandrova AV, Kovalenko AE (2013) Anamorphic fungi of Vietnam III (in Russian). Mikologiya i Fitopatologiya 47: 316-320.

Mercado A (1984) Hifomicetes Demaciáceos de Sierra del Rosario, Cuba. Havana: Editorial Academia.

Mercado A, Delgado G, Mena J, Guarro J (2002) Some hyphomycetes (mitosporic fungi) from "Ciénaga de Zapata" Biosphere Reserve (Cuba). Boletín de la Sociedad Micológica de Madrid 26: 183- 
188.

O'Donnell K (1993) Fusarium and its near relatives. In: The Fungal Holomorph: mitotic, meiotic and pleomorphic speciation in fungal systematics (Reynolds DR \& Taylor JW, eds): 225-233. Wallingford: $C A B$ International.

O'Donnell K, Cigelnik E (1997) Two divergent intragenomic rDNA ITS2 types within a monophyletic lineage of the fungus Fusarium are nonorthologous. Molecular Phylogenetics and Evolution 7: 103-116.

Piepenbring M (2006) Checklist of fungi in Panama. Puente Biologico 1: 1-190.

Piepenbring M (2007) Inventoring the fungi of Panama. Biodiversity and Conservation 16: 73-84.

Prasher IB, Singh G (2015) New and interesting Hyphomycetes from North-Western Himalayas. Kavaka 44: 83-86.

Prasher IB, Sushma (2014) Hermatomyces indicus sp. nov. (Hyphomycetes) from India. Nova Hedwigia 99: 551-556.

Pratibha J, Raghukumar S, Bhat DJ (2012) Diversity of litter degrading microfungi from the forests of Western Ghats, India. In: Biodiversity and Taxonomy (Kumar AB, Nayar MP, Varma RV, Peethambaran CK, eds): 195-210. Delhi: Narendra Publishing House.

Rambaut A, Drummond AJ (2009) Tracer. Version 1.5. Available from: http://beast.bio.ed.ac.uk

Rao V, Hoog GS de (1986) New or critical hyphomycetes from India. Studies in Mycology 28: 1-84.

Rehner SA, Buckley E (2005) A Beauveria phylogeny inferred from nuclear ITS and EF1-alpha sequences: evidence for cryptic diversification and links to Cordyceps teleomorphs. Mycologia 97: 84-98.

Ronquist F, Teslenko M, Van der Mark P, Ayres DL, Darling A, et al. (2012) MrBayes 3.2: Efficient Bayesian phylogenetic inference and model choice across a large model space. Systematic Biology 61: 539-542.
Spegazzini C (1911) Mycetes Argentinenses. Series V. Anales del Museo Nacional de Buenos Aires Series 3: 329-467.

Stamatakis A, Hoover P, Rougemont J (2008) A rapid bootstrap algorithm for the RAxML web-servers. Systematic Biology 75 : 758-771.

Starbäck K (1899) Ascomyceten der ersten Regnell'schen Expedition. I. Bihang till Kongl. Svenska Vetenskaps-akademiens Handlingar 25: $1-68$.

Swofford DL (2002) PAUP*: phylogenetic analysis using parsimony ("and other methods). Version 40b10. Sunderland, MA: Sinauer Associates.

Taylor J, Hyde KD (2003) Microfungi of Tropical and Temperate Palms. [Fungal Diversity Research Series no. 12.] Hong Kong: Fungal Diversity Press.

Tibpromma S, Bhat JD, Doilom M, Lumyong S, Nontachaiyapoom S, et al. (2016) Three new Hermatomyces species (Lophiotremataceae) on Pandanus odorifer from Southern Thailand. Phytotaxa 275: 127-139.

Tibpromma S, Hyde KD, Jeewon R, Maharachchikumbura SSN, Liu J-K, et al. (2017) Fungal diversity notes 491-602: taxonomic and phylogenetic contributions to fungal taxa. Fungal Diversity 83 : $1-261$.

White TJ, Bruns T, Lee S, Taylor J (1990) Amplification and direct sequencing of fungal ribosomal RNA genes for phylogenetics. In: PCR Protocols: a guide to methods and applications (Innis MA, Gelfand DH, Sninsky JJ, White TJ, eds): 315-322. San Diego: Academic Press.

Zhang T, Zhao G, Zhang X, Liu H, Wu Y (2009) 26 Genera of Dematiaceous Dictyosporous Hyphomycetes excluding Alternaria. [Flora Fungorum Sinicorum no. 31.] Beijing: Science Press.

Zhang Y, Crous PW, Schoch CL, Hyde KD (2012) Pleosporales. Fungal Diversity 53: 1-221. 
Declaration of author contributions to the publication / manuscript:

Septonema lohmanii G. Delgado \& O. Koukol, sp. nov., a new species in Mytilinidiales (Dothideomycetes) and the phylogenetic position of $S$. fasciculare (Corda) S. Hughes

Status: published

Name of journal: Cryptogamie, Mycologie 40 (2): 3-21, 2019.

Contributing authors:

Gregorio Delgado (GD)

Ondřej Koukol (OK)

Andrew N. Miller (AM)

Meike Piepenbring (MP)

What are the contributions of the doctoral candidate and his co-authors?

(1) Concept and design

Doctoral candidate GD: $70 \%$

Co-author OK: $30 \%$

(2) Conducting tests and experiments

Doctoral candidate GD: $50 \%$ Carried out the field work

Co-author OK: $50 \%$ Carried out the field work

(3) Compilation of data sets and figures

Doctoral candidate GD: 70\% Obtained morphological, cultural and molecular data, generated figures \& drawings

Co-authors OK: 20\% Obtained molecular data and figures, AM: 5\%, MP: 5\% Obtained molecular data and advised on drawing

\section{(4) Analysis and interpretation of data}

Doctoral candidate GD: $50 \%$ Performed interpretations of the data

Co-authors OK: 40\% Performed analysis and interpretations of data, AM: 5\%, MP: $5 \%$ Advised on interpretation of results 


\section{(5) Drafting of manuscript}

Doctoral candidate GD: $80 \%$

Co-authors OK: 10\%\%, AM: 5\%, MP: 5\%

I hereby certify that the information above is correct.

August 28th, 2019, Houston

Digitally signed by Gregorio

Delgado

$\mathrm{DN}: \mathrm{Cn}=$ Gregorio Delgado, 0

ou=EMLab P\&K Houston,

email=gdelgado@emlabpk.com

, $c=$ US

Date: 2019.08.28 21:38:33

$-05^{\prime} 00^{\prime}$

Date and place

Signature doctoral candidate

August 30th, 2019, Frankfurt am Main

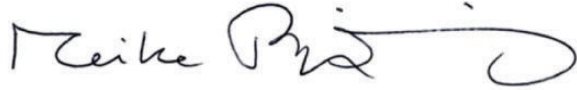

Date and place

Signature supervisor

August 29th, 2019, Champaign $\quad$ Ancrew N1. Miller Andrew N. Miller
Date: 2019.08.29
09:13:26-05'00'

Date and place

Signature supervisor 


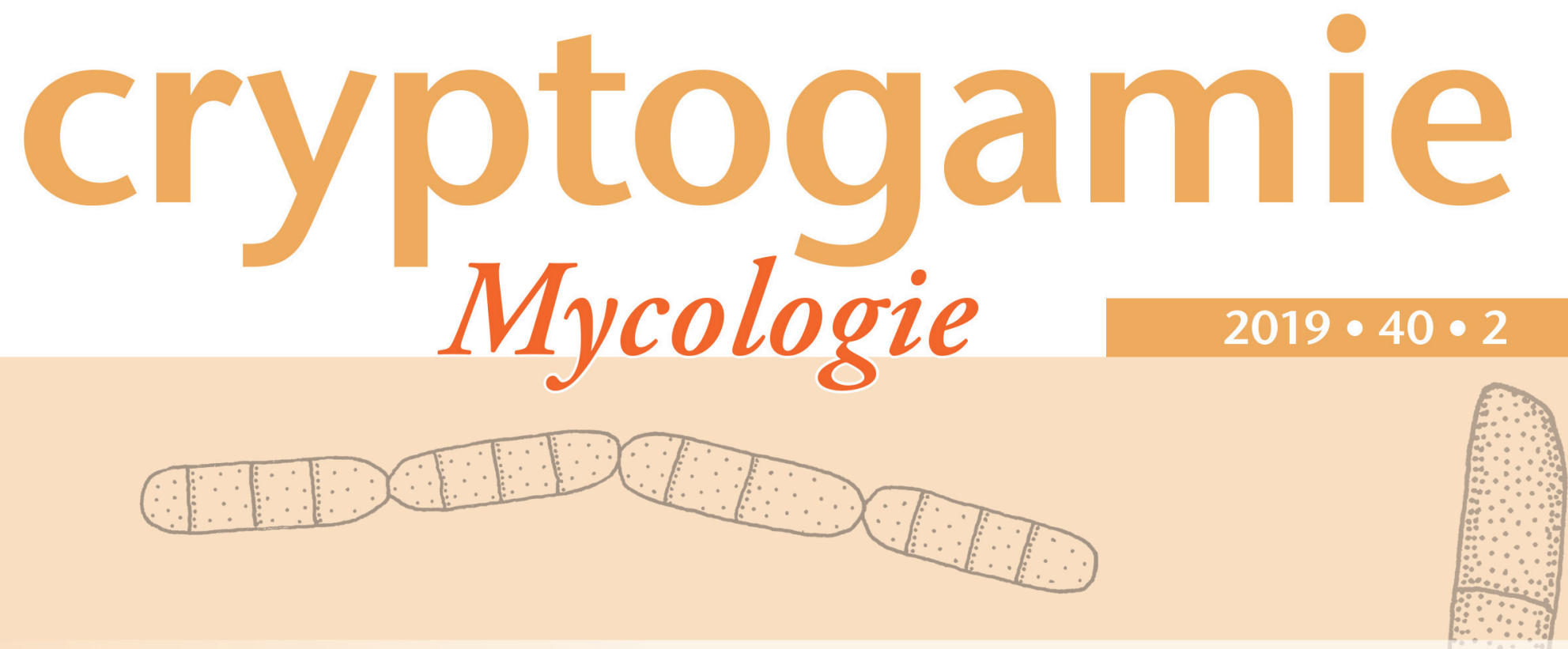

Septonema lohmanii G. Delgado \& O. Koukol, sp. nov., a new species in Mytilinidiales (Dothideomycetes) and the phylogenetic position of S. fasciculare (Corda) S. Hughes

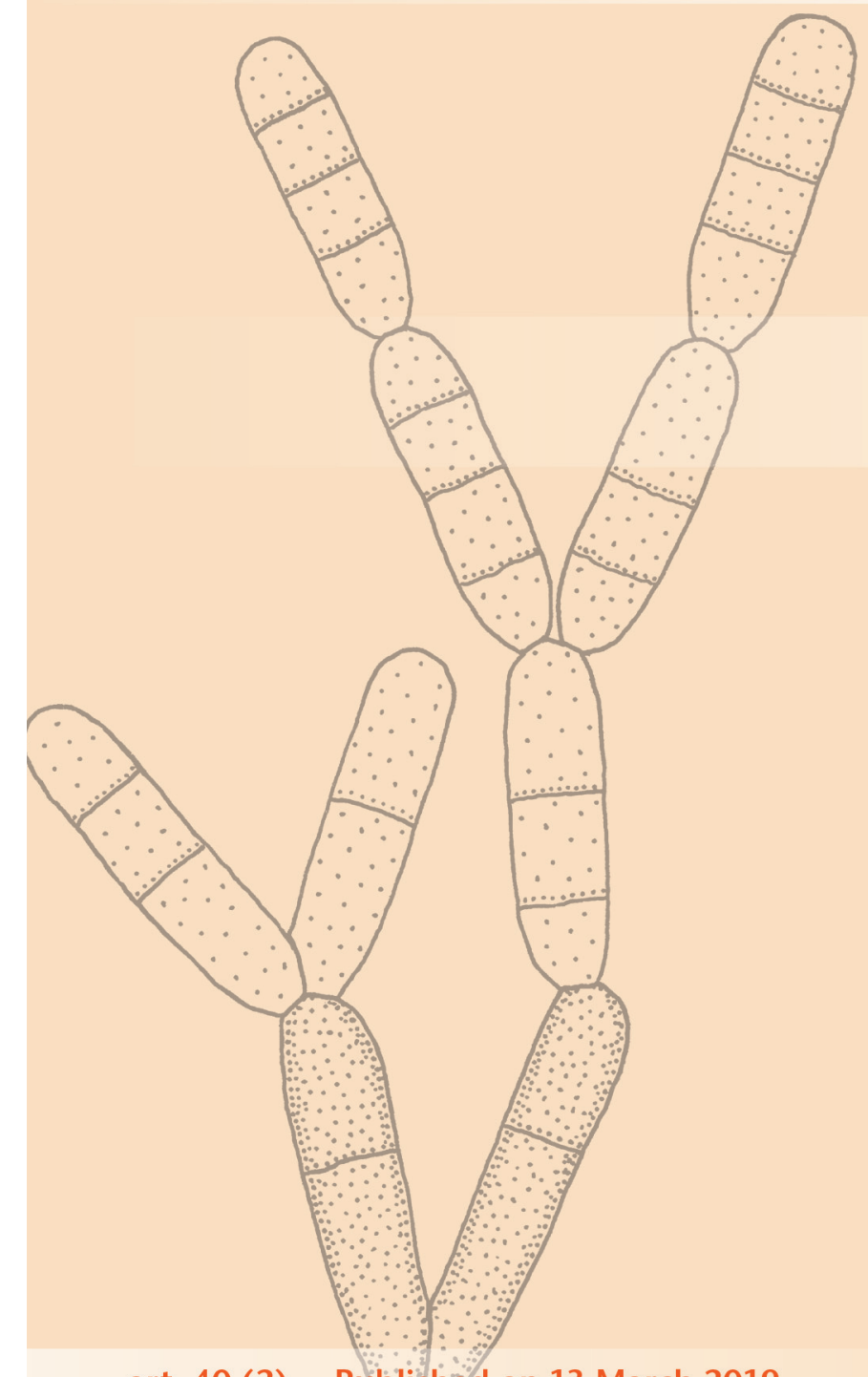

art. 40 (2) - Published on 13 March 2019 www.cryptogamie.com/mycologie

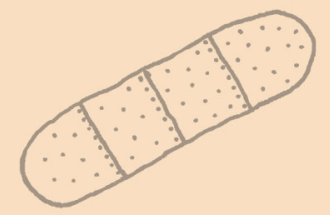

Gregorio DELGADO, Ondřej KOUKOL Andrew N. MILLER \& Meike PIEPENBRING
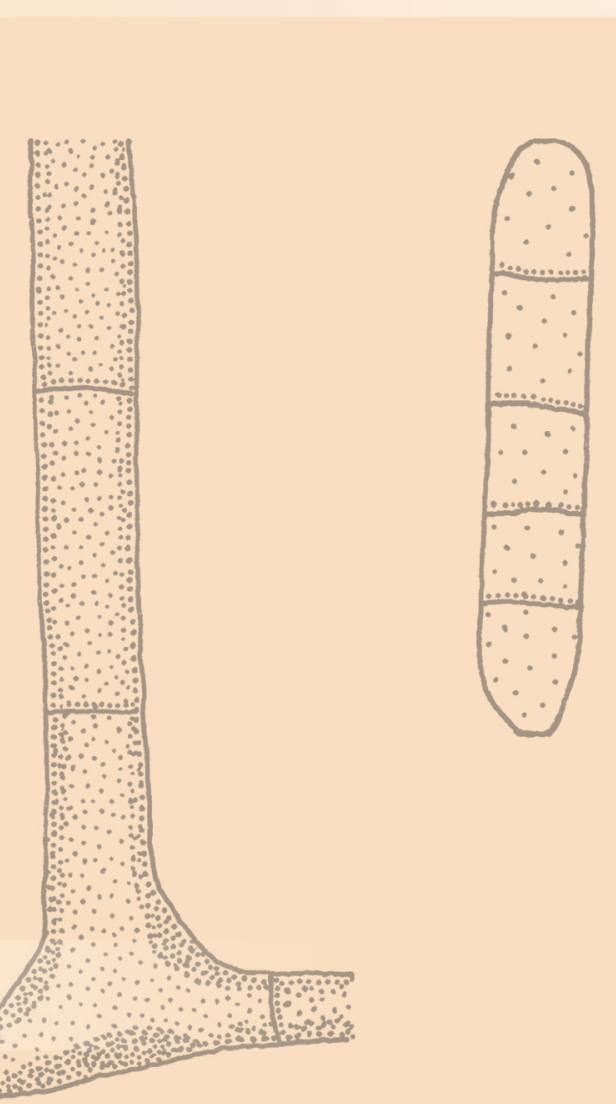


\title{
Septonema lohmanii G. Delgado \& O. Koukol, sp. nov., a new species in Mytilinidiales (Dothideomycetes) and the phylogenetic position of $S$. fasciculare (Corda) S. Hughes
}

\author{
Gregorio DELGADO \\ EMLab P\&K Houston, \\ 10900 Brittmoore Park Drive Suite G, Houston, TX 77041 (United States) \\ and Department of Mycology, Institute of Ecology, Evolution and Diversity, \\ Goethe Universität Frankfurt, Max-von-Laue-Str. 13, \\ 60438 Frankfurt am Main (Germany) \\ gdelgado@emlabpk.com (corresponding author)
}

Ondřej KOUKOL

Department of Botany, Faculty of Science, Charles University, Benátská 2, CZ-128 01 Praha 2 (Czech Republic)

Andrew N. MILLER Illinois Natural History Survey, University of Illinois, 1816 South Oak Street, Champaign, IL 61820 (United States)

Meike PIEPENBRING

Department of Mycology, Institute of Ecology, Evolution and Diversity, Goethe Universität Frankfurt, Max-von-Laue-Str. 13, 60438 Frankfurt am Main (Germany)

Submitted on 5 October 2018 | Accepted on 14 November 2018 | Published on 13 March 2019

Delgado G., Koukol O., Miller A. N. \& Piepenbring M. 2019. - Septonema lohmanii G. Delgado \& O. Koukol, sp. nov., a new species in Mytilinidiales (Dothideomycetes) and the phylogenetic position of S. fasciculare (Corda) S. Hughes. Cryptogamie, Mycologie 40 (2): 3-21. https://doi.org/10.5252/cryptogamie-mycologie2019v40a2. http://cryptogamie. $\mathrm{com} / \mathrm{mycologie} / 40 / 2$

\section{ABSTRACT}

During independent surveys of microfungi associated with Pinus spp. in the United States and the Czech Republic, a distinct fungus matching the generic concept of Septonema Corda was collected. It is characterized by distinctly ornamented conidiophores, branches, conidia and hyphae, ranging from verruculose to strongly verrucose with prominent rounded warts, yellowish brown to brown or reddish brown in color and forming densely floccose, dark brown or dark reddish brown colonies on pine wood and bark. Conidia are cylindrical or subcylindrical and produced in short, simple or branched acropetal chains. Multigene phylogenetic analyses including nuclear ribosomal (LSU) and protein coding gene (EF1-a) sequence data suggest that both collections are conspecific and belong to the order Mytilinidiales (Dothideomycetes, Ascomycota) where they group distant from other mytilinidiaceous fungi with known septonema-like anamorphs. To provide a proper name based on phylogenetic placement and to possibly circumscribe Septonema sensu stricto, a non-sporulating, putative strain belonging to $S$. secedens Corda, the generic type, was included in the analyses. DNA sequence data placed this strain within the family Venturiaceae (Venturiales, Dothideomycetes) but

KEY WORDS

Anamorphic, phylogeny, saprobic, new species. morphological examination of the corresponding herbarium specimen revealed that it belongs instead to $S$. fasciculare (Corda) S. Hughes. Because of the polyphyletic nature of the genus and the unknown phylogenetic position of its type species, our fungus is accommodated in Septonema as a new species named S. lohmanii G. Delgado \& Koukol, sp. nov. 


\begin{abstract}
RÉSUMÉ
Septonema lohmanii G. Delgado \& O. Koukol, sp. nov., une nouvelle espèce chez les Mytilinidiales (Dothideomycetes) et la position phylogénétique de S. fasciculare (Corda) S. Hughes.

Lors d'inventaires indépendants de micromycètes associés aux pins des États-Unis et de la République Tchèque, un champignon correspondant au concept générique de Septonema Corda a été récolté. L'espèce forme des colonies densément floconneuses, d'un brun à brun rougeâtre foncé. Elle est caractérisée par la présence de verrues rondes d'un brun jaunâtre à brun ou brun rougeâtre sur l'ensemble des conidiophores, branches, conidies et hyphes. Les conidies sont cylindriques à subcylindriques et produites en chaines courtes, simples ou ramifiées de façon acropète. Des analyses phylogénétiques multigènes basées sur des séquences LSU et EF1alpha suggèrent que les deux récoltes appartiennent à une même espèce qui se situe dans l'ordre des Mytilinidiales (Dothideomycetes, Ascomycota) mais sans apparenté aux autres espèces possédant des anamorphes du type Septonema. Afin de pouvoir placer cette espèce plus précisément dans une phylogénie, et peut-être aussi de pouvoir délimiter Septonema au sens strict, une souche stérile appartenant possiblement à S. secedens Corda, l'espèce type du genre, a été incluse dans les analyses. Cette dernière a été placée dans la famille des Venturiaceae (Venturiales, Dothideomycetes) par notre analyse phylogénétique, alors que l'étude morphologique de la souche correspondante a montré qu'il s'agissait de Septonema fasciculare (Corda) S. Hughes. Suite au caractère polyphylétique du genre Septonema et l'incertitude de la position phylogénétique de son espèce type, notre moisissure est décrite ici comme une nouvelle espèce, $S$. lohmanii G. Delgado \& Koukol, sp. nov.

MOTS CLÉS

Anamorphe,

phylogenie, saprophyte, nouvelle espèce.
\end{abstract}

\section{INTRODUCTION}

Septonema Corda is a large and heterogeneous genus of anamorphic fungi (Cannon 2009). Septonema secedens Corda, the type species, was first collected on rotten bark of Betula alba L. in Bohemia, Czech Republic (Corda 1837). The genus is characterized by macronematous conidiophores, simple or with short lateral branches, monoblastic or polyblastic, integrated, determinate conidiogenous cells, terminal or intercalary on the main conidiophore axis or branches, and cylindrical, ellipsoidal or fusiform, pale to dark olive, brown or reddish brown conidia with one or several transverse septa and formed in long, often branched acropetal chains (Hughes 1951; Ellis 1971; Holubová-Jechová 1978). Similar to other morphological descriptions at that time, Corda's original diagnosis was very brief and the illustration somewhat vague leading to the subsequent application of a rather broad generic concept for several fungal taxa producing conidia in acropetal chains. Hughes (1951) redescribed and illustrated the type species based on collections from the United Kingdom. He also examined the type specimen deposited in PRM to find out that the material was not well preserved and had almost disappeared from the substrate. Hughes (1952a, 1958) recognized the heterogeneity of the genus, accepted six species, and excluded 18 names from Septonema Corda considering them synonyms of other taxa mostly belonging to Taeniolella Hughes, a morphologically similar genus characterized by semimacronematous, mostly unbranched conidiophores, monoblastic conidiogenous cells and conidia in simple or branched acropetal chains that secede with difficulty. Ellis (1971, 1976) accepted only two species, S. secedens and $S$. fasciculare (Corda) S. Hughes, and transferred three species accepted by Hughes to Heteroconium Petr., a genus characterized by unbranched conidiophores, percurrent or determinate conidiogenous cells and multiseptate conidia in unbranched acropetal chains. Holubová-Jechová (1978) also studied the type specimen of $S$. secedens Corda confirming that conidiophores and conidia are lacking in this material and the type material of Helminthosporium confervoides Corda, a heterotypic synonym of $S$. secedens. She accepted seven taxa in Septonema and accommodated S. tetracoilum (Corda) S. Hughes within Lylea Morgan-Jones, another genus characterized by micronematous, inconspicuous conidiophores and distoseptate, thick-walled conidia in short, frequently branched acropetal chains (Morgan-Jones 1975). Lunghini \& Toscano (1997) expanded the generic concept of Septonema to accommodate $S$. crispulum Lunghini \& F. Toscano having branched, sterile setae, but this fungus, however, seems morphologically close to Hormiactella Sacc. More recently, Crous et al. (2007a) separated Septonema from morphologically similar cladosporium-like genera by the presence of simple or branched conidiophores, monoblastic or occasionally polyblastic conidiogenous cells with subdenticulate, neither thickened nor darkened, inconspicuous conidiogenous loci forming simple or branched chains of conidia, uniform in shape, size and septation. Schubert \& Braun (2007) introduced and lectotypificed S. acicola U. Braun \& K. Schub. based on Cladosporium radians Sacc. \& D. Sacc. on the account of morphological features in common with $S$. secedens Seifert et al. (2011) estimated that there may be ten taxa known in Septonema but recognized that many more are described. Ecologically, Septonema spp. are mainly saprobic and commonly found on rotten bark and wood of deciduous or coniferous trees, frequently on other fungi or rarely recorded from soil (Barron1968; Holubová-Jechová 1978). A septonema-like fungus was also described from a microbial mat on sandstone building material in an unusual lichenized association with coccoid cyanobacteria and green algae (Grondona et al. 1997). 
A comprehensive revision of the genus including morphological and DNA sequence data has not yet been undertaken and phylogenetic relationships are still obscure for many species currently accepted or previously assigned to Septonema, including $S$. secedens, the generic type. However, based on available taxonomic and cultural evidence, the modern generic circumscription emphasizing conidia in single or branched acropetal chains (Hughes 1951; Ellis 1971; Holubová-Jechová 1978) suggest polyphyly and the septonema-like morphology is shared among distant ascomycetous lineages. Lohman (1933a, b), using detailed cultural studies of single ascospores and conidia, linked S. spilomeum Berk. and S. toruloideum Cooke \& Ellis with Oedohysterium insidens (Schwein.) E. Boehm \& C.L. Schoch (Hysteriales, Dothideomycetes) and Mytilinidion scolecosporum M.L. Lohman (Mytilinidiales, Dothideomycetes), respectively. Lohman (1934) found that $S$. multiplex Berk. \& M.A. Curtis is the asexual state of Lophiosphaera velata (Ellis \& Everh.) M.L. Lohman. Barr (1992) transferred this teleomorph to the genus Lophiotrema Sacc. and placed it within Lophiostomataceae (Pleosporales, Dothideomycetes) in her broad concept of this family, but the genus is currently classified in its own pleosporalean family named Lophiotremataceae (Hirayama \& Tanaka 2011; Hyde et al. 2013). Lohman (1939) reported a septonema-like anamorph associated with Mytilinidion rhenanum Fuckel in specimens from Finland and New England. This connection was later confirmed by Bisby (1941) and Bisby \& Hughes (1952) based on specimens collected in the United Kingdom Sivanesan (1984), on the basis of the cultural evidence cited above, described and keyed out Mytilinidion Duby species with Septonema anamorphs.

Recently, molecular phylogenetic studies of a small number of septonema-like taxa confirmed polyphyly. Nuclear ribosomal DNA sequence data placed the root endophytic, saprobic and soil inhabiting fungus S. chaetospira (Grove) S. Hughes within the family Herpotrichiellaceae (Chaetothyriales, Eurotiomycetes) where it clustered with several Cladophialophora species and therefore it was transferred to this genus (Crous et al. 2007c; Narisawa et al. 2007). Koukol (2010) revised the taxonomic and phylogenetic status of seven strains putatively identified as $S$. ochraceum Matsush. This study revealed two new species of Fusicladium Bonord. within the family Venturiaceae (Venturiales, Dothideomycetes), a new species of Cladophialophora Borelli that clustered distantly in Herpotrichiellaceae, and a cryptic species morphologically identical but phylogenetically distinct to Devriesia americana Crous \& Dugan within the family Teratosphaeriaceae (Capnodiales, Dothideomycetes) that was later described as D. pseudoamericana Jana Frank, B. Oertel, Schroers \& Crous (Frank et al. 2010). However, the phylogenetic position of $S$. ochraceum sensu stricto remained unsettled due to the absence of a corresponding type material. Septonema verrucosum Zachariah, Sankaran \& Leelav., originally described from soil in India and characterized by verrucose conidia in acropetal, unbranched or branched chains (Zachariah et al. 1981), was found to be a member of the family Sympoventuriaceae (Venturiales, Dothideomycetes) together with several species of Ochroconis de Hoog \& Arx and therefore it is currently accepted within this genus (Machouart et al. 2014; Samerpitak et al. 2014). As currently circumscribed Septonema is affiliated with the family Hysteriaceae (Hysteriales) as anamorphic Oedohysterium E. Boehm \& C.L. Schoch or Mytilinidiaceae (Mytilinidiales) as anamorphic Mytilinidion (Wijayawardene et al. 2012, 2017) together with the morphologically similar Taeniolella which is known to be highly polyphyletic (Ertz et al. 2016).

During independent surveys of saprobic microfungi associated with Pinus spp. in southwestern United States and the Czech Republic, specimens of a conspicuous septonema-like fungus with strongly ornamented conidiophores, hyphae and conidia in branched, acropetal chains were collected and isolated on agar media. DNA sequence data were obtained for both isolates and their phylogenetic affinities were investigated. A strain putatively assigned to $S$. secedens was also sequenced and included in the analyses in order to elucidate the systematic position of the generic type and to investigate possible relationships with our fungus. The goals of this study are to characterize this septonema-like taxon using morphological, cultural and molecular data, and to test the hypothesis whether it belongs within the generic boundaries of Septonema.

\section{MATERIAL AND METHODS}

\section{ISOLATES AND MORPHOLOGICAL STUDIES}

Pieces of dead wood and bark of Pinus spp. showing fungal colonies were collected during field trips to forested areas of Arizona, the United States, and the Czech Republic in 2014 and 2015, respectively. Specimens were mounted in lactophenol cotton blue or Melzer's reagent for microscopic study and preparations were sealed with nail polish to obtain semi-permanent slides. Isolates were obtained by removing conidia with a sterile needle and transferring them aseptically to $2 \%$ Malt Extract Agar (MEA) for incubation at $25^{\circ} \mathrm{C}$. Original colonies were further subcultured on MEA and Potato Dextrose Agar (PDA). A strain named Septonema secedens was purchased from MUCL for sequencing and comparison with our septonema-like fungus. Isolates were grown on $2 \%$ MEA or water agar with sterile wooden toothpicks to induce sporulation and incubated at room temperature $\left(22-25^{\circ} \mathrm{C}\right)$. Colony features were observed and recorded at 21 days or 1 month due to slow growth. The corresponding dried specimen of the MUCL strain and other herbarium specimens deposited in IMI were borrowed for morphological examination. They were first rehydrated in distilled water and mounted similar to fresh specimens. Measurements are based on a total of 100 randomly selected fungal structures at $1000 \times$ magnification, and minimum, maximum, $5^{\text {th }}$ and $95^{\text {th }}$ percentile values were calculated with outliers given in parentheses. Line drawings were made using a drawing tube (Carl Zeiss, Oberkochen, Germany). Holotype and isotype specimens are deposited in the Herbarium of the U.S. National Fungus Collections (BPI) and the Illinois Natural History Survey Fungarium (ILLS), respectively. A paratype specimen is deposited in the Herbarium of the Charles University, Prague (PRC). Living 
cultures are deposited in the Westerdijk Fungal Biodiversity Institute (CBS) and the Culture Collection of Fungi, Charles University, Prague (CCF). Fungal names follow Index Fungorum (www.indexfungorum.org) and host plant names follow International Plant Names Index (www.ipni.org). Herbaria or culture collection acronyms are cited according to Index Herbariorum (http://sweetgum.nybg.org/science/ih/).

DNA EXTRACTION, PCR AMPLIFICATION, AND SEQUENCING Genomic DNA extraction from three weeks old cultures grown on MEA at $25^{\circ} \mathrm{C}$ together with PCR reactions to amplify the complete internal transcribed spacer (ITS) and partial nuclear ribosomal large subunit (LSU) regions along with a fragment of the translation elongation factor 1-alpha (EF1-a) gene were carried out separately for the Arizona and Czech isolates following the protocols outlined in Kirschner et al. (2013) and Koukol et al. (2018), respectively. In the case of strain MUCL 8886, DNA extraction and PCR amplification protocols were also performed separately for both the ITS-LSU and EF1-a regions based on Mardones et al. (2017) and Promputtha \& Miller (2010), respectively. The primer pairs ITS1/ITS4 in combination with LR0R/LR5 (Vilgalys \& Hester 1990; White et al. 1990) were used for PCR amplification and sequencing of the ITS-LSU regions of the Arizona isolate. The primer pair ITS1F/NL4 (O'Donnell 1993) was used for the same loci in the Czech fungus and the strain MUCL 8886. The EF1-a gene of the three strains used in this study was PCR amplified and sequenced with the primer pair $983 \mathrm{~F} / 2218 \mathrm{R}$ (Rehner \& Buckley 2005). Consensus sequences were generated in Geneious v.6.1.5 (Biomatters, Auckland, New Zealand) and deposited in GenBank.

\section{TAXON SAMPLING AND PHYLOGENETIC ANALYSES}

The newly obtained ITS, LSU and EF1-a sequences of the Arizona and Czech septonema-like isolates were first aligned and compared for pairwise similarities. Megablast searches in the NCBI GenBank database revealed significant similarities with members of the order Mytilinidiales (Dothideomycetes) and top blast hits were used to build datasets. Allied taxa from previous phylogenetic studies (Boehm et al. 2009a, b; Jayasiri et al. 2017) were also included with emphasis on anamorphic fungi with known mytilinidiaceous affinities or hysteriaceous and mytilinidiaceous taxa with known septonema-like anamorphic states e.g. Oedohysterium insidens, Mytilinidion rhenanum and M. scolecosporum. Most members of Mytilinidiales in GenBank lack ITS sequence data and therefore this marker was not used for analyses. In the case of strain MUCL 8886 megablast searches of newly generated sequences revealed highest similarities with members of the order Venturiales (Dothideomycetes) and datasets were assembled with closest hits and additional sequences from recent phylogenies (Crous et al. 2007c; Koukol 2010; Zhang et al. 2011). Details of strains and sequences used in this study are listed in Table 1. The five single gene datasets (LSU, EF1-a for the septonema-like isolates and ITS, LSU, EF1-a for the MUCL strain) were aligned separately using the MUSCLE algorithm implemented in Geneious and manually edited and concatenated in the same software. The best-fit substitution model for each gene was determined in jModeltest v.2.1.5 (Darriba et al. 2012). The selected models using the Bayesian information criterion were $\operatorname{Tr} \mathrm{N}+\mathrm{I}+\mathrm{G}$ for both the LSU and EF1-a datasets of the septonema-like isolates, and TIM2ef+I+G, TrN+I+G and $\operatorname{TrN}+\mathrm{G}$ for the ITS, LSU and EF1-a datasets of the MUCL strain, respectively. Phylogenetic relationships were reconstructed by Bayesian inference and Maximum likelihood (ML) approaches using MrBayes v.3.2 (Ronquist et al. 2012) and RAxML v.8.2.10 (Stamatakis 2014) on the CIPRES Science Gateway server (Miller et al. 2010), respectively. Two independent runs of 4-6 $\mathrm{M}$ generations were run for Bayesian analyses employing the GTRGAMMA model and sampling every 100th generation. The first 25\% of samples were discarded as burn-in and the remaining trees were used to compute a $50 \%$ majority rule consensus trees with Bayesian posterior probabilities (PP) as branch support. The average standard deviation of split frequencies estimating convergence reached the level of 0.003-0.007 at the end of particular analysis. Nonparametric bootstrapping (BS) with 1000 replicates was used for ML branch support.

\section{RESULTS}

\section{Phylogenetic ANaLyses}

A comparison of the newly generated sequences belonging to strains CBS 141174 and CCF 6124 revealed that they were very similar with only minor differences between them. The ITS sequences differ only by one transversion (A-T), one transition (A-G) and three gaps, the LSU by one transversion (T-A) and one transition (T-C) and the EF1-a by four transitions (A-G and T-C) and one deletion that were all located in one intron. The final concatenated LSU-EF1-a dataset consists of 1405 characters and 69 sequences representing 49 taxa including the outgroup. The $50 \%$ majority rule consensus tree resulting from the Bayesian analysis is shown in Figure 1. The two strains of the septonema-like fungus grouped together with high support (1.0 PP, 98\% BS). They were sister to a poorly supported clade consisting of seven Mytilinidion species including M. mytilinellum (Fr.) H. Zogg, the generic neotype, and strains of other mytilinidiaceous fungi such as Lophium elegans $\mathrm{H}$. Zogg, Halokirschsteiniothelia maritima (Linder) Boonmee \& K.D. Hyde and Quasiconcha reticulata M.E. Barr \& M. Blackw. Mytilinidion species with known septonema-like anamorphs such as $M$. rhenanum and M. scolecosporum grouped in a separate clade distant from our septonema-like fungus. They were placed within a monophyletic clade corresponding to the order Mytilinidiales strongly supported only in the Bayesian analysis (1.0 PP). Sequences of species of Gloniaceae grouped outside the order Mytilinidiales and sister to Hysteriales with high Bayesian support only $(0.97 \mathrm{PP})$.

The final concatenated ITS-LSU dataset including the strain MUCL 8886 and venturiaceous fungi consists of 1780 characters and 60 sequences representing 48 taxa including the outgroup. The $50 \%$ majority rule consensus tree generated by 
TABLE 1. - Taxa included in this study, strain information and their GenBank accession numbers. Newly generated sequences are written in bold. Abbreviations: ANM, Andrew N. Miller; ATCC, American Type Culture Collection, Manassas, United States; BCC, BIOTEC Culture Collection, Bangkok, Thailand; BJFU, Beijing Forestry University, Beijing, P.R. China; CBS, Westerdijk Fungal Biodiversity Institute, Utrecht, The Netherlands; CCF, Culture Collection of Fungi, Charles University, Prague, Czech Republic; CPC, Culture collection of Pedro Crous; DAOM, National Mycological Herbarium, Department of Agriculture, Ottawa, Canada; EB, Eric W.A. Boehm; GKM, George K. Mugambi; FMR, Culture Collection at the Faculty of Medicine, Rovira i Virgili University, Reus, Spain; ICMP, International Collection of Micro-organisms from Plants, Manaaki Whenua Landcare Research, Auckland, New Zealand; IFM, Culture Collection of the Medical Mycology Research Center, Chiba University, Chiba, Japan; MFLUCC, Mae Fah Luang University Culture Collection, Chiang Rai, Thailand; MUCL, Agro-food \& Environmental Fungal Collection, Université catholique de Louvain, Louvain-la-Neuve, Belgium; NBRC, NITE Biological Resource Center, Kisarazu, Japan; SMH, Sabine M. Huhndorf; UAMH, University of Alberta Microfungus Collection and Herbarium, University of Toronto, Toronto, Canada.

\begin{tabular}{|c|c|c|c|c|c|c|}
\hline \multirow[b]{2}{*}{ Taxa } & \multirow[b]{2}{*}{ Strain } & \multirow{2}{*}{$\begin{array}{l}\text { Country } \\
\text { of origin }\end{array}$} & \multicolumn{3}{|c|}{ GenBank accession numbers } & \multirow[b]{2}{*}{ References } \\
\hline & & & ITS & LSU & EF1-a & \\
\hline Acrogenospora carmichaeliana & CBS 206.36 & Unknown & - & AY541492 & DQ677931 & Schoch et al. (2006) \\
\hline Acrogenospora sphaerocephala & a CBS 164.76 & Belgium & - & GU301791 & GU349059 & Schoch et al. (2009) \\
\hline Apiosporina collinsii & CBS 118973 & Canada & - & GU301798 & GU349057 & Schoch et al. (2009) \\
\hline Apiosporina collinsii & CPC 12229 & Canada & EU035443 & EU035443 & - & Crous et al. (2007c) \\
\hline Byssothecium circinans & CBS 675.92 & United States & - & GU205217 & GU349061 & Schoch et al. (2009) \\
\hline Cenococcum geophilum & $1-17-2$ & United States & - & JN860135 & JN860114 & Spatafora et al. (2012) \\
\hline Cenococcum geophilum & $2-2-1$ & United States & - & JN860138 & JN860115 & Spatafora et al. (2012) \\
\hline Cenococcum geophilum & $3-10-1$ & United States & - & JN860139 & JN860116 & Spatafora et al. (2012) \\
\hline Cochliobolus heterostrophus & CBS 134.39 & Unknown & - & AY544645 & DQ497603 & Unpublished \\
\hline Cylindrosympodium lauri & CBS 240.95 & Spain & EU035414 & EU035414 & - & Crous et al. (2007c) \\
\hline Dothidea sambuci & DAOM 231303 & Austria & - & AY544681 & DQ497606 & Shoemaker \& Hambleton (2005) \\
\hline Fusicladium africanum & CPC 12829 & South Africa & EU035424 & EU035424 & - & Crous et al. (2007c) \\
\hline Fusicladium africanum & CPC 12828 & South Africa & EU035423 & EU035423 & - & Crous et al. (2007c) \\
\hline Fusicladium amoenum & CBS 254.95 & Cuba & EU035425 & EU035425 & - & Crous et al. (2007c) \\
\hline Fusicladium cordae & CBS 675.82 & The Netherlands & FN549913 & FN398149 & - & Koukol (2010) \\
\hline Fusicladium cordae & CCF 3843 & Czech Republic & FN549910 & FN377748 & - & Koukol (2010) \\
\hline Fusicladium intermedium & CBS 110746 & Madagascar & EU035432 & EU035432 & - & Crous et al. (2007c) \\
\hline Fusicladium pini & CBS 463.82 & The Netherlands & EU035436 & EU035436 & - & Crous et al. (2007c) \\
\hline Fusicladium ramoconidii & CBS 462.82 & The Netherlands & - & EU035439 & - & Crous et al. (2007c) \\
\hline Fusicladium rhodense & CPC 13156 & Greece & EU035440 & EU035440 & - & Crous et al. (2007c) \\
\hline Fusicladium sicilianum & CBS 105.85 & Italy & FN549914 & - & - & Koukol (2010) \\
\hline Gibbera conferta & CBS 191.53 & Switzerland & - & GU301814 & GU349041 & Schoch et al. (2009) \\
\hline Gloniopsis praelonga & CBS 112415 & South Africa & - & FJ161173 & FJ161090 & Boehm et al. (2009a) \\
\hline Gloniopsis praelonga & CBS 123337 & United States & - & FJ161195 & FJ161103 & Boehm et al. (2009a) \\
\hline Gloniopsis subrugosa & GKM 1214 & Kenya & - & GQ221895 & GU397336 & Mugambi \& Huhndorf (2009) \\
\hline Gloniopsis subrugosa & SMH 557 & Cuba & - & GQ221896 & GU397337 & Mugambi \& Huhndorf (2009) \\
\hline Glonium circumserpens & CBS 123343 & Tasmania & - & FJ161200 & FJ161108 & Boehm et al. (2009b) \\
\hline Glonium stellatum & ANM 32 & United States & - & GQ221887 & GQ221926 & Mugambi \& Huhndorf (2009) \\
\hline Halokirschsteiniothelia maritima & CBS 221.60 & United States & - & GU323203 & GU349001 & Schoch et al. (2009) \\
\hline Herpotrichia diffusa & CBS 250.62 & India & - & DQ678071 & DQ677915 & Schoch et al. (2006) \\
\hline Hysterium angustatum & ANM 85 & United States & - & GQ221898 & - & Mugambi \& Huhndorf (2009) \\
\hline Hysterium angustatum & CBS 123334 & United States & - & FJ161207 & FJ161111 & Boehm et al. (2009a) \\
\hline Hysterium angustatum & CBS 236.34 & United States & - & FJ161180 & FJ161096 & Boehm et al. (2009a) \\
\hline Hysterium barrianum & ANM 1442 & United States & - & GQ221884 & - & Boehm et al. (2009a) \\
\hline Hysterium barrianum & ANM 1495 & United States & - & GQ221885 & - & Boehm et al. (2009a) \\
\hline Hysterium pulicare & CBS 123377 & United States & - & FJ161201 & FJ161109 & Boehm et al. (2009a) \\
\hline Hysterium vermiforme & GKM 1234 & Kenya & - & GQ221897 & GQ221929 & Mugambi \& Huhndorf (2009) \\
\hline Hysterobrevium constrictum & SMH 5211.1 & New Zealand & - & GQ221905 & - & Mugambi \& Huhndorf (2009) \\
\hline Hysterobrevium mori & CBS 123563 & United States & - & FJ161196 & FJ161104 & Boehm et al. (2009b) \\
\hline Hysterobrevium mori & SMH 5273 & United States & - & GQ221910 & GQ221936 & Mugambi \& Huhndorf (2009) \\
\hline Hysterobrevium smilacis & CBS 200.34 & United States & - & FJ161177 & - & Boehm et al. (2009a) \\
\hline Hysterobrevium smilacis & SMH 5280 & United States & - & GQ221912 & GQ221914 & Mugambi \& Huhndorf (2009) \\
\hline Hysterographium fraxini & CBS 109.43 & Switzerland & - & FJ161171 & FJ161088 & Boehm et al. (2009b) \\
\hline Hysterographium fraxini & CBS 242.34 & Canada & - & FJ161189 & - & Boehm et al. (2009b) \\
\hline Kirschsteiniothelia atra & DAOM 231155 & Unknown & - & DQ678046 & DQ677884 & Schoch et al. (2006) \\
\hline Kirschsteiniothelia atra & MFLUCC15-0424 & P.R. China & - & KU500578 & - & Su et al. (2016) \\
\hline Kirschsteiniothelia lignicola & MFLU10-0036 & Thailand & - & HQ441568 & - & Boonmee et al. (2012) \\
\hline Lophium arboricola & CBS 758.71 & United Kingdom & - & KU705843 & - & Hernández et al. (2016) \\
\hline Lophium elegans & EB 0366 & France & - & GU323210 & - & Schoch et al. (2009) \\
\hline Lophium mytilinum & CBS 123344 & United States & - & FJ161203 & FJ161110 & Boehm et al. (2009b) \\
\hline Lophium mytilinum & CBS 269.34 & United States & - & EF596817 & DQ677926 & Schoch et al. (2006) \\
\hline Lophium zalerioides & MFLUCC14-0417 & Italy & - & MF621587 & - & Hyde et al. (2017) \\
\hline Magnohelicospora fuscospora & UAMH 8757 & Spain & - & AY856901 & - & Tsui \& Berbee (2006) \\
\hline Magnohelicospora fuscospora & ICMP 14915 & New Zealand & EF029203 & - & - & Unpublished \\
\hline Mycosphaerella punctiformis & CBS 113265 & The Netherlands & - & DQ470968 & DQ471092 & Spatafora et al. (2006) \\
\hline Myriangium duriaei & CBS 260.36 & Argentina & - & DQ678059 & DQ677900 & Schoch et al. (2006) \\
\hline Mytilinidion acicola & EB 0349 & France & - & GU323209 & - & Schoch et al. (2009) \\
\hline Mytilinidion acicola & EB 0379 & France & - & GU397346 & - & Boehm et al. (2009a) \\
\hline Mytilinidion andinense & CBS 123562 & Argentina & - & FJ161199 & FJ161107 & Boehm et al. (2009b) \\
\hline Mytilinidion australe & CBS 301.34 & United States & - & FJ161183 & - & Boehm et al. (2009b) \\
\hline Mytilinidion californicum & EB 0385 & France & - & GU323208 & - & Schoch et al. (2009) \\
\hline
\end{tabular}


TABLE 1. - Continuation.

\begin{tabular}{|c|c|c|c|c|c|c|}
\hline \multirow[b]{2}{*}{ Taxa } & \multirow[b]{2}{*}{ Strain } & \multirow{2}{*}{$\begin{array}{l}\text { Country } \\
\text { of origin }\end{array}$} & \multicolumn{3}{|c|}{ GenBank accession numbers } & \multirow[b]{2}{*}{ References } \\
\hline & & & ITS & LSU & EF1-a & \\
\hline Mytilinidion mytilinellum & CBS 303.34 & United States & - & FJ161184 & FJ161100 & Boehm et al. (2009b) \\
\hline Mytilinidion mytilinellum & EB 0386 & France & - & GU397347 & - & Boehm et al. (2009a) \\
\hline Mytilinidion resinicola & CBS 304.34 & United States & - & FJ161185 & FJ161101 & Boehm et al. (2009b) \\
\hline Mytilinidion rhenanum & CBS 135.45 & Unknown & - & FJ161175 & FJ161092 & Boehm et al. (2009b) \\
\hline Mytilinidion rhenanum & EB 0341 & France & - & GU323207 & - & Schoch et al. (2009) \\
\hline Mytilinidion scolecosporum & CBS 305.34 & United States & - & FJ161186 & FJ161102 & Boehm et al. (2009b) \\
\hline Mytilinidion thujarum & EB 0268 & United States & - & GU323206 & - & Schoch et al. (2009) \\
\hline Mytilinidion tortile & EB 0377 & France & - & GU323205 & - & Schoch et al. (2009) \\
\hline Ochroconis constricta & NBRC 9375 & Unknown & DQ307327 & AB564619 & AB564641 & Abe \& Hamada (2011) \\
\hline Ochroconis humicola & NBRC 32054 & Israel & - & AB564618 & - & Abe \& Hamada (2011) \\
\hline Ochroconis tshawytschae & CBS 100438 & United States & FR832476 & KF282665 & - & Machouart et al. (2014) \\
\hline Oedohysterium insidens & ANM 1443 & United States & - & GQ221882 & - & Mugambi \& Huhndorf (2009) \\
\hline Oedohysterium insidens & CBS 238.34 & United States & - & FJ161182 & FJ161097 & Boehm et al. (2009b) \\
\hline Oedohysterium sinense & CBS 123345 & United States & - & FJ161209 & - & Boehm et al. (2009b) \\
\hline Oedohysterium sinense & EB 0339 & United States & - & GU397348 & GU397339 & Boehm et al. (2009a) \\
\hline Phoma herbarum & CBS 276.37 & Sweden & - & DQ678066 & DQ677909 & Schoch et al. (2006) \\
\hline Phoma herbarum & UAMH 10909 & United States & KT389539 & KT389757 & DQ677909 & Chen et al. (2015) \\
\hline Pleospora herbarum & CBS 191.86 & India & - & GU238160 & - & Aveskamp et al. (2010) \\
\hline Protoventuria barriae & CBS 300.93 & United States & - & JQ036232 & - & Zhang et al. (2011) \\
\hline Pseudocamaropycnis pini & CBS 115589 & P.R. China & - & KU728557 & KU728594 & Crous \& Groenewald (2016) \\
\hline Psiloglonium clavisporum & CBS 123339 & United States & - & FJ167526 & FJ161105 & Boehm et al. (2009b) \\
\hline Psiloglonium clavisporum & CBS 123340 & United States & - & FJ161205 & - & Boehm et al. (2009b) \\
\hline Purpurepithecium murisporum & MFLUCC16-0611 & Thailand & - & KY799173 & KY887666 & Jayasiri et al. (2017) \\
\hline Purpurepithecium murisporum & MFLUCC17-0319 & Thailand & - & KY799174 & KY799177 & Jayasiri et al. (2017) \\
\hline Quasiconcha reticulata & EB QR & United States & - & GU397349 & - & Boehm et al. (2009a) \\
\hline Scolecobasidium terreum & CBS 203.27 & United States & HQ667544 & - & - & Samerpitak et al. (2014) \\
\hline Scolecobasidium terreum & CBS 175.65 & South Africa & HQ667545 & - & DQ307349 & Samerpitak et al. (2014) \\
\hline Scolecobasidium variabile & NBRC 32268 & P.R. China & - & EU107310 & DQ307350 & Unpublished \\
\hline Septonema fasciculare & MUCL 8886 & Belgium & LS998795 & LS998795 & LS998798 & This study \\
\hline Septonema lohmanii sp. nov. & CBS 141174 & United States & LS998797 & LS998797 & LS998800 & This study \\
\hline Septonema lohmanii sp. nov. & CCF 6124 & Czech Republic & LS998796 & LS998796 & LS998799 & This study \\
\hline Slimacomyces isiolus & FP1465 & Japan & - & AB597217 & - & Unpublished \\
\hline Slimacomyces isiolus & P10436 & Japan & - & AB597220 & - & Unpublished \\
\hline Sympodiella acicola & CBS 425.76 & Canada & KY853467 & KY853529 & - & Hernández et al. (2016) \\
\hline Sympodiella acicola & CCF 3736 & Czech Republic & EU449953 & - & - & Unpublished \\
\hline Sympoventuria capensis & CPC 12839 & South Africa & DQ885905 & DQ885905 & - & Crous et al. (2007b) \\
\hline Sympoventuria capensis & CPC 12840 & South Africa & DQ885904 & DQ885904 & - & Crous et al. (2007b) \\
\hline Tothia fuscella & CBS 130266 & Austria & JF927786 & JF927786 & - & Wu et al. (2011) \\
\hline Troposporella fumosa & FMR 12437 & Spain & HF678534 & HF678544 & - & Hernández et al. (2016) \\
\hline Troposporella fumosa & MUCL 15695 & United States & DQ351724 & AY856914 & - & Tsui \& Berbee (2006) \\
\hline Venturia atriseda & CBS 378.49 & Switzerland & EU035449 & EU035449 & - & Crous et al. (2007c) \\
\hline Venturia barriae & CBS 621.84 & The Netherlands & EU035431 & EU035431 & - & Crous et al. (2007c) \\
\hline Venturia barriae & NK145 & Czech Republic & LS998793 & LS998793 & - & Unpublished \\
\hline Venturia carpophila & CBS 497.62 & Switzerland & - & EU035426 & - & Crous et al. (2007c) \\
\hline Venturia chinensis & BJFU 140826-17 & P.R. China & KP689596 & KP689595 & - & Zhang et al. (2016) \\
\hline Venturia chlorospora & CBS 470.61 & France & EU035454 & EU035454 & - & Crous et al. (2007c) \\
\hline Venturia ditricha & CBS 118894 & Finland & EU035456 & EU035456 & - & Crous et al. (2007c) \\
\hline Venturia helvetica & CBS 474.61 & Switzerland & EU035458 & EU035458 & - & Crous et al. (2007c) \\
\hline Venturia hystrioides & ATCC 96019 & United States & - & AF050290 & - & Untereiner \& Naveau (1999) \\
\hline Venturia hystrioides & CBS 117727 & United States & EU035459 & EU035459 & - & Crous et al. (2007b) \\
\hline Venturia inaequalis & CBS 180.47 & Portugal & EU282481 & - & GU349089 & Schoch et al. (2009) \\
\hline Venturia inaequalis & CBS 594.70 & The Netherlands & KF156040 & GU301879 & GU349022 & Schoch et al. (2009) \\
\hline Venturia inaequalis & CBS 476.61 & Unknown & - & - & GU456288 & Zhang et al. (2011) \\
\hline Venturia inaequalis & CBS 815.69 & The Netherlands & - & - & GU349023 & Schoch et al. (2009) \\
\hline Venturia Ionicerae & CBS 445.54 & Switzerland & EU035461 & EU035461 & - & Crous et al. (2007c) \\
\hline Venturia macularis & CBS 477.61 & France & EU035462 & EU035462 & - & Crous et al. (2007c) \\
\hline Venturia maculiformis & CBS 377.53 & France & EU035463 & EU035463 & - & Crous et al. (2007c) \\
\hline Venturia minuta & CBS 478.61 & Switzerland & - & EU035464 & - & Crous et al. (2007c) \\
\hline Venturia oleaginea & CBS 113427 & New Zealand & EU035434 & EU035434 & - & Crous et al. (2007c) \\
\hline Venturia oleaginea & So-91 & Italy & AF338403 & AF338397 & - & González et al. (2002) \\
\hline Venturia phillyreae & CBS 113539 & Portugal & EU035435 & EU035435 & - & Crous et al. (2007c) \\
\hline Venturia polygoni-vivipari & CBS 114207 & Norway & EU035466 & EU035466 & - & Crous et al. (2007c) \\
\hline Venturia populina & CBS 256.38 & Italy & EU035467 & EU035467 & - & Crous et al. (2007c) \\
\hline Venturia saliciperda & CBS 480.61 & Switzerland & EU035471 & EU035471 & - & Crous et al. (2007c) \\
\hline Venturia tremulae var. tremulae & CBS 257.38 & Italy & EU035475 & EU035475 & - & Crous et al. (2007c) \\
\hline Venturia viennotii & CBS 690.85 & France & EU035476 & EU035476 & - & Crous et al. (2007c) \\
\hline Veronaeopsis simplex & CBS 588.66 & South Africa & EU041820 & EU041877 & - & Arzanlou et al. (2007) \\
\hline Verruconis calidifluminalis & IFM 54738 & Japan & AB385698 & AB385698 & - & Yarita et al. (2010) \\
\hline
\end{tabular}


TABLE 1. - Continuation.

\begin{tabular}{|c|c|c|c|c|c|c|}
\hline \multirow[b]{2}{*}{ Taxa } & \multirow[b]{2}{*}{ Strain } & \multirow{2}{*}{$\begin{array}{l}\text { Country } \\
\text { of origin }\end{array}$} & \multicolumn{3}{|c|}{ GenBank accession numbers } & \multirow[b]{2}{*}{ References } \\
\hline & & & ITS & LSU & EF1-a & \\
\hline Verruconis gallopava & IFM 54737 & Japan & - & AB272164 & - & Yarita et al. (2007) \\
\hline Verruconis gallopava & CBS 119641 & Australia & - & - & JF440538 & Samerpitak et al. (2014) \\
\hline Verruconis gallopava & CBS 437.64 & United States & - & - & AB569128 & Abe \& Hamada (2011) \\
\hline Verruconis verruculosa & CBS 119775 & Malaysia & KF156014 & KF282668 & DQ307351 & Samerpitak et al. (2014) \\
\hline
\end{tabular}

the Bayesian analysis is shown in Figure 4. The backbone of the tree representing the order Venturiales lacked significant support but it was topologically congruent with previous studies in the group (Zhang et al. 2011; Boonmee et al. 2014; Machouart et al. 2014) and split into two clades corresponding to the families Venturiaceae and Sympoventuriaceae. The strain MUCL 8886 was placed with high support (1.0 PP, $99 \%$ BS) sister to a monophyletic group supported only in the Bayesian analysis (0.98 PP) including Venturia inaequalis (Cooke) G. Winter, the generic type, as well as several species of Venturia Sacc., Apiosporina Höhn., Protoventuria Berl. \& Sacc. and Gibbera Fr. They clustered with a moderately supported clade (0.94 PP, 90 BS) consisting of Sympodiella acicola W.B. Kendr., Tothia fuscella (Sacc.) Bat. and Cylindrosympodium lauri Crous \& R.F. Castañeda. and they all nested within a poorly supported group representing the family Venturiaceae. Due to poor taxon sampling the EF1-a dataset was analyzed separately. It consisted of 864 characters and 14 sequences representing only 11 taxa including the outgroup. The strain MUCL 8886 grouped without support sister to a highly supported clade (1.0 PP, 100 BS) including Venturia, Gibbera and Apiosporina species (tree not shown).

\section{SYSTEMATICS}

Septonema lohmanii G. Delgado \& Koukol, sp. nov.

$$
\text { (Figs 2, 3) }
$$

ETYMOLOGY. — Named in honor of Dr Marion Lee Lohman (1903-), American mycologist who pioneered the study of hysteriaceous and mytilinidiaceous fungi in culture and whose strains remain today a reference source of molecular data.

Material eXAmined. - United States. Arizona, Coconino County, Forest Lakes Estates, Apache-Sitgreaves National Forest, around Willow Springs Lake, 34¹8'45.7”N, $110^{\circ} 52^{\prime} 46.1^{\prime \prime W}$, on rotting stump of Pinus ponderosa P. Lawson \& C. Lawson, 21.IX.2014, coll. G. Delgado (holo-, BPI[BPI 910175]; iso-, ILLS[ILLS 82053]; ex-holotype culture, CBS[CBS 141174]; ex-holotype sequences, CBS[ITS-LSU LS998797, EF1-a LS998800]).

Czech Republic. Northern Bohemia, Doubice, Tokáň, 5053'14”N, $14^{\circ} 25^{\prime} 11.4^{\prime \prime} \mathrm{E}$, on rotten bark of P. strobus L., 15.X.2015, coll. O. Koukol (para-, PRC[PRC 4117]; ex-paratype culture, CCF[CCF 6124]; ex-paratype sequences, CCF[ITS-LSU LS998796, EF1-a LS998799]).

\section{MYCOBANK MB 829281}

Colonies on natural substrate more or less orbicular, densely floccose, dark brown or dark reddish brown, often conflu- ent and forming irregular patches, sometimes effuse and hairy, with powdery spores easily dispersed when touched. Mycelium mostly superficial consisting of branched, septate, strongly verruculose, echinulate, verrucose or strongly verrucose, subhyaline to pale brown ascending hyphae, sometimes anastomosing, 2-4 $\mu \mathrm{m}$ wide, and septate, smooth or sparingly verrucose, thick-walled, brown to dark brown, interwoven creeping hyphae, often constricted at the septa and forming angular or irregularly swollen cells, 5-9 $\mu \mathrm{m}$ wide, warts when prominent more or less rounded, $2-3.5 \mu \mathrm{m}$ wide. Conidiophores macronematous or semimacronematous, mononematous, arising terminally or laterally from the hyphae, solitary, erect or somewhat repent, flexuous or sinuous, rarely straight, cylindrical or subcylindrical, mostly branched, septate, sometimes constricted at some septa and readily breaking along the constrictions, verruculose, verrucose to strongly verrucose, sometimes locally smooth or thick-walled, yellowish brown to brown or reddish brown to dark brown, up to $515 \mu \mathrm{m}$ long, 3-7(-9) $\mu \mathrm{m}$ wide, width and ornamentation may vary along the length of the conidiophore, warts when prominent similar to those on hyphae, occasionally with brown blobs of mucilage 6-11 $\mu \mathrm{m}$ diam.; branches cylindrical or subcylindrical, straight or flexuous, verruculose or verrucose, similarly ornamented as the near conidiophore, up to $205 \mu \mathrm{m}$ long, 4-6 $\mu \mathrm{m}$ wide, basal cells often attenuated at the junction with the conidiophore to a truncate end and easily breaking off, $2-4 \mu \mathrm{m}$ wide; young hyphae, conidiophores and branches extend by forming subhyaline to pale yellow or pale brown, finely verruculose or sparingly verruculose elongations tapering to an acute, smooth apex 1.5-2 $\mu$ m wide. Conidiogenous cells monoblastic or polyblastic, integrated, terminal or intercalary on conidiophores and branches, determinate, cylindrical or subcylindrical, rounded at the apex or slightly attenuated to a truncate end, 5-15(-18) $\times$ 4.5-7 $\mu \mathrm{m}$, with 1-2 inconspicuous conidiogenous loci. Conidia acrogenous or acropleurogenous, cylindrical, subcylindrical or narrowly ellipsoidal, straight or somewhat flexuous, (1-) 2-11(-13)-septate, slightly constricted at some septa, smooth, verruculose, verrucose or strongly verrucose, sometimes ornamentation not uniform, yellowish brown or brown to reddish brown, formed in simple or branched, short acropetal chains of 2-3(-4) conidia at conidiophores or branches, each conidium with 0-3 apical or lateral inconspicuous or subdenticulate hila or $0-2$ per individual conidial cell, sometimes small isthmi seen between conidia, $12-57(-63) \times 4-6(-8) \mu \mathrm{m}$, apex rounded or somewhat truncate, base truncate. Teleomorph unknown. 


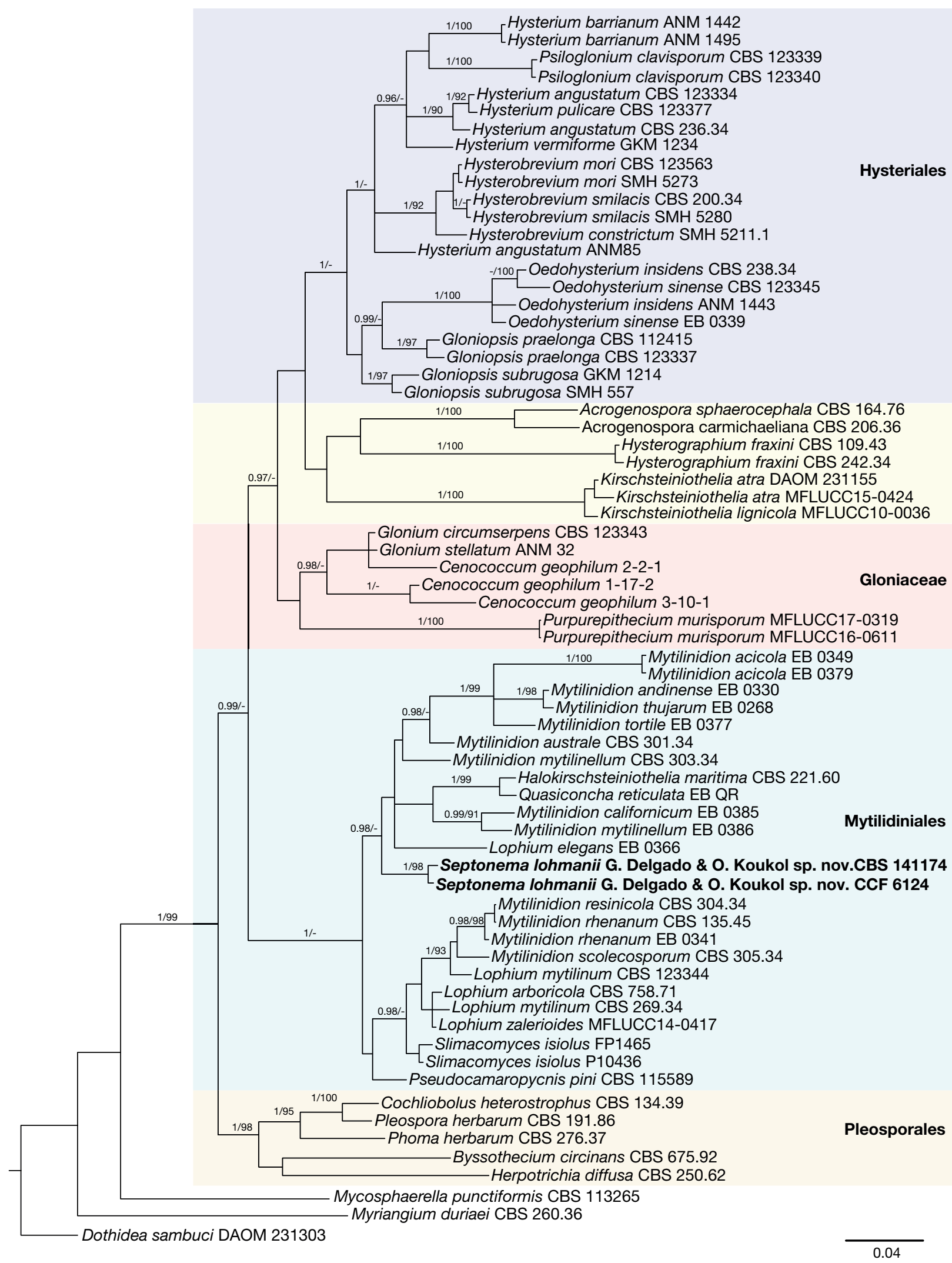

FIG. 1. - Phylogenetic tree inferred from Bayesian and ML analyses of concatenated LSU-EF1-a sequence data showing the placement of Septonema lohmanii G. Delgado \& O. Koukol, sp. nov. within Mytilinidiales and related orders in Dothideomycetes. Numbers above branches represent Bayesian posterior probabilities $\mathrm{PP}>0.95$ followed by $\mathrm{ML}$ bootstrap support values $\mathrm{BS} \geq 90 \%$. Strains belonging to the new taxon are highlighted in bold. 


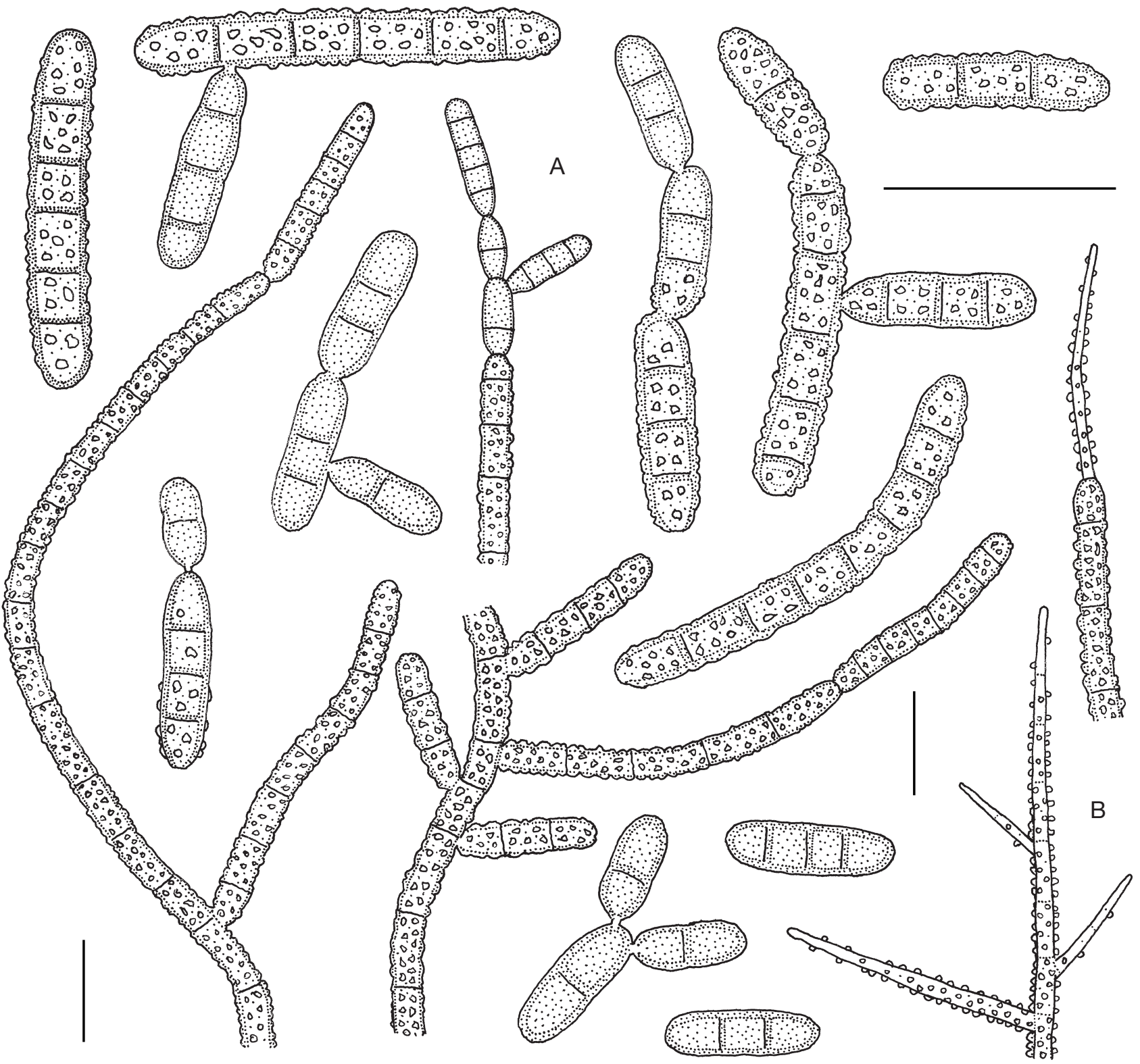

FIG. 2. - Septonema lohmanii G. Delgado \& O. Koukol, sp. nov. (BPI 910175, holotype): A, conidiophores, branches and conidia; B, acute apices of young conidiophores and branches. Scale bars: $20 \mu \mathrm{m}$.

Colonies on MEA moderately slow growing, reaching 16-21 $\mathrm{mm}$ diam. after 21 days at $25^{\circ} \mathrm{C}$, velvety, dark brown, umbonate, raised $1-3 \mathrm{~mm}$ at the center, sulcate, sometimes zonate with 1-2 concentric rings of growth, margin slightly undulate, whitish to pale brown, reverse blackish brown, sporulation late and abundant after 2 months. Colonies on PDA similar to MEA, moderately slow growing, reaching $16-17 \mathrm{~mm}$ diam. after 21 days at $25^{\circ} \mathrm{C}$, velvety, more umbonate than on MEA, raised up to $4 \mathrm{~mm}$ and dark brown at the center, outer zone brown, less sulcate, margin slightly undulate, whitish to paler brown, reverse black, sporulation lacking. Mycelium immersed and superficial, aerial hyphae similar to those on natural substrate but width and ornamentation often not uniform and may gradually vary along the length of the hyphae, anastomosing, often with prominent, brown to dark brown warts, $2-5 \mu \mathrm{m}$ wide and pale brown or with brown blobs of mucilage, 3-4 $\mu \mathrm{m}$ thick, some cells inflated, thick-walled, brown, functioning as conidiogenous cells, 5-9 $\mu \mathrm{m}$ wide. Conidiophores similar to those on natural substrate, often strongly verrucose and distinctly warted, width and ornamentation may also vary along the length of the conidiophores, basal cell sometimes slightly narrower and then conidiophores gradually widening distally, up to $268 \mu \mathrm{m}$ long, (3-) 4-8 $\mu \mathrm{m}$ wide; branches up to $142 \mu \mathrm{m}$ long, 3-7.5 $\mu \mathrm{m}$ wide. Conidia similar to those on natural substrate, cylindrical, subcylindrical or narrowly clavate, with 2-13 transverse septa, 0-1 longitudinal septa and very rarely with 1 oblique septum, slightly constricted at some septa or around the central portion, in short, simple or branched acropetal chains of 2-4 (-5) conidia, each one with 0-4 api- 


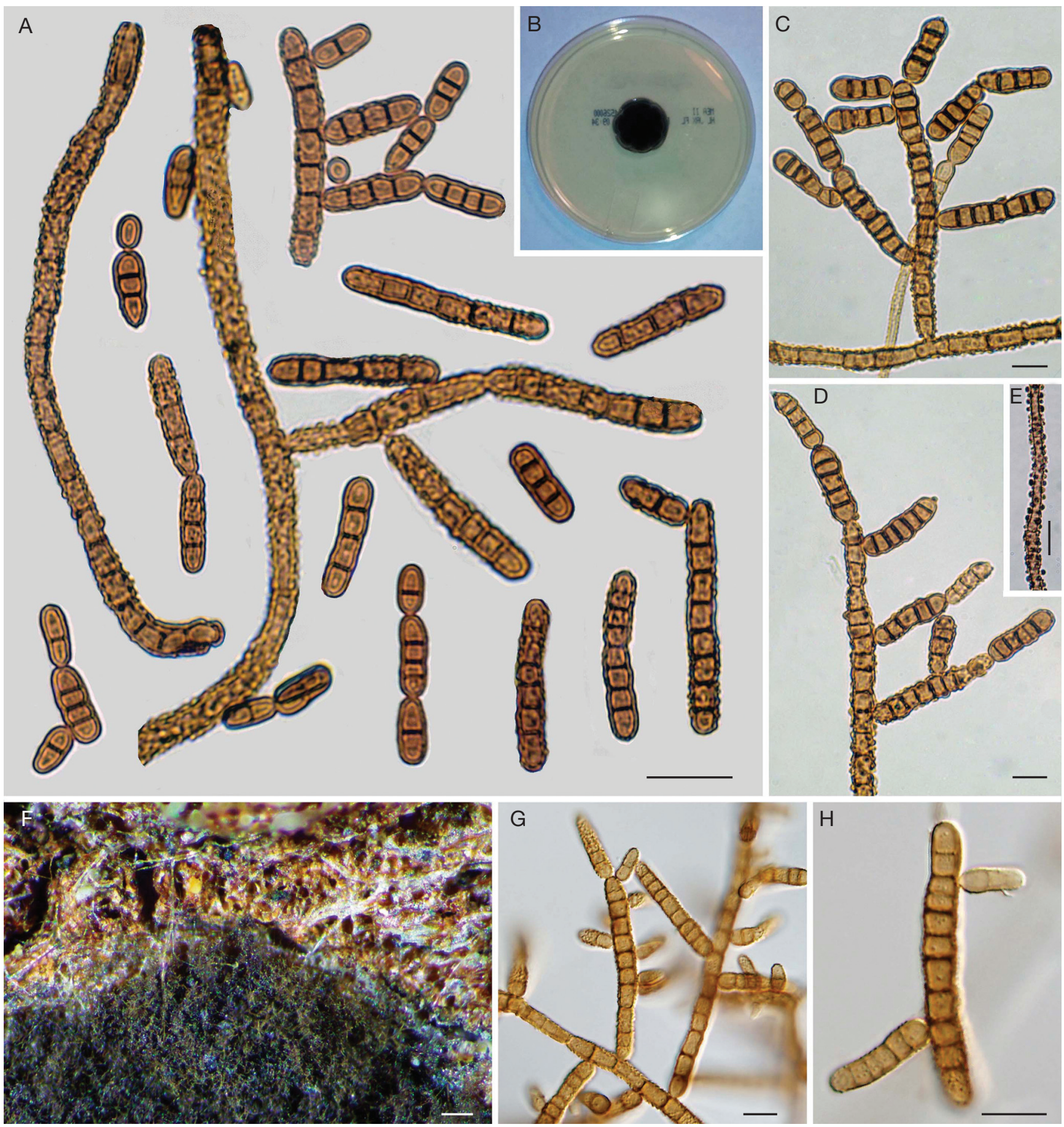

FIG. 3. - Septonema lohmanii G. Delgado \& O. Koukol, sp. nov. (BPI 910175, holotype = CBS 141174). On natural substrate: A, conidiophores, branches and conidia. In culture (MEA); B, colony after 21 days; C, D, conidiophores, branches and conidia; E, hyphal segment showing warts. Ibid. (PRC 4117, paratype); F, colony on natural substrate; G, conidiophores, branches and conidia; H, conidia. Scale bars: A, $20 \mu \mathrm{m}$; C-E, G-H, $10 \mu \mathrm{m} ; \mathrm{F}, 200 \mu \mathrm{m}$.

cal or lateral hila or $0-2$ per single conidial cell, 14-58(-63) $\times(5-) 6-10(-11) \mu \mathrm{m}$.

NOTES

Among species of Mytilinidion forming septonema-like anamorphs, S. lohmanii G. Delgado \& O. Koukol, sp. nov. is morphologically close to anamorphic $M$. rhenanum in having coarsely ornamented semi-macronematous conidiophores, conidia and hyphae, and producing short, simple or branched acropetal chains of 2-3 conidia on natural substrate or 2-4 conidia on PDA or MEA (Lohman 1939; Bisby \& Hughes 1952). Conidia of both species are also similar in width being 6-8 $\mu \mathrm{m}$ wide in the lectotype specimen of $M$. rhenanum from Finland where the anamorph is also present mixed with hysterothecia, and they both occur on bark and wood of Pinus spp. However, colonies of anamorphic $M$. rhenanum on natural 


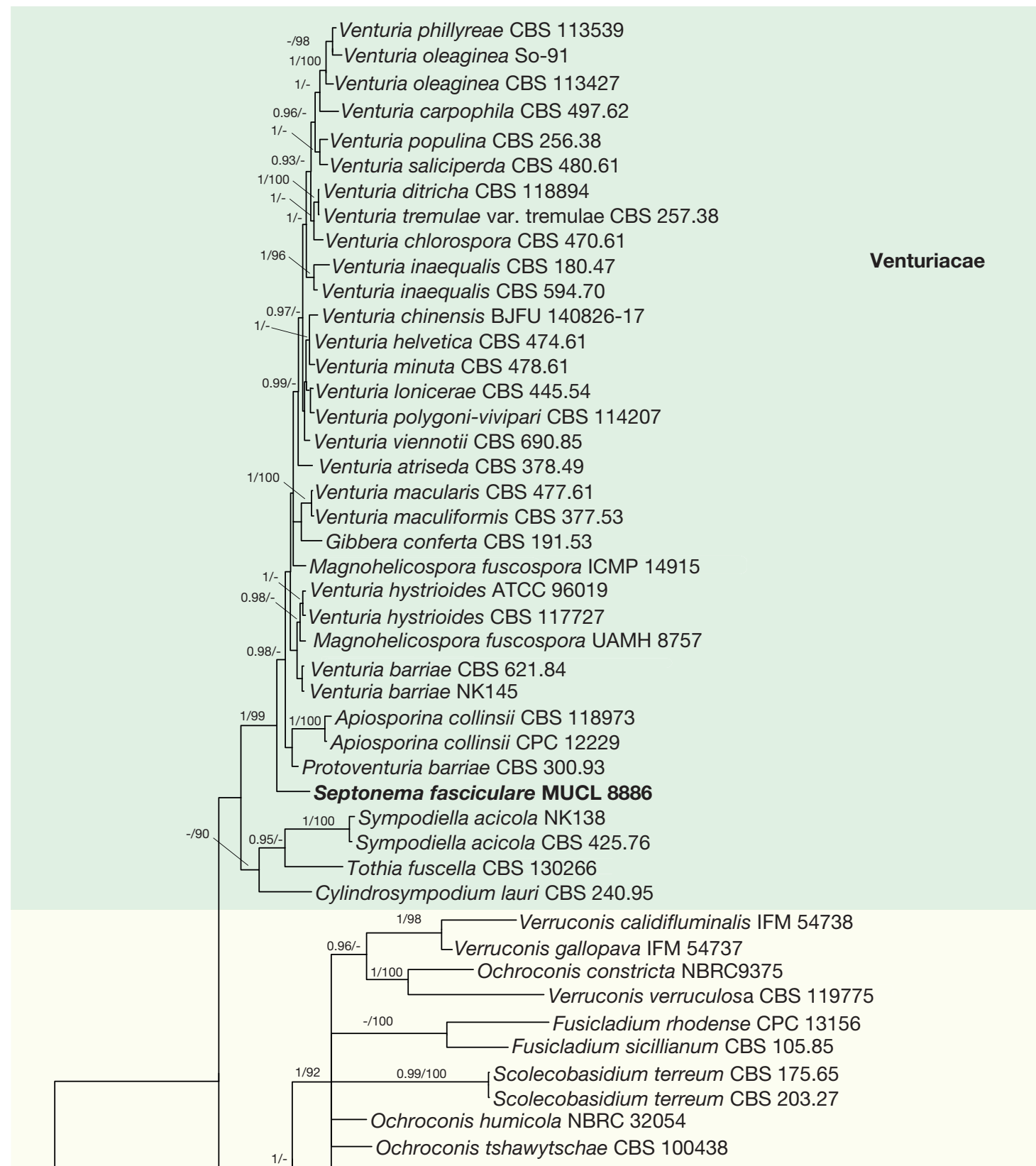

Sympoventuriaceae

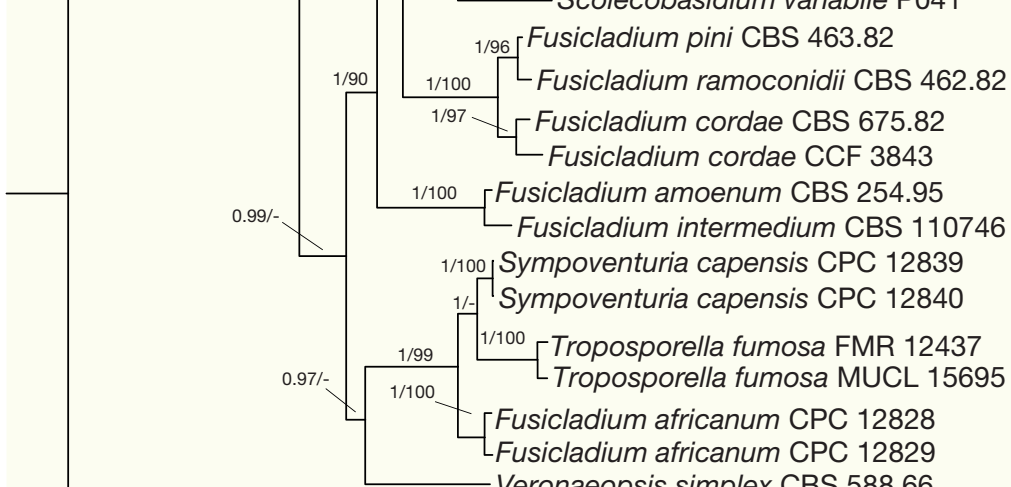

Veronaeopsis simplex CBS 588.66

Phoma herbarum UAMH 10909

FIG. 4. - Phylogenetic tree inferred from Bayesian and ML analyses of concatenated ITS-LSU sequence data showing the placement of Septonema fasciculare (Corda) S. Hughes within the family Venturiaceae (Venturiales, Dothideomycetes). Numbers above branches represent Bayesian posterior probabilities PP $>0.95$ followed by ML bootstrap support values BS $\geq 90 \%$. The studied strain MUCL 8886 is highlighted in bold. 
substrate are dull black and conidiophores are shorter being up to $60 \mu \mathrm{m}$ long. Conidia are different in shape and shorter, fusiform to oblong and 15-35 $\mu \mathrm{m}$ long, with less number of septa and 2-7 per conidium. Our fungus is also comparable to anamorphic Oedohysterium insidens in its strongly verrucose conidiophores and conidial walls (Hughes 1952b; Ellis 1976). However, conidial chains in O. insidens mature basipetally instead of acropetally with the older conidia located at the distal end of longer, simple chains of up to 15 conidia. Conidia of $O$. insidens are oblong or ellipsoidal in shape, wider being 8-18 $\mu \mathrm{m}$ wide with less 3-5(-9) transverse septa and may develop later 1-3 longitudinal septa. Conidiophores are shorter than those of S. lohmanii G. Delgado \& O. Koukol, sp. nov., up to $50 \mu \mathrm{m}$ long, and they arise in a palisade from a conspicuous, pulvinate and erumpent stroma.

Both specimens of S. lohmanii G. Delgado \& O. Koukol, sp. nov. studied here were morphologically similar on natural substrate but minor variations in color, conidiophore length, branching and ornamentation were detected between them. Conidiophores and conidia of the Arizona specimen BPI 910175 were more reddish brown in color whereas the Czech material PRC 4117 was more yellowish brown. The Arizona fungus had shorter conidiophores, up to $268 \mu \mathrm{m}$ long, than the Czech specimen with up to $515 \mu \mathrm{m}$ long. Conidiophores were more uniformly ornamented, more consistent in width and less branched in the Arizona specimen. Segments of conidiophores and branches of the Czech fungus, on the other hand, were unevenly wide, some cells thick-walled, darker in color, smooth or sparingly verrucose, 8-9 $\mu \mathrm{m}$ wide, and abruptly constricted a few times along the length of the same conidiophore reaching 3-3.5 $\mu \mathrm{m}$ in width.

\section{Septonema fasciculare (Corda) S. Hughes}

(Figs 5, 6)

In Canadian Journal of Botany 36: 803 (1958).

Material eXAmined. - Belgium. Haasrode, Meerdaalwoud, on the outer side of bark of Pinus sylvestris L., 16.V.1966, coll. G.L. Hennebert, isol. G.L. Hennebert (MUCL[MUCL 8886], deposited as Septonema secedens).

Canada. Quebec province, Gatineau Parkway, near Pink Lake, on bark of Coniferae, X.1959, coll. W.B. Kendrick, det. W.B. Kendrick (IMI[IMI 84944a]). - Septonema secedens Corda, Great Britain, Surrey County, Ashtead Common, on bark of Betula sp., 12.I.1947, coll. S.J. Hughes, det. S.J. Hughes (IMI[IMI 9939]); ibid., Oxshott, on periderm of Betula sp., 7.III.1948 (IMI[IMI 25538a]).

\section{DESCRIPTION}

Colonies on natural substrate effuse, hairy or cottony, black. Mycelium partly superficial, partly immersed composed of branched, septate, smooth, brown hyphae, 1.5-2 $\mu$ m wide. Conidiophores macronematous, monomenatous, erect, simple, straight or flexuous, sometimes bent at a $90^{\circ}$ angle or rarely bifurcating, cylindrical, septate, smooth, brown, sometimes paler distally and constricted at the septa delimiting terminal or subterminal cells, up to $480 \mu \mathrm{m}$ long, 3-4 $\mu \mathrm{m}$ wide, 5-9 $\mu \mathrm{m}$ wide at the base. Conidiogenous cells monoblastic or polyblastic, integrated, terminal or intercalary, occasionally intercalary-pleurogenous, determinate, cylindrical, subcylindrical or somewhat clavate at the tip, pale brown, brown or grayish brown, 0-1(-4) septate, sometimes constricted at the basal delimiting septa, $17-28 \times 3-5(-6) \mu \mathrm{m}$, with $1-2$ truncate or subdenticulate, neither thickened nor darkened apical conidiogenous loci giving rise to ramoconidia. Ramoconidia cylindrical to narrowly clavate, sometimes fusoid-ellipsoid, 0-1(-3)-septate, thick-walled, smooth, pale brown to brown or dark grayish brown, in chains of up to 3, $15-21(-25) \times 3-5 \mu \mathrm{m}$, with 1-2 truncate or subdenticulate apical conidiogenous loci; conidia cylindrical, sometimes slightly attenuated in their central part, pale grayish brown to grayish brown, 1-4-septate, mostly 3, rarely up to 7 septa, thin-walled, smooth, with rounded ends, (11-)13-22(-30) $\times 4-5 \mu \mathrm{m}$, in simple or rarely branched acropetal chains of up to 9 conidia.

Colonies on MEA restricted, very slow growing, reaching 4-5 $\mathrm{mm}$ diam. after 1 month at room temperature $\left(22-25^{\circ} \mathrm{C}\right)$, circular, black, velvety, convex, raised 1-2 mm, sometimes with a slight amount of dark gray aerial mycelium in the center, margin entire, reverse black, sporulation not observed after four months.

\section{NoTES}

The strain MUCL 8886 did not sporulate on any of the culture media used including nutrient poor water agar with sterile wooden toothpicks. Morphological examination of the herbarium specimen source of this strain showed that it is conspecific with $S$. fasciculare and not with $S$. secedens. The specimen closely matches previous descriptions of $S$. fasciculare (Ellis 1976; Holubovà-Jechovà 1978) in forming black, hairy to cottony colonies on bark of Pinus species, particularly P. sylvestris, and having simple conidiophores up to $880 \mu \mathrm{m}$ long, cylindrical, grayish brown to brown, mostly 3- but also 1-, 2- or 4-septate conidia with rounded ends, 14-20 $\mu \mathrm{m}$ long, consistently 4-5 $\mu \mathrm{m}$ wide and produced in branched, acropetal chains (Fig. 6B-J). Further evidence of conspecificity was found by comparing MUCL 8886 with specimen IMI 84944 a belonging to $S$. fasciculare. Septonema secedens, on the other hand, differs from $S$. fasciculare by forming olivaceous brown to dark brown, velvety colonies on natural substrate, shorter, branched conidiophores up to $200 \mu \mathrm{m}$ long and pale brown to brown, wider conidia 5-7 $\mu \mathrm{m}$ wide, with truncate ends (Fig. 6K-N). A comparison between MUCL 8886 and two specimens of $S$. secedens deposited in IMI (9939 and 25538a) confirmed that they belong to different taxa. Dried cultures found inside the herbarium packet of MUCL 8886 and grown on MA (Malt Agar) or MEA according to their labels were sterile as well.

\section{DISCUSSION}

The novel fungus described in this study agrees well with the morphological concept of Septonema in having multiseptate, cylindrical conidia produced in simple or branched 


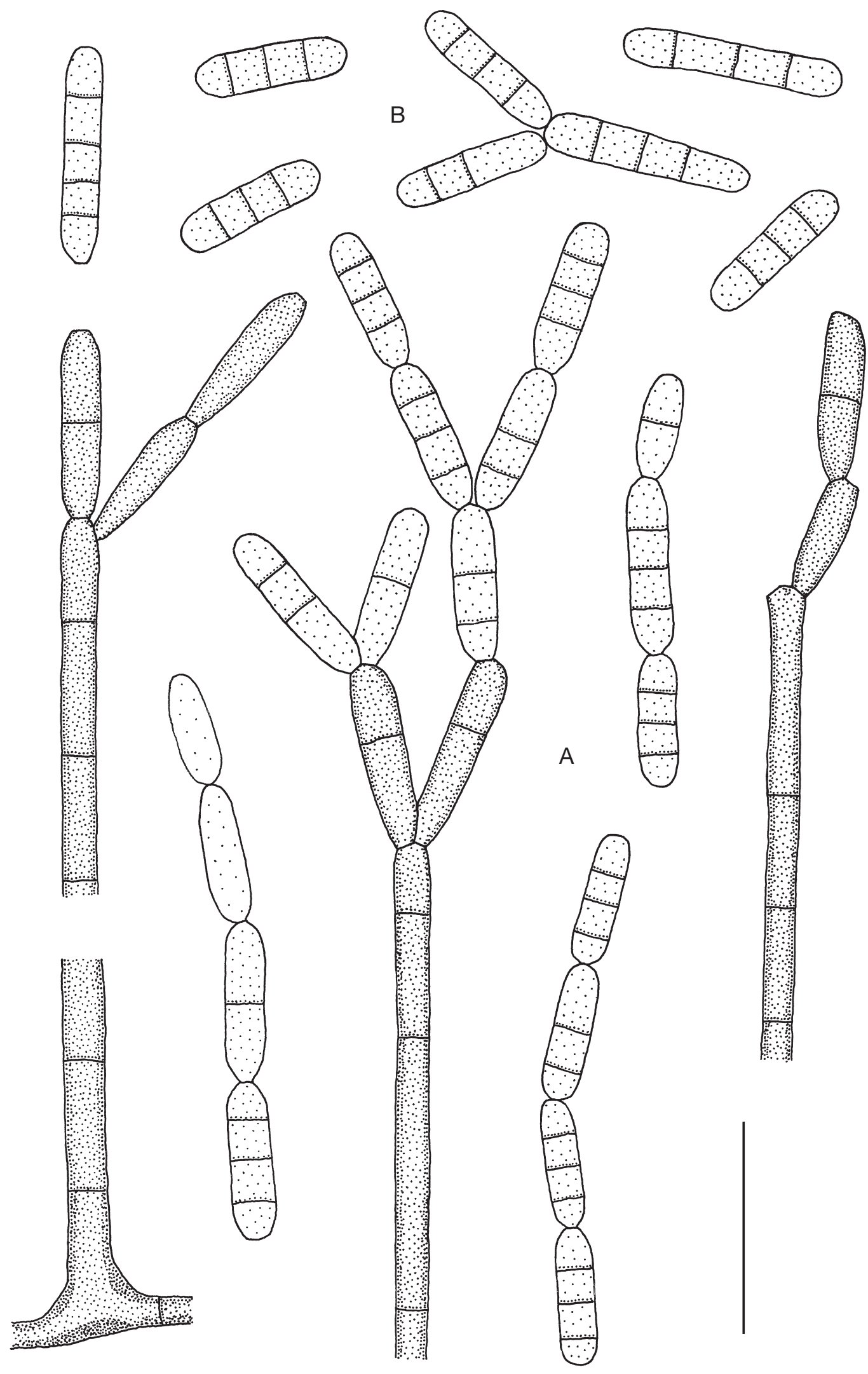

FIG. 5. - Septonema fasciculare (Corda) S. Hughes (MUCL 8886, herbarium specimen): A, conidiophores, ramoconidia and conidia in chains; B, conidia. Scale bar: $20 \mu \mathrm{m}$. 

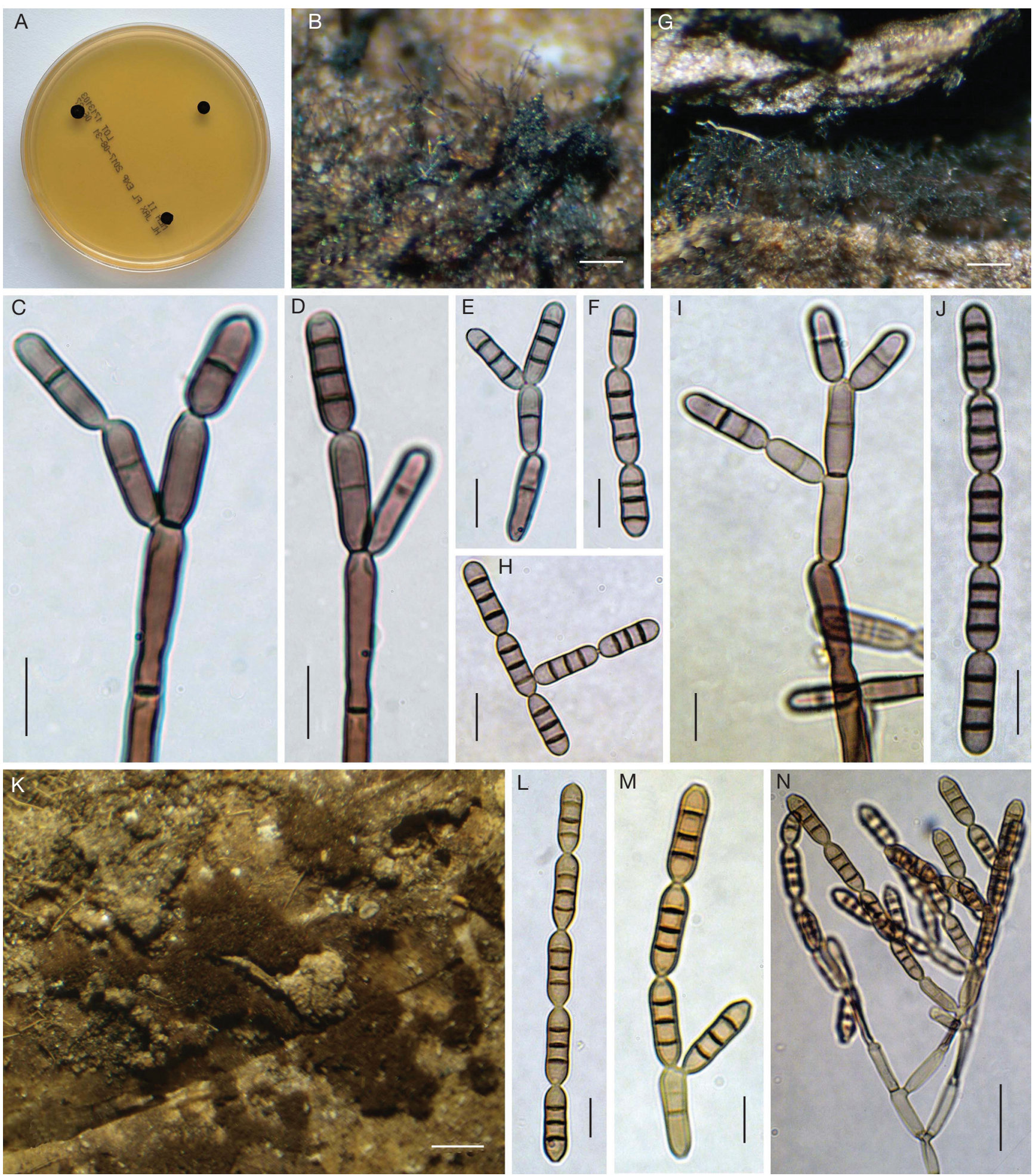

FIG. 6. - Septonema fasciculare (Corda) S. Hughes (MUCL 8886) in culture (MEA): A, colonies after 1 month. Herbarium specimen; B, colonies on natural substrate; C, D, conidiophores, conidiogenous cells and conidia; E, F, conidia. Ibid. (IMI 84944a); G, colonies on natural substrate; H, J, conidia; I, conidiophores, conidiogenous cells and conidia. Septonema secedens (IMI 9939); K, colonies on natural substrate. L, M, conidia. Ibid. (IMI 25538a); N, conidiophore, branches and conidia. Scale bars: B, G, $200 \mu \mathrm{m} ; \mathrm{K}, 500 \mu \mathrm{m} ; \mathrm{C}-\mathrm{F}, \mathrm{H}-\mathrm{J}, \mathrm{L}-\mathrm{M}, 10 \mu \mathrm{m} ; \mathrm{N}, 20 \mu \mathrm{m}$.

acropetal chains born on monoblastic or polyblastic, terminal or intercalary conidiogenous cells arising from branched, macronematous conidiophores (Hughes 1951; Ellis 1971; Holubová-Jechová 1978). The establishment of S. lohmanii
G. Delgado \& O. Koukol, sp. nov. as a new taxon among previously described Septonema species, however, is supported by a distinct morphology and molecular data. The two collections on which this fungus is based, one from southwestern 
United States and the other from central Europe, were morphologically close despite their disjunct geographical distribution. Minor differences observed between them are attributed to intraspecific variation and the age of each specimen, the North American one apparently older and more fragmented, or the influence of environmental conditions affecting each particular location. Arizona is a semiarid region characterized by low annual rainfall and mild to hot temperatures while the Czech Republic has a temperate continental climate, with warm summers and cold, snowy winters. Their conspecificity is also supported by highly similar ITS and LSU rDNA sequence data and the fact that they grouped together with strong support in all phylogenetic analyses. The differences in the EF1-a intron are considered intraspecific variation.

The affinity of S. lohmanii G. Delgado \& O. Koukol, sp. nov. with members of the order Mytilinidiales based on DNA sequence data is in congruence with previous cultural or circumstantial evidence of relatedness between mytilinidiaceous ascomycetes and septonema-like anamorphs (Lohman 1933b, 1939; Bisby 1941; Bisby \& Hughes 1952). Moreover, this is the first time a septonema-like anamorph is linked to the order Mytilinidiales in a phylogenetic framework using molecular data. On the basis of previously known affinities between these fungi and the end of dual nomenclature, a placement of the new species in Mytilinidion sensu lato was considered. However, S. lohmanii G. Delgado \& O. Koukol, sp. nov. strains did not show a close relationship with any particular Mytilinidion species including M. mytilinellum, the proposed generic neotype (Zogg 1962; Hyde et al. 2013), represented by two strains which grouped separate in this and previous studies (Boehm et al. 2009a). The two strains of S. lohmanii G. Delgado \& O. Koukol, sp. nov. were also distant from M. rhenanum and M. scolecosporum, with known septonema-like anamorphs and which grouped together in our phylogeny although without support. Mytilinidion as a whole was revealed to be paraphyletic within the order as seen in previous phylogenies. The genus is in need of further revision and taxonomic rearrangement, particularly regarding the status of the type species which still needs clarification (Vasilyeva 2001). A possible relationship between S. lohmanii G. Delgado \& O. Koukol, sp. nov. and anamorphic Oedohysterium insidens based on their similar, verrucose ornamentation of conidiophores and conidia was not supported by molecular data. In addition to morphological and developmental differences, sequences of $O$. insidens clustered within the order Hysteriales. If the position of Septonema sensu stricto outside Mytilinidiales is confirmed, S. lohmanii G. Delgado \& O. Koukol, sp. nov. may be accommodated in a novel genus.

Mytilinidiaceous ascomycetes and septonema-like anamorphs have often been found associated with conifers, particularly pine trees, similar to S. lohmanii G. Delgado \& O. Koukol, sp. nov. (Lohman 1933b, 1939; Holubová-Jechová 1978; Minter 1981; Minter \& Holubová-Jechová 1981; Schubert \& Braun 2007). Marmolejo \& Minter (2006) recorded six species of Septonema and several mytilinidiaceous taxa belonging to the genera Lophium Fr., Mytilinidion, Ostreichnion Duby, Ostreola Darker and Quasiconcha M.E. Barr \& M. Blackw. on Pinus spp. worldwide. An online search in the Mycology Collections data Portal showed a total of 117 records of these fungi on fourteen Pinus spp. across Europe, Canada and twenty-one U.S. states and territories (MyCoPortal 2018). Boehm et al. (2009b) consider them an ancient and ecologically successful group confined almost exclusively to conifers. In general, anamorphic fungi with mytilinidiaceous affinities are known to be morphologically diverse, primarily coelomycetous and less frequently hyphomycetous (Boehm et al. 2009a; Hyde et al. 2013; Wijayawardene et al. 2012, 2017). In addition to the septonema-like morphology, mytilinidiaceous hyphomycetes also include chalara-like states such as anamorphic Quasiconcha reticulata (Blackwell \& Gilbertson 1985) or helicosporous anamorphs such as Lophium arboricola (Buczacki) Madrid \& Gené (Buczacki 1972; Hernández et al. 2016), L. zalerioides Jin F. Li, Phook., Camporesi \& K.D. Hyde (Hyde et al. 2017) and Slimacomyces isiolus (R.T. Moore) G.Z. Zhao (Moore 1957). The latter was found to be a member of Mytilinidiales in this study based on unpublished sequences under that name available in GenBank. Likewise, all of them have been reported growing on different conifers based on literature and information available together with sequence data. Hyde et al. (2013) provided a key to the anamorphic genera in Mytilinidiaceae including only three hyphomycetous states: Peyronelia Cif. \& Gonz. Frag., Taeniolella and Septonema. The type species of Peyronelia, P. sirodesmioides Cif. \& Gonz. Frag., is of uncertain placement but a couple of peyronelia-like anamorphs have been linked to species of Glyphium Nitschke ex F. Lehm., now within the distant Patellariales (Boehm et al. 2015; Sutton 1970). Taeniolella, on the other hand, is a highly polyphyletic taxon (Ertz et al. 2016) with a taeniolella-like anamorph linked to Mytilinidion gemmigenum Fuckel (Minter \& Holubová-Jechová 1981) but relatedness of this genus to Mytilinidiales is not phylogenetically verified (Heuchert et al. 2018). Septonema is the only genus whose relationships with mytilinidiaceous fungi were documented by cultural as well as circumstantial evidence (Lohman 1933a, b, 1939; Bisby 1941; Bisby \& Hughes 1952) and now also by molecular sequence data.

The present attempt to clarify the phylogenetic affinities of S. secedens, the type species of the genus, and possibly define Septonema sensu stricto using molecular sequence data was unsuccessful and therefore its position within Ascomycota remains unclear. Nevertheless, the phylogenetic placement of $S$. fasciculare, represented by the strain MUCL 8886, was resolved for the first time within the family Venturiaceae (Venturiales, Dothideomycetes) distant from S. lohmanii G. Delgado \& O. Koukol, sp. nov. in Mytilinidiales and confirming once again the polyphyletic nature of the genus. The strongly supported sister-group relationship in the ITS-LSU phylogeny (Fig. 4) between this strain and a large group of Venturia species including the generic type $V$. inaequalis was not supported in the EF1-a tree (not shown). This relationship deserves further study to clarify whether $S$. fasciculare is actually distinct within the family considering that members of the anamorphic genus Fusicladium, traditionally linked to venturiaceous teleomorphs, are now interspersed between 
both Venturiaceae and its sister family Sympoventuriaceae (Machouart et al. 2014). Morphologically, S. fasciculare fits well within a broad concept of Fusicladium in having solitary, simple, smooth conidiophores, monoblastic or polyblastic, integrated, terminal or intercalary, determinate conidiogenous cells, with terminal or lateral, more or less denticle-like conidiogenous loci with truncate apices and 3-septate, smooth, phragmosporous, catenate conidia with rounded to truncate ends in simple or branched acropetal chains and forming blackish colonies (Schubert et al. 2003). The conidia at the base of chains, here referred to as ramoconidia, were found to be morphologically distinct from the terminal ones. They agree well with a broad definition of this term (Cole \& Samson 1979; Seifert et al. 2011): dydimo- or phragmosporous, larger and darker than the apical conidia, truncate at base with one basal scar and two distal scars at the apex, marking the start of the acropetal chain and easily detached carrying the rest of the branching chain (Fig. 6E). Several Fusicladium species also produce ramoconidia at the base of simple or branched, sometimes long acropetal chains including fusicladium-like, anamorphic Venturia hystrioides (Dugan, R.G. Roberts \& Hanlin) Crous \& U. Braun, closely related to $S$. fasciculare in our phylogeny, or Fusicladium rhodense Crous \& M.J. Wingf., F. sicilianum Koukol, Crous \& de Hoog, F. convolvularum Ondřej or F. africanum Crous, more distantly related and nested within Sympoventuriaceae. Holubová-Jechová (1978) considered $S$. fasciculare to be very common in Bohemia, the type locality, on the outer or inner surface of bark of stumps or fallen trunks of pine trees, particularly $P$. sylvestris, but its current distribution and status are unknown.

Similarly, the examination of herbarium specimens of $S$. secedens revealed the presence of ramoconidia at the base of the acropetal chains that detach carrying the rest of the conidia (Fig. 6M). Hughes (1951), based on several specimens including those examined in the present study, also noticed and illustrated morphological differences between the lower, first formed conidium of a chain, often narrower and the only being 1-septate, and those produced later. Seifert et al. (2011), in their diagnosis of Septonema, first introduced the presence of ramoconidia to the genus while Heuchert et al. (2018) recently used this feature to separate Taeniolella from morphologically similar genera such as Septonema or Heteroconium. Speculatively, $S$. secedens as well as other related species such as $S$. pinicola Hol.-Jech. or S. pseudobinum Hol.-Jech. (Holubová-Jechová 1978), currently of uncertain phylogenetic placement, might belong to Venturiaceae considering the close morphological similarities with $S$. fasciculare. However, this hypothesis needs to be tested upon recollection of these fungi and availability of new molecular data. Holubová-Jechová (1978) considered $S$. secedens restricted to a single host genus Betula L. but the fungus has also been occasionally recorded on conifers such as P. sylvestris, Pseudotsuga menziesii (Mirb.) Franco or Picea sp. among other substrates (Hughes 1951; Ellis 1971; Cannon 2009). In the absence of sufficient information regarding the taxonomic and phylogenetic status of the type species we refrain from proposing any generic redispositions at the moment and prefer to use the current broad concept of Septonema to accommodate S. lohmanii G. Delgado \& O. Koukol, sp. nov. as well as $S$. fasciculare until fresh collections and further molecular data become available for study.

\section{Acknowledgements}

We would like to thank Anita Tiller (MERCA) for hosting loans to G.D. at her institution and the curators of IMI and MUCL for providing access to herbarium specimens in their care. G.D. also thanks Rebecca Himebaugh for DNA isolation of the Arizona strain, and Magzoub Ismail, Michael Manning and Kamash Pilai (EMlab P\&K) for lab assistance and provision of facilities. The authors would like to thank the contribution of the anonymous reviewers.

\section{REFERENCES}

Abe N. \& Hamada N. 2011. - Molecular characterization and surfactant utilization of Scolecobasidium isolates from detergentrich indoor environments. Biocontrol Science 16: 139-147. https:// doi.org/10.4265/bio.16.139

Arzanlou M., Groenewald J. Z., Gams W., Braun U., Shin H.-D. \& Crous P. W. 2007. - Phylogenetic and morphotaxonomic revision of Ramichloridium and allied genera. Studies in Mycology 58: 57-93. https://doi.org/10.3114/sim.2007.58.03

Aveskamp M. M., De GruYter J., Woudenberg J. H., Verkley G. J. \& Crous P. W. 2010. — Highlights of the Didymellaceae: A polyphasic approach to characterize Phoma and related pleosporalean genera. Studies in Mycology 65: 1-60. https://doi. org/10.3114/sim.2010.65.01

BARR M. E. 1992. - Notes on the Lophiostomataceae (Pleosporales). Mycotaxon 45: 191-221.

BARRON G. L. 1968. — The genera of Hyphomycetes from soil. The Williams \& Wilkins Co., Baltimore.

BISBY G. R. 1941. — British species of Hysterium, Gloniopsis, Dichaena and Mytilidion. Transactions of the British Mycological Society 25: 127-140. https://doi.org/10.1016/S0007-1536(41)80001-1

Bisby G. R. \& Hughes S. J. 1952. - Summary of the British Hysteriales. Transactions of the British Mycological Society 35: 308-314. https://doi.org/10.1016/S0007-1536(52)80042-7

BLACKWELL M. \& GILBERTSON R. L. 1985. - Quasiconcha reticulata and its anamorph from conifer roots. Mycologia 77: 50-54. https://doi.org/10.1080/00275514.1985.12025061

Boehm E. W. A., Marson G., Mathiassen G. H., Gardiennet A. \& SCHOCH C. L. 2015. - An overview of the genus Glyphium and its phylogenetic placement in Patellariales. Mycologia 107: 607-618. https://doi.org/10.3852/14-191

Boenm E. W. A., Mugambi G. K., Miller A. N., Huhndorf S. M., Marincowitz S., Spatafora J. W. \& SCHOCH C. L. 2009a. - A molecular phylogenetic reappraisal of the Hysteriaceae, Mytilinidiaceae and Gloniaceae (Pleosporomycetidae, Dothideomycetes) with keys to world species. Studies in Mycology 64: 49-83. https://doi.org/10.3114/sim.2009.64.03

Boehm E. W. A., Schoch C. L. \& Spatafora J. W. 2009b. On the evolution of the Hysteriaceae and Mytilinidiaceae (Pleosporomycetidae, Dothideomycetes, Ascomycota) using four nuclear genes. Mycological Research 113: 461-479. https://doi. org/10.1016/j.mycres.2008.12.001

Boonmee S., Bhat J. D., MaharachChikumbura S. S. N. \& Hyde K. D. 2014. - Clavatispora thailandica gen. et sp. nov., a novel taxon of Venturiales (Dothideomycetes) from Thailand. Phytotaxa 176: 92-101. https://doi.org/10.11646/phytotaxa.176.1.11

Boonmee S., Ko T. W., Chukeatirote E., Hyde K. D., Chen H., Cai L., Mckenzie E. H., Gareth- Jones E. B., Kodsueb R. \& 
Hassan B. A. 2012. - Two new Kirschsteiniothelia species with Dendryphiopsis anamorphs cluster in Kirschsteiniotheliaceae fam. nov. Mycologia 104: 698-714. https://doi.org/10.3852/11-089

BUCZACKI S. T. 1972. - Zalerion arboricola, a new helicosporous hyphomycete from conifer stems. Transactions of the British Mycological Society 59:159-161. https://doi.org/10.1016/S00071536(72)80056- 1

CANNON P. F. 2009. - Septonema secedens. IMI Descriptions of Fungi and Bacteria 1818: 1-3.

Chen Q., JiAnG J. R., Zhang G. Z., CaI L. \& Crous P. W. 2015. Resolving the Phoma enigma. Studies in Mycology 82: 137-217. https://doi.org/10.1016/j.simyco.2015.10.003

Cole G. T. \& SAmson R. A. 1979. - Patterns of Development in Conidial Fungi. Pitman Publishing Ltd., London, 190 p.

CORDA A. C. J. 1837. — Icones fungorum hucusque cognitorum Vol. I. J. G. Calve, Prague, 32 p.

Crous P. W., Braun U., Schubert K. \& Groenewald J. Z. 2007a. - Delimiting Cladosporium from morphologically similar genera. Studies in Mycology 58: 33-56. https://doi.org/10.3114/ sim.2007.58.02

Crous P. W. \& Groenewald J. Z. 2016. - They seldom occur alone. Fungal Biology 120: 1392-1415. https://doi.org/10.1016/j. funbio.2016.05.009

Crous P. W., Mohammed C., Glen M., Verkley G. J. M. \& GroenEWALd J. Z. 2007b. - Eucalyptus microfungi known from culture. 3. Eucasphaeria and Sympoventuria genera nova, and new species of Furcaspora, Harknessia, Heteroconium and Phacidiella. Fungal Diversity 25: 19-36.

Crous P. W., Schubert K., Braun U., De Hoog G. S., Hocking A. D., Shin H.-D. \& Groenewald J. Z. 2007c. - Opportunistic, human-pathogenic species in the Herpotrichiellaceae are phenotypically similar to saprobic or phytopathogenic species in the Venturiaceae. Studies in Mycology 58: 185-217. https:// doi.org/10.3114/sim.2007.58.07

Darriba D., Taboada G. L., Doallo R. \& Posada D. 2012. jModelTest 2: more models, new heuristics and parallel computing. Nature Methods 9: 772. https://doi.org/10.1038/nmeth.2109

Ellis M. B. 1971. - Dematiaceous Hyphomycetes. CABI Publishing, Wallingford, $608 \mathrm{p}$.

ELLIS M. B. 1976. - More dematiaceous Hyphomycetes. CABI Publishing, Wallingford, $507 \mathrm{p}$.

ertz D., Heuchert B., Braun U., Freebury C. E., Common R. S. \& DiEDERICH P. 2016. - Contribution to the phylogeny and taxonomy of the genus Taeniolella, with a focus on lichenicolous taxa. Fungal Biology 120: 1416-1447. https://doi.org/10.1016/j. funbio.2016.05.008

Frank J., Crous P. W., Groenewald J. Z., Oertel B., Hyde K. D., Phengsintham P. \& SChroers H.-J. 2010. - Microcyclosporella and Microcyclospora: novel genera accommodating epiphytic fungi causing sooty blotch on apple. Persoonia 24: 93-105. https://doi. org/10.3767/003158510X510560

Gonzàlez R., Segura R., Trapero A., Baldoni L., Botella M. A. \& Valpuesta V. 2002. - Phylogeny of the fungus Spilocaea oleagina, the causal agent of peacock leaf spot in olive. FEMS Microbiology Letters 210: 149-155. https://doi. org/10.1111/j.1574-6968.2002.tb11174.x

Grondona I., Monte E., Rives V. \& Vicente M. A. 1997. Lichenized association between Septonema tormes sp. nov., a coccoid cyanobacterium, and a green alga with an unforseen biopreservation effect of Villamayor sandstone at 'Casa Lis' of Salamanca, Spain. Mycological Research 101: 1489-1495. https:// doi.org/10.1017/S0953756297004309

Hernández M., SCHUMacher R. K., WingField M. J., AhMAd I., Cai L., Duong T. A., Edwards J., Gené J., Groenewald J. Z., Jabeen S., Khalid A. N., Lombard L., Madrid H., Marin Y., Marincowitz S., Miller A. N., RajeshKumar K.-C., Rashid A., Sarwar S., Stchigel A. M., Taylor P. W. J., Zhou N. \& Crous P. W. 2016. — Fungal Systematics and Evolution: FUSE
2. Sydowia 68: 193-230.

Heuchert B., Braun U., Diederich P. \& Ertz D. 2018. Taxonomic monograph of the genus Taeniolella s. lat. (Ascomycota). Fungal Systematics and Evolution 2: 69-261. https://doi. org/10.3114/fuse.2018.02.06

HiraYAMA K. \& TANAKA K. 2011. - Taxonomic revision of Lophiostoma and Lophiotrema based on reevaluation of morphological characters and molecular analyses. Mycoscience 52: 401-412. https://doi.org/10.1007/S10267-011-0126-3

HolubOVÁ-JeCHOVÁ V. 1978. - Lignicolous Hyphomycetes from Czechoslovakia 5. Septonema, Hormiactella and Lylea. Folia Geobotanica \& Phytotaxonomica 13: 421-442. https://doi. org/10.1007/BF02851944

HugHes S. J. 1951. - Septonema secedens Corda. The Naturalist 839: $173-176$

HugHes S. J. 1952a. - Four species of Septonema. The Naturalist 840: 7-12.

Hughes S. J. 1952b. - Sirodesmium granulosum and Torula diversa. The Naturalist 842: 93-98.

Hughes S. J. 1958. - Revisiones Hyphomycetum aliquot cum appendice de nominibus rejiciendis. Canadian Journal of Botany 36: 727-836. https://doi.org/10.1139/b58-067

Hyde K. D., Gareth-Jones E. B., Liu J.-K., Ariyawansa H. A., Boehm E. W. A., Boonmee S., Braun U., Chomnunti P., Crous P. W., Dai D. S., Diederich P., Dhammika A. M. S., Dissanayake M., Dollom M., Doveri F., Hongsanan S., JayaWARdena R. S., LaWReY J. D., Li Y.-M., LiU Y.-X., LUCKing R. K., Monkai J., Muggia L., Nelsen M. P., Pang K. K.Y, Phookamsak R., Senanayake I. C., Shearer C. A., Suetrong S., Tanaka K., Thambugala K. M., Wijayawardene N. N., Wikee S., Wu H.-X., Zhang Y., Aguirre-Hudson B., Alias S. A., Aptroot A., Bahkali A. H., Bezerra J. L. M., Bhat D., Camporesi E., ChuKeatirote E., GUEIDAN C., HaWksWorth D. L., Hirayama K., De Hoog S., Kang J.-C., Knudsen K., LI W.-J., Li X.-H., LIU Z.-Y., MAPOOK A., MCKenZIE E. H., Miller A. N., Mortimer P. E., Phillips A. J. L., Raja H. A., Scheuer C., Schumm F., Taylor J., Tian Q., Tibpromma S., Wanasinghe D. N., Wang Y. F., XU J.-C., YaCharoen S., YaN J.-Y. \& ZHANG M. 2013. - Families of Dothideomycetes. Fungal Diversity 63: 1-313. https://doi.org/10.1007/s13225-013-0263-4

Hyde K. D., Norphanphoun C., Abreu V. P., Bazzicalupo A., Chethana K. W.t, Clericuzio M., Dayarathne M. C., DisSanayake A. J., Ekanayaka A. H., He M. Q., Hongsanan S., Huang S. K., Jayasiri S. C., Jayawardena R. S., Karunarathna, A., Konta S., KuŠAn I., LeE H., Li J. F., LiN C. G., LiU N. G., Lu Y. Z., LuO Z. L., Manawasinghe I. S., Mapook A., Perera R. H., Phookamsak R., Phukhamsakda C., Siedlecki I., Soares A. M., Tennakoon D. S., Tian Q., Tibpromma S., Wanasinghe D. N., Xiao Y. P., Yang J., Zeng X. Y., AbDEL-AZIZ F. A., Li W. J., Senanayake I. C., Shang Q. J., Daranagama D. A., De Silva N. I., Thambugala K. M., AbDel-Wahab M. A., Bahkali A. H., Berbee M. L., Boonmee S., Bhat D. J., Bulgakov T. S., Buyck B., Camporesi E., Castañeda-Ruiz R. F., Chomnunti P., Doilom M., Dovana F., Gibertoni T. B., Jadan M., JeEwon R., Gareth Jones E. B. G., KanG J. C., Karunarathna S. C., .Lim Y. W., LiU J. K., LiU Z. Y., Plautz JR. H. L., Lumyong S., Maharach Chikumbura S. S. N., Matočec N., Mckenzie E. H. C., Mešıć A., Miller D., PaWŁowska J., Pereira O. L., Promputtha I., Romero A. I., Ryvarden L., Su H. Y., Suetrong S., Tkalčec Z., VizZini A, Wen T. C., Wisitrassameewong K., Wrzosek M., Xu J. C., Zhao Q., Zhao R. L. \& Mortimer P. E. 2017. — Fungal diversity notes 603-708: taxonomic and phylogenetic notes on genera and species. Fungal Diversity 87: 1-235. https://doi. org/10.1007/s13225-017-0391-3

Jayasiri S. C., Hyde K. D., Gareth-Jones E. B., Ariyawansa H. A., BahKali A. H., Elgorban A. M. \& KANG J.-C. 2017. — A new hysteriform dothideomycete (Gloniaceae, Pleosporomycetidae 
incertae sedis), Purpurepithecium murisporum gen. et sp. nov. on pine cone scales. Cryptogamie, Mycologie 38: 241-251. https:// doi.org/10.7872/crym/v38.iss2.2017.241

Kirschner K., Pang K.-L. \& Gareth-Jones E. B. 2013. - Two cheirosporous hyphomycetes reassessed based on morphological and molecular examination. Mycological Progress 12: 29-36. https://doi.org/10.1007/s11557-012-0812-3

KOUKOL O. 2010. - Revision of "Septonema ochraceum" revealed three new species of Venturiaceae and Herpotrichiellaceae. Mycological Progress 9: 369-378. https://doi.org/10.1007/s11557-009-0645-x

Koukol O., Delgado G., Hofmann T. A. \& Piepenbring M. 2018. - Panama, a hot spot for Hermatomyces (Hermatomycetaceae, Pleosporales) with five new species, and a critical synopsis of the genus. IMA Fungus 9: 107-141.

LOHMAN M. L. 1933a. - Hysteriaceae: Life histories of certain species. Papers of the Michigan Academy of Sciences 17: 229-288.

LOHMAN M. L. 1933b. — Septonema toruloideum: a stage of Mytilidion scolecosporum. Mycologia 25: 34-43. https://doi.org/10.1 080/00275514.1933.12020647

LOHMAN M. L. 1934. - Lophiosphaera (Glonium) velata, with a critical study of its Septonema multiplex stage. American Journal of Botany 21: 314-327. https://doi.org/10.1002/j.1537-2197.1934. tb04965.x

LOHMAN M. L. 1939. — Karsten's type specimens of Hysteriaceae on conifers. Mycologia 31: 354-365. https://doi.org/10.1080/0 0275514.1939 .12017350

Lunghini D. \& Toscano F. 1997. — Studies on Mediterranean hyphomycetes. VII. Septonema crispulum anam.-sp. nov. Mycotaxon 63: 329-334

Machouart M., Samerpitak K., De Hoog G. S. \& Gueidan C. 2014. - A multigene phylogeny reveals that Ochroconis belongs to the family Sympoventuriaceae (Venturiales, Dothideomycetes). Fungal Diversity 65: 77-88. https://doi.org/10.1007/ s13225-013-0252-7

Mardones M., Trampe-JaschiK T., Oster S., Elliott M., Urbina H., SchmitT I. \& Piepenbring M. 2017. — Phylogeny of the order Phyllachorales (Ascomycota, Sordariomycetes): among and within order relationships based on five molecular loci. Persoonia 39: 74-90. https://doi.org/10.3767/persoonia.2017.39.04

Marmolejo J. G. \& Minter D. W. 2006. - Fungi on Pines. http://www.cybertruffle.org.uk/pinefung [website, version 1.00]. Accession date - March 2018.

Miller M. A., Pfeiffer W. \& SchWartz T. 2010. — Creating the CIPRES Science Gateway for inference of large phylogenetic trees. In: Proceedings of the Gateway Computing Environments Workshop (GCE), 14 Nov. 2010, New Orleans: 1-8. https://doi. org/10.1109/GCE.2010.5676129

MinTER D. W. 1981. - Microfungi on needles, twigs and cones of pines in Czechoslovakia. Ceská Mykologie 35: 90-101.

Minter D. W. \& HolubOVÁ-JeCHOVÁ V. 1981. — New or interesting Hyphomycetes on decaying pine litter from Czechoslovakia. Folia Geobotanica \& Phytotaxonomica 16: 195-217. https://doi. org/10.1007/BF02851863

Morgan-Jones G. 1975. — Notes on Hyphomycetes. VIII. Lylea, a new genus. Mycotaxon 3: 129-132.

MoOre R. T. 1957. — Index to the Helicosporae: addendum. Mycologia 49: 580-587. https://doi.org/10.1080/00275514.1 957.12024670

Mugambi G. K. \& Huhndorf S. M. 2009. — Parallel evolution of hysterothecial ascomata in ascolocularous fungi (Ascomycota, Fungi). Systematics and Biodiversity 7: 453-464. https://doi. org/10.1017/S147720000999020X

Mycoportal 2018. — http//:mycoportal.org/portal/index.php. Accession date - August 21st.

NarisaWa K., Hambleton S. \& Currah R. S. 2007. - Heteroconium chaetospira, a dark septate root endophyte allied to the Herpotrichiellaceae (Chaetothyriales) obtained from some forest soil samples in Canada using bait plants. Mycoscience 48: 274-
281. https://doi.org/10.1007/S10267-007-0364-6

O'DONNELL K. 1993. - Fusarium and its near relatives; In ReYNolds D. R. \& TAYlor J. W. (eds), The Fungal Holomorph: Mitotic, Meiotic and Pleomorphic Speciation in Fungal Systematics. CAB International, Wallingford: 225-233.

Promputtha I. \& Miller A. N. 2010. - Three new species of Acanthostigma (Tubeufiaceae, Dothideomycetes) from Great Smoky Mountains National Park. Mycologia 102: 574-587. https://doi.org/10.3852/09-051

Rehner S. A. \& BuCKley E. 2005. - A Beauveria phylogeny inferred from nuclear ITS and EF1-alpha sequences: evidence for cryptic diversification and links to Cordyceps teleomorphs. Mycologia 97: 84-98. https://doi.org/10.3852/mycologia.97.1.84

Ronguist F., Teslenko M., Van Der Mark P., Ayres D. L., Darling A., Höhna S., Larget B., Liu L., Suchard M. A. \& HuElsenBECK J. P. 2012. - MrBayes 3.2: Efficient Bayesian phylogenetic inference and model choice across a large model space. Systematic Biology 61: 539-542. https://doi.org/10.1093/ sysbio/sys029

Samerpitak K., Van Der Linde E., Choi H.-J., Gerrits VAn DeN Ende A. H. G., Machouart M., Gueidan C. \& De Hoog G. S. 2014. - Taxonomy of Ochroconis, genus including opportunistic pathogens on humans and animals. Fungal Diversity 65: 89-126. https://doi.org/10.1007/s13225-013-0253-6

Schoch C. L., Crous P. W., Groenewald J. Z., Boehm E. W. A., Burgess T. I., Degruyter J., De Hoog G. S., Dixon L. J., Grube M., Gueidan C., Harada Y., Hatakeyama S., Hirayama K., Hosoya T., Huhndorf S. M., Hyde K. D., GarethJones E. B., Kohlmeyer J., Kruys Å., Li Y. M., LÜCKInG R., Lumbsch H. T., Marvanová L., Mbatchou J. S., McVay A. H., Miller A. N., Mugambi G. K., Muggia L., Nelsen M. P., Nelson P., Owensby C. A., Phillips A. J. L., Phongpaichit S., Pointing S. B., Pujade-Renaud V., Raja H. A., Rivas-Plata E., Robbertse B., Ruibal C., Sakayaroj J., Sano T., Selbmann L., Shearer C. A., Shirouzu T., Slippers B., Suetrong S., TANAKA K., Volkmann-Kohlmeyer B., Wingfield M. J., WoOdA. R., WoudenberG J. H. C., YoneZAWA H., ZHANG Y. \& SPATAFORA J. W. 2009. - A class-wide phylogenetic assessment of Dothideomycetes. Studies in Mycology 64: 1-15. https://doi. org/10.3114/sim.2009.64.01

Schoch C. L., Shoemaker R. A., Seifert K. A., Hambleton S., SPATAFORA J. W. \& CROUS P. W. 2006. — A multigene phylogeny of the Dothideomycetes using four nuclear loci. Mycologia 98: 1041-1052. https://doi.org/10.1080/15572536.2006.11832632

Shoemaker R. A. \& Hambleton S. 2005. — Dothidea sambuci and Diaporthe spiculosa. Canadian Journal of Botany 83: 484-490. https://doi.org/10.1139/b05-023

SCHUBERT K. \& BRAUN U. 2007. - Taxonomic revision of the genus Cladosporium s. lat. 6. New species, reallocations to and synonyms of Cercospora, Fusicladium, Passalora, Septonema and Stenella. Nova Hedwigia 84: 189-208. https://doi.org/10.1127/00295035/2007/0084-0189

Schubert K., Ritschel A. \& Braun U. 2003. - A monograph of Fusicladium s.lat. (Hyphomycetes). Schlechtendalia 9: 1-132.

Seifert K., Morgan-Jones G., GAMS W. \& Kendrick B. 2011. The Genera of Hyphomycetes. CBS-KNAW Fungal Biodiversity Centre, Utrecht, 997 p.

Sivanesan A. 1984. - The Bitunicate Ascomycetes and their Anamorphs. J. Cramer, Vaduz, 701 p.

Spatafora J. W., Owensby C. A., Douhan G. W., Boehm E. W. \& SCHOCH C. L. 2012. - Phylogenetic placement of the ectomycorrhizal genus Cenococcum in Gloniaceae (Dothideomycetes). Mycologia 104: 758-765. https://doi.org/10.3852/11-233

Spatafora J. W., Sung G.H., Johnson D., Hesse C., O’rourke B., Serdani M., Spotts R., Lutzoni F., Hofstetter V., Miadlikowska J., Reeb V., Gueidan C., Fraker E., Lumbsch T., LÜCKING R., SchmitT I., Hosaka K., Aptroot A., Roux C., Miller A. N., Geiser D. M., Hafellner J., Hestmark G., 
Arnold A. E., Büdel B., Rauhut A., Hewitt D., Untereiner W. A., Cole M. S., Scheidegger C., Schultz M., Sipman H. \& SCHOCH C.L. 2006. — A five-gene phylogeny of Pezizomycotina. Mycologia 98: 1018-1028. https://doi.org/10.1080/ 15572536.2006.11832630

STAMATAKIS A. 2014. - RAxML version 8: a tool for phylogenetic analysis and post-analysis of large phylogenies. Bioinformatics 30: 1312-1313. https://doi.org/10.1093/bioinformatics/btu033

Su H.Y., Hyde K. D., MaHarachChiKumbUra S. S. N., ARIYAWANSA H. A., Luo Z., Promputtha I., Tian Q., Lin C., Shang Q., ZhaO Y., Chai H., LiU X., Bahkali, A. H., Bhat J. D., MCKENZIE E. H. C. \& ZHOU D. 2016. - The families Distoseptisporaceae fam. nov., Kirschsteiniotheliaceae, Sporormiaceae and Torulaceae, with new species from freshwater in Yunnan Province, China. Fungal Diversity 80: 375-409. https://doi.org/10.1007/ s13225-016-0362-0

SuTTON B. C. 1970. - Glyphium leptothecium (Earle) comb. nov., G. schizosporum (Maire) Zogg, and their imperfect states. Transactions of the British Mycological Society 54: 255-264. https://doi. org/10.1016/S0007-1536(70)80039-0

Tsui C. K. \& Berbee M. L. 2006. — Phylogenetic relationships and convergence of helicosporous fungi inferred from ribosomal DNA sequences. Molecular Phylogenetics and Evolution 39: $587-$ 597. https://doi.org/10.1016/j.ympev.2006.01.025

UNTEREINER W. \& NAVEAU F. 1999. - Molecular systematics of the Herpotrichiellaceae with an assessment of the phylogenetic positions of Exophiala dermatitidis and Phialophora americana. Mycologia 91: 67-83. https://doi.org/10.2307/3761194

VASILYEVA L. 2001. - Hysteriaceous fungi in the Russian Far East. IV. Glyphium, Lophium and Mytilinidion. Mikologiya i Fitopatologiya 35: 15-18.

Vilgalys R. \& Hester M. 1990. — Rapid genetic identification and mapping of enzymatically amplified ribosomal DNA from several Cryptococcus species. Journal of Bacteriology 172: 42394246. https://doi.org/10.1128/jb.172.8.4238-4246.1990

White T. J., Bruns T., LeE S. \& TAYlor J. W., 1990. — Amplification and direct sequencing of fungal ribosomal RNA genes for phylogenetics; In: INNIS M. A., GELFAND D. H., SNINSKY J. J. \& White T. J. (eds), PCR Protocols: A Guide to Methods and
Applications. Academic Press, San Diego: 315-322. https://doi. org/10.1016/B978-0-12-372180-8.50042-1

Wijayawardene D. N. N., Mckenzie E. H. C. \& Hyde K. D. 2012. - Towards incorporating anamorphic fungi in a natural classification - checklist and notes for 2011. Mycosphere 3: 157228. https://doi.org/10.5943/mycosphere/3/2/5

Wijayawardene D. N. N., Hyde K. D., Tibpromma S., Wanasinghe D. N., Thambugala K. M., Tian Q. \& Wang Y. 2017. Towards incorporating asexual fungi in a natural classification: checklist and notes 2012-2016. Mycosphere 8: 1457-1555. https:// doi.org/10.5943/mycosphere/8/9/10

Wu H., Jaklitsch W. M., Voglmayr H. \& Hyde K. D. 2011. Epitypification, morphology, and phylogeny of Tothia fuscella. Mycotaxon 118: 203-211. https://doi.org/10.5248/118.203

Yarita K., Sano A., Murata Y., Takayama A., Takahashi Y., TAKahashi H., Yaguchi T., OHORI A., Kamei K., MiYaji M. \& NisHimURA K. 2007. - Pathogenicity of Ochroconis gallopava isolated from hot springs in Japan and a review of published reports. Mycopathologia 64: 135-147. https://doi.org/10.1007/ s11046-007-9034-7

Yarita K., Sano A., Samerpitak K., Kamei K., De Hoog G. S. \& NishimURA K. 2010. - Ochroconis calidifluminalis, a sibling of the neurotropic pathogen O. gallopava, isolated from hot spring. Mycopathologia 170: 21-30. https://doi.org/10.1007/ s11046-010-9292-7

Zachariah S., Sankaran K. V. \& Leelavathy K. M. 1981. - A new species of Septonema from Indian soil. Mycologia 73: 208210. https://doi.org/10.1080/00275514.1981.12021335

Zhang J., Dou Z., Zhou Y., He W., Zhang X. \& Zhang Y. 2016. - Venturia chinensis sp. nov., a new venturialean ascomycete from Khingan Mountains. Saudi Journal of Biological Sciences 23: 592-597. https://doi.org/10.1016/j.sjbs.2015.06.019

Zhang Y., CROUS P. W., SCHOCH C. L., BAHKALi A. H., GUO L. D. \& HydE K. D. 2011. - A molecular, morphological and ecological re-appraisal of Venturiales - a new order of Dothideomycetes. Fungal Diversity 51: 249-277. https://doi.org/10.1007/s13225-011-0141-x

ZoGg H. 1962. — Die Hysteriaceae s. str. und Lophiaceae unter besonderer Berücksichtigung der mitteleuropäischen Formen. Beiträge zur Kryptogamenflora der Schweiz Band 11: 1-190. 